\title{
The impact of (adapted) organized sports participation on health in youth with a chronic disease or physical disability
}

Health in adapted youth sports

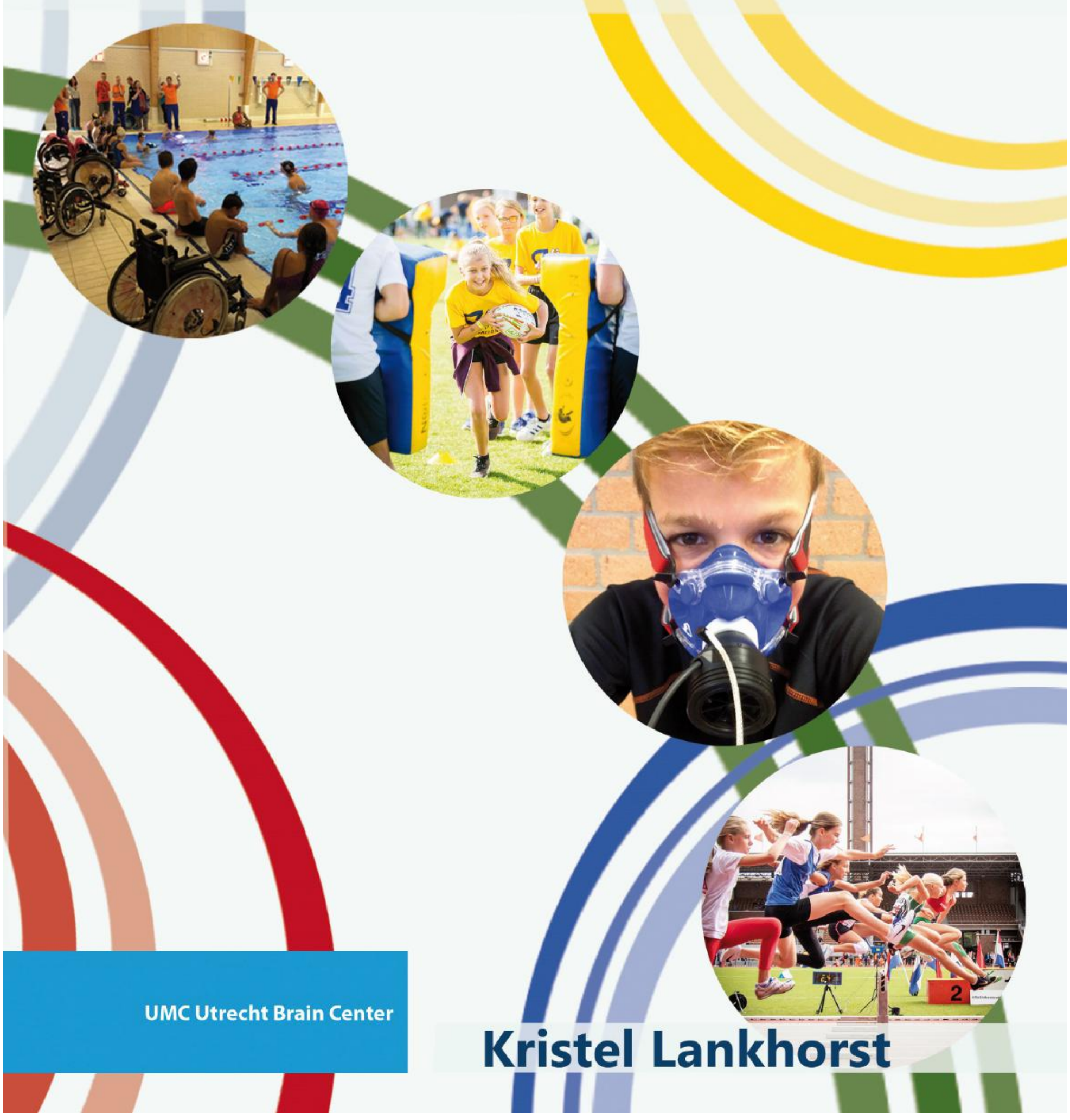


The impact of (adapted) organized sports participation on health in youth with a chronic disease or physical disability

Health in adapted youth sports

Kristel Lankhorst 
Printed by Proefschriftmaken.nl

Layout Anne Leijdekkers

Cover design Ilse Schaffers I www.iqphotoart.nl

Kristel Lankhorst

ISBN

978-94-6380-560-5

\section{() 2019 Kristel Lankhorst}

All rights reserved. No part of this publication may be reproduced, stored in a retrieval system, or transmitted, in any form or by any means, electronically, mechanically, by photocopying, recording or otherwise, without the prior written permission of the author. 


\section{The impact of (adapted) organized sports participation on health in youth with a chronic disease or physical disability}

Health in adapted youth sports

De impact van (aangepast) georganiseerd sporten op de gezondheid van jongeren met een chronische ziekte of een fysieke beperking

Aangepast sporten en gezondheid bij jongeren

(met een samenvatting in het Nederlands)

\section{Proefschrift}

ter verkrijging van de graad van doctor aan de

Universiteit Utrecht op gezag van de

rector magnificus, prof.dr. H.R.B.M. Kummeling, ingevolge het besluit van het college voor promoties

in het openbaar te verdedigen op

woensdag 20 november 2019 des middags te 12.45 uur

door

Kristel Maria Lankhorst

geboren op 11 maart 1984

te Wijhe 


\section{Promotor:}

Prof. dr. F.J.G. Backx

\section{Copromotoren:}

Dr. T. Takken

Dr. J.F. de Groot

The studies presented in this thesis were funded by a grant from the Dutch Organization of Health Research (ZonMw), grant number: 525001005 and from the Dutch Foundation Innovation Alliance (SIA-RAAK), part of the Dutch Organization for Scientific Research (NWO), grant number (PRO-4-03).

Financial support for the printing of this thesis has been generously provided by University of Applied Sciences Utrecht, Prof. Dr. Frank Backx, University Medical Center Utrecht, Esther Vergeer Foundation, Double Performance, ChipSoft, Nederlandse Vereniging voor Kinderfysiotherapie, Motekforce Link and MVOTV. 


\section{CONTENT}

Voorwoord Esther Vergeer

Chapter 1 General introduction

Chapter 2 Health in Adapted Youth Sports study (HAYS): health

effects of sports participation in children and adolescents with a chronic disease or physical disability

Chapter 3 A novel tool for quantifying and promoting physical activity in youths with typical development and youths who are ambulatory and have motor disability

Chapter 4 Sports participation, physical activity, and health-related fitness in youth with chronic diseases or physical disabilities: the health in adapted youth sports study

Chapter 5 Associations of sport participation with self-perception, 95 exercise self-efficacy and quality of life among children and adolescents with a physical disability or chronic disease-across-sectional study

Chapter 6 The associations of cardiorespiratory fitness, adiposity and sports participation with arterial stiffness in youth with chronic diseases or physical disabilities

Chapter $7 \quad$ Sports participation related to injuries and illnesses among youth with chronic diseases: results of the health in adapted youth sports study

Chapter 8 Instruments measuring physical activity in persons who 163 use a wheelchair: a systematic review of measurement properties

Chapter $9 \quad$ General discussion

Samenvatting

Dankwoord

About the author

Curriculum vitae 252

Publications 254 



\section{Gewoon lekker sporten!}

Het lijkt zo vanzelfsprekend: gewoon lekker sporten. Helaas is het in Nederland (maar ook in de rest van de wereld) nog lang niet vanzelfsprekend dat kinderen met een lichamelijke beperking wekelijks sporten en/of lid zijn van een sportvereniging. En dat terwijl sport zo veel voor je kan betekenen. Dat heb ik nadat ik op mijn 8-ste een dwarslaesie kreeg, aan den lijve ondervonden. Sport heeft mij ongelooflijk veel gebracht. Het heeft mij gemaakt tot wie ik nu ben. Ik heb geleerd wat ik wel en wat ik niet kan. Ik ben er dan ook van overtuigd dat wekelijks sporten er voor zorgt dat je ook de kracht van zelfvertrouwen leert kennen. Zelfvertrouwen dat je zo ongelooflijk hard nodig hebt om verder te komen in het leven. Ik vind het dan ook fantastisch dat Kristel haar proefschrift heeft gewijd aan de sportparticipatie onder kinderen/jongeren met een chronische ziekte of fysieke beperking.

Met mijn foundation zijn wij actief op bijna 30 sportverenigingen in Nederland. Op al die verenigingen geven wij kinderen/jongeren met een fysieke beperking de kans om 'gewoon' te sporten; net als ieder ander kind. Wij zien dat de impact die dit heeft enorm is. Regelmatig komen de kinderen met knikkende knieën bij een clinic kijken. Ze vinden het spannend en weten niet of ze het wel kunnen. Als ik dan een aantal maanden later nog een keer op een training kom kijken, en ik zie dan ondeugende, stoere kids, dan weet ik dat dat dus de kracht van sport is!

En ook ouders spelen een enorm belangrijke rol, zeker in het begin. De keuze om wel of niet te starten met een sport, wordt veelal genomen door de ouders. Vaak wordt het door de ouders in eerste instantie gezien als "weer een wekelijkse verplichting". Tot het moment dat ze zien wat sport (en samen spelen met andere kids, en onderdeel zijn van een clubje) met hun kind doet. Die glimlach op het gezicht van hun kind, het plezier wat de kinderen samen beleven, maakt dat de meeste ouders toch overstag gaan. Gelukkig maar!

Ik heb eens gelezen dat bijna 70\% van de kinderen/jongeren met een lichamelijke beperking aangeeft eenzaam te zijn. Ook in het oplossen van het gevoel van eenzaamheid, wat afschuwelijk is, speelt wekelijks sporten een hele belangrijk rol. Los dus van alle fysieke voordelen die sport biedt, draagt het ook bij aan de mentale gezondheid en aan de persoonlijke ontwikkeling van de kinderen op sociaal gebied.

Ik ben ervan overtuigd dat dit proefschrift ook weer bijdraagt aan de ontwikkeling van sportparticipatie voor kinderen en jongeren met een chronische ziekte of fysieke beperking. Ik wil Kristel bedanken voor al haar inzet en haar werk. En laten we samen werken aan een toekomst vol sportende kinderen.

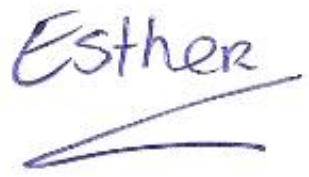

Esther Vergeer 

1

\section{General introduction}

Kristel Lankhorst 


\section{Chronic disease and physical disability}

One in four Dutch youngsters is growing up with a chronic disease or disability
In 2018, over 1.3 million children

or adolescents in the Netherlands have a chronic condition. This means that 1 in 4 youngsters (26.2\%) are growing up with a chronic disease or disability ${ }^{1}$. The group, children and adolescents with a chronic condition, represents a diverse array of medical diagnoses with varying prevalence. A chronic condition refers to diseases and disabilities that can be divided into somatic and psychological (mental) conditions. Asthma is the most common chronic disease $-4.6 \%$ of children and adolescents in the Netherlands are affected, followed by anxiety and mood disorders (4.1\%) or attention deficit hyperactivity disorder (ADHD) $(3.6 \%)^{1}$. Of all somatic disorders in youngsters, pulmonary diseases (mainly asthma) have the largest prevalence of $13.7 \%$, followed by neurological diseases $(8.9 \%)$, skeletal diseases (7.2\%), heart diseases (2.1\%), rheumatism (1.4\%), oncological diseases (0.9\%) and immunological diseases $(0.5 \%)^{1}$.

\footnotetext{
A chronic disorder is considerate to be a chronic condition in childhood if;

1) It occurs in children aged 0 up to 18 years,

2) The diagnosis is based on medical scientific knowledge, using reproducible and valid methods or instruments, according to professional standards,

3) It is not (yet) curable, and

4) It has been present longer than three months, or it has occurred three times or more during the past year and will probably reoccur ${ }^{29}$.
}

In this thesis, our research will focus on children and adolescents with chronic somatic conditions in childhood, i.e. chronic disease or physical disability (CDPD) (Table 1). For the classification of the different medical diagnoses, we used the categories of the American College of Sports Medicine (ACSM): cardiovascular disease (e.g. congenital heart disease), pulmonary disease (e.g. asthma), metabolic disease (e.g. diabetes), musculoskeletal or orthopedic disability, neuromuscular disorder (e.g. cerebral palsy, spina bifida), immunological or hematological disease, cancer and epilepsy². 
Table 1: Focus on children and adolescents with chronic diseases or physical disabilities in the Health in Adapted Youth Sports study, classified according to categories of the American College of Sports Medicine (ACSM)2.

\begin{tabular}{|l|r|}
\hline \multicolumn{2}{|c|}{ Health in Adapted Youth Sports study } \\
\hline \multicolumn{1}{|c|}{ Chronic disease } & \multicolumn{1}{|c|}{ Physical disability } \\
\hline - Pulmonary disease (asthma) & - Neuromuscular disorder \\
- Metabolic disease (diabetes) & $\begin{array}{l}\text { (cerebral palsy, spina bifida) } \\
\text { - Immunological / hematological } \\
\text { (rheumatism) }\end{array}$ \\
- Epilepsy & $\begin{array}{l}\text { Musculoskeletal / orthopedic } \\
\text { disability (amputation) }\end{array}$ \\
- Cancer & $\begin{array}{l}\text { Cardiovascular } \\
\text { (congenital heart diseases) }\end{array}$ \\
\hline
\end{tabular}

\section{Model of Shephard \& Bouchard}

Various factors influence self-reliance in society. Shephard \& Bouchard ${ }^{3}$ have described a model in which relationships between physical activity (PA), health-related fitness and health are being presumed (Figure 1) in adults, while at the same time genetics and environment play an important role in this interaction.

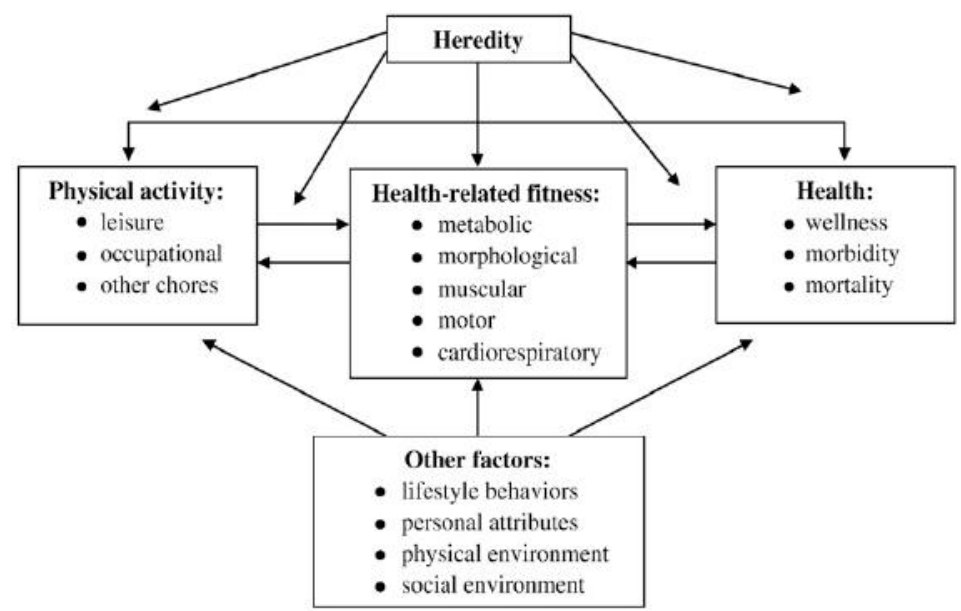

Figure 1: Principal components of fitness: relationship to physical activity and lifestyle. Model of Shephard \& Bouchard, 1994. 
In the model, health-related fitness is defined as a state characterized by 1) an ability to perform and sustain daily activities and 2) demonstration of traits or capacities that are associated with a low risk of premature development of diseases and conditions related to movement ${ }^{4}$. Health-related fitness refers to those components of fitness that are affected by PA and relate to health status. PA is any bodily movement produced by the contraction of skeletal muscles that results in energy expenditure ${ }^{5}$. There are several subdomains of physical activity where children and adolescents are physically active, such as: physical education lessons at school, leisure time sport and play, active transport (walking, cycling to their school), and sports participation. As a counterpart to beneficial factors like PA for health-related fitness, time spent being sedentary (inactive) contributes also to health-related fitness as a component with negative influence.

Sedentary behavior is any waking behavior characterized by an energy expenditure $\leq 1.5$ metabolic equivalents (METs), while in a sitting, reclining or lying posture.

In general, this means that, when a person is sitting or lying down, they are engaging in sedentary behavior ${ }^{6}$.

\section{Physical (in)activity and sports participation}

For typically-developing youngsters, it is already difficult to meet recommended levels of PA; it is even more difficult for youngsters with CDPD. Such youngsters participate even less in competitive and recreational sports than their healthy peers ${ }^{7,8}$. Only $26 \%$ of youngsters with CDPD participate in sports once a week, compared to $71 \%$ of their healthy peers. Several studies have reported significant barriers for youngsters with CDPD to participate in sports. These include both personal and environmental factors ${ }^{7,9}$. The latter include the accessibility of the physical environment, and also attitudes from the social environment, e.g. parents, teachers, health-care professionals and policy makers. Such attitudes include thinking that sports might be too difficult, lack of knowledge of the importance of PA for youngsters with CDPD, practical considerations such as the difficulty of transportation to an adapted sports facility, or fear of sportrelated injuries and/or illnesses ${ }^{10}$.

There are many opportunities for creating a healthy active lifestyle. Structured and weekly participation in (organized) sports is one of these that has the potential to maintain and/or optimize health-related fitness, physical activity and psychosocial wellbeing in youngsters with CDPD. To overcome some of these social barriers, research is needed 
showing that there are positive associations between sports participation, health-related fitness, and psychosocial health, and into how far the fear of sport-related injuries and illnesses is justified for youngsters with CDPD. With this knowledge, attitudes towards the importance of sports participation for youngsters with CDPD may change. To test this hypothesis, two studies, the Health in Adapted Youth Sports (HAYS) study and Sport2-Stay-Fit (S2SF), were initiated by the Shared Utrecht Pediatric Exercise Research Lab (SUPER-Lab) research group in Utrecht.

The S2SF study investigated whether a school-based sports program could maintain or increase the results of a High Intensity Training (HIT) program in children and adolescents with CDPD who go to schools for special education ${ }^{11}$, specifically Cluster III schools, which are specifically for people with physical, mental or multiple disabilities, and people with a chronic disorder.

The aim of the HAYS study was to determine the associations between sports participation, as a specific subdomain of PA, and health outcomes in youngsters with CDPD, by comparing sports participants in organized sports to their non-sporting peers and those who participate in sports once per week. Children and adolescents of all levels of education can participate in this study, including primary and secondary education, and regular and special education.

Figure 2 is a schematic representation of the relations and risks that were investigated in the HAYS study. This is based on the model of Shephard \& Bouchard for adults, as introduced and displayed in Figure 1. We adapted this model specifically for children and adolescents. We will examine the associations between participation in sports and health-related fitness, physical activity, psychosocial health and physical health (the incidence and risks of injuries and illnesses) in youngsters with CDPD. Each domain will be introduced in the following paragraphs. The impact of sports participation on 'other factors' and the personal and social environment will not be investigated in this thesis. 


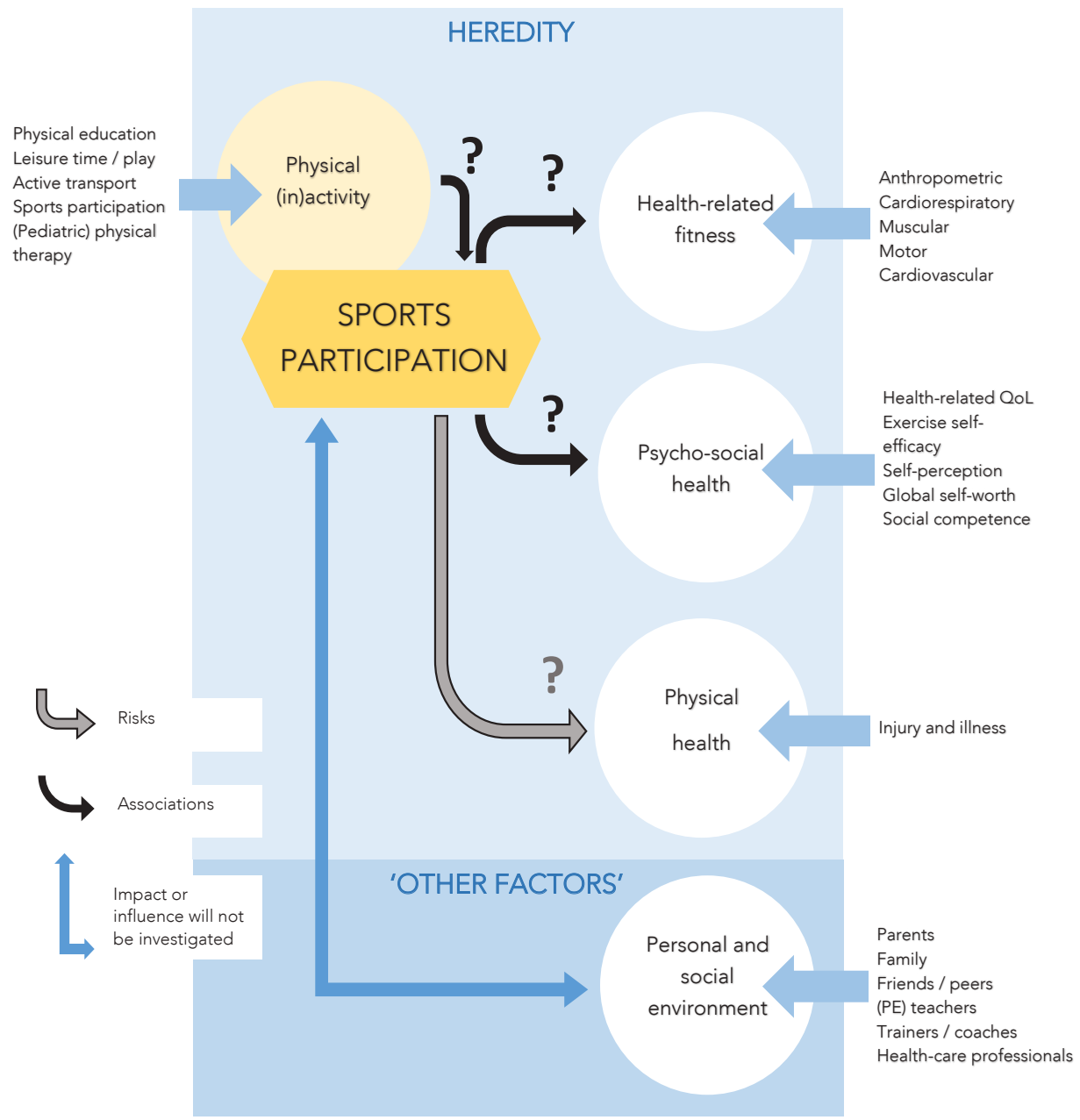

Figure 2: Schematic representation of the relationships and risks being investigated with the HAYS study. QoL: quality of life; PE: physical education.

\section{Sports participation and health-related fitness}

Youngsters with CDPD have lower fitness levels ${ }^{12}$, lower levels of PA ${ }^{13,14}$ and a higher prevalence of adiposity ${ }^{15}$ than their healthy peers. The detrimental health effects of physical inactivity in healthy youngsters are well established ${ }^{15-17}$. In typically-developing youngsters, insufficient PA levels are highly associated with low cardiorespiratory fitness, 
higher levels of obesity and increased cardiovascular risk ${ }^{18,19}$. While health benefits related to sports and PA are reported in healthy youngsters, there is only limited evidence on the extent to which sports participation may affect PA and healthrelated fitness in youngsters with CDPD. At the same time, training studies have shown that youngsters with CDPD indeed can improve their PA level and health-related fitness through supervised intervention programs in rehabilitation settings ${ }^{12,20}$. However, the positive results achieved are often not maintained in the longer term after these programs end ${ }^{21-23}$. Regular participation in (organized) sports, as a subdomain of PA, seems therefore an important goal for youngsters with CDPD, to maintain or even improve on the results achieved with a training program or supervised intervention program, to meet PA guidelines ${ }^{7}$ and to develop a healthy active lifestyle.

\section{Sports participation and psychosocial health}

Supervised intervention programs in a rehabilitation environment pursue goals that are often focused on physical functioning, i.e. mobility, strength and fitness. Sports participation can contribute to one's health and wellbeing at both physical functioning and psychosocial levels. Sports participation can contribute to the development of athletic skills, and competing with others can be a positive challenge. In addition, due to its social nature, sports participation provides opportunities for social interaction and companionship and may therefore have greater benefits for psychosocial health than other domains of PA (leisure or occupational)24-26. Involvement in sports can encourage focus on children's abilities (personal attributes) rather than on their inabilities ${ }^{24}$, which gives autonomy and control in their lives. Youngsters with CDPD engage less often in PA and sport compared to their healthy peers. These children and adolescents may therefore experience low levels of self-worth and quality of life due to their physical limitations and body image concerns. The current thesis will therefore focus on the potential beneficial effects of sports participation, as a specific subdomain of PA, on psychosocial health.

\section{Sports participation and physical health}

For youngsters with CDPD, it is already a challenge to reach adequate levels of PA, as mentioned before, due to existing social and environmental barriers to sports and exercise participation. It is even harder to pursue an active and healthy lifestyle through participation in sports when sports participation is associated with (fear of) sport-related 
injuries or illnesses. A long-lasting injury or illness can limit participation in sports or lead to dropping out of sports or fear of return to sports ${ }^{27,28}$. There is a reasonable fear among parents of children with CDPD that sports participation may lead to sportrelated injuries. As a consequence of such injury, their child might experience additional limitations in their daily lives, e.g. no longer being able to perform their daily activities independently or needing more help with these from their parents or caregivers. These negative experiences and beliefs about sports participation can further limit the support given to allow their child to be active in sports. The current thesis will therefore focus on the incidence, type, severity and risks of (sports-related) injuries and illnesses among youngsters with CDPD, to see whether the fear of sport-related injuries and illnesses is justified.

\section{Aims and outline of this thesis}

The current thesis focuses on the impact of sports participation on health and fitness in youngsters with CDPD. Chapter 2 describes the design of the Health in Adapted Youth Sports study, a cross-sectional study comparing youngsters with CDPD who participate in organized sports at least twice weekly with their non-sporting peers or those who participate in sports once a week. Chapter 3 introduces the criterion validity of the Activ8 for quantifying and promoting physical activity in youngsters with typical development and youngsters who are ambulatory but have motor disability. Chapter 4, 5, $\mathbf{6}$ and $\mathbf{7}$ addresses the results of the HAYS study. Chapter $\mathbf{4}$ shows the results of sports participation on health-related fitness and physical activity in youngsters with CDPD; Chapter 5, the associations of sports participation with self-perception, exercise selfefficacy, and quality of life. Chapter $\mathbf{6}$ summarizes the association of cardiorespiratory fitness, adiposity and sports participation with arterial stiffness. Chapter 7 shows the risks of (sports-related) injuries and illnesses among youngsters with CDPD. Chapter $\mathbf{8}$ presents a systematic review that summarizes the evidence of instruments measuring physical activity in persons who use a wheelchair. Finally, Chapter 9 comprises the general discussion of this thesis including: the main findings, theoretical considerations, interpretation of results, methodological considerations, practical implementation, future perspectives, recommendations and conclusions. 


\section{REFERENCES}

1. Hal van L, Tierolf B, Rooijen van M, Hoff van der M. Een actueel perspectief op kinderen en jongeren met een chronische aandoening in Nederland: Omvang, samenstelling en participatie. Verwey-Jonker Instituut, Utrecht April 2019;ISBN 978-90-5830-936-5.

2. Durstine LJ, Moore GE, Painter PL, Roberts SO. ACSM's exercise management for persons with chronic diseases and disabilities. 3rd ed. Champaign, IL: Human Kinetics; 2009.

3. Shephard RJ, Bouchard C. Principal components of fitness: Relationship to physical activity and lifestyle. Can J Appl Physiol 1994;19(2):200-214.

4. Winnick, JP \& Short, FX, ed. The Brockport Physical Fitness Test Manual. Champaign, IL: Human Kinetics; 1999.

5. Caspersen CJ, Powell KE, Christenson GM. Physical activity, exercise, and physical fitness: Definitions and distinctions for health-related research. Public Health Rep 1985;100(2):126131.

6. Bussmann JB, van den Berg-Emons RJ. To total amount of activity..... and beyond: Perspectives on measuring physical behavior. Front Psychol 2013;4:463. doi: 10.3389/ fpsyg.2013.00463.

7. Burghard M, de Jong NB, Vlieger S, Takken T. 2017 Dutch Report Card+: Results from the first physical activity report card plus for Dutch youth with a chronic disease or disability. Front Pediatr 2018;6:122. doi: 10.3389/fped.2018.00122.

8. Burghard M, Knitel K, van Oost I, Tremblay MS, Takken T, Dutch Physical Activity Report Card Study Group. Is our youth cycling to health? Results from the Netherlands' 2016 report card on physical activity for children and youth. J Phys Act Health 2016;13(11 Suppl 2):S218-S224. doi: 10.1123/jpah.2016-0299.

9. Jaarsma EA, Dijkstra PU, de Blecourt AC, Geertzen JH, Dekker R. Barriers and facilitators of sports in children with physical disabilities: A mixed-method study. Disabil Rehabil 2015;37(18):1617-23; quiz 1624-5. doi: 10.3109/09638288.2014.972587.

10. Verschuren $O$, Wiart L, Hermans D, Ketelaar M. Identification of facilitators and barriers to physical activity in children and adolescents with cerebral palsy. J Pediatr 2012;161(3):488494. doi: 10.1016/j.jpeds.2012.02.042.

11. Zwinkels M. From exercise training to school-based sports, the effects on fitness and health in youth with physical disabilities [Dissertation]; Utrecht University, 2018.

12. van Brussel M, van der Net J, Hulzebos E, Helders PJ, Takken T. The Utrecht approach to exercise in chronic childhood conditions: The decade in review. Pediatr Phys Ther 2011;23(1):2-14. doi: 10.1097/PEP.0b013e318208cb22. 
13. Carlon SL, Taylor NF, Dodd KJ, Shields N. Differences in habitual physical activity levels of young people with cerebral palsy and their typically developing peers: A systematic review. Disabil Rehabil 2013;35(8):647-655. doi: 10.3109/09638288.2012.715721.

14. Neter JE, Schokker DF, de Jong E, Renders CM, Seidell JC, Visscher TL. The prevalence of overweight and obesity and its determinants in children with and without disabilities. J Pediatr 2011;158(5):735-739. doi: 10.1016/j.jpeds.2010.10.039.

15. Azevedo MR, Araujo CL, Reichert FF, Siqueira FV, da Silva MC, Hallal PC. Gender differences in leisure-time physical activity. Int J Public Health 2007;52(1):8-15.

16. Jimenez-Pavon D, Kelly J, Reilly JJ. Associations between objectively measured habitual physical activity and adiposity in children and adolescents: Systematic review. Int J Pediatr Obes 2010;5(1):3-18. Accessed 7/7/2017 9:28:46 AM. doi: 10.3109/17477160903067601.

17. LaMonte MJ, Blair SN. Physical activity, cardiorespiratory fitness, and adiposity: Contributions to disease risk. Curr Opin Clin Nutr Metab Care 2006;9(5):540-546. doi: 10.1097/01. mco.0000241662.92642.08.

18. Janssen I, Leblanc AG. Systematic review of the health benefits of physical activity and fitness in school-aged children and youth. Int J Behav Nutr Phys Act 2010;7:40-5868-7-40. doi: 10.1186/1479-5868-7-40.

19. Riddoch CJ, Mattocks C, Deere K, Saunders J, Kirkby J, Leary SD, Blair SN, Ness AR. Objective measurement of levels and patterns of physical activity. Arch Dis Child 2007;92(11):963-969. doi: adc.2006.112136.

20. Edouard P, Gautheron V, D'Anjou MC, Pupier L, Devillard X. Training programs for children: Literature review. Ann Readapt Med Phys 2007;50(6):510-9, 499-509. doi: S01686054(07)00129-8.

21. de Groot JF, Takken T, van Brussel M, Gooskens R, Schoenmakers M, Versteeg C, Vanhees L, Helders P. Randomized controlled study of home-based treadmill training for ambulatory children with spina bifida. Neurorehabil Neural Repair 2011;25(7):597-606. doi: $10.1177 / 1545968311400094$.

22. Zwinkels M, Verschuren O, de Groot JF, Backx FJG, Wittink H, Visser-Meiley A, Takken T. Effects of high-intensity interval training on fitness and health in youth with physical disabilities. Pediatr Phys Ther 2019;31(1):84-93. doi: 10.1097/PEP.0000000000000560.

23. Zwinkels M, Verschuren O, Balemans A, Lankhorst K, Te Velde S, van Gaalen L, de Groot J, Visser-Meiley A, Takken T. Effects of a school-based sports program on physical fitness, physical activity, and cardiometabolic health in youth with physical disabilities: Data from the sport-2-stay-fit study. Front Pediatr 2018;6:75. doi: 10.3389/fped.2018.00075. 
24. Eime RM, Young JA, Harvey JT, Charity MJ, Payne WR. A systematic review of the psychological and social benefits of participation in sport for children and adolescents: Informing development of a conceptual model of health through sport. Int J Behav Nutr Phys Act 2013;10:98-5868-10-98. doi: 10.1186/1479-5868-10-98.

25. Eime RM, Harvey JT, Brown WJ, Payne WR. Does sports club participation contribute to health-related quality of life? Med Sci Sports Exerc 2010;42(5):1022-1028. doi: 10.1249/ MSS.0b013e3181c3adaa.

26. Street $\mathrm{G}$, James $\mathrm{R}$, Cutt $\mathrm{H}$. The relationship between organised physical recreation and mental health. Health Promot J Austr 2007;18(3):236-239.

27. Siesmaa EJ, Blitvich JD, Finch CF. A systematic review of the factors which are most influential in children's decisions to drop out of organised sport. In: Farelli AD, ed. Sport participation: Health benefits, injuries and psychological effects. Hauppauge, NY: Nova Science Publishers, Inc.; 2011:1-45.

28. Siesmaa EJ, Blitvich JD, Telford A, Finch CF. Factors that are most influential in children's continued and discontinued participation in organized sport: The role of injury and injury risk perceptions. In: Farelli AD, ed. Sport participation: Health benefits, injuries and psychological effects. Nova Science Publishers, Inc.; 2011:47-84.

29. Mokkink L, Lee van der J, Grootenhuis M, Offringa M, Praag van B, Heymans H. Omvang en gevolgen van chronische aandoeningen bij kinderen.

Tijdschrift voor Kindergeneeskunde Feb 2007;75:154-158. 

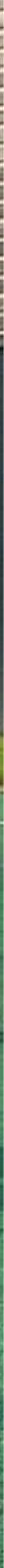


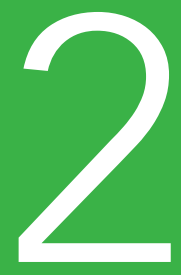

\section{Health in Adapted Youth Sports study (HAYS): Health effects of} sports participation in children and adolescents with a chronic disease or physical disability

Kristel Lankhorst

Karin van der Ende-Kastelijn

Janke de Groot

Maremka Zwinkels

Olaf Verschuren

Frank Backx

Anne Visser-Meily

Tim Takken 


\section{ABSTRACT}

Introduction. In typically developing children, participation in sports has been proven to be positively correlated to both physical and psychosocial health outcomes. In children and adolescents with a physical disability or chronic disease participation in both recreational and competitive sports is often reduced, while for this population an active lifestyle may be even more important in reaching optimal levels of physical and psychosocial health. Therefore, the aim of the Health in Adapted Youth Sports (HAYS) Study is to determine both negative and positive effects of sports on children and adolescents with a chronic disease or disability. Methods. In this cross-sectional study differences will be compared in regards to physical and psychosocial health, cognitive functioning, school performance, daily physical activity and injuries between children and adolescents with a chronic disease or physical disability who participate in sports and those who do not. Children and adolescents, both ambulatory and wheelchair dependent, in the age of 10-19 years with a physical disability or chronic disease will be included. "Sports" is defined as participation in an organized sport at least two times a week for a duration of three months or more prior to the assessment. Parametric and non-parametric statistics will be used to determine the differences between the two groups. Discussion. This study provides insight in the effects of sports participation in relation to health, psychosocial functioning, physical activity and school performance in children and adolescents (10-19 years) with a chronic disease or physical disability. Results will guide healthcare professionals working with these children to better guide this population in reaching optimal levels of health and physical activity levels. 


\section{INTRODUCTION}

Children with disabilities often show reduced fitness levels and physical activity patterns and they participate less in competitive and recreational sports compared to their nondisabled peers ${ }^{1,2}$. The relationship between health and physical fitness has been studied by many authors.

In the general population, low level of physical activity is highly associated with low physical fitness, an increased cardiovascular and overall mortality ${ }^{3-6}$. In typically developing children, participation in sports has been proven to be positively correlated to both physical and psychosocial health outcomes ${ }^{3}$. Also for adults with various disabilities the physical, psychological, social, and economic benefits of participation in sports and recreational activities are described previously ${ }^{8-11}$. Because of the reduced fitness levels and physical activity pattern in children with a disability or chronic disease, support for an active lifestyle, including participation in sports, may be even more important in this population.

Next to the possible benefits of sports on health and fitness level, increasing evidence also shows benefits from physical activity on school performance and level of cognition could be influenced in a positive way. Children and adolescents without a medical condition are already known to perform better at school when being physically active ${ }^{12-15}$. Childhood physical fitness is also associated with higher levels of cognition and appeared to be a good predictor of school performance and level of cognition 1 year later ${ }^{16-20}$.

Participation in sports could also have an positive influence on health related quality of life (HRQoL) and self-worth ${ }^{21}$. HRQoL refers to the impact of health and illness on an individual's quality of life. In relation to sports, adult athletes with cerebral palsy for example reported a positive influence of sports participation on their HRQoL 22,23 .

When looking at competence levels, Special Olympics participants with developmental disorders showed higher levels of self-worth and perceived physical competence in comparison to nonparticipants ${ }^{24}$. These findings might support the hypothesis that sports participation will enlarge the global self-worth of children and adolescents with a chronic disease and/or disability. But when motor competence is inadequate for the type of sport, a feeling of failure could predominate.

While there are many positive reasons for participating in sports or other physical activities for children with a chronic disease and/or disability, attention must be paid to the risk of acute and overuse injuries but also illness. Indeed parents and healthcare providers are wary of injuries due to participation in sports, which could further limit 
their child's physical functioning. These worries are confirmed in healthy children. A recent study reported a higher absolute risk of getting injured and a high probability of sustaining the injury when adding physical education hours at school or increasing organized sports outside school25-27. At the same time though, the relative risk of injury seems higher for children with low levels of habitual physical activity ${ }^{28}$. Studies also reported children with disabilities to have a higher risk of injury than children without disabilities, but these studies were limited to just one type of disability, sport, or injury ${ }^{29}$. Identifying injury patterns and illness in children with disabilities is important to provide safety in sports activities and to prevent dropout in physical activities and return to an inactive lifestyle ${ }^{28,30,31}$.

In summary, children with chronic disease and/or disabilities often show reduced levels of physical activity and fitness and participate less in organized sports compared to their non-disabled peers. The positive effects of sports and daily activities on the psychosocial and physical health, cognition and injury risk as depicted in Fig 1 already have been reported in a healthy population and disabled adults.

To date, however, limited evidence exists for these effects of participation in sports by children and adolescents with a physical disability or chronic disease. Therefore, the aim of the HAYS study is to determine both the positive and negative effects of sports related to health outcomes in children with disabilities and chronic childhood onset conditions. Therefore the Health in Adapted Youth Sports (HAYS) Study is designed to determine the positive and negative effects of participation in sports in this specific population.

\section{METHODS}

\section{Design}

The HAYS study will be a cross-sectional study comparing children and adolescents with a physical disability or chronic disease, age 10 to 19 years, who are actively participating in organized sports to their non-sporting peers. The subjects who participate in sports will be matched on gender, age and diagnosis to their non-sporting peers, Fig 2.

The current study is part of a larger project in which a controlled clinical trial will take place to evaluate the effectiveness of an after school sports program following a standardized interval training in children and adolescents with a chronic disease or physical disability. This study, titled The Sport-2-Stay-Fit study (S2SF; Trialregister.nl registration number: NTR4698), will use the same outcome instruments 32 . 


\section{Participants}

Eligible for this study are all children and adolescents aged from 10 up to 19 years with a physical chronic disease or condition, including cardiovascular, pulmonary, musculoskeletal, metabolic or neuromuscular disorders. Table 1 shows the in- and exclusion criteria. Both children who are ambulatory or those propelling a wheelchair are eligible for this study. Participants have to understand the Dutch language, understand simple instructions and be able to perform a physical fitness test. Children and adolescents in electric wheelchair, having a progressive disease or participate in other research projects which might influence the current study results will be excluded. Contraindications for performing an exercise test, based on the exercise pre-participation screening questionnaire, may lead to exclusion on the cardiopulmonary exercise test ${ }^{33}$. Informed consent must be provided by all parents, as well as by subjects up from 12 years till 17 years. In line with Dutch law, no parental informed consent is required for subjects aged 18 years and over.

This study was approved by the Medical Ethics Committee of the University Medical Center Utrecht, the Netherlands.

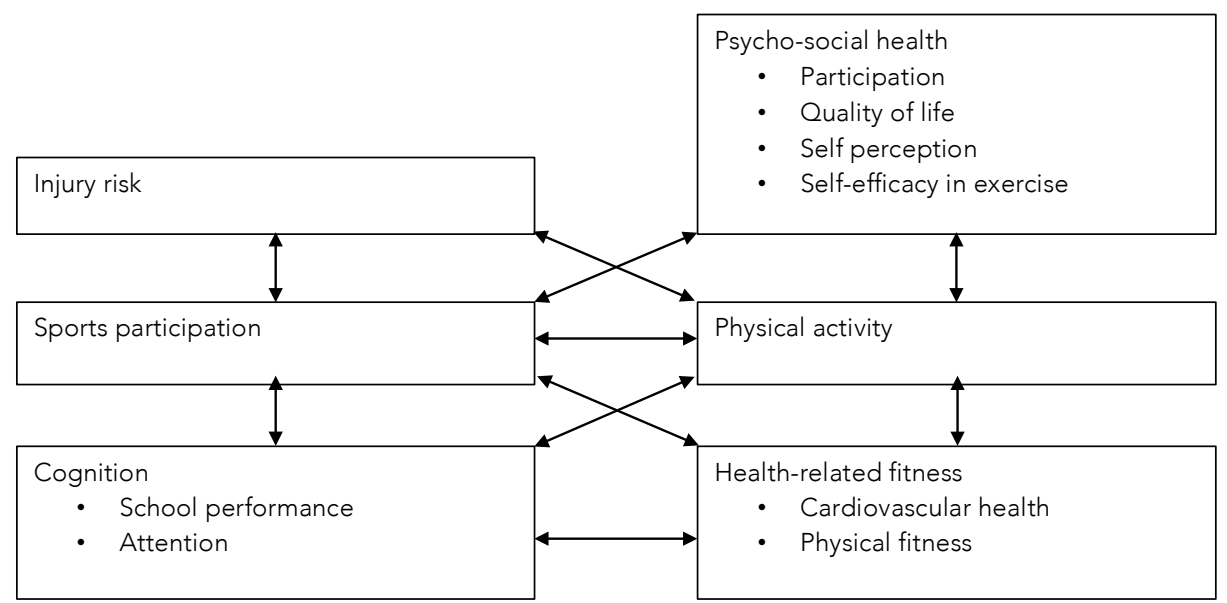

Figure 1: Overview of positive relations already established within a population of children and adolescents without a chronic disease and/or disability, and within a population of adults with and without a disability. 
Table 1: Eligibility and exclusion criteria.

\section{Eligibility}

\section{Exclusion}

- Children and adolescents with a physical disability or chronic disease: cardiovascular, pulmonary, musculoskeletal or neuromuscular disorder

- Children and adolescents between the age of 10 and 19 years

- Children and adolescents have to understand simple instructions

- Children and adolescents are able to perform physical fitness tests
- Children and adolescents with progressive diseases

- Children and adolescents using an electric wheelchair

- During the length of the study, children are not allowed to participate in other research projects which might influence the current study results

- For the sporting group of the HAYS-study only: subjects who have not participated in any sports for the preceding three months.

- No signed informed consent

\section{Recruitment}

The children and adolescents will be recruited in the Netherlands among different patients associations, pediatric physical therapy practices, Wilhelmina Children's Hospital in Utrecht, De Hoogstraat Rehabilitation Center in Utrecht, Fitkids, schools for children with a disability and sports clubs. Athletes will be recruited from a broad range of participation in sports: from recreational level to high level competitive sports.

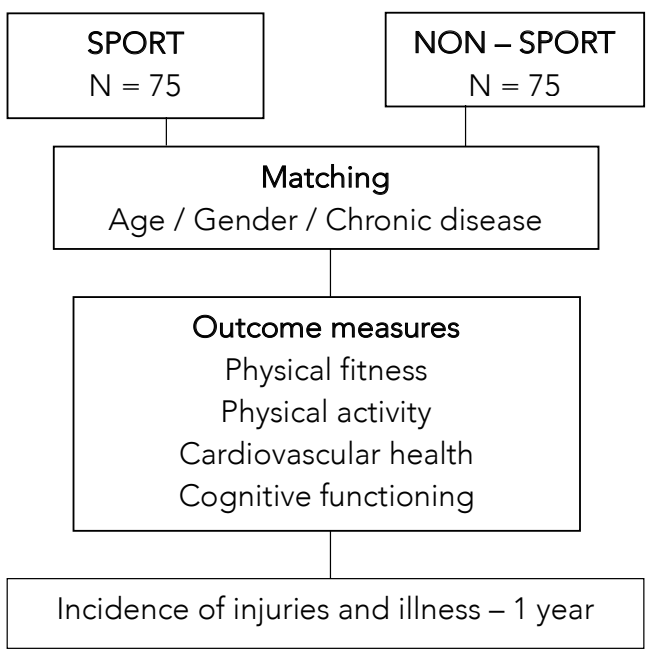

Figure 2: Overview of the design of the HAYS study. 


\section{Setting}

This study is a collaboration between the exercise lab at the University of Applied Sciences Utrecht, Wilhelmina Children's Hospital and De Hoogstraat Rehabilitation Center in Utrecht, the Netherlands.

\section{Procedures}

Criteria for eligibility and exclusion of subjects are depicted in Table 1. After permission of the subject and when the subject is eligible to participate in the study, the subject is scheduled for the assessment. Thereafter a secured link to four of the questionnaires will be sent to the participants or their parents by email in order to fill out the questionnaires online 1 week before the first testing moment. The researchers will assess the subjects subsequently, once on physical fitness, cognition, psychosocial- and cardiovascular health. Physical activity will be monitored during 1 week. The incidence of injuries and illness will be monitored for the duration of 1 year, by sending a secured link to a 5-item questionnaire every 2 weeks by email. If an injury or illness is reported, a telephone conversation will follow, to get insight and to classify the sort of injury or illness. Table 2 shows the procedure for the principle researchers and the subjects in the HAYS study, from recruitment to the end of participation.

\section{Outcome measures}

Table 3 shows an overview of the outcome measures and chosen measurement instruments in this study. The participants' characteristics such as date of birth, gender, medical diagnosis, functional mobility scale (FMS) score and type and frequency of sport activity will be identified by a general questionnaire. An exercise pre-participation screening questionnaire will inquire about possible factors influencing the outcomes of the test and the participants' safety during the tests. These questionnaires will take approximately 5 minutes to be filled out by the participant and / or parent. 
Table 2: Organisational and subject flow of the HAYS study.

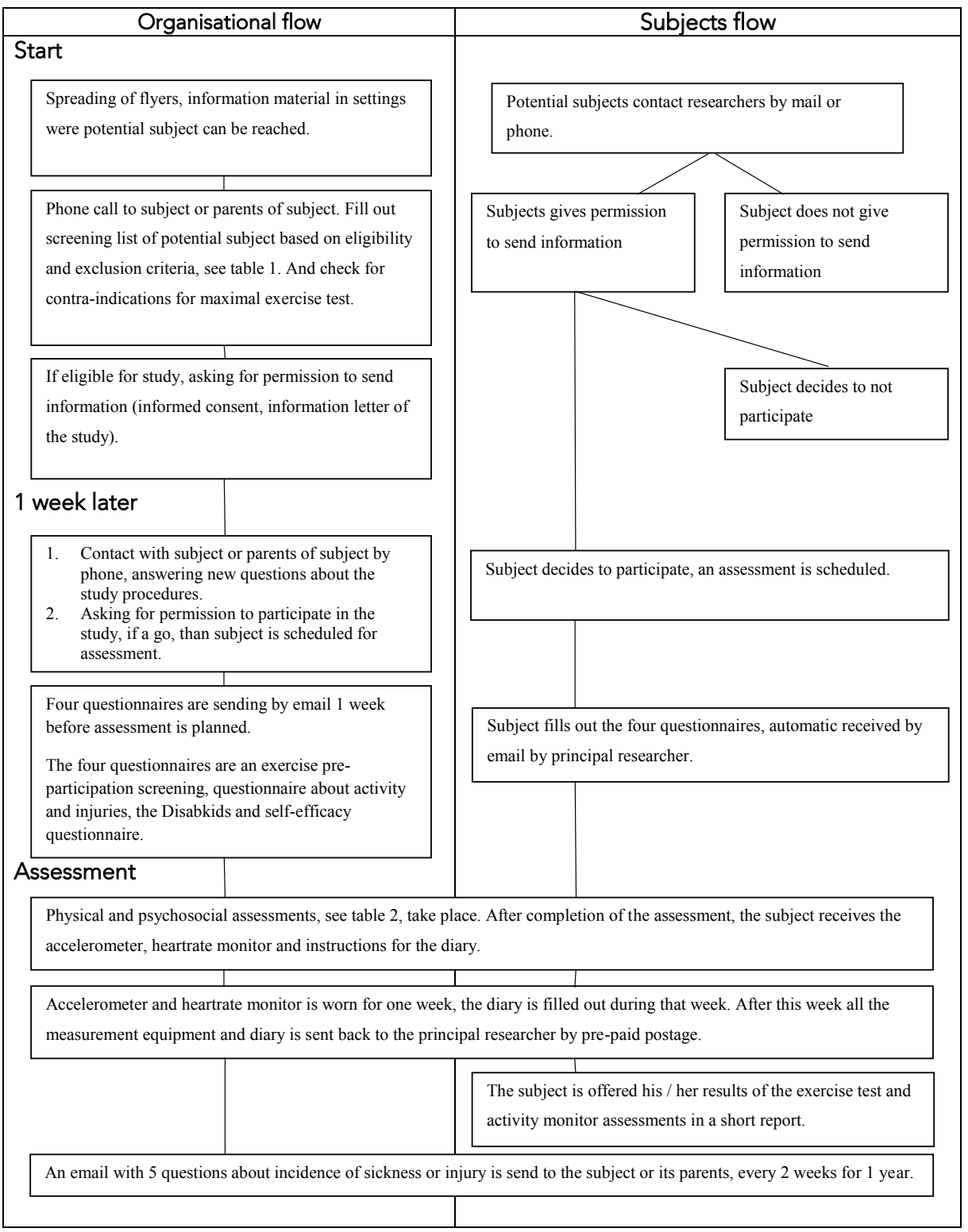


Table 3: Overview of assessments used instruments, questionnaires and time schedule.

\begin{tabular}{|c|c|c|c|c|c|}
\hline Outcome measure & Parameter & Variable & Measurement & $\begin{array}{l}\text { Time at } \\
\text { location }\end{array}$ & $\begin{array}{c}\text { Time at } \\
\text { home }\end{array}$ \\
\hline General & Demographics & $\begin{array}{l}\text { DOB, Gender, } \\
\text { Diagnosis, FMS } \\
\text { score, } \\
\text { activity level }\end{array}$ & General questionnaire & & $5 \mathrm{~min}$ \\
\hline \multirow[t]{5}{*}{ Cardiovascular Health } & Metabolic & BMI & Length, Weight & $5 \mathrm{~min}$ & \\
\hline & parameters & Fat Free Mass & $\mathrm{BIA}$ & & \\
\hline & & Blood pressure & Sphygmomanometer & $10 \mathrm{~min}$ & \\
\hline & & Arterial stiffness & Arteriograph & & \\
\hline & & Pulse wave velocity & & & \\
\hline \multirow[t]{12}{*}{ Physical Fitness } & Aerobic fitness & $\mathrm{VO}_{2 \text { peak }}$ & CPET & $30 \mathrm{~min}$ & \\
\hline & & RER & Shuttle run/ride test & & \\
\hline & & $\begin{array}{l}\text { Anaerobic } \\
\text { threshold }\end{array}$ & Bicycle test & & \\
\hline & Anaerobic & Peak power & MPST & $5 \mathrm{~min}$ & \\
\hline & fitness & Mean power & & & \\
\hline & Muscle & Isometric muscle & Grip strength & $10 \min$ & \\
\hline & strength & strength & Reverse curl & & \\
\hline & & & Seated push up & & \\
\hline & & $\begin{array}{l}\text { Explosive muscle } \\
\text { strength }\end{array}$ & $\begin{array}{l}\text { Standing broad jump } \\
\text { or One stroke push }\end{array}$ & & \\
\hline & Flexibility & & Modified Apley test & $5 \mathrm{~min}$ & \\
\hline & & & Modified Thomas test & & \\
\hline & Agility & & $10 \times 5$ meter sprint & $5 \mathrm{~min}$ & \\
\hline \multirow[t]{2}{*}{ Physical activity } & Intensity & Heart rate & Actiheart & $5 \mathrm{~min}$ & 7 days \\
\hline & Modality & Type of activity & $\begin{array}{l}\text { Activ8 and } \\
\text { Activity diary }\end{array}$ & $5 \min$ & 7 days \\
\hline \multirow[t]{4}{*}{ Cognitive functioning } & $\begin{array}{l}\text { School } \\
\text { performance }\end{array}$ & Educational level & $\begin{array}{l}\text { Type of education } \\
\text { Recent CITO-score }\end{array}$ & $0 \mathrm{~min}$ & \\
\hline & Attention & Focused attention & Bourdon-Vos & $15 \min$ & \\
\hline & & Sustained attention & Cancellation task & $5 \mathrm{~min}$ & \\
\hline & & $\begin{array}{l}\text { Strategy } \\
\text { Distractibility }\end{array}$ & Capture task & & \\
\hline \multirow[t]{4}{*}{ Injury and illness } & Incidence & Retrospective 3 & Online questionnaire & & $3 \mathrm{~min}$ \\
\hline & injury and & months & & & \\
\hline & illness & $\begin{array}{l}\text { Longitudinal one } \\
\text { year, every } 2 \text { weeks }\end{array}$ & Online questionnaire & & \\
\hline & $\begin{array}{l}\text { Classification } \\
\text { of injury or } \\
\text { illness (if } \\
\text { applicable) }\end{array}$ & & $\begin{array}{l}\text { Telephone } \\
\text { conversation }\end{array}$ & & $5 \min$ \\
\hline \multirow[t]{4}{*}{ Psychosocial health } & $\begin{array}{l}\text { Self- } \\
\text { perception }\end{array}$ & & $\begin{array}{l}\text { Self-Perception Profile } \\
\text { for Children (SPPC) }\end{array}$ & $10 \min$ & \\
\hline & Quality of life & & Disabkids & & $10 \mathrm{~min}$ \\
\hline & Self-efficacy & & Exercise Self-efficacy & & $2 \min$ \\
\hline & & & Scale & & \\
\hline
\end{tabular}

DOB; date of birth, FMS; functional movement score, BMI; body mass index, BIA; body impedance analysis, VO 2peak; peak oxygen uptake, CPET; cardio-pulmonary exercise test, RER; respiratory exchange ratio, MPST; muscle power sprint test. 


\section{General information}

\section{Cardiovascular health}

Cardiovascular health is divided in several aspects in this study: fat free mass, body mass index, arterial stiffness and blood pressure.

Fat free mass will be determined with bioelectrical impedance analysis (BIA), using the Bodystat Quadscan 4000 (EuroMedix, Leuven, Belgium). BIA is a non-invasive easy test to measure lean body mass and fat by comparing conductivity and resistance in the body ${ }^{34}$. Body mass index will be calculated as weight $(\mathrm{kg}) /$ length $(\mathrm{m})^{2}$. Weight will be measured using a wheelchair scale in case of subjects who are in the wheelchair group. In other cases a person weighing scale will be used. Height will be measured standing in case of ambulant subjects and supine in case of wheelchair bound persons. In case of spasticity, arm span width will be measured. Arm span length will be measured to the nearest centimeter from middle finger?tip to finger?tip. Body mass index (BMI) will then be calculated as the body mass divided by the square of arm span length that will be adjusted using arm span $\times 0.95$ for mid? 3 lumbar lesions and arm span $\times 0.90$ for high lumbar/thoracic lesions in case of central neurological disorders ${ }^{35}$.

Arterial stiffness has two independent measurement values: augmentation index: (AIX) and pulse wave velocity (PWV). Measurement will take place with the Arteriograph (Arteriograph.nI/LITRA, Amsterdam, the Netherlands). The Arteriograph measures the PWV and the AIX through the brachioradial artery using oscillometric tonometry. Each subject rests supine for at least 10 minutes before recordings are made. The measurement will take place with an inflatable cuff (similar to blood pressure measurement) at the right upper arm. Instructions to the subject are no food intake 3 hours before measurement and no talking during the measurement. Blood pressure will also be measured using the Arteriograph within the same measurement.

After the pulse wave velocity measurement, the child is allowed to eat something, before continuing with the rest of the tests.

\section{Physical fitness}

Physical fitness consists of a combination of aerobic fitness, anaerobic fitness, muscle strength, flexibility and agility. Using the FMS for 500 meters the group of subjects will be divided in two sets depending on their mode of locomotion on this distance: wheelchair users and subjects who are able to walk with or without mobility aids. For these two groups, different testing tools will be used, appropriate for the type of locomotion. 
Subsequently, within the group of subjects who are ambulatory different levels of mobility can be identified in order to apply a proper testing protocol, see Table 4.

\section{Aerobic fitness}

In exercise testing peak, oxygen uptake $\left(\mathrm{VO}_{\text {2peak }}\right)$ is considered to be the single best indicator of the cardio-respiratory system, often referred to as aerobic fitness. A cardiopulmonary exercise testing system, the Cortex Metamax 3X (Samcon bvba, Melle, Belgium), will be used for evaluating the respiratory gasses and $\mathrm{VO}_{\text {2peak }}$.

Bhambani et al. concluded that maximal exercise testing during the main mode of ambulation elicits the highest oxygen uptake. Therefore the type of sports or daily locomotion determines whether the shuttle run, shuttle ride or a cycling test will be used $^{36}$.

Children who are able to walk will be tested with an (adapted) shuttle run test ${ }^{37,38}$. The speed of the shuttle run test will be adjusted based on the results of the muscle power sprint test and the agility test and the level of mobility, see Table 4.

In children with a congenital cardiopulmonary disease a cycling test will be used, because of the monitoring of the heart for safety issues. The cycling test, using the Godfrey protoco ${ }^{39}$, will also be applied to evaluate the aerobic fitness in children who are active on a bike in sports or daily living. Load depends on height of the child and the expected level of fitness.

A shuttle ride test will be used in children using a wheelchair. Shuttle tests are field tests in which a participant walks or runs between 2 markers. In this case they have to ride a distance of 10 meters in their own wheelchair, if applicable their sports wheelchair, between two cones. The starting speed is $2.0 \mathrm{~km} / \mathrm{h}$ and the speed is increased with 0.25 $\mathrm{km} / \mathrm{h}$ every minute. The children have to keep on riding, until they fail to reach the cone two times in a row, despite encouragements. This protocol has been proven valid as a maximal exercise test in youth with $\mathrm{CP}$ and spina bifida ${ }^{40,41}$.

Regardless of the testing modality, the test will start with a resting steady state measurement for 3 minutes. To reach a total exercise time of at least 6 (children) and 8 (adolescents) minutes the protocol will be adapted based on the expected level of fitness. This might be due to the subjects high competition level for example or extreme athletic physique but also when a very low fitness is expected. In case of the cycling test, an unloaded phase of 1 minute will precede the exercise phase. Each test will be until volitional exhaustion. Usual emergency procedures are in place to ensure health and 
safety in the very unlikely event of an emergency.

\section{Anaerobic fitness}

The muscle power sprint test is used to measure anaerobic fitness ${ }^{42,43}$. Subjects have to complete six 15-meter runs at a maximum pace. The MPST is an intermittent sprint test, in which the child stops and starts at standardized intervals. For children who self-propel manual a wheelchair, the MPST has also been proven a reproducible test for measuring anaerobic fitness and agility in children and adolescents with CP and SB ${ }^{44,45}$.

Power output will be calculated for each of the six sprints: power $=$ weight $\times(\text { distance })^{2}$ / (time) $)^{3}$. Peak power will be defined as the highest calculated power, while mean power was defined as average power over the six sprints.

Table 4: Level of mobility for identifying testing protocol.

\begin{tabular}{ll}
\hline Category & Level of mobility \\
\hline I & Subjects with a very low level of mobility (able to walk $<400$ meter in 6 minutes) \\
II & Subjects with a low level of mobility (able to walk $>400$ meter in 6 minutes) \\
III & $\begin{array}{l}\text { Subjects with average level of mobility: walking indoors and outdoors and climbing } \\
\text { stairs without limitations and able to perform gross motor skills including running and } \\
\text { jumping. }\end{array}$ \\
IV & $\begin{array}{l}\text { Subjects with an excellent level of mobility, who are used to run at a speed of } 8 \mathrm{~km} / \mathrm{h} \\
\text { during their practicing their sports or during competition. }\end{array}$ \\
\hline
\end{tabular}

\section{Strength}

To test the strength of the subjects, tests from the Brockport fitness test are chosen ${ }^{46}$. The handgrip strength will be tested through the use of a hand held hydraulic dynamometer (HHD) as described by Beenakker et al. ${ }^{47}$ The subjects dominant hand will be tested.

To measure the functionality of hand, wrist, and arm the reverse curl is used ${ }^{48}$. The participant attempts to pick up a $(0.5-\mathrm{kg})$ dumb-bell with the preferred arm while seated in a chair or wheelchair.

The seated push up test is designed to measure upper-body strength and endurance ${ }^{48}$. Participants attempt to perform a seated push-up and hold it for up to 20 s.

The standing Broad jump (only for the ambulatory group) will be used to evaluate the 
explosive strength of the lower limbs by measuring the distance jumped with two legs together from standing position ${ }^{49}$. In wheelchair dependent participants, the one stroke push will evaluate the explosive strength of the upper limbs by measuring the distance one can cover in a wheelchair by one push ${ }^{44}$.

\section{Flexibility}

To measure upper-body flexibility, the modified Apley test will be applied. The participant attempts to reach back and touch with one hand the superior medial angle of the opposite scapula. The modified Thomas test is designed to assess the length of the participant's hip flexor muscles (M. Iliopsoas and M. Rectus Femoris) ${ }^{48}$.

\section{Agility}

The 10x5 Meter Sprint Test will be used to measure agility ${ }^{44}$. During this test, the child has to sprint (for ambulatory and wheelchair users as well) as fast as possible, 10 times, in between 2 lines that are 5 meter apart. There is no resting period, so the child/adolescent has to turn as fast as possible during this test. Time will be recorded using a stopwatch.

\section{Physical activity}

Accelerometry in combination with heart rate monitoring will be used to measure the type, duration, frequency and intensity of physical activity in daily life. The Activ8 (2M Engineering Ltd. Valkenswaard) will measure the modality of physical activity. The Activ8 system is new and has been recently be validated in cooperation with the Erasmus Medial Centre's rehabilitation department in Rotterdam (Lankhorst, K. et al. work in progress). Participants who are able to walk wear one small sensor on the dominant leg. Participants in a wheelchair have to wear 2 small sensors (chest, one wrist). Participants will wear these monitors during the tests and during 7 days in their own environment. Wearing the activity monitor will not alter the activity pattern of the participants; all activities in daily life and in sport can be performed. The Actiheart (Camntech), will be used to detect the intensity of physical activity ${ }^{50}$. The Actiheart is a small device detecting the heart rate frequency via two electrode-stickers on the chest and has been used previously in children with Spina Bifida ${ }^{51}$. During the one week of wearing the activity monitor, the participant will also fill out an activity diary in order to interpret missing data of the activity monitor. The completion of the activity diary will only take approximately 5 minutes per day. 


\section{Injuries and illness}

The incidence and type of injury and illness of the participant at TO and 3 months in retrospective will be filled out via a digital questionnaire and takes 5 minutes to complete. The injury density (ID) will be calculated per 1000 hours of scheduled physical activity ${ }^{52}$. Besides the retrospective registration, the injuries and illnesses will also be monitored longitudinal for one year, every 2 weeks. The parent and / or participant receives a short digital questionnaire of 5 simple questions, send by email and takes approximately 1 minute to complete. If a question will be answered positively, there will be a telephone conversation with the child, young adult or parent, to detect the cause and severity to register the diagnosis of injury or illness. The researcher will register the injury by using a classification list. Only if the diagnosis remains unclear after the telephone conversation, a physical examination of a sports physician or a physical therapist will take place.

\section{School performance}

The type of education of the participant will be noted. If available, outcomes of a national educational achievement test (CITO) will be used for quantifying school performance, in both 'elementary school' and 'secondary school'.

\section{Cognition}

To evaluate cognitive functioning, attention will be measured. To overcome locomotive influences attention tests will be carried out on a tablet (Asus Eee Slate Tablet, with a 12.1 inch display and clock speed of $1.33 \mathrm{GHz}$ ).

Three types of attention will be measured: sustained attention, search strategy and distractibility. Sustained attention will be measured using an adapted digitalized version of the Bourdon-Vos task ${ }^{53}$. This task is a time-limited test. Children had to continue until the whole test was finished, or stop after 10 minutes. For distractibility an object cancellation task will be used and takes 5 minutes to complete. The search strategy of the participant during this cancellation test for distractibility is computed afterwards via software of this tablet test. Another test for measuring distractibility is the capture task. This test was adapted from Van Der Stigchel \& Nijboer ${ }^{54}$. In each trial the participant is asked to focus on a central fixation cross. When the cross disappears, the target, represented as an apple, appears in one of the corners. In $50 \%$ of the trials, a distractor will appear as well. Reaction time will be measured for both conditions to calculate distractibility. 


\section{Psychosocial health}

To evaluate self-perception in this study, the Dutch translation of the self-perception profile scale (SPPS) for children and for adolescents will be used ${ }^{55}$. This questionnaire has been validated to measure self-perception. The questionnaire will take approximately 10 minutes to complete.

\section{Quality of life}

To evaluate the quality of life satisfaction, the Dutch version of the Disabkids will be used. This questionnaire measures the quality of life and the independence of children with chronic health conditions. It takes approximately 10 minutes to fill out.

\section{Self-efficacy}

To assess self-efficacy specific for exercise and physical activity a Dutch questionnaire is filled out digitally at home by the child and will take approximately 2 minutes ${ }^{56}$.

\section{Sample size}

The sample size of the HAYS-study is based on a study of Verschuren \& Takken ${ }^{57}$. In this study children and adolescents with cerebral palsy had an average peak oxygen uptake of $42 \pm 8.2 \mathrm{ml} / \mathrm{kg} / \mathrm{min}$. To prove a difference of $10 \%$ between sporting or nonsporting subjects, with an alpha of 0.05 and bèta of 0.20 (power of 0.80 ) a sample size of 66 subjects per group is required. When taking a failure rate of $10 \%$ into account, 146 subjects should be included in total.

\section{Statistical analysis}

Data will be checked for normal distribution before applying the right type of parametric or non-parametric tests. First, descriptive statistics will be used to describe the two samples. Independent sample T-tests or appropriate non-parametric tests will be used to determine the differences between the sport and non-sport group. 


\section{DISCUSSION}

The current paper describes the rationale, design and methods of a cross-sectional study concerning participation in sports focused on children and adolescents with a physical disability or chronic disease.

To our knowledge this is the first study to evaluate this effect of sport participation on physical, social and mental health within this population. The aim is to determine both the positive and negative effects of sports related to health outcomes in children with disabilities and chronic childhood onset conditions. We hypothesize that the group participating in sports regularly will show higher levels of physical activity associated with better health outcomes, a relative lower incidence density, better cognitive functioning and school performance.

New insights gained from this study could stimulate the improvement of facilities for adapted sports by the government. Also children with a chronic disease or physical disability and their caregivers, sport coaches, physical therapists and other interested parties will be more easily convinced of the advantages of sports participation for this population.

Although we carefully chose our study settings according to its population, we are aware of some limitations of the study.

Objective measurements are chosen where possible. To achieve the best results possible, the best fitting testing modality will be chosen for each participant. The testing modality has to mimic the type of sport participated in. In children who do not participate in sport, the most common form of physical activity in daily life will be chosen as an indicator for the test modality. In general, some test modalities have been proven to elicit a higher $\mathrm{VO}_{2 \text { peak }}$ in the same subject ${ }^{36}$. The test modality could therefore influence the test outcome. To minimalize this bias we will pursue a comparable number of testing modality types in both groups.

In conclusion, this study will provide insight in the effects of sports participation on the health of children and adolescents with a chronic disease or physical disability. 


\section{REFERENCES}

1. Murphy NA, Carbone PS, American Academy of Pediatrics Council on Children With Disabilities: Promoting the participation of children with disabilities in sports, recreation, and physical activities. Pediatrics 2008; 121(5):1057-1061.

2. van Brussel M, van der Net J, Hulzebos E, Helders PJ, Takken T: The Utrecht approach to exercise in chronic childhood conditions: the decade in review. Pediatr Phys Ther 2011; 23(1):2-14.

3. Arraiz GA, Wigle DT, Mao Y: Risk assessment of physical activity and physical fitness in the Canada Health Survey mortality follow-up study. J Clin Epidemiol 1992; 45(4):419-428.

4. Blair SN, Kohl HW, Paffenbarger RS, Clark DG, Cooper KH, Gibbons LW: Physical fitness and all-cause mortality: A prospective study of healthy men and women. JAMA 1989; 262(17):2395-2401.

5. Colditz GA, Samplin-Salgado M, Ryan CT, Dart H, Fisher L, Tokuda A, Rockhill B: Harvard Report on Cancer Prevention, Volume 5 Fulfilling the potential for cancer prevention: policy approaches. Cancer Causes \& Control 2002; 13(3):199-212.

6. Erikssen G: Physical fitness and changes in mortality. Sports Med. 2001; 31(8):571-576.

7. Eime RM, Young JA, Harvey JT, Charity MJ, Payne WR: A systematic review of the psychological and social benefits of participation in sport for children and adolescents: informing development of a conceptual model of health through sport. Int J Behav Nutr Phys Act 2013; 10(98):16.

8. Richter KJ, Gaebler Spira D, Mushett CA: Sport and the person with spasticity of cerebral origin. Dev Med Child Neurol 1996; 38(9):867-870.

9. Klapwijk A: The multiple benefits of sports for the disabled. Disabil Rehabil 1987; 9(2):8789.

10. Jackson RW, Davis GM: The value of sports and recreation for the physically disabled. Orthop Clin North Am 1983; 14(2):301-315.

11. Hutzter Y, Bar Eli M: Psychological benefits of sports for disabled people: A review. Scand J Med Sci Sports 1993; 3(4):217-228.

12. Basch CE: Healthier students are better learners: a missing link in school reforms to close the achievement gap. J Sch Health 2011; 81(10):593-598.

13. Donnelly JE, Greene JL, Gibson CA, Smith BK, Washburn RA, Sullivan DK, DuBose K, Mayo MS, Schmelzle KH, Ryan JJ: Physical Activity Across the Curriculum (PAAC): a randomized controlled trial to promote physical activity and diminish overweight and obesity in elementary school children. Prev Med. 2009; 49(4):336-341. 
14. Sallis JF, McKenzie TL, Kolody B, Lewis M, Marshall S, Rosengard P: Effects of healthrelated physical education on academic achievement: Project SPARK. Res Q Exerc Sport 1999; 70(2):127-134.

15. Singh A, Uijtdewilligen L, Twisk JW, Van Mechelen W, Chinapaw MJ: Physical activity and performance at school: a systematic review of the literature including a methodological quality assessment. Arch Pediatr Adolesc Med. 2012; 166(1):49-55.

16. Chaddock L, Pontifex MB, Hillman CH, Kramer AF: A review of the relation of aerobic fitness and physical activity to brain structure and function in children. J Int Neuropsychol Soc 2011; 17(06):975-985.

17. Pontifex MB, Scudder MR, Drollette ES, Hillman CH: Fit and vigilant: the relationship between poorer aerobic fitness and failures in sustained attention during preadolescence. Neuropsychology 2012; 26(4):407.

18. Tomporowski PD, Davis CL, Miller PH, Naglieri JA: Exercise and children's intelligence, cognition, and academic achievement. Educ Psychol Rev 2008; 20(2):111-131.

19. Chaddock L, Hillman CH, Pontifex MB, Johnson CR, Raine LB, Kramer AF: Childhood aerobic fitness predicts cognitive performance one year later. J Sports Sci 2012; 30(5):421430.

20. London RA, Castrechini S: A longitudinal examination of the link between youth physical fitness and academic achievement. J Sch Health 2011; 81(7):400-408.

21. Eime RM, Young JA, Harvey JT, Charity MJ, Payne WR: A systematic review of the psychological and social benefits of participation in sport for children and adolescents: informing development of a conceptual model of health through sport. International Journal of Behavioral Nutrition \& Physical Activity 2013; 10(1).

22. Groff DG, Lundberg NR, Zabriskie RB: Influence of adapted sport on quality of life: Perceptions of athletes with cerebral palsy. Disability \& Rehabilitation 2009; 31(4):318-326.

23. Verschuren O, Ketelaar M, Gorter JW, Helders PJ, Uiterwaal CS, Takken T: Exercise training program in children and adolescents with cerebral palsy: a randomized controlled trial. Arch Pediatr Adolesc Med 2007; 161(11):1075-1081.

24. Weiss J, Diamond T, Demark J, Lovald B: Involvement in Special Olympics and its relations to self-concept and actual competency in participants with developmental disabilities. Res Dev Disabil 2003; 24(4):281-305.

25. Adirim TA, Cheng TL: Overview of injuries in the young athlete. Sports Med. 2003; 33(1):75-81.

26. Trifonov Rexen C, Andersen LB, Ersboll AK, Jespersen E, Franz C, Wedderkopp N: Injuries 
in children with extra physical education in primary schools. Med Sci Sports Exerc 2014; 46(4):745-752.

27. World Health Organization: Excessive Physical Training in Children and Adolescents. A Position Statement from the International Federation of Sports Medicine (FIMS). Schweiz Z Med Traumatol 1991; 39(1):32-34.

28. Bloemers F, Collard D, Paw MC, Van Mechelen W, Twisk J, Verhagen E: Physical inactivity is a risk factor for physical activity-related injuries in children. Br J Sports Med 2012; 46(9):669-674.

29. Sinclair SA, Xiang $\mathrm{H}$ : Injuries among US children with different types of disabilities. Am J Public Health 2008; 98(8):1510-1516.

30. Collard DC, Chinapaw MJ, Van Mechelen W: Design of the iPlay Study. Sports Med. 2009; 39(11):889-901.

31. Webborn N, Willick S, Reeser JC: Injuries among disabled athletes during the 2002 Winter Paralympic Games. Med Sci Sports Exerc 2006; 38(5):811-815.

32. Zwinkels M, Verschuren $O$, Lankhorst K, van der Ende-Kastelijn K, de Groot F, Backx F, Visser-Meily J, Takken T: Sport-2-Stay-Fit study: health effects of after-school sport participation in children and adolescents with a chronic disease or physical disability. BMC Sports Sci Med Rehabil 2015; 7: 22.

33. Balady GJ, Chaitman B, Driscoll D, Foster C, Froelicher E, Gordon N, Pate R, Rippe J, Bazzarre T: Recommendations for cardiovascular screening, staffing, and emergency policies at health/fitness facilities. Circulation 1998; 97(22):2283-2293.

34. Mok E, Beghin L, Gachon P, Daubrosse C, Fontan JE, Cuisset JM, Gottrand F, Hankard R: Estimating body composition in children with Duchenne muscular dystrophy: comparison of bioelectrical impedance analysis and skinfold-thickness measurement. Am J Clin Nutr 2006; 83(1):65-69.

35. Dosa NP, Foley JT, Eckrich M, Woodall-Ruff D, Liptak GS: Obesity across the lifespan among persons with spina bifida. Disability \& Rehabilitation 2009; 31(11):914-920.

36. Bhambhani YN, Holland LJ, Steadward RD: Maximal aerobic power in cerebral palsied wheelchair athletes: validity and reliability. Archives of Physical Medicine \& Rehabilitation 1992; 73(3):246-252.

37. Léger LA, Lambert J: A maximal multistage 20-m shuttle run test to predict 1 dot VO2 max. Eur J Appl Physiol Occup Physiol 1982; 49(1):1-12.

38. Verschuren O, Takken T, Ketelaar M, Gorter JW, Helders PJ: Reliability and validity of data for 2 newly developed shuttle run tests in children with cerebral palsy. Phys Ther 2006; 
86(8):1107-1117.

39. Washington RL, Bricker JT, Alpert BS, Daniels SR, Deckelbaum RJ, Fisher EA, Gidding SS, Isabel-Jones J, Kavey RE, Marx GR: Guidelines for exercise testing in the pediatric age group. From the Committee on Atherosclerosis and Hypertension in Children, Council on Cardiovascular Disease in the Young, the American Heart Association. Circulation 1994; 90(4):2166-2179.

40. Verschuren O, Zwinkels M, Ketelaar M, Reijnders-van Son F, Takken T: Reproducibility and validity of the 10-meter shuttle ride test in wheelchair-using children and adolescents with cerebral palsy. Phys Ther 2013; 93(7):967-974.

41. Bloemen MA, de Groot JF, Backx FJ, Westerveld RA, Takken T: Arm cranking versus wheelchair propulsion for testing aerobic fitness in children with spina bifida who are wheelchair dependent. J Rehabil Med 2015; 47(5):432-437.

42. Verschuren O, Takken T, Ketelaar M, Gorter JW, Helders PJ: Reliability for running tests for measuring agility and anaerobic muscle power in children and adolescents with cerebral palsy. Pediatr Phys Ther 2007; 19(2):108-115.

43. Verschuren O, Zwinkels M, Obeid J, Kerkhof N, Ketelaar M, Takken T: Reliability and validity of short term performance tests for wheelchair using children and adolescents with cerebral palsy. Dev Med Child Neurol 2013; 55(12):1129-1135.

44. Verschuren $O$, Zwinkels M, Obeid J, Kerkhof N, Ketelaar M, Takken T: Reliability and validity of short term performance tests for wheelchair using children and adolescents with cerebral palsy. Dev Med Child Neurol 2013; 55(12):1129-1135.

45. Verschuren $\mathrm{O}$, Bloemen M, Kruitwagen C, Takken T: Reference values for anaerobic performance and agility in ambulatory children and adolescents with cerebral palsy. Developmental Medicine \& Child Neurology 2010; 52(10):e222-e228.

46. Vanhees L, Lefevre J, Philippaerts R, Martens M, Huygens W, Troosters T, Beunen G: How to assess physical activity? How to assess physical fitness? Eur J Cardiovasc Prev Rehabil 2005; 12(2):102-114.

47. Beenakker EA, van der Hoeven JH, Fock JM, Maurits NM: Reference values of maximum isometric muscle force obtained in 270 children aged 4-16 years by hand-held dynamo- metry. Neuromuscul Disord 2001; 11(5):441-446.

48. Winnick J, Short F: The Brockport physical fitness test manual: a health-related test for youths with physical and mental disabilities. Champaign, IL: Human Kinetics 1999.

49. Deitz JC, Kartin D, Kopp K: Review of the Bruininks-Oseretsky test of motor proficiency, (BOT-2). Phys Occup Ther Pediatr 2007; 27(4):87-102. 
50. Brage S, Brage N, Franks P, Ekelund U, Wareham N: Reliability and validity of the combined heart rate and movement sensor Actiheart. Eur J Clin Nutr 2005; 59(4):561-570.

51. De Groot J, de Jong A, Visser T, Takken T: Validation of the Actical and Actiheart monitor in ambulatory children with Spina Bifida. J Pediatr Rehabil Med: An Interdisciplinary Approach 2013; 6:103-111.

52. van Mechelen W, Hlobil H, Kemper HC: Incidence, severity, aetiology and prevention of sports injuries. Sports Med. 1992; 14(2):82-99.

53. Vos P: De Bourdon concentratietest voor kinderen.[The Bourdon concentration test for children]. 1992 Swetz \& Zeitlinger, Lisse (the Netherlands)

54. Van der Stigchel S, Nijboer TC: The imbalance of oculomotor capture in unilateral visual neglect. Conscious Cogn 2010;19(1):186-197.

55. Harter S: Self-perception profile for children: revision of the perceived competence scale for children. Denver, CO: University of Denver, Department of Psychology; 1985.

56. Nooijen CF, Post MW, Spijkerman D, Bergen MP, Stam HJ, van den Berg-Emons, Rita JG: Exercise self-efficacy in persons with spinal cord injury: Psychometric properties of the Dutch translation of the exercise self-efficacy scale. J Rehabil Med 2013; 45(4):347-350.

57. Verschuren O, Takken T: Aerobic capacity in children and adolescents with cerebral palsy. Res Dev Disabil 2010; 31(6):1352-1357. 


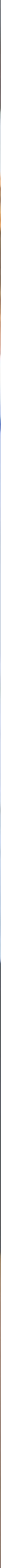




\section{A novel tool for quantifying and promoting physical activity in youths with typical development and youths who are ambulatory and have motor disability}

Kristel Lankhorst Rita van den Berg-Emons Johannes Bussmann Herwin Horemans Janke de Groot 


\section{ABSTRACT}

Background. Several device-based instruments have been validated in the pediatric population, but none of these are clinically applicable and provide real-time feedback on actual physical activity in terms of postures and movements. A new device (Activ8) is promising for that purpose.

Objective. The objective of this study was to investigate the criterion validity of the Activ8 for measuring static (sitting, standing) and dynamic (walking, bicycling, running) activities, and for separating postures and movements within basic and complex activities in youths with typical development (TD) and peers with motor disability (not typical development [NTD]).

Design. This was a criterion validation study.

Methods. Ten participants with TD (mean age $=14$ years; SD $=2.5$ ) and 10 participants with NTD (mean age $=12.9$ years; SD $=2.1$ ) performed a standardized series of basic and daily life (complex) activities. The Activ8 measured postures and movements, while camera recording served as a reference. The outcome measures were the mean time differences between the Activ8 output and video data for the merged categories "static" and "dynamic" and for the separate postures and movements.

Results. For the merged categories static and dynamic, the criterion validity was found to be excellent in both participants with TD and participants with NDT within basic activities and was found to be good to excellent in participants with TD and moderate to good in participants with NTD within complex activities. The detection of separate postures and movements was found to be poor to excellent in both groups within complex activities. Limitations. The sample of youths with NTD was small and limited to youths who could be considered to be at least ambulatory within a household.

Conclusions. Activ8 is a valid tool when the merged categories static and dynamic are used to interpret physical activity in daily life in both youths with TD and youths with NTD and mild motor impairment. To optimize the quantification of separate postures and movements, adjustment of the existing algorithm is required. 


\section{INTRODUCTION}

The level of being physically active and sedentary are 2 independent factors related to health outcomes in youths. ${ }^{1-4}$ Children and adolescents who are physically active have positive health outcomes. This fact is evident not only in youths with typical development (TD) but also in youths with motor disability-in whom the prevention of health-related problems is an important reason for being active..$^{5-7}$ Therefore, a growing number of physical activity (PA) guidelines address the importance of being physically active and limiting sedentary time to reduce the risk of developing chronic diseases. ${ }^{6,8-12}$ In order to determine whether a child meets the PA guidelines and whether interventions targeting PA are indicated and successful, valid instruments to measure PA in daily life are needed. Self-reported instruments, like questionnaires, are frequently used to assess PA, but are not proven valid..$^{13}$ Device-based instruments, like accelerometers, have been proven more valid to assess PA. ${ }^{14-16}$ Most of the currently used activity monitors ${ }^{17}$ are, however, expensive and not easy to use in clinical practice. Clinical use is limited due to complexity of the data analysis, need for additional software and related to the limited clinical applicability of the obtained information regarding PA levels. Moreover, most of the currently validated activity monitors lack a goal-setting and direct feedback function which can support physical therapists in coaching their patients toward healthy active lifestyles.

The Activ8 is a newly developed accelerometry-based activity monitor (developed by $2 \mathrm{M}$ Engineering). Given its low costs and easy-to-use features, it seems promising as a new outcome measure for both research and clinical purposes. Next to being a measurement instrument of PA, it also provides a feedback function that can be used as an intervention tool. The Activ8 is a 1-sensor ambulatory 3-dimensional accelerometer with dimensions of $30 \times 32 \times 10 \mathrm{~mm}$ and a weight of $20 \mathrm{~g}$. The Activ 8 contains a battery, a real-time clock, and a medium for data storage (up to 1 month). The Activ8 aims to detect the actual PA not in terms of movement counts, but in terms of body postures and movements, including bicycling, besides sitting, standing, walking, and running. Activ8 also has the possibility to provide real-time feedback to the user, health care professional, or both about the volume and distribution of postures and movements either through light-emitting diodes on the device itself or a smartphone. Good criterion validity of the Activ8 to quantify PA has recently been established in both healthy adults and in adults with cerebral palsy (CP) $)^{18,19}$ but not yet in youths. Because the validation of accelerometers in the adult population may not translate to children and adolescents, ${ }^{20,21}$ 
the reestablishment of validity for this group as well is recommended. For use in clinical pediatric physical therapist practice, it is of interest whether the Activ8 is able to distinguish static (ie, sitting and standing) from dynamic activities (ie, walking, bicycling, and running), as such information can be used to monitor and encourage active behavior in youths. With children often moving in short bouts, it is also of interest whether the Activ8 is able to distinguish the separate postures and movements (ie, sitting, standing, walking, bicycling, running) during short-duration activities. Finally, it is also important to determine the validity of the Activ8 in youths with a pathological gait, such as $\mathrm{CP}$ and spina bifida (SB), the 2 largest patient groups within pediatric rehabilitation medicine. Because of muscle atrophy and spasticity, these children and adolescents perform activities in a different way than their peers with TD—a fact that may affect the validity of accelerometers for quantifying PA in these populations. Establishing validity in both youths without and with a pathological gait, would enable physical therapists to use this device in a wide range of patients.

The aim of this study was to investigate the criterion validity of the Activ8 using the current algorithm to quantify static and dynamic activities and to separate postures and movements within basic and complex activities in youths with TD and youths with motor disability (not typical development [NTD]) and who would be considered at least ambulatory in a household.

\section{METHODS}

\section{Participants}

Children and adolescents were recruited through pediatric physical therapists associated with the research group (Fit for the Future consortium). ${ }^{22}$ In total, 10 children and adolescents with TD and 10 children and adolescents with CP or SB (NTD) were identified as appropriate samples of the target population in which the measurement instrument will ultimately be used. ${ }^{23}$

We used the Functional Mobility Scale (FMS) ${ }^{24}$ in all participants to objectify the functional mobility at different distances. To specify the functional mobility in more detail in youths with motor disability (NTD), the Gross Motor Function Classification System was used for participants with $\mathrm{CP}^{25,26}$ and the adapted Hoffer classification was used for participants with SB. ${ }^{27}$

The 6 inclusion criteria for both groups were as follows: age of 10 to 18 years; ability to understand the instructions necessary to perform the activity protocol; ability to perform 
the activities in the activity protocol; FMS score of 6 for TD group; FMS score of $\geq 4$ and Gross Motor Function Classification System 1 or 2 for youths with CP (1); and FMS score $\geq 4$ and adapted Hoffer classification $\geq 4$ for youths with SB. ${ }^{25-27}$ Person- and diseaserelated characteristics of the participants are described in Table 1. All participants and their parents gave written informed consent.

Table 1: Characteristics of Youths Who Had Typical Development (TD) and Youths Who Did Not Have Typical Development (NTD) ${ }^{\mathrm{a}}$

\begin{tabular}{|c|c|c|c|c|c|c|c|}
\hline Participant & Age (y) & $\begin{array}{l}\text { Height } \\
(\mathrm{cm})\end{array}$ & $\begin{array}{l}\text { Weight } \\
(\mathrm{kg})\end{array}$ & Sex & Diagnosis & Classification $^{b}$ & FMS $^{c}$ \\
\hline \multicolumn{8}{|l|}{ TD } \\
\hline 1 & 16 & 167 & 52 & M & & & 6 \\
\hline 2 & 16 & 186 & 70 & M & & & 6 \\
\hline 3 & 10 & 151 & 44 & M & & & 6 \\
\hline 4 & 10 & 150 & 32 & $\mathrm{~F}$ & & & 6 \\
\hline 5 & 14 & 167 & 50 & $\mathrm{~F}$ & & & 6 \\
\hline 6 & 15 & 173 & 57 & $F$ & & & 6 \\
\hline 7 & 14 & 174 & 62 & M & & & 6 \\
\hline 8 & 17 & 162 & 51 & $\mathrm{~F}$ & & & 6 \\
\hline 9 & 16 & 178 & 64 & $\mathrm{~F}$ & & & 6 \\
\hline 10 & 12 & 165 & 45 & M & & & 6 \\
\hline Mean (SD) & $14.0(2.5)$ & $167.3(11.3)$ & $52.7(11.1)$ & & & & \\
\hline \multicolumn{8}{|l|}{ NTD } \\
\hline 11 & 14 & 171 & 62 & M & $\mathrm{CP}$ & GMFCS 1 & 5 \\
\hline 12 & 13 & 167 & 63 & M & $\mathrm{CP}$ & GMFCS 1 & 5 \\
\hline 13 & 11 & 145 & 49 & M & $\mathrm{CP}$ & GMFCS 1 & 5 \\
\hline 14 & 12 & 161 & 48 & M & $C P$ & GMFCS 1 & 5 \\
\hline 15 & 15 & 182 & 61 & M & $\mathrm{CP}$ & GMFCS 1 & 5 \\
\hline 16 & 14 & 172 & 62 & M & $\mathrm{CP}$ & GMFCS 1 & 5 \\
\hline 17 & 16 & 167 & 98 & $\mathrm{~F}$ & SB & $\begin{array}{l}\text { Community } \\
\text { walkers }\end{array}$ & 5 \\
\hline 18 & 10 & 142 & 32 & M & SB & $\begin{array}{l}\text { Community } \\
\text { walkers }\end{array}$ & 5 \\
\hline 19 & 14 & 180 & 92 & M & SB & $\begin{array}{l}\text { Household } \\
\text { walkers }\end{array}$ & 4 \\
\hline 20 & 10 & 136 & 34 & M & SB & $\begin{array}{l}\text { Household } \\
\text { walkers }\end{array}$ & 4 \\
\hline Mean (SD) & $12.9(2.1)$ & $162.3(16.1)$ & $60.1(21.6)$ & & & & \\
\hline
\end{tabular}

a Youths who did not have typical development were ambulatory and had motor disability; $C P=c e r e b r a l$ palsy; SB = spina bifida; FMS = Functional Mobility Scale; GMFCS = Gross Motor Function Classification System. ${ }^{b}$ GMFCS ${ }^{25}$ or Hoffer classification. ${ }^{27}{ }^{c}$ Score on the FMS. ${ }^{24,26}$ 


\section{Testing Procedure}

Participants performed a series of basic and complex activities according to a standardized protocol (Tab. 2) in a natural setting which was either at home or at school. We used a standardized protocol in which participants were instructed following the same way. The standardized protocol, used in previous validation studies in adults ${ }^{19,28-30}$ was adapted for validation in youths in close collaboration with pediatric physical therapists, and researchers working in the field of pediatric physical therapy and human movement sciences of the Activ8. ${ }^{22}$ Three activities (vacuuming, hanging laundry to dry, and doing the dishes) of the adult validation protocol were removed from the adult validation protocol since they were not considered representative for daily activities of children. In addition, we added the following new activities: setting a table, arts and crafts, walking in a slalom, dribbling a ball, and playing a ball game. According to the experts and previous studies with youths, these new activities are more in line with the movement behavior (sport and play) of children in their leisure time.

In line with the adult validation protocol, 2 important distinctions were made between basic and complex activities. Where a basic activity was defined as an activity consisting of a single body posture or movement, like sitting or walking, a complex activity was defined as a combination of postures and movements, during a short period of time. For instance, a ball game could consist of both standing (static), walking and running (dynamic). ${ }^{30,31}$ To ensure validity during real life activities, participants were instructed to perform the activities in their own manner. The researchers asked the participants after each performed activity whether they felt ready to continue the activity protocol; if not, further resting was allowed. The duration of rest that was needed was determined by the participants. The duration of each activity was 1 minute 30 seconds. The total measurement time of the activity protocol was approximately 45 minutes.

\section{Activ8 Activity Monitor}

Activ8 recording. The Activ8 was fixated to the front of the upper leg of the participants with Tegaderm (3M) skin tape to ensure a fixed position on the leg (Fig. 1). The postures and movements that the Activ8 can distinguish in the adult healthy population are sitting, standing, walking, bicycling and running. To determine the type of postures and movements, the Activ8 uses an algorithm that combines orientation of the sensor with respect to gravity with movement intensity. For example, during standing or walking the 
orientation of the Activ8 is both mainly vertical but movement intensity for walking is higher.

An epoch window was set at 5 seconds, in which each 0.63 second a posture or a movement was detected. This approach resulted in 8 data points per 5 -second epoch. Within these 5-second epochs, multiple postures and movements can be recorded. For example, within 1 epoch, 5 samples of standing still (3.1 seconds) and 3 samples of walking (1.9 seconds) can be detected separately. The Activ8 detection of non-wear is based on the absence of movement or signal variability for a time interval of $>5$ minutes.

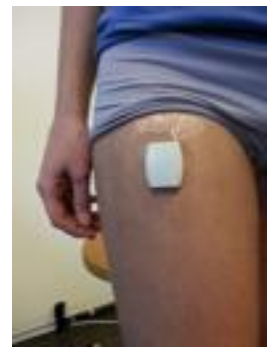

Figure 1: Ventral placement of Activ8 (2M Engineering) on the dominant leg.

Video observation. During performance of the protocol activities, video recordings were made with a handheld digital video camera and used as reference method (Fig. 2). The use of video is an appropriate standard for the assessment and observation of postures and movements. ${ }^{14,28}$ To ensure good viewing of the activities, a standardized protocol was used in line with earlier research in adults 19,30 and youths who (partly) used a wheelchair. ${ }^{28}$ The video recordings were visually scored independently by 2 trained research assistants (1 pediatric physical therapist and 1 human movement scientist) using a standardized protocol ${ }^{19,32}$ of scoring the postures and movements using 1-second time intervals. The 2 research assistants were trained and supervised by an experienced researcher who is a human movement scientist and familiar with the method and analysis technique of the study. ${ }^{19,33}$ To assure interrater reliability of the observation and scoring of the video, 2 training sessions took place before the actual scoring of the videos. In total, 2 videotapes were used for the calculation of the interrater agreement between the 2 research assistants, in which all activities in the protocol of 1920 time points of activity scores were assessed. The intraclass correlation coefficient was 0.95 . To further ensure good data collection and analysis, the 2 research assistants were monitored during the 
actual data collection and data analysis was rechecked by the third trained researcher. If there was no consensus between the 2 researchers, a third person (physical therapist and human movement scientist) was asked to define the posture or movement for final allocation. The third researcher was consulted 4 times during the actual observation and scoring of the videos. In 2 participants, it was difficult to distinguish between walking at a slow pace and walking at a normal pace. In 2 other participants, the distinction between walking and standing was difficult when the participants made a turn during both the activities setting a table and the activity walking in a slalom.

Each 1-second interval was scored for the posture or movement at that moment. The video scoring categories were sitting, standing, walking, bicycling, and running. For the complex activities, multiple activities were performed during the measurement period. As with setting a table, the participant walked and stood still within 1 measurement period. During the complex activities, the posture or movement were also scored each second. Within our protocol staircase climbing was defined as walking.

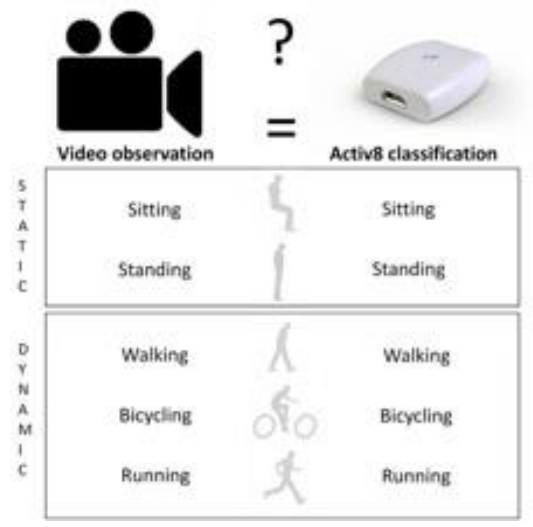

Figure 2: Video observation vs Activ8 (2M Engineering) classification within static and dynamic categories and within separate postures and movements.

\section{Data Analysis}

The Activ8 epochs of 5 seconds were synchronized with the 1-second video data. To avoid the effect of protocol activities that were not directly started or that were finished before the scheduled end of the 90-second period, the first 20 seconds and the last 10 seconds from each performed protocol activity were excluded from our analysis. 
This approach resulted in a 60-second period of each protocol activity, consisting of twelve 5-second epochs. Thereafter, for each participant the number of seconds of each posture or movement category was calculated for both the Activ8 recording and the video observation. This was the input for further analysis. This method is commonly used for the validation of accelerometers for the assessment of postures and movements. ${ }^{28,33}$

\section{Outcome Parameters}

The relative time difference as a percentage was calculated as [(Activ8 recording video observation)/video observation] × 100 for the merged categories "static" (sitting, standing) and "dynamic" (walking, bicycling, running) within basic and complex activities. The relative time difference as a percentage was calculated as [(Activ8 recording - video observation)/video observation) $\times 100$ for the separate postures and movements (sitting, standing, walking, bicycling, running) within basic and complex activities.

Criterion validity was determined from the differences between the Activ8 recording and the video observation. We defined a priori and in line with earlier research a maximum $10 \%$ mean time difference between the Activ8 recording and the video observation as excellent criterion validity, $10 \%$ to $20 \%$ as good, $20 \%$ to $30 \%$ as moderate, and $>30 \%$ as poor. ${ }^{19,28,33,34}$

\section{Role of the Funding Source}

This study was funded by an unconditional grant (PRO-4-03) from the Dutch Foundation Innovation Alliance (SIA-RAAK), part of the Dutch Organization for Scientific Research (NWO). The funding source had no role in the study's design, conduct, and reporting.

\section{RESULTS}

There were no significant differences in age, weight, and height between the TD group and the NTD group. Table 2 shows the participants who were included in the analysis within basic and complex activities. The differences in numbers of participants per activity were due to the ability of a participant to perform an activity, the availability of a staircase, or correct execution of the activity according to the activity protocol. 
Table 2: Basic and complex activities in the activity protocol and number of participants for whom data were available for analysisa.

\begin{tabular}{|c|c|c|}
\hline \multirow[t]{2}{*}{ Activities } & \multicolumn{2}{|c|}{$\begin{array}{l}\text { No. of Participants included in } \\
\text { analysis }^{b}\end{array}$} \\
\hline & TD & NTD \\
\hline \multicolumn{3}{|l|}{$\operatorname{Basic}^{c}(n=9)$} \\
\hline Sitting & 10 & 10 \\
\hline Sitting slouched on a couch or chair & 10 & 10 \\
\hline Standing & $9(3)$ & 10 \\
\hline Walking at a slow pace ${ }^{d}$ & 10 & 10 \\
\hline Normal walking $^{d}$ & 10 & 10 \\
\hline Walking at a fast pace ${ }^{d}$ & 10 & 10 \\
\hline Running over a distance of $10 \mathrm{~m}^{d}$ & $9(5)$ & 8 (17 and 18) \\
\hline Cycling at a slow pace ${ }^{d}$ & 10 & 8 (18 and 20) \\
\hline Cycling at a fast pace ${ }^{d}$ & 10 & $7(14,18$, and 20$)$ \\
\hline \multicolumn{3}{|l|}{ Complex $^{e}(n=7)$} \\
\hline $\begin{array}{l}\text { Climbing stairs at a preferred pace (forbidden to run on the } \\
\text { stairs) }\end{array}$ & 10 & $8(15$ and 16$)$ \\
\hline Setting a table & $9(5)$ & 10 \\
\hline Engaging in arts and crafts while sitting in a chair & 10 & 10 \\
\hline $\begin{array}{l}\text { Walking in a slalom }{ }^{d}(6 \mathrm{~m} \text {, at } 0,1.5,3,4.5 \text {, and } 6 \mathrm{~m} \text { a pawn } \\
\text { was placed })\end{array}$ & 10 & 10 \\
\hline Dribbling a ball over a distance of $10 \mathrm{~m}$ & 10 & 10 \\
\hline $\begin{array}{l}\text { Throwing a ball to a wall (with the participant standing } 3 \mathrm{~m} \\
\text { from the wall) }\end{array}$ & $9(3)$ & 10 \\
\hline $\begin{array}{l}\text { Sitting in a chair, standing up, walking } 5 \mathrm{~m} \text {, returning to the } \\
\text { chair, and sitting down }\end{array}$ & 10 & 10 \\
\hline
\end{tabular}

${ }^{a} \mathrm{NTD}=$ not typical development (ie, ambulatory and with motor disability); TD = typical development. ${ }^{b}$ Numbers in parentheses are the designations of participants who were excluded from the analysis. ${ }^{c}$ Activities similar to those in the Activ8 (2M Engineering) classification. ${ }^{d}$ Participants performed the activities at their own preferred and constant pace, ${ }^{e}$ Activities of daily living (including combined activities, such as walking, running, and standing during a ball game). 


\section{Merged Categories Static and Dynamic}

The results concerning the merged categories static and dynamic are presented in Table 3, for both participants with TD and NTD and basic and complex activities. For the basic activities, the relative time difference between the Activ8 recordings and the video observation ranged from $-1.3 \%$ to $0.7 \%$ in participants with TD and from $-0.4 \%$ to $0.7 \%$ in participants with NTD. The criterion validity was therefore rated excellent in both groups for both merged categories static and dynamic. For the complex activities, the relative time difference between the Activ8 recordings and the video observation for static activities was $-17 \%$; for dynamic activities, it was $8.3 \%$. Therefore criterion validity during complex activities was rated good to excellent in participants with TD. In participants with NTD, the relative time differences were $-24.3 \%$ for static activities and $13.3 \%$ for dynamic activities; therefore, the criterion validity was rated moderate to good.

Table 3: Mean and relative time differences between video data and activ8 output within static and dynamic activities.

\begin{tabular}{|c|c|c|c|c|c|c|c|}
\hline Group $^{b}$ & $\begin{array}{l}\text { Activity } \\
\text { Category }\end{array}$ & Activities & Video (s) & Activ8 (s) & $\begin{array}{c}\text { Mean Time } \\
\text { Difference }(s)^{c}\end{array}$ & $\begin{array}{l}\text { Relative Time } \\
\text { Difference }(\%)^{d}\end{array}$ & $\begin{array}{c}\text { Criterion } \\
\text { Validity } \\
\text { Score }\end{array}$ \\
\hline \multirow[t]{2}{*}{ TD } & Basic & Static $^{e}$ & 1764 & 1741 & -23 & -1.3 & Excellent \\
\hline & & Dynamic $^{f}$ & 3516 & 3539 & 23 & 0.7 & Excellent \\
\hline \multirow[t]{2}{*}{ NTD } & Basic & Static $^{e}$ & 1802 & 1815 & 13 & 0.7 & Excellent \\
\hline & & Dynamic $^{f}$ & 3178 & 3165 & -13 & -0.4 & Excellent \\
\hline \multirow[t]{2}{*}{ TD } & Complex & Static $^{e}$ & 1515 & 1258 & -257 & -17.0 & Good \\
\hline & & Dynamic $^{f}$ & 3105 & 3362 & 257 & 8.3 & Excellent \\
\hline \multirow[t]{2}{*}{ NTD } & Complex & Static $^{e}$ & 1658 & 1256 & -402 & -24.3 & Moderate \\
\hline & & Dynamic $^{f}$ & 3022 & 3424 & 402 & 13.3 & Good \\
\hline
\end{tabular}

${ }^{2} 2 \mathrm{M}$ Engineering. ${ }^{b} \mathrm{NTD}=$ not typical development (ie, ambulatory and with motor disability); $T D=$ typical development. ${ }^{C}$ Calculated as (Activ8 - video). ${ }^{d}$ Calculated as [(Activ8 time - video time)/video time] $\times 100 .{ }^{e}$ Merged category of sitting and standing. ${ }^{f}$ Merged category of walking, bicycling, and running.

\section{Separate Analysis of Postures and Movements}

The results concerning the separate postures and movements are presented in Table 4. For the basic activities, the relative time difference between the Activ8 recordings and the video observation ranged from $-14.7 \%$ (standing) to $-0.2 \%$ (walking) in participants 
with TD. This difference in standing was mainly the result of standing being sometimes classified as sitting by the Activ8.

In participants with NTD, the relative time difference between Activ8 recordings and the video observation ranged from 3.4\% (running) to 39.7\% (bicycling). In 1 participant (designated 20), the posture standing was detected as sitting, while for another participant (designated 16), the activity bicycling at a slow pace was detected as sitting. This resulted in an overestimation of sitting. Furthermore, in 3 participants (designated 16, 19, and 20), the activities walking at a slow pace, walking at a normal pace, and walking at a fast pace were, for several seconds, detected as bicycling. This finding resulted in an overestimation of bicycling and an underestimation of walking.

Within basic activities, the criterion validity was rated good for standing and excellent for the other activities (sitting, walking, bicycling and running) in participants with TD. In participants with NTD, the criterion validity was rated excellent for sitting (6.9\%) and running (3.4\%), good for standing $(-11.6 \%)$, moderate for walking $(-21 \%)$, and poor for the activity bicycling (39.7\%).

Within complex activities, the relative time difference between Activ8 recordings and video observation varied from $-42.1 \%$ (standing) to $3.4 \%$ (walking) in participants with TD. Within setting a table, ball game, and stand up from a chair, walk back and sit down, standing was underestimated and detected as walking. In 4 participants (designated 1, $3,8$, and 10$)$, the complex activity climbing stairs was detected as bicycling instead of walking. This resulted in an overestimation of bicycling (182 seconds).

For participants with NTD, the time difference ranged from $-8.1 \%$ (sitting) to $265.2 \%$ (running). Overall, in 2 participants (designated 16 and 20), the Activ8 overestimated bicycling (713 seconds) in disadvantage of walking and standing, which were underestimated ( -372 seconds and -296 seconds, respectively). The underestimation of walking was seen in all complex activities that included the activity walking (setting a table, walking in a slalom, ball game, dribbling with a ball, and stand up from a chair, walk back and sit down).

Within complex activities, the criterion validity in participants with TD was rated excellent for walking, good for sitting, moderate for running and poor for standing. In participants with NTD, the criterion validity was rated excellent for sitting, good for walking and poor for standing and running. 
Table 4: Mean and relative time differences between video data and activ8 ${ }^{a}$ output within basic and complex activities.

\begin{tabular}{|c|c|c|c|c|c|c|c|}
\hline Group $^{b}$ & $\begin{array}{l}\text { Activity } \\
\text { Category }\end{array}$ & Activities & Video (s) & Activ8 (s) & $\begin{array}{c}\text { Mean Time } \\
\text { Difference }(s)^{c}\end{array}$ & $\begin{array}{c}\text { Relative Time } \\
\text { Difference (\%) }\end{array}$ & $\begin{array}{c}\text { Criterion } \\
\text { Validity } \\
\text { Score }\end{array}$ \\
\hline \multirow[t]{2}{*}{ TD } & Basic & Static $^{e}$ & 1764 & 1741 & -23 & -1.3 & Excellent \\
\hline & & Dynamic $^{f}$ & 3516 & 3539 & 23 & 0.7 & Excellent \\
\hline \multirow[t]{2}{*}{ NTD } & Basic & Static $^{e}$ & 1802 & 1815 & 13 & 0.7 & Excellent \\
\hline & & Dynamic $^{f}$ & 3178 & 3165 & -13 & -0.4 & Excellent \\
\hline \multirow[t]{2}{*}{ TD } & Complex & Static $^{e}$ & 1515 & 1258 & -257 & -17.0 & Good \\
\hline & & Dynamic $^{f}$ & 3105 & 3362 & 257 & 8.3 & Excellent \\
\hline \multirow[t]{2}{*}{ NTD } & Complex & Static $^{e}$ & 1658 & 1256 & -402 & -24.3 & Moderate \\
\hline & & Dynamic $^{f}$ & 3022 & 3424 & 402 & 13.3 & Good \\
\hline
\end{tabular}

${ }^{a} 2 \mathrm{M}$ Engineering. ${ }^{b} \mathrm{NTD}=$ not typical development (ie, ambulatory and with motor disability); TD = typical development. ${ }^{\circ}$ Calculated as (Activ8 - video). ${ }^{d}$ Calculated as [(Activ8 time - video time)/video time] $\times 100 .{ }^{e}$ Merged category of sitting and standing. ${ }^{f}$ Merged category of walking, bicycling, and running.

\section{DISCUSSION}

The aim of the current study was to investigate the criterion validity of the Activ8, using the current algorithm to quantify (1) static and dynamic activities and (2) separate postures and movements within both basic and complex activities in youths with TD and youths with motor disability (NTD) and who would be considered at least ambulatory in a household.

The results of our study indicate that the current version of the Activ8 is a valid device for distinguishing between static and dynamic activities in daily life in both youths with TD and youths with mild motor disabilities and for quantifying separate movements and postures in youths with TD, with the exception of standing, which was often quantified as the non-dynamic posture sitting. At the same time, though, the currently used algorithm in the Activ8 is not valid for quantifying separate postures and movements during some complex activities in youths with motor disability. These data imply that the Activ8, in its current state, can be used in clinical practice and research only for the quantification of static and dynamic activities and not for the quantification of separate postures and movements in children with motor disability. 
Furthermore, the Activ8 can validly distinguish separate postures and movements within basic activities in youths with TD (criterion validity: good to excellent). In youths with NTD, a more varied criterion validity was found, which ranged from poor (bicycling) to excellent (sitting and running), probably due to the presence of a so called crouched posture and gait (more degrees of hip and knee flexion in standing position or during gait) which is common in persons with CP or SB. Exclusion of the 2 participants with a pronounced crouched posture and gait from the analysis, resulted in excellent classifications of the posture standing and the activities walking and bicycling within basic activities (Supplement I). These results are in line with studies in adults with CP and patients after stroke, where Activ8 also had difficulty recognizing certain postures and movement in participants with a more pronounced crouched posture or gait, due to a different hip angle (different angular position of Activ8). ${ }^{32,35}$ At the same time these results indicate, that for youths with more severe motor impairments, further validation is still recommended.The existing thresholds used in the algorithm of the Activ8, developed for use in healthy adults are not yet sufficient enough to quantify separate postures and movements within complex activities or during short bouts of activities. In both youths with TD and youths with NTD, the Activ8 had difficulty to distinguish standing from other postures or movements within complex activities (Supplement II). For example, walking and standing were alternated during an activity as setting a table. If the posture standing was performed for 1 second and was immediately followed by walking, the Activ8 did not detect standing because the posture standing was too short for an adequate detection. These results are also in line with 2 earlier studies, also reporting the inaccurate detection of standing by Activ8 in free-living conditions in adults with $\mathrm{CP}$ and adults after stroke. ${ }^{32,35}$ One might question how accurately the Activ8 needs to quantify short-term activities in daily life because that affects the determined acceleration threshold used in the algorithm. ${ }^{32,35}$ Furthermore, climbing stairs was sometimes classified as bicycling instead of walking in both participants with TD and participants with NTD. This finding is most likely related to the height difference between children and adults resulting in a larger hip flexion during stair climbing in youths.

Comparing the criterion validity of the Activ8 with that of other accelerometers quantifying postures and movements in daily life in youths is difficult. Accelerometers that are often used to measure PA in youths focus only on estimating energy expenditure of PA rather than the type of PA. 14,20,36-39 The activPAL (PAL Technologies) is one of the few activity monitors that measures several body postures and motions (lying, sitting, 
standing, and walking) and that was evaluated for criterion validity in free-living conditions in youths. ${ }^{40,41}$ Studies showed an acceptable agreement of detecting sitting, standing and walking activities separately or distinguishing lying or sitting from upright activities with the activPAL compared to direct observation in youths with TD and peers with CP. In participants with a crouched posture/gait or toe walk also lower levels of agreement were found, ${ }^{40,41}$, similar to the validity results in our study.

The VitaMove (2M Engineering) as the manufacturer of VitaMove, which is a 3-sensor activity monitor and the precursor of the Activ8, showed good validity for detecting the types of postures and movements in youths who were ambulatory and had motor disability and in the adult clinical population. ${ }^{28,33,42,43}$ The use of the Activ8 is, however, preferred over the activPAL and the VitaMove because the Activ8 can measure for a longer period of time (ie, 1 month instead of 1 week), is low-priced, has easy to use data analysis and interpretation and consist of only 1 small sensor (instead of 3 for the VitaMove). In addition, a feedback tool on the device and a smartphone is available for the Activ8, while this is not available for other devices like the VitaMove or the activPAL.

\section{Strengths and Limitations}

There were some limitations in this study. The sample size was small in both groups. At the same time, this sample size is common in comparable studies evaluating criterion validity of accelerometers. 19,32,40,43 In addition, the 1-second scoring of the video within complex activities was sometimes difficult. Postures and movements during daily life activities (complex activities) performed by the participants were difficult to allocate to 1 posture or movement category on a second-by-second basis. Finally, the sample of youths with NTD was limited to participants with mild motor impairments and those who could be considered to be at least ambulatory in a household. At the same time, including a mixed sample of both youths with and youths without motor impairments, also enlarges the generalizability of the results to a clinical population ranging from household to normal ambulatory level. Another strength was the involvement of a multidisciplinary group of experts in the adaptation of the standardized protocol used in adults to a protocol for the pediatric population. Finally, the labor intensive data recording was performed by trained researchers using robust protocols and expertise from several other validation studies in the PA field of research. 


\section{Clinical Implications and Recommendations}

Our results indicate that the Activ8 can validly distinguish static from dynamic activities in both youths with TD and youths with NTD during both basic activities and complex activities. At the same time, though, the Activ8, with the current setting for adults, was not valid for distinguishing separate postures and movements during more complex activities similar to those in daily life, in both youths with TD and youths with NTD. Misdetections were related to a greater hip angle in youths, a (relative) inability to detect short-duration activities and the presence of crouched posture or gait in those with more severe motor impairments. Based on the results of this study and 2 other studies determining the validity of Activ8, 32,35 developers of Activ8 recently adapted the algorithm for hip angle and specific thresholds to resolve the inaccurate detection of separate postures and movements when using the Activ8 in youths and in participants with a crouched posture or gait. Future validation studies should include youths with more severe motor impairment.

The advantage of the Activ8, in addition to monitoring PA in a clinician friendly way, is its possibilities to provide real-time feedback to patients using a goal-setting function. Activ8 can therefore be used in encouraging behavioral change, as part of tailored interventions targeting PA in youths with motor disability and youths without motor disability. In that perspective, using the Activ8 provides new possibilities to assess associations between PA and health, to monitor change of PA over time, and to estimate population prevalence of meeting PA guidelines in both youths with TD and youths with NTD.

In conclusion, when interested in assessment of static and dynamic activities in daily life, the Activ8 is a valid device in youths with TD and youths who are ambulatory and have mild motor disabilities for both research and clinical purposes. The existing thresholds of Activ8 to quantify separate postures and movements were not valid and the algorithm has now been adapted. Future research should study the validity of an adapted algorithm in a larger sample of participants, with special attention to those with more severe motor impairments and other pediatric diagnos 
Supplement I: Mean and Relative Time Differences Between Video Data and Activ8 Output Within Basic and Complex Activities in participants with $\mathrm{NTD}^{\mathrm{b}}(\mathrm{N}=8)$ with exclusion of 2 participants.

\begin{tabular}{|c|c|c|c|c|c|c|}
\hline $\begin{array}{l}\text { Activity } \\
\text { Category }\end{array}$ & Activity & Video (s) & Activ8 (s) & $\begin{array}{l}\text { Mean Time } \\
\text { Difference (s) }\end{array}$ & \begin{tabular}{|l|} 
Relative Time \\
Difference $(\%)^{d}$
\end{tabular} & $\begin{array}{l}\text { Criterion } \\
\text { Validity } \\
\text { Score }\end{array}$ \\
\hline \multirow[t]{2}{*}{ Basic } & Static $^{e}$ & 1442 & 1440 & -2 & -0.1 & Good \\
\hline & Dynamic $^{f}$ & 2698 & 2700 & 2 & 0.1 & Excellent \\
\hline \multirow[t]{5}{*}{ Basic } & Sitting & 960 & 960 & 0 & 0.0 & Excellent \\
\hline & Standing & 482 & 480 & -2 & \begin{tabular}{|l|}
-0.4 \\
\end{tabular} & Excellent \\
\hline & Walking & 1470 & 1390 & -80 & -5.4 & Excellent \\
\hline & Bicycling & 840 & 844 & 4 & 0.5 & Excellent \\
\hline & Running & 388 & 466 & 78 & 20.1 & Moderate \\
\hline \multirow[t]{2}{*}{ Complex } & Static ${ }^{e}$ & 1368 & 1016 & -352 & -25.7 & Moderate \\
\hline & Dynamic $^{f}$ & 2352 & 2704 & 352 & 15.0 & Good \\
\hline \multirow[t]{5}{*}{ Complex } & Sitting & 1047 & 962 & -85 & -8.1 & Excellent \\
\hline & Standing & 321 & 54 & -267 & -83.2 & Poor \\
\hline & Walking & 2329 & 2604 & 275 & 11.8 & Good \\
\hline & Bicycling & 0 & 76 & 76 & NA & NA \\
\hline & Running & 23 & 24 & 1 & 4.4 & Excellent \\
\hline
\end{tabular}

${ }^{a} 2 \mathrm{M}$ Engineering. ${ }^{\mathrm{b}} \mathrm{NTD}=$ not typical development (ie, ambulatory and with motor disability); TD = typical development. ${ }^{C}$ Calculated as (Activ8 - video). ${ }^{d}$ Calculated as [(Activ8 time - video time)/video time $] \times 100 . N A=$ not applicable. 
Supplement II: Mean and relative time differences between video data and Activ8 output within complex activities in both participants with TD and participants with NTD

\section{COMPLEX ACTIVITIES}

\begin{tabular}{|c|c|c|c|c|c|c|c|c|c|}
\hline & Video & Activ8 & $\begin{array}{l}\text { Mean time } \\
\text { difference } \\
(\mathrm{s})^{c}\end{array}$ & $\begin{array}{l}\text { Relative time } \\
\text { difference } \\
(\%)^{d}\end{array}$ & $\begin{array}{l}\text { Posture or } \\
\text { movement }\end{array}$ & Video & Activ8 & $\begin{array}{l}\text { Mean time } \\
\text { difference } \\
(\mathrm{s})^{c}\end{array}$ & $\begin{array}{l}\text { Relative time } \\
\text { difference } \\
(\%)^{d}\end{array}$ \\
\hline & TD & & & & & NTD & & & \\
\hline \multirow[t]{3}{*}{ Climbing stairs } & 580 & 423 & -157 & -27.1 & Walking & 480 & 356 & -124 & -25.8 \\
\hline & 0 & 176 & 176 & NA & Bicycling & 0 & 124 & 124 & NA \\
\hline & 20 & 1 & -19 & -95.0 & Running & . & . & . & . \\
\hline \multirow[t]{3}{*}{ Setting the table } & 154 & 82 & -72 & -46.8 & Standing & 99 & 26 & -73 & -73.7 \\
\hline & 386 & 458 & 72 & 18.7 & Walking & 501 & 477 & -24 & -4.8 \\
\hline & . & . & . & . & Bicycling & 0 & 97 & 97 & NA \\
\hline Art and craft & 600 & 600 & 0 & 0 & Sitting & 600 & 600 & 0 & 0 \\
\hline work while & & & & & & & & & \\
\hline sitting & & & & & & & & & \\
\hline \multirow{3}{*}{$\begin{array}{l}\text { Walking in a } \\
\text { slalom }\end{array}$} & 600 & 600 & 0 & 0 & Walking & 600 & 431 & -169 & -28.2 \\
\hline & . & . & . & . & Bicycling & 0 & 168 & 168 & NA \\
\hline & . & . & . & . & Running & 0 & 1 & 1 & NA \\
\hline Dribbling with a & 2 & 0 & -2 & -100 & Standing & & & & \\
\hline \multirow[t]{3}{*}{ ball } & 515 & 523 & 8 & 1.6 & Walking & 577 & 433 & -144 & -25.0 \\
\hline & . & . & . & . & Bicycling & 0 & 144 & 144 & NA \\
\hline & 83 & 77 & -6 & -7.2 & Running & 23 & 23 & 0 & 0 \\
\hline \multirow[t]{4}{*}{ Ball game } & 75 & 50 & -25 & -33.3 & Standing & 251 & 28 & -223 & -88.8 \\
\hline & 447 & 475 & 28 & 6.3 & Walking & 349 & 452 & 103 & 29.5 \\
\hline & 0 & 6 & 6 & NA & Bicycling & 0 & 120 & 120 & NA \\
\hline & 18 & 9 & -9 & -50.0 & Running & . & . & . & . \\
\hline Sitting in a chair, & 162 & 8 & -154 & -95.1 & Sitting & 108 & 2 & -106 & -98.2 \\
\hline stand up, 5 & 438 & 584 & 146 & 33.3 & Walking & 492 & 478 & -14 & -2.9 \\
\hline meter walk and & . & . & . & . & Bicycling & 0 & 60 & 60 & NA \\
\hline $\begin{array}{l}\text { back to the chair } \\
\text { and sit down }\end{array}$ & 0 & 8 & 8 & NA & Running & 0 & 60 & 60 & NA \\
\hline
\end{tabular}

${ }^{\mathrm{a}} 2 \mathrm{M}$ Engineering. ${ }^{\mathrm{b}} \mathrm{NTD}=$ not typical development (ie, ambulatory and with motor disability); $T \mathrm{TD}=$ typical development. ${ }^{~ C}$ Calculated as (Activ8 - video). ${ }^{d}$ Calculated as [(Activ8 time - video time)/video time] $\times$ 100. NA $=$ not applicable. 


\section{REFERENCES}

1. Jimenez-PavonD, Kelly J, Reilly JJ. Associations between objectively measured habitual physical activity and adiposity in children and adolescents: Systematic review. Int J Pediatr Obes 2010;5:3-18.

2. LaMonte MJ, Blair SN. Physical activity, cardiorespiratory fitness, and adiposity: contributions to disease risk. Curr Opin Clin Nutr Metab Care 2006;9:540-546.

3. Riddoch CJ, Mattocks C, Deere K, Saunders J, Kirkby J, Tilling K, et al. Objective measurement of levels and patterns of physical activity. Arch Dis Child 2007;92:963-969.

4. Saunders TJ, Gray CE, Poitras VJ, Chaput JP, Janssen I, Katzmarzyk PT, et al. Combinations of physical activity, sedentary behaviour and sleep: relationships with health in children and youth. Med Sci Sports Exerc 2016;48(5 suppl 1):912.

5. Balemans ACJ, Van Wely L, Becher JG, Dallmeijer AJ. Associations between fitness and mobility capacity in school-aged children with cerebral palsy: a longitudinal analysis. Dev Med Child Neurol 2015;57:660-667.

6. Verschuren $O$, de Haan F, Mead G, Fengler B, Visser-Meily A. Characterizing energy expenditure during sedentary behavior after stroke. Arch Phys Med Rehabil 2016;97:232237.

7. Schoenmakers MA, de Groot JF, Gorter JW, Hillaert JL, Helders PJ, Takken T. Muscle strength, aerobic capacity and physical activity in independent ambulating children with lumbosacral spina bifida. Disabil Rehabil 2009;31:259-266.

8. Biddle SJ, Gorely T, Stensel DJ. Health-enhancing physical activity and sedentary behaviour in children and adolescents. J Sports Sci 2004;22:679-701.

9. Penedo FJ, Dahn JR. Exercise and well-being: a review of mental and physical health benefits associated with physical activity. Curr Opin Psychiatry 2005;18:189193.

10. Janssen I, Leblanc AG. Systematic review of the health benefits of physical activity and fitness in school-aged children and youth. Int J Behav Nutr Phys Act 2010;7:40.

11. Roman-Vinas B, Chaput JP, Katzmarzyk PT, Fogelholm M, Lambert EV, Maher C, et al. Proportion of children meeting recommendations for 24-hour movement guidelines and associations with adiposity in a 12-country study. Int J Behav Nutr Phys Act 2016;13:123.

12. Burghard M, Knitel K, van Oost I, Tremblay MS, Takken T; Dutch Physical Activity Report Card Study Group. Is our youth cycling to health? Results from the Netherlands' 2016 report card on physical activity for children and youth. J Phys Act Health 2016;13(11 suppl 2):S218-S224. 
13. Hidding LM, Altenburg TM, Mokkink LB, Terwee CB, Chinapaw MJ. Systematic review of childhood sedentary behavior questionnaires: what do we know and what is next? Sports Med 2017;47:677-699.

14. Sirard JR, Pate RR. Physical activity assessment in children and adolescents. Sports Med $2001 ; 31: 439-454$.

15. Aminian S, Hinckson EA. Examining the validity of the ActivPAL monitor in measuring posture and ambulatory movement in children. Int $\mathrm{J}$ Behav Nutr Phys Act 2012;9:119.

16. Basterfield L, Adamson AJ, Pearce MS, Reilly JJ. Stability of habitual physical activity and sedentary behavior monitoring by accelerometry in 6- to 8-year-olds. J Phys Act Health 2011;8:543-547.

17. Montoye AH, Moore RW, Bowles HR, Korycinski R, Pfeiffer KA. Reporting accelerometer methods in physical activity intervention studies: a systematic review and recommendations for authors. Br J Sports Med 2016. doi: 10.1136/bjsports-2015-095947.

18. Erasmus MC University Medical Center. Validation of Activ8 Activity Monitor: Detection of Body Postures and Movements. Rotterdam, the Netherlands: Erasmus MC University Medical Center; 2013.

19. Claridge EA, McPhee PG, Timmons BW, Martin Ginis KA, Macdonald MJ, Gorter JW. Quantification of physical activity and sedentary time in adults with cerebral palsy. Med Sci Sports Exerc 2015;47:1719-1726.

20. Strath SJ, Pfeiffer KA, Whitt-Glover M. Accelerometer use with children, older adults, and adults with functional limitations. Med Sci Sports Exerc 2012;44:S77-S85.

21. Hildebrand M, VAN Hees VT, Hansen BH, Ekelund U. Age group comparability of raw accelerometer output from wrist- and hip-worn monitors. Med Sci Sports Exerc 2014;46:18161824.

22. de Groot JF, Overvelde A. Healthy Active Living in Youth With Neuromotor Disability (HALYNeD) Project: a translational project with researchers, pediatric physical therapists, and patients working together toward evidence-based exercise prescription. Pediatr Phys Ther 2013;25:228-229.

23. de Vet HCW, Terwee CB, Mokkink LB, Knol DL. Measurement in Medicine: A Practical Guide. New York, NY: Cambridge University Press; 2011:159.

24. Graham HK, Harvey A, Rodda J, Nattrass GR, Pirpiris M. The Functional Mobility Scale (FMS). J Pediatr Orthop 2004;24:514-520.

25. Wood E, Rosenbaum P. The Gross Motor Function Classification System for 
cerebral palsy: a study of reliability and stability over time. Dev Med Child Neurol 2000;42:292-296.

26. Palisano RJ, Rosenbaum P, Bartlett D, Livingston $\mathrm{MH}$. Content validity of the expanded and revised Gross Motor Function Classification System. Dev Med Child Neurol 2008;50:744-750.

27. Schoenmakers MA, Gulmans VA, Gooskens RH, Pruijs JE, Helders PJ. Spinal fusion in children with spina bifida: influence on ambulation level and functional abilities. Eur Spine J 2005;14:415-422.

28. Nooijen CF, de Groot JF, Stam HJ, van den Berg-Emons RJ, Bussmann HB; Fit for the Future Consortium. Validation of an activity monitor for children who are partly or completely wheelchair-dependent. J Neuroeng Rehabil 2015;12:11.

29. Postma K, Bussmann J, Sluis T, Bergen M, Stam H. Validity of the detection of wheelchair propulsion as measured with an activity monitor in patients with spinal cord injury. Spinal Cord 2005;43:550-557.

30. Bussmann J, Martens W, Tulen J, Schasfoort F, Van Den Berg-Emons H, Stam H. Measuring daily behavior using ambulatory accelerometry: the activity monitor. Behav Res Methods Instrum Comput 2001;33:349-356.

31. Bouisset S, Do MC. Posture, dynamic stability, and voluntary movement. Neurophysiol Clin 2008;38:345-362.

32. Fanchamps MHJ, Horemans HLD, Ribbers GM, Stam HJ, Bussmann JBJ. The accuracy of the detection of body postures and movements using a physical activity monitor in people after a stroke. Sensors (Basel) 2018;18: E2167.

33. Bussmann JB, Tulen JH, van Herel EC, Stam HJ. Quantification of physical activities by means of ambulatory accelerometry: a validation study. Psychophysiology 1998;35:488-496.

34. Altman DG, ed. Practical Statistics for Medical Research. Boca Raton, FL: Chapman \& Hall/CRC; 1990.

35. Claridge EA, McPhee PG, Timmons BW, Martin Ginis KA, Macdonald MJ, Gorter JW. Quantification of physical activity and sedentary time in adults with cerebral palsy. Med Sci Sports Exerc 2015;47:1719-1726.

36. Corder K, Ekelund U, Steele RM, Wareham NJ, Brage S. Assessment of physical activity in youth. J Appl Physiol 2008;105:977-987.

37. Oliver M, Schofield GM, Kolt GS. Physical activity in preschoolers: understanding prevalence and measurement issues. Sports Med 2007;37:1045-1070. 
38. Reilly JJ, Penpraze V, Hislop J, Davies G, Grant S, Paton JY. Objective measurement of physical activity and sedentary behaviour: review with new data. Arch Dis Child 2008;93:614-619.

39. Rowlands AV. Accelerometer assessment of physical activity in children: an update. Pediatr Exerc Sci 2007;19:252-266.

40. Tang KT, Richardson AM, Maxwell D, Spence WD, Stansfield BW. Evaluation of an activity monitor for the objective measurement of free-living physical activity in children with cerebral palsy. Arch Phys Med Rehabil 2013;94:2549-2558.

41. O'Donoghue D, Kennedy N. Validity of an activity monitor in young people with cerebral palsy Gross Motor Function Classification System level I. Physiol Meas. 2014;35:2307-2318.

42. Bussmann JB, van de Laar YM, Neeleman MP, Stam HJ. Ambulatory accelerometry to quantify motor behaviour in patients after failed back surgery: a validation study. Pain 1998;74:153-161.

43. van den Berg-Emons HJ, Bussmann JB, Balk AH, Stam HJ. Validity of ambulatory accelerometry to quantify physical activity in heart failure. Scand J Rehabil Med 2000;32:187-192. 



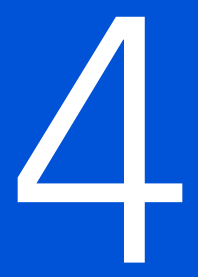

\section{Sports participation, physical activity, and health-related fitness in youth with chronic diseases or physical disabilities: the health in adapted youth sports study}

Kristel Lankhorst

Tim Takken

Maremka Zwinkels

Leendert van Gaalen

Saskia te Velde

Frank Backx

Olaf Verschuren

Harriet Wittink

Janke de Groot 


\section{ABSTRACT}

Background. Youth with chronic diseases or physical disabilities (CDPD) often show reduced fitness and physical activity (PA) levels and participate less in organized sports compared to healthy peers. The purpose of this study was to examine the associations between participation in sports and health-related fitness and PA in youth with CDPD.

Methods. A total of 163 participants (mean age 14; range 8-19 years) with CDPD were included in this cross-sectional study, with 81 participating in organized sports and 82 not. Participants were recruited between October 2014 and November 2016. Aerobic and anaerobic fitness, agility and muscle strength were assessed in the lab while PA was monitored in daily life using accelerometry during one week. Linear regression analyses were used to assess the associations of sports participation (independent variable) with health-related fitness and PA (dependent variables).

Results. Results show that youth with CDPD participating in organized sports two times a week performed better on all outcome measures. They reached a higher peak oxygen uptake (difference of $4.9 \mathrm{ml} \mathrm{O} / \mathrm{kg} / \mathrm{min}, \mathrm{P}=0.001$ ) compared to their peers not participating in sports. Also, anaerobic fitness, agility, muscle strength and PA were all positively associated with sports participation. Moreover, the association between sports participation and aerobic fitness was mediated by PA for 31\% ( $P=0.045)$.

Conclusion. Participation in sports is associated with both higher levels of PA and healthrelated fitness in youth with CDPD. Promotion and stimulation of participation in sports seems a good way to promote health-related fitness as well as a healthy active lifestyle in youth with CDPD. 


\section{INTRODUCTION}

Youth with chronic diseases or physical disabilities (CDPD) have lower fitness level', lower levels of physical activity (PA) ${ }^{2,3}$ and a higher prevalence of adiposity ${ }^{4}$ than their healthy peers. The detrimental health effects of physical inactivity in healthy youth are well established ${ }^{5-7}$. In healthy youngsters, insufficient PA levels are highly associated with low cardiorespiratory fitness, higher levels of obesity and increased cardiovascular risk ${ }^{8,9}$. Many studies have reported the benefits of sports in promoting PA ${ }^{10,11}$ and its contribution of moderate-to-vigorous physical activity (MVPA) to daily recommended PA in healthy youth ${ }^{12}$. The current recommendations for youth (5-17 years), including those with CDPD, state that they should accumulate at least $60 \mathrm{~min}$ of MVPA daily for healthy development or 20 min of vigorous physical activity (VPA) for at least three times weekly to achieve the same health effect ${ }^{13,14}$. Shorter exercise time with a higher intensity (VPA) support sports participation to meet PA guidelines and to develop a healthy active lifestyle.

While the health benefits related to sports and PA have been reported in healthy youth, there is only limited evidence as to what extent sports participation may affect PA and health-related fitness in youth with CDPD. A recent study did report a significant correlation between aerobic fitness and cardiovascular health and also an inverse relationship between adiposity and cardiovascular health in youth with CDPD ${ }^{15}$. Finding ways to improve health-related fitness and cardiovascular health therefore seems an important goal for youth with CDPD. At the same time, training studies have shown that youth with CDPD indeed can improve their PA level and health-related fitness through supervised intervention programs in rehabilitation settings ${ }^{1,16}$. However, the positive results achieved are often not maintained in the longer term after these programs end ${ }^{17,18}$. Weekly participation in sports could be, based on what we know in healthy youth, a solution to maintain and optimize PA levels and health-related fitness in youth with CDPD.

A recent study showed that youth with CDPD often do not meet the guidelines for healthy PA. While already difficult for healthy peers to meet recommended levels of PA, a Dutch publication showed that youth with CDPD participate even less in competitive and recreational sports ${ }^{13,14}$. Only $26 \%$ of youth with CDPD participate in sports once a week ${ }^{14}$ compared to $71 \%$ of their healthy peers ${ }^{13}$.

While this low adherence to PA guidelines might be detrimental to health-related fitness and physical functioning, several studies have reported important barriers for youth with 
CDPD making it difficult to participate in sports. These barriers include both personal factors, e.g. the lack of energy, fatigue and lack of 'leisure' time due to longer school hours and more time spent in activities of daily living, and environmental factors ${ }^{14,19}$. The latter includes accessibility of the physical environment, but also attitudes from the social environment, e.g. parents, teachers, healthcare professionals and policy makers, including fear of injury, thinking sports might be too difficult, lack of knowledge regarding the importance of PA for youth with CDPD, or more practical considerations such as transportation to an adapted sport facility ${ }^{20}$. To overcome some of these social barriers, research is needed showing that there are positive associations between sports participation and health-related fitness. With this knowledge, attitudes might change towards the importance of sports participation for youth with CDPD.

We hypothesize that youth with CDPD who participate in sports are more active and show better health-related fitness outcomes than those who are not. Therefore, the aim of the present study was to investigate the associations of sports participation with health-related fitness and PA in youth with CDPD.

\section{METHODS}

\section{Experimental approach to the problem}

This study is part of the larger Health in Adapted Youth Sports (HAYS) study. We used a cross-sectional prospective design to investigate the associations of sports participation with physical fitness, PA, cognition, cardiovascular health and quality of life in youth with CDPD. The current paper focuses on the associations of sports participation with physical activity and health-related fitness in youth with CDPD. The associations of sport participation with self-perception, exercise self-efficacy and quality of life were published previously ${ }^{21}$. All assessments were performed between October 2014 and November 2016. A detailed description of the research design and testing procedures has been published previously ${ }^{22}$. An overview of the outcome measures and used measurement instruments of the current study are summarized in Table 1. 
Table 1: Overview of the outcome measures and chosen measurement instruments in this study.

\begin{tabular}{|c|c|c|c|}
\hline Outcome measure & Parameter & Variable & Measurement \\
\hline \multicolumn{4}{|l|}{ General } \\
\hline & Demographics & $\begin{array}{l}\text { DOB, gender, medical } \\
\text { diagnosis, } \\
\text { Activity level and participation } \\
\text { in sports }\end{array}$ & General questionnaire \\
\hline \multicolumn{4}{|l|}{ Health-related fitness } \\
\hline \multirow[t]{6}{*}{ Cardio-vascular health } & Metabolic & $\mathrm{BMI}$ & Height, weight \\
\hline & & Body composition & Waist and hip circumference \\
\hline & & Fat Mass & BIA \\
\hline & & Blood pressure & Arteriograph \\
\hline & & Arterial stiffness & Arteriograph \\
\hline & & Pulse wave velocity & Arteriograph \\
\hline \multirow[t]{7}{*}{ Physical fitness } & Muscle strength & Isometric muscle strength & Grip strength \\
\hline & & Explosive muscle strength & Standing broad jump \\
\hline & Agility & Time & $10 \times 5$ meter sprint \\
\hline & Anaerobic fitness & Mean power & MPST \\
\hline & Aerobic fitness & $\mathrm{VO}_{2 \text { peak }}$ & CPET, Shuttle run test or \\
\hline & & RER & Bicycle test, Godfrey protoco \\
\hline & & Heartrate & \\
\hline
\end{tabular}

\section{Physical activity}

Modality

Type of activity

Activity monitor (Activ8) and

Activity diary

DOB; date of birth, BMl; body mass index, BIA; body impedance analysis, $V_{2 p e a k}$; peak oxygen uptake, CPET; cardiopulmonary exercise test, RER; respiratory exchange ratio, MPST; muscle power sprint test.

\section{Subjects}

Participants were eligible for this study when they were ambulatory, aged from 8 up to 19 years with CDPD and diagnosed with either cardiovascular, pulmonary, musculoskeletal, metabolic or neuromuscular disorder. Table 2 shows the eligibility and exclusion criteria. The characteristics of the participants such as age, sex, medical diagnosis, identification of sports participation and non-sport are displayed in Table 3. The medical diagnoses 
were further classified into categories according to the American College of Sports Medicine (Table 3) ${ }^{23}$.

Written informed consent was provided by all participants and as required by Dutch law also by the parents of participants under 18 years of age. In line with Dutch law, no parental informed consent was required for participants aged 18 years and above. This study was approved by the Medical Ethics Committee of the University Medical Center Utrecht, the Netherlands (METC number: 14-332/c).

Table 2: Eligibility and exclusion criteria.

\section{Eligibility}

\section{Exclusion}

- Children and adolescents with a physical disability or chronic disease: cardiovascular, pulmonary, musculoskeletal or neuromuscular disorder

- Children and adolescents between the age of 8 and 19 years

- Children and adolescents had to understand simple instructions

- Children and adolescents who were able to perform physical fitness tests
- Children and adolescents with progressive diseases

- Children and adolescents using a wheelchair as main mode of mobility

- During the length of the study, children were not allowed to participate in other research projects which might influenced the current study results

- For the sporting group of the HAYS-study only: subjects who have not participated in any sports for the preceding three months.

- No signed informed consent

\section{Procedures}

\section{Independent variable}

Sports participation Sports participation was identified using three standardized questions used by the National Institute for Public Health and the Environment (RIVM) ${ }^{24}$ : 1) do you participate in organized sports?, 2) what is / are the type of organized sport(s)? and, 3) what is the frequency of participation in organized sports per week?. When participants were involved in organized sports at least two times per week, they were classified as the 'sports group' (SG), all others were classified as the 'non'-sporting group (NSG).

Dependent variables Physical activity and health-related fitness including cardiovascular health and physical fitness, were assessed (Table 1). Measurement instruments and tests which were valid and reliable in children and adolescents with physical disabilities were used. Specific details about the validity and reliability of the measurement instruments and tests were described in detail previously ${ }^{22}$. One week before the testing session, the general questionnaire was completed by the participant. Each assessment was 
performed using a standardized test protocol. All measurements related to healthrelated fitness took place on one day and were carried out in the following order; height and weight, bioelectric impedance analysis, waist and hip circumference measurements, Arteriograph measurement, grip strength, standing broad jump, 10x5 meter sprint, muscle power sprint test (MPST) and cardiopulmonary exercise test. Finally, the use of the PA monitor and activity diary was explained to the participant for the PA monitoring in the home situation (Table 1). In general, instructions were given by the researcher and if needed a practice session took place before the actual test started. When this was the case, the participant received sufficient rest before the actual test took place. Between each test there was time for recovery. In addition, the researchers asked the participants after each test and recovery period if the participant felt ready to continue the test protocol; if not further resting was allowed. The need extra of recovery was determined by the participant.

\section{Health-related fitness}

Cardiovascular health Height and weight were measured, body mass index (BMI) was calculated using body weight $(\mathrm{kg}) /$ body height ${ }^{2}(\mathrm{~m})$. For waist and hip circumference, a measure in standing position was taken at the umbilicus and trochanter major and waist / hip ratio was defined. To control for differences in age, Z-scores were calculated of body height, weight, BMI, waist and hip circumference and waist / hip ratio according to Dutch reference values ${ }^{23}$. Fat mass was measured in supine position with bioelectrical impedance analysis (Bodystat Quadscan 4000, EuroMedix, Leuven, Belgium).

Arterial stiffness was determined by aortic pulse wave velocity (PWVao), as a measure of arterial stiffness, and augmentation index (AIX\%), as measure of peripheral arterial tone. The measurements were performed in a supine position after ten-minute rest by a non-invasive oscillometric tonometry device (Arteriograph, TensioMed Ltd, Budapest, Hungary) at the right arm. A higher PWVao indicates a higher aortic stiffness and a higher AIX\% indicates a higher peripheral arterial tone. Blood pressure (systolic and diastolic) and resting heart rate were also measured using the Arteriograph within the same measurement. Instructions to the subject were no food intake three hours before measurement and no talking during the measurement. After the measurement of arterial stiffness, the child was allowed to eat something, before continuation of the other tests.

Physical fitness To test the strength of the subjects, tests from the Brockport fitness test were chosen ${ }^{24}$. The isometric muscle strength was tested through the use of a hand 
held hydraulic dynamometer (HHD) ${ }^{25}$. The participants' dominant hand was tested and one practice session took place before the actual test started. Mean grip strength was calculated out of three attempts.

The standing broad jump was used to evaluate the explosive strength of the lower limbs by measuring the distance jumped with two legs together from standing position ${ }^{26}$. Mean distance was calculated of three trials and used for analysis. One practice session took place before the actual test started.

Agility was measured using the 10x5 Meter Sprint Test ${ }^{27}$ and also valid for use in children and adolescents with and without a pathological gait pattern ${ }^{28}$. During this test, the child was asked to sprint as fast as possible, 10 times, in between 2 lines that were 5 meter apart. There was no resting period, so the child / adolescent had to turn as fast as possible during this test. Time was recorded using a stopwatch.

Anaerobic fitness was determined by the Muscle Power Sprint Test (MPST), which has been validated for use in children and adolescents with and without a pathological gait pattern ${ }^{29-32}$. Subjects had to complete six $15-m$ runs at a maximum pace. One sprint was performed by the participant for practice, before the actual test started. The MPST is an intermittent sprint test, in which the child stops and starts at standardized intervals. Power was calculated ((weight $x$ distance $)^{2} /$ time $\left.^{3}\right)$ for each of the six sprints and mean power was defined as the average power over the six sprints and used for further analysis.

Aerobic fitness was determined using an incremental exercise test. In exercise testing, peak oxygen uptake $\left(\mathrm{VO}_{\text {2peak }}\right)$ is considered to be the single best indicator of cardiorespiratory fitness, or aerobic fitness. A cardiopulmonary exercise testing system, the Cortex Metamax 3X (Samcon bvba, Melle, Belgium) was used for evaluation of the respiratory gasses and $\mathrm{VO}_{\text {2peak. }}$. Aerobic fitness was assessed by an adapted 10-meter incremental shuttle run test ${ }^{32}$ or by an incremental exercise test on an electronically braked cycle ergometer (Ergoline, Ergoselect 200 K, Ergoline, Bitz, Germany). In persons with disability the main mode of locomotion / mobility elicits the highest $\mathrm{VO}_{2 \text { peak }}{ }^{33}$. Therefore the type of sports or daily locomotion determined whether the shuttle run test or a cycling ergometry test was used. In children with a congenital cardiopulmonary disease a cycling test was always used, because of the electrocardiography monitoring of the heart for safety issues.

The speed of the shuttle run test was adjusted based on the results of the muscle power 
sprint test and the agility test. The cycling test, using the Godfrey protocol ${ }^{34}$, was used to test the aerobic fitness in children who are active on a bike in sports or daily living. Load depended on height of the child and the expected level of fitness. Regardless of the testing modality, the test started with a resting measurement for 3 min. Participants were verbally encouraged to keep on exercising until voluntary exhaustion. Exercise tests were considered maximal and included for analysis if two out of three of the following criteria were achieved: 1) peak heart rate $>180$ beats/min, 2) peak Respiratory Exchange Ratio $>1.0$ and or 3 ) subjective signs of exhaustions (out of breath, sweating, or plateau of $\mathrm{VO}_{2}$ ) or unable to continue the test ${ }^{35}$. Cardiorespiratory fitness was defined as $\mathrm{VO}_{\text {2peak }}$ per body weight, $\mathrm{VO}_{\text {2peak }}$ in liter per minute and to control for differences in age, Z-scores of $\mathrm{VO}_{2 \text { peak }}$ were calculated according to Dutch reference values ${ }^{36}$.

Physical activity PA was measured using an activity monitor, the Activ8 (2M Engineering BV. Valkenswaard, the Netherlands). The Activ8 is a valid one-sensor ambulatory monitoring system and has been validated for use in youth with and without motor impairments ${ }^{37}$. Each subject wore the sensor on the dominant leg, fixed with Tegaderm ${ }^{\mathrm{TM}}$ (3M, Delft, the Netherlands) waterproof skin tape during seven consecutive days for 24 hours each day. In order to calculate and interpret the data of waking hours gathered with the activity monitor, sleeping time was recorded in a diary. A minimum of one weekend day and two schooldays with a minimum of 600 minutes per day was required for further analysis ${ }^{38}$. The time in minutes per day were calculated for each activity (lying, sitting, standing, walking, bicycling and running) during awake hours and calculated for school and weekend days separately. The physical activity data were divided into sedentary and active categories. Sedentary activity consisted of lying and sitting, whereas active activities entailed walking, bicycling and running.

Power analysis The sample size of the HAYS-study was based on a study of Verschuren et al. ${ }^{39}$. In this study children and adolescents with cerebral palsy had a $\mathrm{VO}_{2 \text { peak }}$ of $42 \mathrm{ml}$ $\mathrm{O}_{2} / \mathrm{kg} / \mathrm{min}(\mathrm{SD} \pm 8.2$ ). To prove a difference of $10 \%$ between the SG and NSG, with an alpha of 0.05 and beta of 0.20 (power of 0.80 ) a sample size of 66 subjects per group was required. When taking a failure rate of $10 \%$ into account, a minimum of 146 subjects was required in total.

\section{Statistical analyses}

All analyses were performed using the SPSS Statistics, Version 23.0 (IBM Corp., Armonk, 
NY, USA). First, descriptive statistics was used to describe the outcomes in the two groups. Independent Student's t-tests, the Mann-Whitney U-test and chi-square test were used to determine the differences between the SG and NSG. Linear regression analyses were used to assess the relationship between sports participation (independent variable) with health-related fitness and PA (dependent variables). Assumptions regarding normality of residuals were checked and met the assumptions. The regression models were adjusted for potential confounders such as age, sex and diagnosis.

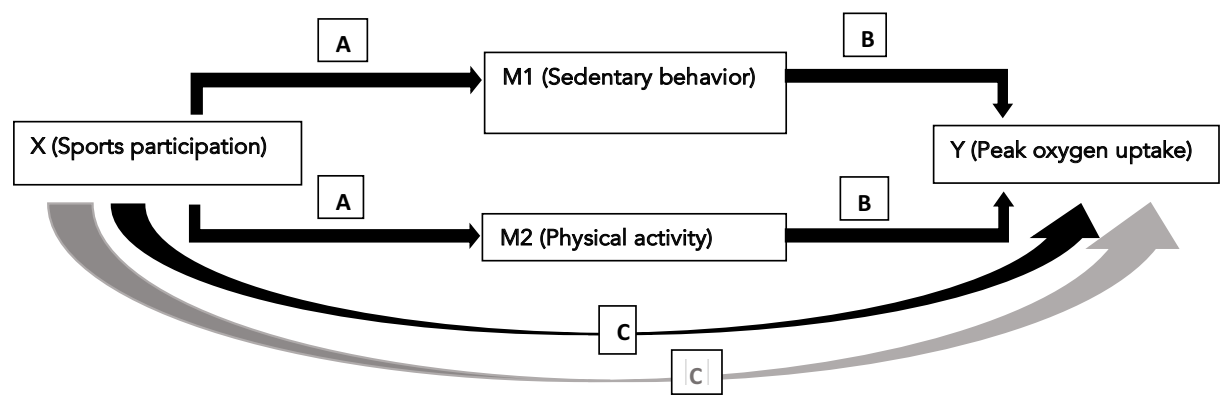

Figure 1: Mediation analysis.

To determine whether the association between sports participation and the primary outcome variable $\mathrm{VO}_{2 \text { peak }}$ was mediated by $\mathrm{PA}$, mediation regression analyses were conducted using the product-of-coefficient method, see figure 1 and Table $8^{40}$. Firstly, the overall relationship between participation in sports and the outcome variable $\mathrm{VO}_{2 \text { peak }}$ was estimated (the $\mathrm{C}$ coefficient). Secondly, the relationship between participation in sports and the potential mediator variables, the two categories; M1) sedentary and M2) active was estimated (the A coefficient). Thirdly, the relationship between the mediator variables and the outcome $\mathrm{VO}_{2 \text { peak }}$ was estimated (the B coefficient). Finally, the effect of participation in sports on $\mathrm{VO}_{2 \text { peak }}$ adjusted for the mediator was estimated (the $\mathrm{C}^{\prime}$ coefficient or mediator adjusted effect). The proportion of the total effect of participation in sports on $\mathrm{VO}_{2 \text { peak }}$ measure that was mediated by any of the potential mediators tested was also calculated (dividing the mediated effect by the total effect (A coefficient*B coefficient / $\mathrm{C}$ coefficient). Mediation was considered partial when the mediator adjusted association between participation in sports and the outcome (the $C^{\prime}$ coefficient) remained significant. The PROCESS module in SPSS was used to conduct the mediation analyses ${ }^{41}$. The mean time in minutes of the total week (school and weekend days) for the clustered categories 
sedentary and active were calculated and used for this mediation regression analyses. For each coefficient estimated, 95\% bootstrapped confidence intervals (Cls), P values and adjusted R square were calculated. A P value $<0.05$ was considered statistically significant.

\section{RESULTS}

\section{Participants' characteristics}

A total of 163 ambulatory participants with CDPD were included for this study between September 2014 and October 2016 (96 boys (mean age 14.3 years, SD \pm 2.8 ) and 67 girls (mean age 14.2 years, SD \pm 3.0 ). Descriptive statistics of the sample are presented in Table 3.

Table 3: Characteristics of the non-sport (NSG) and sport group (SG).

\begin{tabular}{|c|c|c|c|c|}
\hline & $\begin{array}{l}\text { Total } \\
\mathrm{N}=163\end{array}$ & $\begin{array}{l}\text { Non-sport group } \\
\text { (SD) } N=82\end{array}$ & $\begin{array}{l}\text { Sport group (SD) } \\
N=81\end{array}$ & P-value \\
\hline Boys / Girls ${ }^{a}$ & $96 / 67$ & $38 / 44$ & $58 / 23$ & $0.001^{*}$ \\
\hline Age in years ${ }^{b}$ & & $14.31(3.1)$ & $14.15(2.7)$ & 0.725 \\
\hline Diagnose group in $\%^{\text {a }}$ & & & & 0.532 \\
\hline Cardiovascular disease & 12.9 & 17.1 & 8.6 & \\
\hline Pulmonary disease & 4.9 & 3.7 & 6.2 & \\
\hline Metabolic disease & 9.8 & 8.5 & 11.1 & \\
\hline Musculoskeletal / orthopedic disability & 6.1 & 4.9 & 7.4 & \\
\hline Neuromuscular disorder & 49.1 & 51.2 & 46.9 & \\
\hline Immunological / hematological disease & 10.4 & 11.0 & 9.9 & \\
\hline Cancer & 1.8 & 1.2 & 2.5 & \\
\hline Epilepsy & 4.9 & 2.4 & 7.4 & \\
\hline
\end{tabular}

Age is presented as mean and standard deviations (SD), diagnose group is presented as percentages and the $P$-values from the $t$-test for independent samples for continuous variables with normal distribution. ${ }^{a}=$ Chisquare test for sex and prevalence of diseases or disabilities, ${ }^{b}=$ Mann Whitney- $U$ test for continuous variables with skewed distribution. *significant difference. Diagnose group classifications according to the guidelines of the American College of Sports Medicine (24). 


\section{Health-related fitness}

Youth who participated in sports had a significant higher $\mathrm{VO}_{2 \text { peak' }}$ a higher power on the MPST, were faster on the $10 \times 5$ meter sprint test, had a higher mean grip strength and were able to jump horizontally further compared with the NSG (Table 2). In addition, the participants in the SG had a significant lower waist / hip circumference ratio SDS and lower percentage of fat mass compared with the NSG (Table 4). There were no significant differences between participants in the SG and NSG for blood pressure (systolic and diastolic), resting heart rate and the arterial stiffness (PWV and AIX) (Table 4). The number of participants who performed an incremental shuttle run test or an incremental exercise test on a cycle ergometer were equally distributed between the NSG and SG.

\section{Physical Activity}

Youth participating in sports were more active than those who did not during both school and weekend days. The mean total minutes of bicycling and running were significantly higher for the SG compared with the NSG (Table 5). In addition, the total active time (walking, bicycling and running) was significantly higher in the SG compared with the NSG. Sedentary time (lying and sitting) did not significantly differ between the groups during both the weekend and school days (Table 5).

Table 4: Health-related fitness in relation to outcome variables of the non-sport (NSG) and sport group (SG).

\begin{tabular}{llll}
\hline Metabolic variables $\mathbf{N}=162$ & NSG (SD) N = 81 & SG (SD) N = 81 & P-value \\
\hline Body mass index $\left(\mathrm{kg} / \mathrm{m}^{2}\right)$ & $21.28(4.82)$ & $20.33(3.72)$ & 0.159 \\
Body mass index $\left(\mathrm{kg} / \mathrm{m}^{2}\right)$ SDS & $0.75(1.55)$ & $0.61(1.23)$ & 0.537 \\
Waist circumference (cm) & $77.16(14.4)$ & $74.4(12.2)$ & 0.195 \\
Waist circumference SDS & $1.05(1.4)$ & $0.72(1.26)$ & 0.123 \\
Hip circumference (cm) & $87.6(12.5)$ & $86.9(11.2)$ & 0.696 \\
Hip circumference SDS & $0.40(1.34)$ & $0.41(1.11)$ & 0.937 \\
Waist / hip ratio & $0.88(0.10)$ & $0.86(0.08)$ & 0.087 \\
Waist / hip ratio SDS & $1.17(1.38)$ & $0.63(1.40)$ & 0.013 * \\
Fat mass (\%) & $25.4(9.2)$ & $20.8(8.1)$ & 0.001 * \\
78 & & &
\end{tabular}




\begin{tabular}{|c|c|c|c|}
\hline Aerobic fitness variables $N=151^{\wedge}$ & NSG (SD) N = 74 & SG (SD) $N=77$ & P-value \\
\hline Peak oxygen uptake (L/min) & $2.16(0.7)$ & $2.48(0.9)$ & 0.019 * \\
\hline Peak oxygen uptake (L/min) SDS & $-0.91(1.3)$ & $-0.29(1.3)$ & $0.005^{a}$ * \\
\hline Peak oxygen uptake $(\mathrm{ml} / \mathrm{kg} / \mathrm{min})$ & $39.2(7.7)$ & $45.6(9.6)$ & $0.000^{a}$ * \\
\hline Peak oxygen uptake $(\mathrm{ml} / \mathrm{kg} / \mathrm{min})$ SDS & $-0.97(1.3)$ & $-0.21(1.5)$ & $0.001 a *$ \\
\hline Maximal heart rate & $191(10.6) n=72$ & $192(12.5)$ & 0.723 \\
\hline RER & $1.10(0.07)$ & $1.10(0.10)$ & 0.943 \\
\hline Cardio-vascular variables $\mathbf{N}=160$ & NSG (SD) $N=79$ & SG (SD) $N=79$ & P-value \\
\hline Systolic blood pressure $(\mathrm{mmHg})$ & $124.5(14.0)$ & $126.8(16.6)$ & 0.348 \\
\hline Diastolic blood pressure (mmHg) & $69.1(10.1)$ & $67.7(10.3)$ & 0.392 \\
\hline AIX (\%) & $9.5(8.3) n=76$ & $8.3(6.8) n=76$ & 0.331 \\
\hline $\mathrm{PWV}(\mathrm{m} / \mathrm{s})$ & $6.1(0.9) n=76$ & $5.8(0.9) n=76$ & 0.119 \\
\hline Resting heart frequency & $71(11.0) n=75$ & $69(12.3) n=81$ & 0.334 \\
\hline Motor variables $\mathbf{N}=160$ & NSG (SD) $N=82$ & SG (SD) $N=78$ & P-value \\
\hline MPST - mean power (Watt) & $230.9(145.6)$ & $301.7(180.7)$ & $0.007^{b *}$ \\
\hline $10 \times 5$ (sec) & $24.2(4.7)$ & $22.0(4.6) n=77$ & 0.003 * \\
\hline Mean grip strength (Newton) & $212.5(114.4)$ & $267.9(127.1) n=77$ & $0.004 *$ \\
\hline Mean standing broad jump (cm) & $103.5(39.8) n=81$ & $124.9(41.5) n=78$ & $0.001 *$ \\
\hline
\end{tabular}

Outcome variables are presented as mean or standard deviation scores (SDS; Z-score) and standard deviations (SD) with the $P$-values from the students $t$-test for independent samples for continuous variables with normal distribution or a Mann-Whitney $U$ test for non-normal distributed data ${ }^{a} \cdot{ }^{b}$ equal variances not assumed, *significant difference. NSG; non-sport, SG; sport group, RER; respiratory exchange ratio, AIX; augmentation index, PWV; pulse wave velocity, MPST; muscle power sprint test. $\wedge$ Drop-out of seven participants during cardio-pulmonary exercise test, reasons; four participants stopped earlier due to musculoskeletal pain, and three did not wanted to do the test on beforehand. Of five participants data was inaccurate due to device problems. 
Table 5: Objective measured physical activity during school days and weekend-days in the nonsport group (NSG) and sport group (SG).

\begin{tabular}{|c|c|c|c|}
\hline $\begin{array}{l}\text { Physical activity during school days } \\
\text { in minutes per day; } N=126\end{array}$ & NSG (SD) N = 65 & SG (SD) $N=61$ & P-value \\
\hline Sedentary time (lying - sitting) & $588.0(89.2)$ & $581.0(71.1)$ & 0.627 \\
\hline - Lying & $4.3(6.8)$ & $6.1(11.7)$ & 0.301 \\
\hline - Sitting & $583.7(88.7)$ & $574.9(72.8)$ & 0.546 \\
\hline Standing & $115.7(43.8)$ & $119.2(42.0)$ & 0.651 \\
\hline $\begin{array}{l}\text { Active time (walking - cycling - } \\
\text { running) }\end{array}$ & $155.9(50.0)$ & $186.8(44.0)$ & $0.000 *$ \\
\hline - Walking & $128.0(42.3)$ & $141.7(43.4)$ & 0.074 \\
\hline - Cycling & $24.8(24.5)$ & $37.5(25.0)$ & $0.005 *$ \\
\hline - Running & $3.1(3.2)$ & $7.5(5.3)$ & $0.000^{a} \star$ \\
\hline $\begin{array}{l}\text { Physical activity during weekend days } \\
\text { in minutes per day; } N=116\end{array}$ & NSG (SD) N = 59 & $S G(S D) N=57$ & P-value \\
\hline Sedentary time (lying - sitting) & $543.2(100.8)$ & $561.8(102.7)$ & 0.327 \\
\hline - Lying & $6.0(9.4)$ & $11.6(20.9)$ & $0.060^{a}$ \\
\hline - Sitting & $537.2(100.3)$ & $550.1(101.2)$ & 0.490 \\
\hline Standing & $119.2(57.5)$ & $123.2(47.3)$ & 0.681 \\
\hline $\begin{array}{l}\text { Active time } \\
\text { (walking - cycling - running) }\end{array}$ & $134.3(62.9)$ & $159.0(62.0)$ & $0.035^{\star}$ \\
\hline - Walking & $115.4(57.1)$ & $123.6(53.3)$ & 0.424 \\
\hline - Cycling & $17.3(14.6)$ & $28.4(24.1)$ & $0.004^{a *}$ \\
\hline - Running & $1.6(2.0)$ & $7.0(8.2)$ & $0.000^{a *}$ \\
\hline
\end{tabular}

Outcome variables are presented as mean and standard deviations (SD) with the P-values from the students t-test for independent samples for continuous variables with normal distribution. Criteria for analysis; 1) > 600 minutes awake time per day 2) at least one measured weekend-day and at least two school days. ${ }^{a}$ equal variances not assumed, *statistical difference, NSG; non-sport group, SG; sport group. 


\section{Sports participation associated with health-related fitness}

Sports participants showed a higher $\mathrm{VO}_{2 \text { peak }}$. We found significant positive associations for both boys and girls between participation in sports and $\mathrm{VO}_{2 \text { peak }}$. Boys had a higher $\mathrm{VO}_{\text {2peak }}$ compared with girls. The effect of sports participation was independent of the medical diagnosis (Table 6).

The mean power on the MPST, the time on the $10 \times 5$ meter sprint test, the mean grip strength and the mean standing broad jump were all positively associated with sports participation (Table 6). Overall, participation in sports, sex and age were associated with a better performance on all these outcome measurements. Participants with a pathological gait pattern scored lower on all outcomes (see motoric gait function, Table 6).

Youth participating in sports had a lower percentage of fat mass compared to peers not participating in sports. (Table 6). Youth with a pathological gait pattern had a significantly higher percentage of fat and higher waist/hip circumference SDS. Sports participation, sex and age was positively associated with the waist/hip circumference SDS.

\section{Sports participation associated with physical activity}

Sports participation was positively associated with the amount of active time during both school and weekend days (Table 7). Age was negatively associated with the amount of active time during weekend days. Participants with a pathological gait pattern spent a lower number of minutes in active time during school days compared with peers without a pathological gait pattern.

Sports participation was positively associated with both bicycling and running during school days. The motoric gait function was negatively associated with bicycling, while sex and age was negatively associated with running during school days. In addition, sports participation was positively associated with bicycling during weekend days, while age was negatively associated with bicycling. Youth in the SG ran more in the weekend compared to peers from the NSG.

\section{Mediation regression analysis}

PA mediated the association between sports participation and $\mathrm{VO}_{\text {2peak }}$ (Table 8). The mediating effect of PA on $\mathrm{VO}_{\text {2peak }}$ was $0.033 \mathrm{ml} \mathrm{O} / \mathrm{kg} / \mathrm{min}$. For every additional minute of $\mathrm{PA}, \mathrm{VO}_{2 \text { peak }}$ increased with $0.033 \mathrm{ml} / \mathrm{kg} / \mathrm{min}$. The proportion mediated was $31 \%$. Sedentary time did not mediate the association between sports participation and $\mathrm{VO}_{2 \text { peak. }}$. 
Table 6: Associations of sports participation with health-related fitness in youth with chronic diseases or physical disabilities.

\begin{tabular}{|c|c|c|c|c|}
\hline Health-related fitness & $B(S D)$ & $95 \% \mathrm{Cl}$ & P-value & $\begin{array}{l}\text { Adjusted } \\
\text { R Square }\end{array}$ \\
\hline \multicolumn{5}{|c|}{ Peak oxygen uptake (ml/kg/min); $N=151$} \\
\hline Constant & $42.438(1.215)$ & 40.036 to 44.840 & $0.000^{*}$ & \\
\hline Sports participation & $4.891(1.389)$ & 2.145 to 7.636 & $0.001^{\star}$ & \\
\hline Gender & $-6.242(1.419)$ & -9.046 to -3.437 & $0.000^{*}$ & 0.213 \\
\hline \multicolumn{5}{|c|}{ Peak oxygen uptake (L/min); N = 151} \\
\hline Constant & $-0.125(0.252)$ & -6.23 to 3.74 & 0.622 & \\
\hline Sports participation & $0.248(0.094)$ & 0.062 to 0.433 & $0.009^{\star}$ & \\
\hline Gender & $-0.667(0.095)$ & -0.856 to -0.478 & $0.000^{\star}$ & \\
\hline Age in years & $0.180(0.016)$ & -0.148 to 0.212 & $0.000^{\star}$ & 0.559 \\
\hline
\end{tabular}

\begin{tabular}{|c|c|c|c|c|}
\hline \multicolumn{5}{|c|}{ MPST - mean power $(\mathrm{W}) ; \mathrm{N}=160$} \\
\hline Constant & $-175.516(46.409)$ & -267.191 to -83.841 & $0.000^{\star}$ & \\
\hline Sports participation & $41.203(17.872)$ & 5.899 to 76.508 & $0.022^{\star}$ & \\
\hline Gender & $-124.794(18.104)$ & -160.556 to -89.032 & $0.000^{\star}$ & \\
\hline Age in years & $35.245(2.983)$ & 29.355 to 41.135 & $0.000^{\star}$ & \\
\hline Motoric gait function & $-60.422(17.263)$ & -94.523 to -26.322 & $0.001^{\star}$ & 0.575 \\
\hline \multicolumn{5}{|c|}{$10 \times 5$ meter sprint test $(\mathrm{sec}) ; N=159$} \\
\hline Constant & $31.924(1.602)$ & 28.759 to 35.089 & $0.000^{\star}$ & \\
\hline Sports participation & $-1.718(0.617)$ & 28.759 to 35.099 & $0.006^{*}$ & \\
\hline Gender & $1.719(0.626)$ & 0.483 to 2.956 & $0.007^{\star}$ & \\
\hline Age in years & $-0.724(0.103)$ & -0.927 to -0.521 & $0.000^{\star}$ & \\
\hline Motoric gait function & $3.424(0.594)$ & 2.250 to 4.597 & $0.000^{\star}$ & 0.389 \\
\hline
\end{tabular}




\section{Mean grip strength (Newton); $\mathrm{N}=159$}

\begin{tabular}{|c|c|c|c|c|}
\hline Constant & $-90.542(35.263)$ & -160.203 to -20.880 & $0.011 *$ & \\
\hline Sports participation & $40.384(13.584)$ & 13.549 to 67.219 & $0.003^{*}$ & \\
\hline Gender & $-59.404(13.751)$ & -86.569 to -32.240 & $0.000^{*}$ & \\
\hline Age in years & $25.965(2.263)$ & 21.493 to 30.436 & $0.000^{*}$ & \\
\hline Motoric gait function & $-71.497(13.131)$ & -97.436 to -45.557 & $0.000^{*}$ & 0.553 \\
\hline \multicolumn{5}{|c|}{ Mean standing broad jump (cm); N = 157} \\
\hline Constant & $44.308(12.477)$ & 19.657 to 68.960 & $0.001 *$ & \\
\hline Sports participation & $17.447(4.801)$ & 7.962 to 26.933 & $0.000^{*}$ & \\
\hline Gender & $-23.056(4.857)$ & -32.652 to -13.459 & $0.000^{*}$ & \\
\hline Age in years & $6.224(0.805)$ & 4.634 to 7.814 & $0.000^{*}$ & \\
\hline Motoric gait function & $-35.073(4.652)$ & -44.264 to -25.882 & $0.000^{*}$ & 0.504 \\
\hline
\end{tabular}

\section{Fat mass (\%)}

\begin{tabular}{|c|c|c|c|c|}
\hline Constant & $25.740(3.369)$ & 19.086 to 32.394 & $0.000^{*}$ & \\
\hline Sports participation & $-3.303(1.285)$ & -5.840 to -0.765 & $0.011^{*}$ & \\
\hline Gender & $4.583(1.303)$ & 2.009 to 7.157 & $0.001 *$ & \\
\hline Age in years & $-0.395(0.216)$ & -0.821 to 0.031 & $0.069^{\star}$ & \\
\hline Motoric gait function & 5.777 (1.239) & 3.131 to 8.024 & $0.000^{\star}$ & 0.223 \\
\hline \multicolumn{5}{|l|}{ Waist / hip ratio SDS } \\
\hline Constant & $0.968(0.035)$ & 0.900 to 1.036 & $0.000^{\star}$ & \\
\hline Sports participation & $-0.033(0.013)$ & -0.059 to -0.007 & $0.014^{\star}$ & \\
\hline Gender & $-0.037(0.013)$ & -0.064 to -0.011 & $0.006^{*}$ & \\
\hline Age in years & $-0.007(0.002)$ & -0.011 to -0.002 & $0.003^{*}$ & \\
\hline Motoric gait function & $0.056(0.013)$ & 0.031 to 0.081 & $0.000^{\star}$ & 0.178 \\
\hline
\end{tabular}

The data are standardized regression coefficients (B) with standard deviation (SD) and their $95 \%$ confidence intervals (CI), $P$-values and explained variance (adjusted $R$-square). Outcome variables are adjusted for sports participation, sex, age and motoric gait function. MPST; muscle power sprint test, SDS; standard deviation scores (Z-score). 
Table 7: Associations of sports participation with physical activity in youth with chronic diseases or physical disabilities.

\begin{tabular}{|c|c|c|c|c|}
\hline $\begin{array}{l}\text { Mean PA during school days } \\
\text { in minutes per day; } \\
N=126\end{array}$ & $B(S D)$ & $95 \% \mathrm{Cl}$ & P-value & $\begin{array}{l}\text { Adjusted } \\
\text { R Square }\end{array}$ \\
\hline \multicolumn{5}{|l|}{ Cycling } \\
\hline Constant & 30.491 (3.907) & 22.758 to 38.225 & $0.000^{\star}$ & \\
\hline Sports participation & $11.956(4.351)$ & 3.343 to 20.569 & $0.007^{*}$ & \\
\hline Motoric gait function & $-9.965(4.358)$ & -18.590 to -1.339 & $0.024^{*}$ & 0.087 \\
\hline \multicolumn{5}{|l|}{ Running } \\
\hline Constant & $11.210(1.871)$ & 7.506 to 14.914 & $0.000^{*}$ & \\
\hline Sports participation & $4.187(0.744)$ & 2.715 to 5.659 & $0.000^{*}$ & \\
\hline Gender & $-1.724(0.752)$ & -3.212 to -0.245 & $0.024^{*}$ & \\
\hline Age in years & $-0.511(0.125)$ & -0.759 to -0.264 & $0.000^{*}$ & 0.315 \\
\hline
\end{tabular}

\section{Active time (walking - cycling - running)}

Constant

Sports participation

Motoric gait function

Mean PA during weekend

in minutes per day

$\mathrm{N}=116$

\section{Cycling}

Constant

Sports participation

Age years

Age years

\section{Running}

\begin{tabular}{lllll}
\hline Constant & $1.563(0.770)$ & 0.038 to 3.089 & $0.045^{\star}$ & \\
Sports participation & $5.452(1.099)$ & 3.275 to 7.628 & $0.000^{*}$ & 0.170 \\
\hline
\end{tabular}

Active time (walking - cycling - running)
Constant

Sports participation

Age in years
$37.658(9.628)$

11.368 (3.627)

$-1.429(0.653)$
153.250 to $182.6160 .000 *$

12.968 to 45.674$) \quad 0.001$ *

$\begin{array}{lll}-37.605 \text { to }-4.850 & 0.012^{\star} \quad 0.130\end{array}$

\section{B (SD)}

$95 \% \mathrm{Cl}$

P-value Adjusted

\section{R Square}

The data are standardized regression coefficients (B) with standard deviation (SD) and their 95\% confidence intervals (Cl), $P$-values and explained variance (adjusted $R$-square). Outcome variables are adjusted for sports participation, sex, age and motoric gait function. 


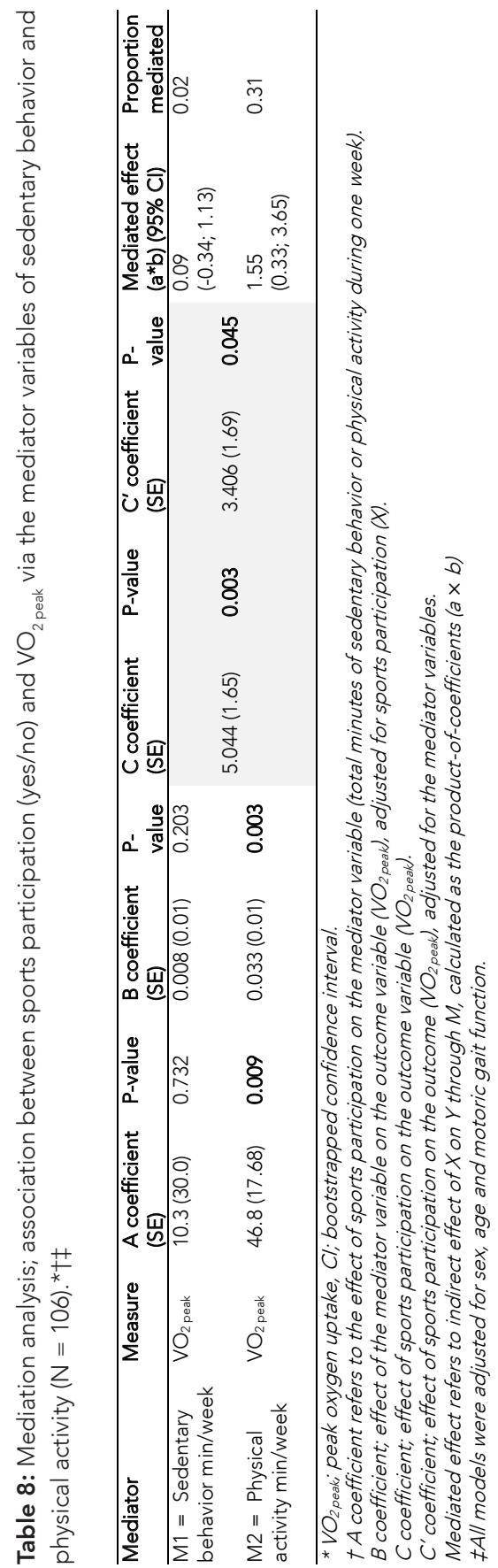




\section{DISCUSSION}

The results from this study demonstrate that sports participation was strongly associated with better health-related fitness and increased PA level in children and adolescents with CDPD. Youth participating at least twice weekly in organized sports performed better on all outcome measures. Our results also suggest that the association between sports participation and aerobic fitness was mediated for $31 \%$ by an increased PA level. We did not observe any significant association between sports participation and sedentary time. We found significant positive associations for both boys and girls between participation in sports and $\mathrm{VO}_{2 \text { peak }}$. These findings are in line with current literature. Earlier studies have shown an association between fitness and sports and exercise in both girls and boys ${ }^{42,43}$. We found levels of aerobic fitness comparable to values observed in healthy youth (mean values $41.5 \mathrm{ml} / \mathrm{kg} / \mathrm{min}$ and $46-49 \mathrm{ml} / \mathrm{kg} / \mathrm{min}$ for females and males respectively) ${ }^{36}$. Previous studies have reported lower aerobic fitness in youth with a neuromuscular disorder ${ }^{44,45}$. A large proportion (49.1\%) in our study population consisted of participants with neuromuscular disorders. Despite this condition, sports participants with neuromuscular disorders in our study show that they can achieve $\mathrm{VO}_{2 \text { peak }}$ values within the normal range for healthy Dutch peers. From a health perspective is this a remarkable and promising finding, because it shows that sports seems effective in optimizing aerobic fitness and this is currently not achieved in the longer term with rehabilitation programs in youth with CDPD ${ }^{46,47}$.

Youth participating in sports also performed significantly better on outcomes of anaerobic fitness, agility and strength measurements. Other cross-sectional studies have reported similar results with in healthy peers, where those participation in recreational sports scored higher in anaerobic fitness and muscular strength than youth those who did not ${ }^{48}$. Short bursts of high intensity sprints are required in youth sports, which may have resulted in a higher anaerobic fitness than their non-sporting peers. In contrast to aerobic fitness, the medical diagnosis did influence the outcomes of anaerobic fitness, agility and muscle strength in our study. Participants with a neuromuscular disorder like Cerebral Palsy or Spina Bifida scored lower on all anaerobic fitness and performance measures compared with those without a neuromuscular disorder. These results are in line with existing evidence which shows that a motor impairment affect anaerobic fitness negatively and the motor impairment influenced anaerobic fitness more strongly compared to aerobic fitness ${ }^{45,49}$. A muscle impairment results in a reduced muscle strength and coordination in muscles that have been affected due to the neuromuscular 
disorder. Due to lower level of coordination, youth with motor impairment often need more time to complete motor tasks. Tasks including stops, turns and accelerations, as part of the agility measures will therefore take more time in youth with motor impairment compared to those without. While youth with a neuromuscular disorder perform less well because of their medical condition, our study showed that participation in sports can significantly contribute to better muscle function and better performance on the anaerobic fitness and performance tests compared to their non-sporting peers with a neuromuscular disorder.

In our study, youth with CDPD who participated in sports were more active during both school and weekend days. At the same time, this higher physical activity level explained $31 \%$ of the association between sports participation and $\mathrm{VO}_{2 \text { peak }}$. A total of 47 minutes more active time per week resulted in a higher $\mathrm{VO}_{\text {2peak }}$ of $1.55 \mathrm{ml} / \mathrm{kg} / \mathrm{min}$. In contrast with the current finding, studies in healthy youth have shown only small correlations between $\mathrm{VO}_{2 \text { peak }}$ and MVPA ${ }^{50,51}$. Youth with CDPD are less active compared with their healthy peers, but do achieve positive effects on health-related fitness when they become active.

This study was the first large study to evaluate the associations between sports and health-related fitness and PA. Strong points are the objective direct measurement of both $\mathrm{VO}_{\text {2peak }}$ and accelerometry-based PA. Obviously, this study also has some limitations. Firstly, the cross-sectional design limits the ability to establish causality and direction. At the same time establishing associations is an important first step for further research. Secondly, we only included ambulatory youth with CDPD and therefore our results are limited to ambulatory youth with CDPD. Moreover, there were more boys in the SG compared to the NSG, which we did correct for in the statistical modelling. Sex stratification is recommended for future studies as outcomes do differ among sex. Finally, using the standardized questionnaire on sports, we did not have information regarding the training history of the sports group (e.g. how many years they have been doing sports). We only recorded whether they have participated in organized sports at least twice weekly during the past 3 months. We would recommend future research to include information of the number of years of sports participation as well as the duration, type and characteristics of the sports activities, as it give more insight into the longterm effects of sports. Despite these limitations, this study still demonstrates positive associations of sports participation with PA and health-related fitness independent of age, sex and motoric gait function in ambulatory youth with CDPD. 


\section{Practical applications}

While in healthy youth only a weak relationship has been demonstrated between PA and aerobic fitness ${ }^{52}$, physical activity was a strong predictor of aerobic fitness in youth with CDPD, as shown with the mediation regression analysis in our study. Our data shows that youth with CDPD who participate in organized sports at least twice weekly benefit from the positive effects of sports on health-related fitness and physical activity. Especially in children and adolescents with CP or SB with muscle weakness, which is a major problem, organized sports contributes to a better muscular function.

As described earlier, youth with CDPD are able to improve their PA level and healthrelated fitness through supervised intervention programs in rehabilitation settings ${ }^{1,16}$, however achieved results are often not maintained in the longer term ${ }^{17,18}$. Data of the current study suggest that participation in sports is an excellent way to improve or maintain health-related physical fitness in youth with CDPD.

Therefore, this study also shows it is important to focus on reducing barriers to sports participation for youth with CDPD, with special attention for girls ${ }^{53}$ and adolescents. In this group the drop-out from sports is high ${ }^{11}$, physical activity decreases and sedentary time increases ${ }^{54}$. This will most likely involve a multidisciplinary approach, with professionals from the medical, social and educational domain working together with the youth with CDPD to overcome barriers and find the possibilities to participate in sports.

For professionals, the training guidelines developed for healthy youth ${ }^{55}$ are mostly applicable for youth with CDPD, but some characteristics and physical possibilities for certain types of sports should be taken into account. Adapted guidelines for both exercise testing and training have been published to guide coaches and trainers of the young athlete with $\mathrm{CDPD}^{56}$. In addition, it is advisable to use relevant registration and assessment tools to monitor training loads. All measurement instruments and performance tests used in this study are feasible, easy to use and proven valid and reliable in youth with CDPD. The measurement outcomes of all tests of the current study could be used as a reference, which makes it possible to put the test outcome of your young patient or sports participant with CDPD in perspective with their sporting and non-sporting peers.

In conclusion, participation in sports is associated with both higher levels of PA and health- related fitness in youth with CDPD. Promotion and stimulation of healthy active lifestyles including sports participation is therefore highly recommended in this special population. 


\section{Acknowledgement}

The authors have no conflicts of interests to disclose.

The authors would like to thank the Dutch Organization of Health Research (ZONMW) for their unconditional grant. Grant number: 525001005.

\section{REFERENCES}

1. van Brussel M, van der Net J, Hulzebos E, Helders PJ, Takken T. The Utrecht approach to exercise in chronic childhood conditions: the decade in review. Pediatr Phys Ther 2011 Spring;23(1):2-14.

2. Carlon SL, Taylor NF, Dodd KJ, Shields N. Differences in habitual physical activity levels of young people with cerebral palsy and their typically developing peers: a systematic review. Disabil Rehabil 2013 Apr;35(8):647-655.

3. Neter JE, Schokker DF, de Jong E, Renders CM, Seidell JC, Visscher TL. The prevalence of overweight and obesity and its determinants in children with and without disabilities. J Pediatr 2011 May;158(5):735-739.

4. Kotte EM, Winkler AM, Takken T. Fitkids exercise therapy program in the Netherlands. Pediatr Phys Ther 2013 Spring;25(1):7-13.

5. Dencker M, Andersen LB. Health-related aspects of objectively measured daily physical activity in children. Clin Physiol Funct Imaging 2008 May;28(3):133-144.

6. Jimenez-Pavon D, Kelly J, Reilly JJ. Associations between objectively measured habitual physical activity and adiposity in children and adolescents: Systematic review. Int J Pediatr Obes 2010;5(1):3-18.

7. LaMonte MJ, Blair SN. Physical activity, cardiorespiratory fitness, and adiposity: contributions to disease risk. Curr Opin Clin Nutr Metab Care 2006 Sep;9(5):540-546.

8. Janssen I, Leblanc AG. Systematic review of the health benefits of physical activity and fitness in school-aged children and youth. Int J Behav Nutr Phys Act 2010 May 11;7:405868-7-40.

9. Riddoch CJ, Mattocks C, Deere K, Saunders J, Kirkby J, Tilling K, et al. Objective measurement of levels and patterns of physical activity. Arch Dis Child 2007 Nov;92(11):963-969.

10. Kjonniksen L, Anderssen N, Wold B. Organized youth sport as a predictor of physical activity in adulthood. Scand J Med Sci Sports 2009 Oct;19(5):646-654.

11. Vella SA, Schranz NK, Davern M, Hardy LL, Hills AP, Morgan PJ, et al. The contribution 
of organised sports to physical activity in Australia: Results and directions from the Active Healthy Kids Australia 2014 Report Card on physical activity for children and young people. J Sci Med Sport 2016 May;19(5):407-412.

12. Telford RM, Telford RD, Cochrane T, Cunningham RB, Olive LS, Davey R. The influence of sport club participation on physical activity, fitness and body fat during childhood and adolescence: The LOOK Longitudinal Study. J Sci Med Sport 2016 May;19(5):400-406.

13. Burghard M, Knitel K, van Oost I, Tremblay MS, Takken T. Dutch physical activity report card study group. Is our youth cycling to health? Results from The Netherlands'2016 report card on physical activity for children and youth. J Phys Act Health 13:S218-S224, 2016.

14. Burghard M, de Jong NB, Vlieger S, Takken T. 2017 Dutch Report Card(+): Results From the First Physical Activity Report Card Plus for Dutch Youth With a Chronic Disease or Disability. Front Pediatr 2018 Apr 30;6:122.

15. Haapala EA, Lankhorst K, de Groot J, Zwinkels M, Verschuren O, Wittink H, et al. The associations of cardiorespiratory fitness, adiposity and sports participation with arterial stiffness in youth with chronic diseases or physical disabilities. Eur J Prev Cardiol 2017 Jul;24(10):1102-1111.

16. Edouard P, Gautheron V, D'Anjou MC, Pupier L, Devillard X. Training programs for children: literature review. Ann Readapt Med Phys 2007 Jul;50(6):510-9, 499-509.

17. de Groot JF, Takken T, van Brussel M, Gooskens R, Schoenmakers M, Versteeg C, et al. Randomized controlled study of home-based treadmill training for ambulatory children with spina bifida. Neurorehabil Neural Repair 2011 Sep;25(7):597-606.

18. Verschuren O, Ketelaar M, Gorter JW, Helders PJ, Uiterwaal CS, Takken T. Exercise training program in children and adolescents with cerebral palsy: a randomized controlled trial. Arch Pediatr Adolesc Med 2007 Nov;161(11):1075-1081.

19. Jaarsma EA, Dijkstra PU, de Blecourt AC, Geertzen JH, Dekker R. Barriers and facilitators of sports in children with physical disabilities: a mixed-method study. Disabil Rehabil 2015;37(18):1617-23; quiz 1624-5.

20. Verschuren O, Wiart L, Hermans D, Ketelaar M. Identification of facilitators and barriers to physical activity in children and adolescents with cerebral palsy. J Pediatr 2012 Sep;161(3):488-494.

21. Te Velde SJ, Lankhorst K, Zwinkels M, Verschuren O, Takken T, de Groot J, et al. Associations of sport participation with self-perception, exercise self-efficacy and quality of life among children and adolescents with a physical disability or chronic disease-a cross-sectional study. Sports Med Open 2018 Aug 15;4(1):38-018-0152-1. 
22. Lankhorst K, van der Ende-Kastelijn K, de Groot J, Zwinkels M, Verschuren O, Backx F, et al. Health in Adapted Youth Sports Study (HAYS): health effects of sports participation in children and adolescents with a chronic disease or physical disability. Springerplus 2015 Dec 22;4:796-015-1589-z. eCollection 2015.

23. Talma H. Growth charts 2010: A manual to measure and weigh children and completing growth charts, Delft: TNO. 2010.

24. Winnick, J.P. \& Short, F.X. editor. The Brockport Physical Fitness Test Manual. : Champaign, IL: Human Kinetics; 1999.

25. Beenakker KG, Ling CH, Meskers CG, de Craen AJ, Stijnen T, Westendorp RG, et al. Patterns of muscle strength loss with age in the general population and patients with a chronic inflammatory state. Ageing Res Rev 2010 Oct;9(4):431-436.

26. Deitz JC, Kartin D, Kopp K. Review of the Bruininks-Oseretsky Test of Motor Proficiency, Second Edition (BOT-2). Phys Occup Ther Pediatr 2007;27(4):87-102.

27. Verschuren $O$, Takken T, Ketelaar M, Gorter JW, Helders PJ. Reliability for running tests for measuring agility and anaerobic muscle power in children and adolescents with cerebral palsy. Pediatr Phys Ther 2007 Summer;19(2):108-115.

28. Vrijkotte S, de Vries S, Jongert T. Fitheidstesten voor de jeugd. Leiden;TNO Kwaliteit van Leven. 2007;031.10038.

29. Douma-van Riet D, Verschuren O, Jelsma D, Kruitwagen C, Smits-Engelsman B, Takken T. Reference values for the muscle power sprint test in 6- to 12-year-old children. Pediatr Phys Ther 2012 Winter;24(4):327-332.

30. Steenman K, Verschuren O, Rameckers E, Douma-van Riet D, Takken T. Extended Reference Values for the Muscle Power Sprint Test in 6- to 18-Year-Old Children. Pediatr Phys Ther 2016 Spring;28(1):78-84.

31. Verschuren O, Bongers BC, Obeid J, Ruyten T, Takken T. Validity of the muscle power sprint test in ambulatory youth with cerebral palsy. Pediatr Phys Ther 2013 Spring;25(1):25-28.

32. Verschuren O, Takken T, Ketelaar M, Gorter JW, Helders PJ. Reliability and validity of data for 2 newly developed shuttle run tests in children with cerebral palsy. Phys Ther 2006 Aug;86(8):1107-1117.

33. Bhambhani YN, Holland LJ, Steadward RD. Maximal aerobic power in cerebral palsied wheelchair athletes: validity and reliability. Arch Phys Med Rehabil 1992 Mar;73(3):246-252.

34. Godfrey S, Davies CT, Wozniak E, Barnes CA. Cardio-respiratory response to exercise in normal children. Clin Sci 1971 May;40(5):419-431.

35. Verschuren $\mathrm{O}$, Maltais DB, Takken T. The 220-age equation does not predict maximum 
heart rate in children and adolescents. Dev Med Child Neurol 2011 Sep;53(9):861-864.

36. Bongers B, Hulzebos E, van Brussel M, Takken T. Pediatric Norms for Cardiopulmonary Exercise Testing. 2nd ed. Den Bosch: Boxpress; 2015.

37. Lankhorst K, Berg Emons van den R, Bussmann J, Horemans H, de Groot JF. A novel tool for quantifying and promoting physical activity in youths with typical development and youths who are ambulatory and have motor disability. Phys Ther 99:1-10, 2019.

38. Montoye AH, Moore RW, Bowles HR, Korycinski R, Pfeiffer KA. Reporting accelerometer methods in physical activity intervention studies: a systematic review and recommendations for authors. Br J Sports Med 2016.

39. Verschuren $\mathrm{O}$, Takken T. Aerobic capacity in children and adolescents with cerebral palsy. Res Dev Disabil 2010 Nov-Dec;31(6):1352-1357.

40. Hayes AF, Preacher KJ. Statistical mediation analysis with a multicategorical independent variable. Br J Math Stat Psychol 2014 Nov;67(3):451-470.

41. Hayes AF. The Process macro for SPSS and SAS. 2016; Available at: http://afhayes.com/ index.html.

42. Armstrong N, Tomkinson G, Ekelund U. Aerobic fitness and its relationship to sport, exercise training and habitual physical activity during youth. $\mathrm{Br} J$ Sports Med 2011 Sep;45(11):849-858.

43. Armstong N, McNarry M. Aerobic Fitness and Trainability in Healthy Youth: Gaps in Our Knowledge. Pediatr Exerc Sci 2016 May;28(2):171-177.

44. Verschuren O, Ketelaar M, Gorter JW, Helders PJ, Takken T. Relation between physical fitness and gross motor capacity in children and adolescents with cerebral palsy. Dev Med Child Neurol 2009 Nov;51(11):866-871.

45. Schoenmakers MA, de Groot JF, Gorter JW, Hillaert JL, Helders PJ, Takken T. Muscle strength, aerobic capacity and physical activity in independent ambulating children with lumbosacral spina bifida. Disabil Rehabil 2009;31(4):259-266.

46. Zwinkels M, Takken T, Visser-Meiley JMA, Verschuren O. Effects of high-intensity interval training on fitness and health in youth with physical disabilities. Pediatr Phys Ther 31:8493, 2019.

47. Bloemen M, Van Wely L, Mollema J, Dallmeijer A, de Groot J. Evidence for increasing physical activity in children with physical disabilities: a systematic review. Dev Med Child Neurol 2017 Oct;59(10):1004-1010.

48. Hoffman JR, Kang J, Faigenbaum AD, Ratamess NA. Recreational sports participation is associated with enhanced physical fitness in children. Res Sports Med 2005 AprJun;13(2):149-161. 
49. Verschuren O, Maltais DB, Douma-van Riet D, Kruitwagen C, Ketelaar M. Anaerobic performance in children with cerebral palsy compared to children with typical development. Pediatr Phys Ther 2013 Winter;25(4):409-413.

50. Armstrong N. Aerobic fitness and physical activity in children. Pediatr Exerc Sci 2013 Nov;25(4):548-560.

51. Poitras VJ, Gray CE, Borghese MM, Carson V, Chaput JP, Janssen I, et al. Systematic review of the relationships between objectively measured physical activity and health indicators in school-aged children and youth. Appl Physiol Nutr Metab 2016 Jun;41(6 Suppl 3):S197-239.

52. McManus AM, Armstrong N. Maximal oxygen uptake. . In: Rowland TW, editor. Cardiopulmonary Exercise Testing in Children and Adolescents: Champaign IL, Human Kinetics.; 2018.

53. Azevedo MR, Araujo CL, Reichert FF, Siqueira FV, da Silva MC, Hallal PC. Gender differences in leisure-time physical activity. Int J Public Health 2007;52(1):8-15.

54. Ortega FB, Konstabel K, Pasquali E, Ruiz JR, Hurtig-Wennlof A, Maestu J, et al. Objectively measured physical activity and sedentary time during childhood, adolescence and young adulthood: a cohort study. PLoS One 2013 Apr 23;8(4):e60871.

55. Lloyd RS, Cronin JB, Faigenbaum AD, Haff GG, Howard R, Kraemer WJ, et al. National Strength and Conditioning Association Position Statement on Long-Term Athletic Development. J Strength Cond Res 2016 Jun;30(6):1491-1509.

56. Durstine LJ, Moore GE, Painter P, Roberts S,O. ACSM's Exercise Management for Persons with Chronic Diseases and Disabilities. 3rd ed.: Human Kinetics; Champaign, IL, 2009. 


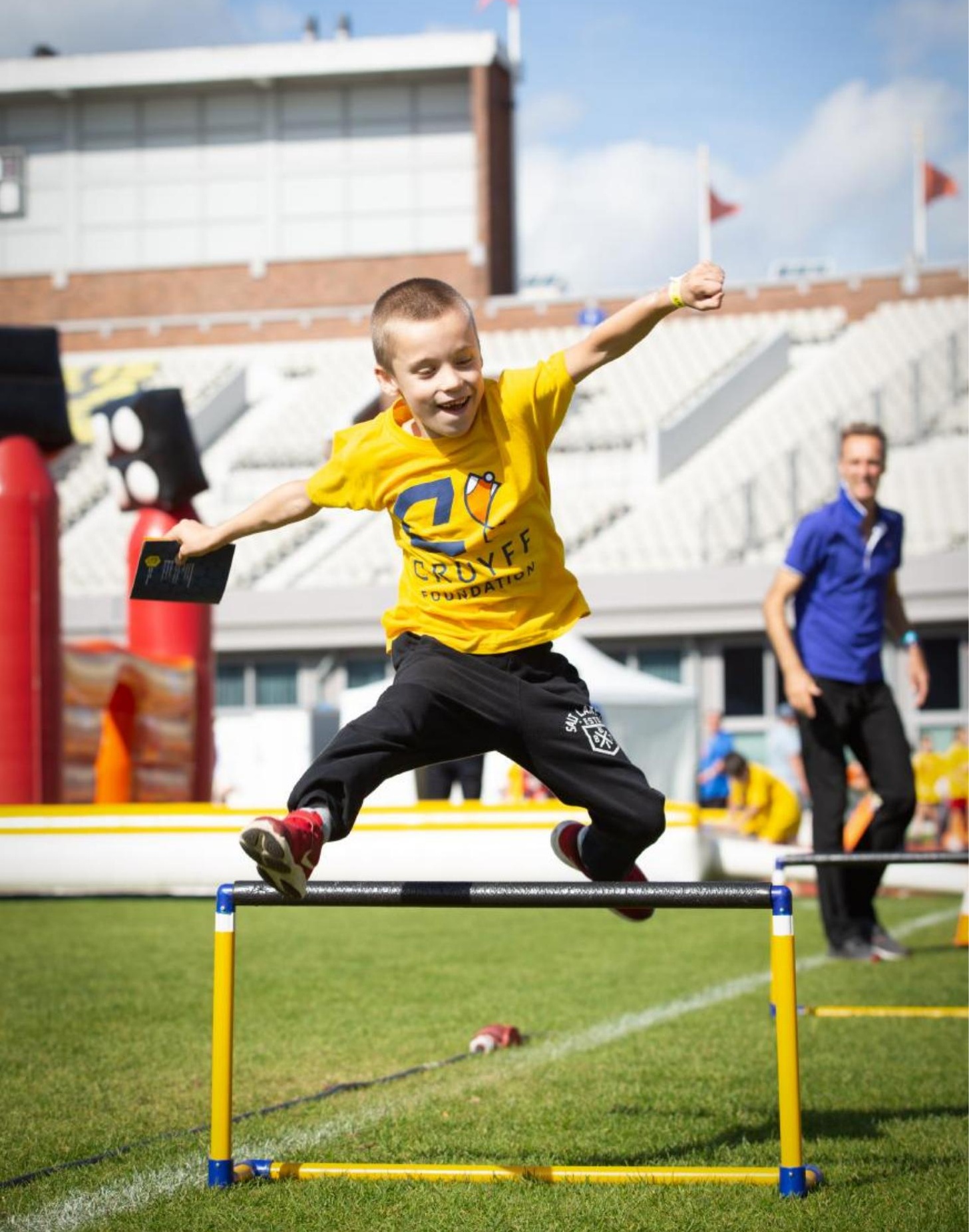




\section{Associations of sport participation with self-perception, exercise self-efficacy and quality of life among children and adolescents with a physical disability or chronic disease: a cross-sectional study}

Saskia te Velde

Kristel Lankhorst

Maremka Zwinkels

Olaf Verschuren

Tim Takken

Janke de Groot 


\section{ABSTRACT}

Background. Little evidence is available about how sports participation influences psychosocial health and quality of life in children and adolescents with a disability or chronic disease. Therefore, the aim of the current study is to assess the association of sports participation with psychosocial health and with quality of life, among children and adolescents with a disability.

Methods. In a cross-sectional study 195 children and adolescents with physical disabilities or chronic diseases (11\% cardiovascular, 5\% pulmonary, $8 \%$ metabolic, $8 \%$ musculoskeletal/-orthopaedic, 52\% neuromuscular and 9\% immunological diseases and 1\% with cancer), aged 10-19 years, completed questionnaires to assess sports participation, health related quality of life (DCGM-37), self-perceptions and global selfworth (SPPC or SPPA) and exercise self-efficacy.

Results. Regression analyses showed that those who reported to participate in sports at least twice a week, had more beneficial scores on the various indicators compared to their peers who did not participate in sport or less than twice a week. Those participating in sports scored better on all scales of the DCGM-37 scale, on the scales for feelings of athletic competence and children but not adolescents participating in sports reported greater social acceptance. Finally, we found a strong association between sport participation and exercise self-efficacy.

Conclusion. This study provides the first indications that participating in sports is beneficial for psychosocial health among children and adolescents with a disability. However, more insight is needed in the direction of the relationships.

\section{Key points}

- Children and adolescents with a physical disability or chronic disease who are participating in sports scored better on all scales of the DCGM-37 scale reflecting a better health related quality of life

- Participating in sports was associated with feelings of athletic competence in children and adolescents with a disability or chronic disease. In addition, children, but not adolescents, participating in sports reported higher feelings of social acceptance.

- Sport participation among children and adolescents with a physical disability or chronic disease was strongly positively associated with exercise self-efficacy. 


\section{INTRODUCTION}

Physical activity and sports participation have several health benefits for people of all ages ${ }^{1}$. Engaging in sufficient levels of physical activity improves cardiopulmonary health, strength, flexibility, and endurance and has been related to reduced risks for cardiovascular diseases and specific cancers ${ }^{2,3}$. Moreover, physical activity, especially sports, exercise and leisure time activities, has been related to reductions in mortality ${ }^{4}$. In addition, due to its social nature, sports participation provides opportunities for social interaction, companionship and may therefore have greater benefits for social and mental well-being than other domains of physical activity ${ }^{5-8}$. Furthermore, sports participation may enhance health-related quality of life in adults as well as in children and adolescents ${ }^{9,10}$. Health-related quality of life is a broadly defined construct evaluating the health status from the person's perspective covering physical, emotional, mental, social and functional domains ${ }^{11}$ and has been used in evaluations of sport and exercise interventions ${ }^{12,13}$.

The benefits of sport and physical activity for psychosocial health, i.e. one's mental processes, self-reflections and interactions with others, are universal and not restricted to healthy adults and typically developing children and adolescents. In the contrary, children and adolescents with a chronic disease or physical disability (CDPD) may benefit even more ${ }^{14}$. Both children with a physical disability as well as children with a chronic disease may experience similar barriers for sport participation. They both have lower fitness levels, lower levels of physical activity and a higher prevalence of overweight and obesity ${ }^{15-17}$. Sport and physical activity does not only improve the physical functioning and physical independence in both groups, it may enhance inclusion and well-being. For example, a review about leisure time activities and quality of life among children and adolescents with neurological disabilities reported that participation in active leisure time activities was associated with better physical well-being, improved sense of self, emotional well-being and promote social well-being ${ }^{18}$. Unfortunately, children and adolescents with CDPD engage less often in physical activities and sports 17,19,20. Furthermore, these children and adolescents may experience low levels of self-worth and quality of life due to their physical limitations and body image concerns ${ }^{21-24}$. Therefore, insight in the potential beneficial effects of physical activity and in particular sports participation, as a specific sub-domain of physical activity, are important for subsequent interventions promoting sports participation among children and adolescents with disabilities.

So far, only a few studies addressed the association of sports participation with psychosocial health and quality of life in children and adolescents in general or in children and adolescents with CDPD. Dinomais and colleagues ${ }^{25}$ showed that young 
people with disabilities who participated in competitive sports scored high on social functioning, which is in line with the review by Sahlin and Lexel ${ }^{9}$ who concluded that children and adolescents with a disability who engaged in sports reported similar scores on self-concept than non-disabled athletes. However, it remains unclear whether positive associations were the result of the physical activity itself, or of the social interaction and learning environment of the sports club. A study among 15-69 year-old French men and women showed that across all levels of physical activity, sports participation was positively associated with quality of life ${ }^{26}$. In addition, the review by Eime and colleagues ${ }^{5}$ reported that club-based and team-based sports participation resulted in better psychosocial health outcomes than individual forms of sports.

The aforementioned studies used different indicators, each measuring different but related aspects of psychosocial health. Positive self-worth, self-perceptions, self-esteem, social support and self-efficacy are acknowledged indicators of psychosocial health and quality of life ${ }^{23,27}$. Involvement in sports, and the interaction with others in this context, allows children and adolescents to develop their self-concept, especially related to the physical and social domains ${ }^{28}$. A systematic review found that physical activity was strongly associated with perceived (athletic) competence ${ }^{29}$. A meta-analysis supported the proposition that physical activity positively influences body image, and this effect was larger in adolescents compared to students, adults and older adults ${ }^{30}$. In summary, participation in physical activity may have an impact on many aspects of psychosocial health, however the evidence available about how sports participation influences psychosocial health and quality of life in children and adolescents with a disability is still scarce. Therefore, the aim of the current study is to assess the association of sports participation with psychosocial health, specifically, self-perceptions, exercise self-efficacy and quality of life, among children and adolescents with a disability. Based on previous studies, we hypothesize that children and adolescents who participate in sport have more favourable scores on these indicators of psychosocial health and quality of life.

\section{METHODS}

\section{Design and sample}

Cross-sectional data from two related studies using identical outcomes were combined. Firstly, the cross sectional Health in Adapted Youth Sports (HAYS) study that includes children and adolescents aged 10-19 years old with a chronic disease or physical disability $(C D P D)^{31}$. Secondly, the baseline data from the Sports-2-Stay Fit (S2SF) study which is a clinically controlled trial among children and adolescents aged 6-19 years with a CDPD ${ }^{32}$. For both studies, children and adolescents were recruited through patient organisations, 
pediatric physical therapy practices, Wilhelmina Children's Hospital in Utrecht, De Hoogstraat Rehabilitation Center, Fitkids and schools (for special education) in the Netherlands.

Inclusion criteria were: having a physical disability or a chronic disease (cardiovascular, pulmonary, musculoskeletal or neuromuscular disorder), aged between 10 and 19 years (HAYS) or between 6 and 19 years (S2SF), ability to understand simple instructions, able to perform physical fitness tests. Children and adolescents were not eligible for participation in these studies if they had a progressive disease, used an electric wheelchair, participated in other (research) projects that may influence the results of the current studies, or did not sign the informed consent form.

For the current study, children and adolescents were included in the analyses if they had valid data on sports participation and valid data on at least one of the outcome variables (quality of life, self-efficacy, self-perceptions, general self-worth). Eight children and adolescents from the S2SF-study did not complete the online questionnaires during their first assessment, but did during the second assessment (8 weeks later). For that reason, we included data from these eight children or adolescents from their second assessment. We assumed that even though their scores may have been improved in that 8 week period, this will not affect the association between sports participation and these variables.

In total, 197 participants had complete data on sports participation, of whom two had no valid data on the outcome variables. Of the remaining 195 participants, 177 participants had complete data on all outcome variables, another 13 participants had valid data on two of the three outcome variables and 5 participants had valid data on only one outcome variables. The distribution of valid data on the outcome variables did not differ by sport participation status $(p=0.428)$ or by diagnosis (ACSM category) $(p=0.346)$ or by gender $(p=0.393)$. We included 195 children and adolescents who had complete data on sports participation and at least one outcome variable. Of those included children and adolescents, 145 participated in the HAYS study, while 50 participated in the S2SF study.

\section{Procedures}

The procedures and protocols for the HAYS and the S2SF study have been described elsewhere in more detail ${ }^{31,32}$. Briefly, participants who agreed to participate and met the inclusion criteria were scheduled for an assessment at the lab (University of Applied Science, Utrecht). One week before this visit to the laboratory, the participants or their parents received a secured link to an online questionnaires assessing exercise self-efficacy and quality of life. These questionnaires took about $10-15$ minutes to complete. When the children visited the laboratory, they were first asked to compete the questionnaires 
on self-perceptions and global self-worth in the presence of one of the researchers or research assistants, which took about 10 minutes. When they finished the questionnaires their physical fitness, cognition, and cardiovascular health was assessed, which took on average about two hours ${ }^{31,32}$.

The studies were approved by the Medical Ethics Committee of the University Medical Center Utrecht, the Netherlands. (METC number: 14-332/c and 14-118/m). All participants and the parents of participants under 18 years of age provided their informed written consent. Studies were conducted in accordance with the Helsinki Declaration.

\section{Measurements}

\section{Independent variable}

\section{Sports participation}

Sports participation was assessed by means of a questionnaire that was completed before the start of the physical fitness tests. Sports participation was identified using three standardized questions used by the National Institute for Public Health and the Environment (RIVM) ${ }^{33}$ 1) "do you participate in organized sports?" 2) "what is / are the type of organized sport(s)?" and, 3) "what is the frequency of participation in organized sports per week?". When participants indicated that they participate in organized sports at least 2 times per week, they were classified as 'participating in sports', all others were classified as 'non-sporting'. This cut-off was based on the Consensus statement for the Dutch Guidelines for Physical Activity for youth $(<18 \text { years old })^{34}$. This guideline was developed for typically developing children and was in place at the time of the start of the current research project. It advises that children and adolescents should be physically active for at least one hour per day at least a moderate intensity. In addition, children and adolescents should engage in activities that specifically address physical fitness at least two times a week. Sport activities are typically activities in which physical fitness, including strength, flexibility and coordination, are addressed. However, there are no universally accepted guidelines for children and adolescents with a chronic disease of physical disability and Van Brussel and colleagues ${ }^{35}$ advise to use a training frequency of minimally 2 times per week. This is in line with recommendations for people with Cerebral Palsy that were based on a comprehensive literature review, expert opinions and extensive clinical experience ${ }^{36}$. 


\section{Dependent variables}

\section{Health-related Quality of Life}

To evaluate the quality of life, the Dutch version of the Disabkids (DCGM-37) was used, which was completed online by either the participant alone $(n=45)$, together with one of the parents/caregivers $(n=54)$ or the parent alone $(n=9)$ (unknown for $n=89$ ). This questionnaire measures the quality of life and the independence of children and adolescents with chronic health conditions. The questionnaire has been used in other paediatric populations and has been tested for internal consistency and validity ${ }^{37-39}$ The questionnaire includes 37 items that cover six subscales, i.e. mental independence, mental emotion (inner strength), social inclusion, social exclusion (social equality), physical limitations (physical ability) and physical treatment (i.e. the impact of taking medication, receiving injections, etc. ${ }^{38}$. All items were scored on a 5-point Likert scale ranging from 1 = never to 5 = always. For each scale a sum score was calculated by following the instructions of the developers of the DCGM-37 and the provided syntax file ${ }^{38}$. If one item was missing, this missing value was substituted by the mean of the non-missing values. If more than 1 item of a domain was missing, no sum score was calculated. These scores were transformed so that they had a range from $0-100$ with higher scores indicating a higher perceived quality of life.

\section{Self-perception and global self-worth}

To evaluate self-perception, the Dutch translations of the self-perception profile for children (SPPC) and for adolescents (SPPA) were used ${ }^{40}$. We used the children's version for children of 12 years old and younger, or with cognitive capabilities of this age group, and the adolescent version for those older than 12 years. Based on the researcher's expertise, an older child was provided the children's version or when the child clearly was not able to complete the adolescent version or did not understand the questions. The children's version uses 36 items to measure five domains, i.e. 'scholastic competence', 'social acceptance', 'athletic competence', 'physical appearance', 'Behavioural conduct', and the general concept 'global self-worth' ${ }^{\prime 41,42}$. All six scales consist of 6 items that include bipolar statements (e.g. 'some kids feel they are very good at school, but other kids worry about whether they do the schoolwork assigned to them'). The children have to choose which of the two statements resembles them, and how much, i.e. 'sort of true for me' or 'really true for me'. All items were scored on a 4-point scale and sum scores were calculated. The questionnaire has been tested in a Dutch norm group and showed reasonable to good internal consistency and test-retest reliability ${ }^{42}$.

The adolescent version includes 35 items which make up 7 scales; i.e. 'scholastic competence', 'social acceptance', 'athletic competence', 'physical appearance', 
'behavioural conduct', 'close friendship' and the general concept 'global self-worth'. Similar to the child version of the questionnaire, all items included bipolar statements that were scored on a 4-point scale by which the adolescents indicated which statement resembled them 'sort of true' or 'really true'43.

If one item of the scale was missing, the scale score was not calculated $(n=3)$. All scores on each scale were compared to Dutch norm scores to indicate whether the participants scored 'below average', i.e. below the $15^{\text {th }}$ percentile, or above average, i.e. at or higher than the $85^{\text {th }}$ percentile. For the child version, different norms have been formulated for boys and girls ${ }^{41}$. For the adolescent version different norms were formulated by school level for the scales 'scholastic competence' and 'behavioural conduct' and a distinction by sex was made for all scales except 'social acceptance'43. In the current study, results regarding these norm scores were only used for descriptive purposes.

\section{Exercise Self-Efficacy}

To assess whether sport participation was associated with exercise self-efficacy, the Dutch version of the Exercise Self-Efficacy Scale ${ }^{44,45}$ was filled out digitally at home by the child. Self-efficacy is a well-known behavioural determinant and described in several behavioural theories such as the Social Cognitive Theory by Bandura ${ }^{46}$ in which self-efficacy is seen as important influencer of behaviour. In the current study we hypothesise that behaviour, in this study engaging in sport, can have a positive impact on self-efficacy in relation to physical activity and exercise. This hypothesis is based on the fact that mastery experiences and vicarious experiences are important sources of self-efficacy ${ }^{47}$ and when participating in sport, children may learn new skills and may see others like themselves performing specific tasks or behaviours. The questionnaire takes approximately $2 \mathrm{~min}$ to complete. The questionnaire consists of 10 items about the level of self-confidence with regard to performing regular physical activities and exercise that could be rated on a 4-point Likert scale ranging from 'not true at all' to 'always'. A sample item is: "I am confident that I can overcome barriers and challenges with regard to physical activity and exercise if I try hard enough". A sum score was calculated when all 10 items were answered. Internal consistency of the scale was high, Cronbach's alpha $=0.99$. A higher score indicates a higher exercise self-efficacy. Validity and reliability of the scale have been tested in a sample with spinal cord injury and showed good validity and adequate reliability ${ }^{44}$.

\section{Potential confounders and co-variates Demographic variables}

The demographic questionnaire that included questions about date of birth, sex, and school level. 


\section{Medical Diagnosis}

The general questionnaire assessed the medical diagnosis. The medical diagnosis were further classified in categories according to The American College of Sports Medicine (ACSM)48: 1. Cardiovascular (e.g. ventricular septal defect, tetralogy of Fallot, cardiomyopathy), 2. Pulmonary (Asthma), 3. Metabolic (Diabetes), 4. Musculoskeletal or orthopaedic (Amputation, clubfoot, Hereditary Multiple Exostoses - Multiple Osteochondromas, congenital anomalies), 5. Neuromuscular (Cerebral palsy, spina bifida, neurofibromatosis, Kabubi syndrome, centronuclear myopathy, psychomotor retardation, Martsolf syndrome, acquired brain injury), 6. Immunological or haematological (Rheumatism, Fanconi anaemia), 7. Cancer (Tumor in hypophysis), 8. Epilepsy. In the regression analyses categories were merged distinguishing disabilities or disease related to the metabolic system or oxygen transport (1. Cardiovascular, 2 Pulmonary, and 3. Metabolic) from the other disabilities or diseases, mostly related to the musculoskeletal or neurological system.

\section{School type}

Children participating in the current study attended either regular education or special education for children with physical disabilities (so called mytyl schools). These schools, dedicated to children with CDPD, have similar learning objectives as regular schools, but the children receive additional attention and support. Children attending special education may have different references for social comparison which may influence how they perceive themselves. Therefore, school type was added as a potential confounder in the analyses.

\section{Statistical analyses}

Continuous data was described by means or medians and standard deviations or interquartile ranges and categorical data by frequencies and proportions. Crude comparisons on the outcome variables between the sporting and non-sporting participants were made using ANOVA. Adjusted associations between sports participation and the outcome variables were estimated by linear (or logistic) regression analyses. Assumptions were checked and residuals showed an acceptable normal distribution, except for the Exercise Self-Efficacy scale. Therefore the scale was dichotomized at the third tertile (score $\geq 37$ ) and associations with sports participation were assessed by means of logistic regression analyses. Sensitivity analyses were run with and without outliers, i.e. those with standardized residual scores below -3 or higher than 3 .

Different models will be presented, unadjusted as well as adjusted for potential confounders sex, age, school type, diagnosis or ACSM category. All analyses were 
checked for potential interaction by age. In case of significant interactions, results will be presented for two age groups. For the analyses, the ACSM categories were merged into two categories, i.e. one including those with cardiovascular, pulmonary and metabolic conditions, and another including those with musculoskeletal, neuromuscular, immunological, cancer or epileptic conditions. Results are reported as regression coefficients or odds rations and their $95 \%$ confidence intervals.

\section{RESULTS}

Of the 195 children included in the current study, 96 were classified as participating in sports (see Table 1). Based on the ACSM classification, most children ( $n=104(52.8 \%)$ ) had a neuromuscular condition (Table 1), followed by cardiovascular disease ( $n=22$ (11.3\%)). One third of the children attended special education.

Table 1: Characteristics of the study sample $(\mathrm{N}=195)$.

\begin{tabular}{lll}
\hline & mean & Standard deviation \\
\hline Age (years) & 14.3 & 2.8 \\
\hline Study ${ }^{1}$ (HAYS) & $\mathbf{n}$ & $\%$ \\
\hline Sex (boys) & 145 & 74.4 \\
\hline Sports participation ${ }^{2}$ (yes) & 116 & 59.5 \\
\hline ACSM & 96 & 49.2 \\
\hline Cardiovascular & & \\
\hline Pulmonary & 22 & 11.3 \\
\hline Metabolic & 9 & 4.6 \\
\hline Musculoskeletal or orthopedic & 16 & 8.2 \\
\hline Neuromuscular & 16 & 8.2 \\
\hline Immunological or heamatological & 103 & 52.8 \\
\hline Cancer & 18 & 9.2 \\
\hline Epileptic & 3 & 1.5 \\
\hline
\end{tabular}

\section{Education type ${ }^{3}$}

Special-education 65 33.3

${ }^{1}$ participating in either the HAYS or the S2SF study; ${ }^{2}$ sport participation is defined here as participating in sport at least 2 times a week; ${ }^{3}$ Education type could be regular education or special education. 
Table 2 shows the descriptive statistics regarding the outcome variables. The mean scores on the different subscales for the DCGM-37 varied, it was lowest for the social exclusion scale (62.9 (17.7)) and highest for the mental emotion $(77.9(17.8))$ and physical treatment $(77.1(22.1))$. When looking at the norm scores for the SPPC and SPPA, a relative highly proportion of children scores below the norm for social acceptance (SPPA: $21.3 \%$ ) and athletic competence (SPPC: 25\%, SPPA: 23.45). On the other hand, relatively many children score above the $85^{\text {th }}$ percentile for scholastic competence (SPPA: 29.2\%), social acceptance (SPPC: 25.7\%), athletic competence (SPPC, 23.6\%) and behavioural conduct (SPPC: $35.0 \%$, SPPA: 33.3\%).

Table 3 displays the unadjusted comparisons on the outcome variables between sporting and non-sporting participants. Those participating in sports scored higher on all subscales of the DCGM-37, except on the physical treatment scale. The significant differences in the unadjusted analyses remained statistically significant after adjustment for potential confounders, indicating that school type and medical diagnosis did not substantially confound the association. (Table 4).

Children participating in sports reported higher scores on social acceptance and athletic competence than their non-sporting peers, while no differences were observed for the other scales of the SPPC (Table 3). These differences became slightly stronger after adjustment for potential confounders (Table 4).

The adolescents who participated in sports, scored higher on athletic competence than the non-sporting adolescents (SPPA, Table 3). Moreover, this difference became slightly larger after adjustment of age, gender, school type and ACSM classification (Table 4). In addition, after adjustment for potential confounders, the scores on the scale for close friendships was significantly higher for adolescents participating in sports compared to their non-sporting peers.

Those participating in sports scored more often in the upper tertile on the exercise self-efficacy scale than their non-sporting peers (Table 3 and Table 4). After adjustment for school type and medical diagnosis the odds ratio decreased slightly, but remained significant. Those who participate in sports were 2.55 more likely to score in the upper tertile for exercise self-efficacy, independent of sex, school type or medical diagnosis. (Table 4). 


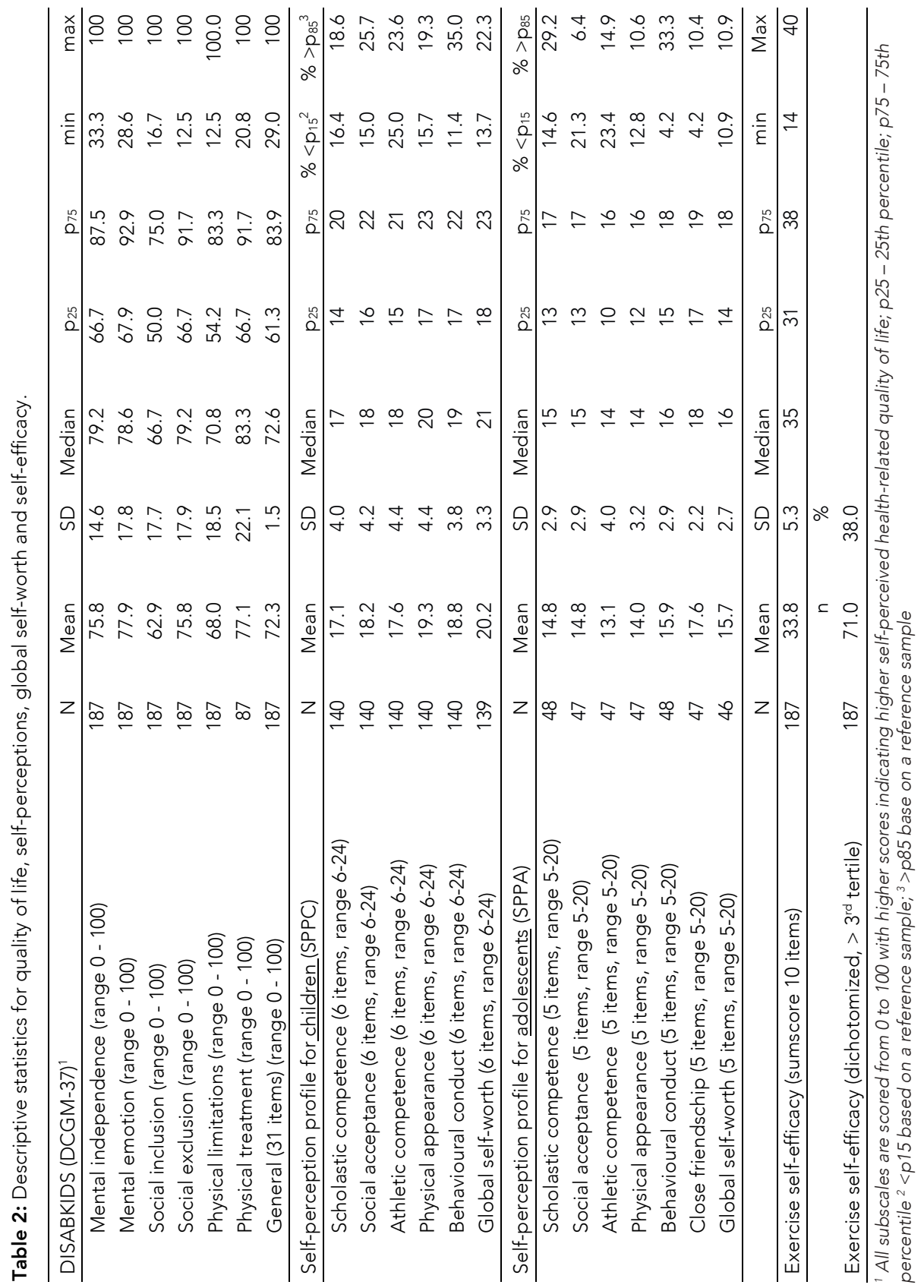




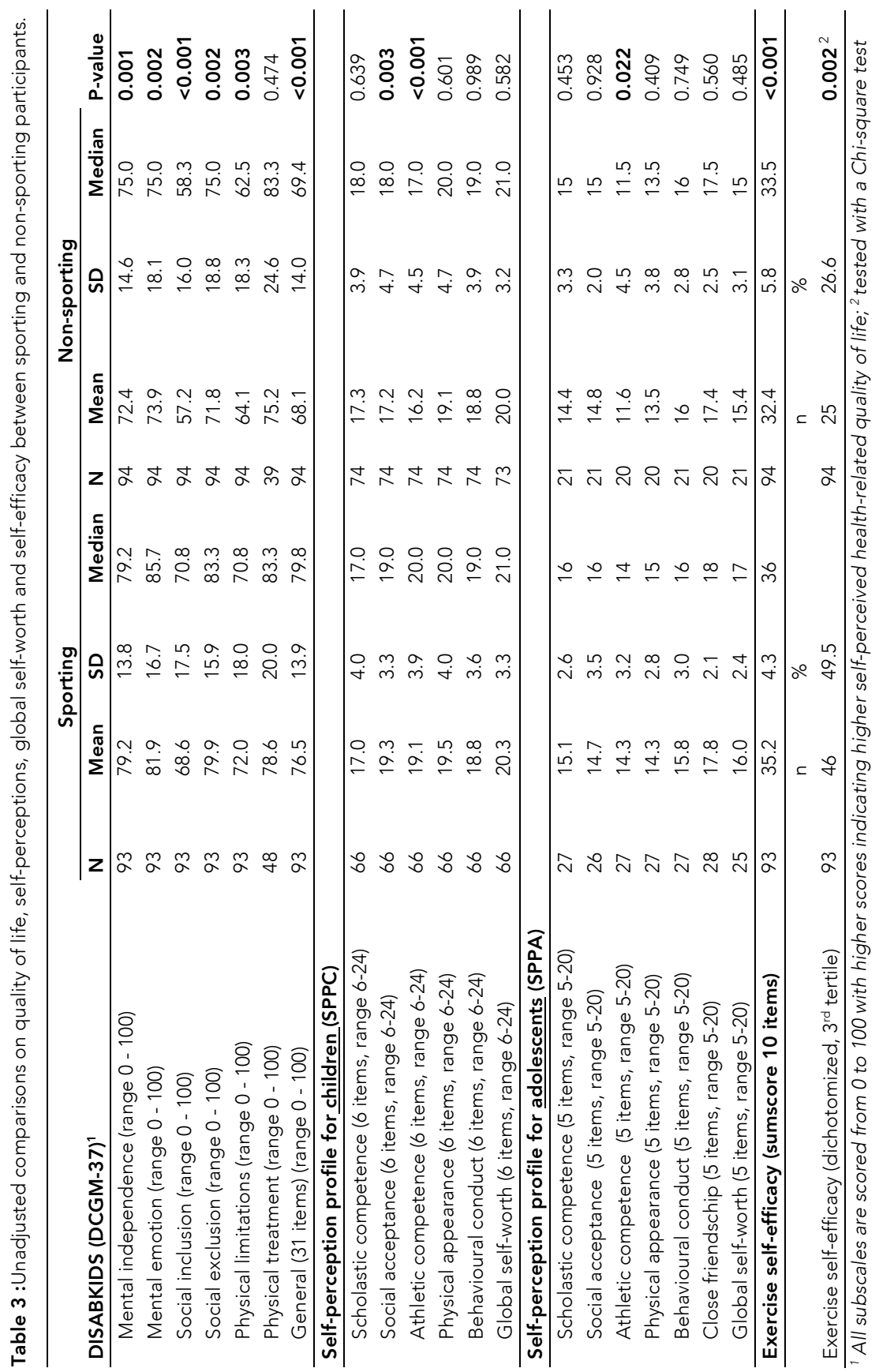




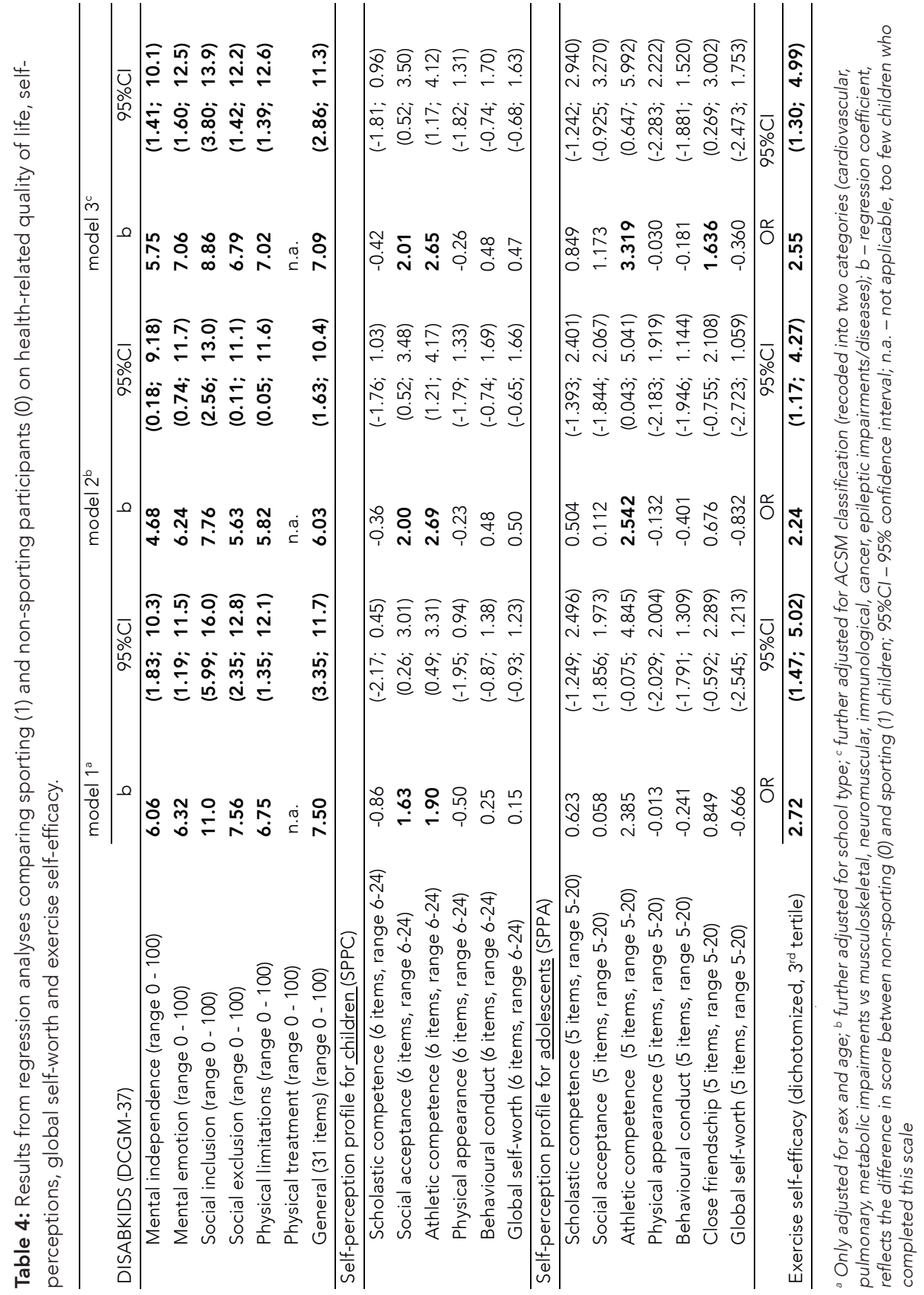




\section{DISCUSSION}

The current study aimed to assess the associations between sports participation and psychosocial health among children and adolescents with a disability. In general, those who reported to participate in sports at least twice a week, had more beneficial scores on the various indicators compared to their peers who did not participate in sports or less than twice a week. This was independent of age, sex, school type or medical diagnosis and largely in line with our hypotheses.

Those participating in sports scored better on all scales of the DCGM-37 scale. The effect sizes were quite substantial, for the total score the difference between the groups was about 7 points. Although the fact that the DCGM-37 distinguishes six subscales reflecting different concepts, these sub-scales were strongly correlated in the current sample. Therefore, it is not surprising that the groups differed on all sub-scales. Unfortunately, it is difficult to compare these findings with other studies, due to the fact that other instruments to assess quality of life were used, or that other studies did not made comparisons between sporting and non-sporting participants. However, our findings support the hypothesis that participating in organized sports by children and adolescents with a CDPD can contribute to all domains of quality of life and are in line with two studies among adults ${ }^{49,50}$.

Furthermore, our findings regarding the self-perceptions are in line with the existing reviews among adults, children and adolescents 29,30 , and show that participating in organized sports contributes to feelings of athletic competence in children and adolescents with a CDPD. In addition, children, but not adolescents, participating in sports reported higher feelings of social acceptance. It may be that adolescents have more networks besides a sports club that influence their feelings of social acceptance, while children have a more controlled and limited network and that participating in sports with other children therefore has a greater influence on their feelings of social acceptance. On the other hand, the effect estimate was in favour of the sporting adolescents and it may be that for these analyses not enough participants were included to show a significant difference. In addition, a study among high school students found a positive association between sports participation and self-belief, that included feelings of social acceptance ${ }^{51}$. Lastly, it may be that children who do not feel accepted withdraw from sport participation. That we did not find significant differences between the groups on most of the other self-perception scales, may be due to the fact that our study population scored relatively high on most scales, at least when compared with the $15^{\text {th }}$ and $85^{\text {th }}$ percentile norm values. However, compared to a study sample described by Shapiro and colleagues, the current sample scored lower on the social acceptance, athletic competence and physical appearance scales ${ }^{52}$. That in the current 
study no associations between sport participation and self-perception concepts were found may be because of other factors than sports participation play a more crucial role in these scales or that different types of sports may have different effects that could not be detected in the current study design.

Finally, despite the fact that the self-efficacy scale was dichotomized which may have led to reduced power, we found a strong association between sports participation and exercise self-efficacy. Self-efficacy is a well know behavioural determinant of physical activity ${ }^{53}$ assuming that exercise self-efficacy influences physical activity. In the current study, we hypothesized another causal pathway, i.e. that sports participation would result in beneficial scores on a range of psychosocial health indicators, including exercise selfefficacy. Sources of influence of self-efficacy are vicarious experiences or modelling and past experiences ${ }^{46}$, therefore it can be expected that those who participate in sports see others performing sports, and also experience themselves that they are able to perform sports, which both positively impact on their exercise self-efficacy.

An important limitation of the current study is its cross sectional design limiting the conclusions regarding causality. It may as well be that those who experience a better quality of life, or who feel socially accepted and athletically competent, are more likely to participate in organized sports. Therefore, experimental and longitudinal studies are required to study causal or reciprocal relationships. These longitudinal designs would also allow for mediation analyses to study underlying pathways. For instance, in a longitudinal design we could analyse whether changes in sport participation result in changes in intermediate variables (e.g. self-perception) that in turn result in changes in health-related quality of life. Another limitation is the crude measure of sports participation, which did not include information on duration, quality and type of sports. It may be that team sports have different impact on psychosocial health indicators than individual sports. Furthermore, we did not report whether they participated in regular sports or in adapted forms of sports. The advantage of participation in adapted forms of sports is that children can better focus on their abilities rather than their inabilities ${ }^{49}$. Additionally, the DCGM-37 was in a few cases $(n=9)$ completed by the parent, which may have biased the findings as parents tend to report lower scores than children ${ }^{37,54}$. However, if this is a systematic bias, it will not affect the association between sport participation and health related quality of life. Finally, those defined as participating in sports may perform sports at different intensities and frequencies. In conclusion, the group defined as participating in sport is very heterogeneous and this may have biased the results such that potential associations between sport participation and the outcome may not have been detected. Therefore, future studies should take these aspects into account and may also investigate how the level of sport participation is related to self- 
perceptions. However, even with the use of this crude measure for sports participation, significant associations with psychosocial health and quality of life were detected.

\section{CONCLUSIONS}

Despite some limitations and considering the fact that this is fone of the first studies addressing this topic in children and adolescents with a CDPD, the current study provides the first indications that participating in sports in beneficial in this population for their psychosocial health. A next step would be to perform experimental and longitudinal studies to see what type of sports, duration and intensities are most promising for improving psychosocial health.

\section{Acknowledgement}

The authors gratefully acknowledge the children and adolescents who participated in the studies. The authors would like to thank the Dutch Organization of Health Research (ZONMW) for their unconditional grant. Grant number: 525001005. 


\section{REFERENCES}

1. Warburton DER, Nicol CW, Bredin SSD. Health benefits of physical activity: the evidence. CMAJ 2006;174:801-9.

2. Kubota Y, Evenson KR, MacLehose RF, Roetker NS, Joshu CE, Folsom AR. Physical Activity and Lifetime Risk of Cardiovascular Disease and Cancer. Med Sci Sport Exerc 2017;1.

3. Alves AJ, Viana JL, Cavalcante SL, Oliveira NL, Duarte JA, Mota J, et al. Physical activity in primary and secondary prevention of cardiovascular disease: Overview updated. World J Cardiol 2016;8:575-83.

4. Samitz G, Egger M, Zwahlen M. Domains of physical activity and all-cause mortality: Systematic review and dose-response meta-analysis of cohort studies. Int J Epidemiol 2011;40:1382-400.

5. Eime RM, Harvey JT, Brown WJ, Payne WR. Does Sports Club Participation Contribute to Health-related Quality of Life? Med Sci Sport Exerc 2010;42:1022-8.

6. Street $\mathrm{G}$, James $\mathrm{R}$, Cutt $\mathrm{H}$. The relationship between organised physical recreation and mental health. Heal Promot J Aust 2007;18:236-9.

7. Seippel $\varnothing$. The meanings of sport: fun, health, beauty or community? Sport Soc 2017;9:5170.

8. Eime RM, Young JA, Harvey JT, Charity MJ, Payne WR. A systematic review of the psychological and social benefits of participation in sport for adults: informing development of a conceptual model of health through sport. Int J Behav Nutr Phys Act 2013;10:135.

9. Sahlin KB, Lexell J. Impact of Organized Sports on Activity, Participation, and Quality of Life in People With Neurologic Disabilities. PM R. Am J Phys Med Rehabil; 2015;7:1081-8.

10. Mitchell TMDF, Barlow CEMS. Review of the Role of Exercise in Improving Quality of Life in Healthy Individuals and in Those With Chronic Diseases. Curr Sports Med Rep 2011;10:211-6.

11. Bullinger M, Schmidt S, Petersen C. Assessing quality of life of children with chronic health conditions and disabilities: a European approach. Int J Rehabil Res 2002;25:197-206.

12. Crosbie A. The Effect of Physical Training in Children With Asthma on Pulmonary Function, Aerobic Capacity and Health-Related Quality of Life: A Systematic Review of Randomized Control Trials. Pediatr Exerc Sci 2012;24:472-89.

13. Kotte EMW, De Groot JF, Winkler AMF, Huijgen BCH, Takken T. Effects of the Fitkids Exercise Therapy Program on Health-Related Fitness, Walking Capacity, and Healthrelated Quality of Life. Phys Ther 2014;94:1306-18.

14. Koldoff EA, Holtzclaw BJ. Physical Activity Among Adolescents with Cerebral Palsy: An Integrative Review. J Pediat. Nurs Elsevier Inc.; 2015;30:e105-17. 
15. Kotte EMW, Winkler AMF, Takken T. Fitkids exercise therapy program in the Netherlands. Pediatr Phys Ther 2013;25:7-13.

16. Neter JE, Schokker DF, de Jong E, Renders CM, Seidell JC, Visscher TLS. The Prevalence of Overweight and Obesity and Its Determinants in Children with and without Disabilities. J Pediatr 2011;158:735-9.

17. Carlon SL, Taylor NF, Dodd KJ, Shields N. Differences in habitual physical activity levels of young people with cerebral palsy and their typically developing peers: a systematic review. Disabil Rehabil 2013;35:647-55.

18. Dahan-Oliel N, Shikako-Thomas K, Majnemer A. Quality of life and leisure participation in children with neurodevelopmental disabilities: A thematic analysis of the literature. Qual Life Res 2012;21:427-39.

19. Rimmer JA, Rowland JL, Rimmer JA, Rowland JL. Physical activity for youth with disabilities : A critical need in an underserved population. Dev Neurorehabil. 2008;11:141-8.

20. Buffart LM, Roebroeck ME, Rol M, Stam HJ, Van Den Berg-Emons RJG, Netherlands Transition Research Group South-West. Triad if Physical Activity, Aerobic Fitness and Obeisty in Adolescents and Young Adults with Myelomeningocele J Rehabil Med 2008;40:70-5.

21. Rimmer JH, Riley B, Wang E, Rauworth A, Jurkowski J. Physical Activity Participation Among Persons with Disabilities. Am J Prev Med Introd 2004;26::419-425.

22. Sawin KJ, Bellin MH. Quality of life in individuals with spina bifida: A research update. Dev Disabil Res Rev 2010;16:47-59.

23. Ferguson MK, Kovacs $\mathrm{AH}$. Quality of life in children and young adults with cardiac conditions. Curr Opin Cardiol 2013;28:115-21.

24. Houben-van Herten M, Bai G, Hafkamp E, Landgraf JM, Raat H. Determinants of healthrelated quality of life in school-aged children: A general population study in the Netherlands. PLoS One 2015;10:1-13.

25. Dinomais M, Gambart G, Bruneau A, Bontoux L, Deries X, Tessiot C, Richard I. Social functioning and self-esteem in young people with disabilities participating in adapted competitive sport. Neuropediatrics 2010;41:49-54.

26. Abdou Y, Erpelding OM. Contribution of taking part in sport to the association between physical activity and quality of life. Qual Life Res 2013;22:2021-9.

27. Drakouli M, Petsios K, Giannakopoulou M, Patiraki E, Matziou V, M. D, et al. Determinants of quality of life in children and adolescents with CHD: a systematic review. Cardiol Young 2015;1027-36.

28. Balaguer I, Atienza-Gonzalez FL, Duda JL. Self-Perceptions, Self-Worth and Sport Participation in Adolescents. Span J Psychol 2012;15:624-30. 
29. Babic MJ, Morgan PJ, Plotnikoff RC, Lonsdale C, White RL, Lubans DR. Physical Activity and Physical Self-Concept in Youth: Systematic Review and Meta-Analysis. Sport Med 2014;44:1589-601.

30. Hausenblas HA, Fallon EA. Exercise and body image: a meta-analysis. Psychol Health 2006;21:33-47.

31. Lankhorst K, van der Ende-Kastelijn K, de Groot J, Zwinkels M, Verschuren O, Backx F, et al. Health in Adapted Youth Sports Study (HAYS): health effects of sports participation in children and adolescents with a chronic disease or physical disability. Springerplus Springer International Publishing; 2015;4:796.

32. Zwinkels M, Verschuren $O$, Lankhorst K, van der Ende-Kastelijn K, de Groot J, Backx F, et al. Sport-2-Stay-Fit study: Health effects of after-school sport participation in children and adolescents with a chronic disease or physical disability. BMC Sports Sci Med Rehabil 2015;7:22.

33. de Hollander EL, Milder I, Proper K. Beweeg- en sportgedrag van mensen met een chronische aandoening of lichamelijke beperking. Bilthoven; RIVM 2015.

34. Kemper HCG, Ooijendijk WT., Stiggelbout M. Consensus over de Nederlandse norm voor gezond bewegen (consensus about the Dutch norm for physical activity). Sport en Geneeskunde. 2000;78:180-3.

35. 3Van Brussel M, Van Der Net J, Hulzebos E, Helders PJM, Takken T. The Utrecht approach to exercise in chronic childhood conditions: The decade in review. Pediatr Phys Ther 2011;23(1):2-14.

36. Verschuren O, Peterson MD, Balemans ACJ, Hurvitz EA. Exercise and physical activity recommendations for people with cerebral palsy. Dev Med Child Neurol 2016;58(8):798808.

37. Mueller-Godeffroy E, Thyen U, Bullinger M. Health-Related Quality of Life in Children and Adolescents with Cerebral Palsy: A Secondary Analysis of the DISABKIDS Questionnaire in the Field-Study Cerebral Palsy Subgroup. Neuropediatrics 2016;47:97-106.

38. Froisland DH, Markestad T, Wentzel-Larsen T, Skrivarhaug T, Dahl-Jorgensen K, Graue M. Reliability and validity of the Norwegian child and parent versions of the DISABKIDS Chronic Generic Module (DCGM-37) and Diabetes-Specific Module (DSM-10). Health Qual. Life Outcomes. BioMed Central Ltd; 2012;10:19.

39. Simeoni MC, Schmidt S, Muehlan H, Debensason D, Bullinger M, Petersen C, et al. Field testing of a European quality of life instrument for children and adolescents with chronic conditions: The 37-item DISABKIDS Chronic Generic Module. Qual Life Res 2007;16:88193. 
40. Harter S. The Self-Perception Profile for Children: Revision of the Perceived Competence Scale for Children. Denver, CO; 1985.

41. Veerman JWE, Treffers DA, Van der Bergh BRH, Ten Brink LT. Competentiebelevingsschaal voor kinderen. Amsterdam: Harcourt Test Publishers; 2004.

42. eerman JW, Ten Brink LT. Measuring childrens self-concept Factorial validity. J Per. Assess 1996;67:142-54.

43. Treffers, Ph. D, Goedhardt AW, Veerman JW, Van den Bergh BRH, Ackaert L, de Rycke L. Handleiding Competentie Belevingsschaal voor Adolescenten. Lisse: Swets Test Publishers; 2002.

44. Nooijen CFJ, Post MWM, Spijkerman DCM, Bergen MP, Stam HJ, Van Den Berg-Emons RJG. Exercise self-efficacy in persons with spinal cord injury: Psychometric properties of the Dutch translation of the exercise self-efficacy scale. J Rehabil Med 2013;45:347-50.

45. Kroll T, Kehn M, Ho P-S, Groah S. The SCI Exercise Self-Efficacy Scale (ESES): development and psychometric properties. Int J Behav Nutr Phys Act 2007;4:34.

46. Bandura A. Health promotion from the perspective of social cognitive theory. 2012;37-41.

47. Bandura A. Self-efficacy. The Exercise of control. New York: Freeman; 1997.

48. Durstine LJ, Moore GE, Painter P, Roberts SO. ACSM's exercise management for persons with chronic diseases and disabilities. 3rd ed. Humen Kinetics; Champaign, IL, 2009.

49. Yazicioglu K, Yavuz F, Goktepe AS, Tan AK. Influence of adapted sports on quality of life and life satisfaction in sport participants and non-sport participants with physical disabilities. Disabil Health J 2012: 249-53.

50. Groff DG, Lundberg NR, Zabriskie RB. Influence of adapted sport on quality of life: perceptions of athletes with cerebral palsy. Disabil Rehabil 2009;31:318-26.

51. Dodge T, Lambert AESF. Positive Self-Beliefs as a Mediator of the Relationship Between Adolescents' Sports Participation and Health in Young Adulthood. J Youth Adolesc 2009;38:813-25.

52. Shapiro DR, Martin JJ. The relationships among sport self-perceptions and social wellbeing in athletes with physical disabilities. Disabil Health J Elsevier Inc; 2014;7:42-8.

53. Plotnikoff RC, Costigan SA, Karunamuni N, Lubans DR. Social cognitive theories used to explain physical activity behavior in adolescents: a systematic review and meta-analysis. Prev Med. 2013;56:245-53.

54. Baca CB, Vickrey BG, Hays RD, Vassar SD, Berg AT. Differences in child versus parent reports of the child's health-related quality of life in children with epilepsy and healthy siblings. Value Heal. International Society for Pharmacoeconomics and Outcomes Research (ISPOR); 2010;13:778-86. 

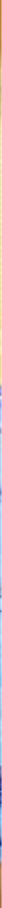

18
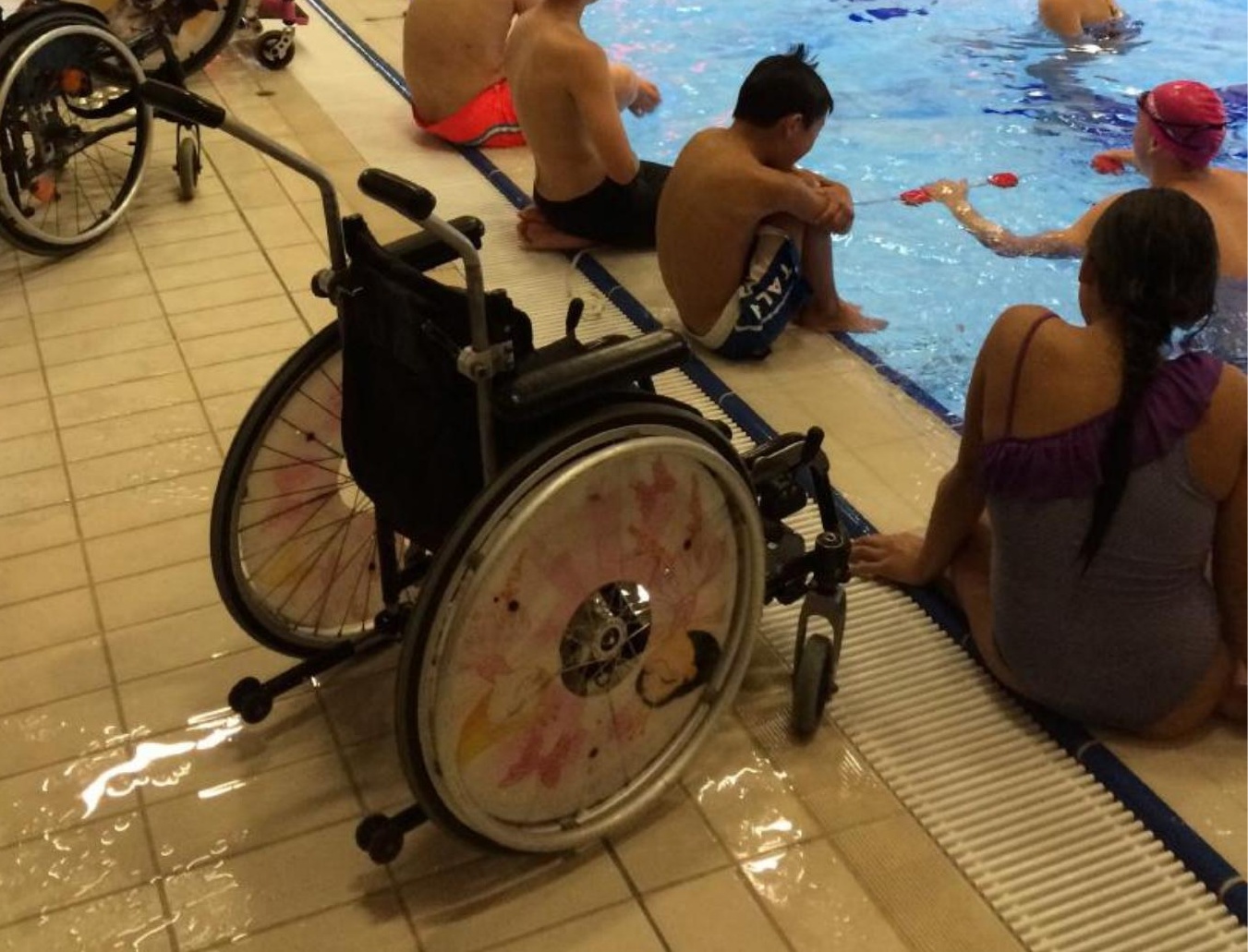


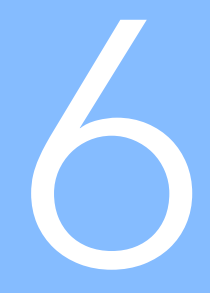

\section{The associations of} cardiorespiratory fitness, adiposity and sports participation with arterial stiffness in youth with chronic
diseases or physical disabilities

Kristel Lankhorst

Eero Haapala

Janke de Groot

Maremka Zwinkels

Olaf Verschuren

Harriet Wittink

Frank Backx

Anne Visser-Meily

Tim Takken 


\section{ABSTRACT}

Background. The evidence on the associations of cardiorespiratory fitness, body adiposity, and sports participation with arterial stiffness in children and adolescents with chronic diseases or physical disabilities is limited.

Design. Cross-sectional.

Methods. Altogether 140 children and adolescents with chronic diseases or physical disabilities participated in the study. Cardiorespiratory fitness was assessed using maximal exercise test with respiratory gas analyses either using shuttle run, shuttle ride, or cycle ergometer test. Cardiorespiratory fitness was defined as peak oxygen uptake $\left(\mathrm{VO}_{\text {2peak }}\right)$ by body weight or fat free mass (FFM). Body adiposity was assessed using waist circumference, body mass index standard-deviation score (BMI-SDS), and body fat percentage. Sports participation was assessed by a questionnaire. Aortic pulse wave velocity PWV (PWVao) and augmentation index (AIX\%) were assessed by a non-invasive oscillometric tonometry device.

Results. $\mathrm{VO}_{2 \text { peak }} /$ body weight (standardized regression coefficient $B=-0.222,95 \% \mathrm{Cl}=-$ 0.386 to $-0.059, \mathrm{P}=0.002$ ) and $\mathrm{VO}_{2 \text { peak }} / \mathrm{FFM}(B=-0.173,95 \% \mathrm{Cl}=-0.329$ to $-0.017, \mathrm{P}=0.030$ ) were inversely and waist circumference directly $(B=0.245,95 \%$ confidence interval $(\mathrm{Cl})=0.093$ to $0.414, \mathrm{P}=0.002$ ) associated with PWVao. However, the associations of the measures of cardiorespiratory fitness with PWVao were attenuated after further adjustment for waist circumference. $A$ higher waist circumference $(B=-0.215,95 \% \mathrm{Cl}=-$ 0.381 to $-0.049, P=0.012)$ and a higher $\mathrm{BMI}-\mathrm{SDS}(B=0.218,95 \% \mathrm{Cl}=-0.382$ to -0.054 , $\mathrm{P}=0.010$ ) were related to lower AIX\%.

Conclusions. Poor cardiorespiratory fitness and higher waist circumference were associated with increased arterial stiffness in children and adolescents with chronic diseases and physical disabilities. The association between cardiorespiratory fitness and arterial stiffness was partly explained by waist circumference. 


\section{INTRODUCTION}

Arteriosclerotic cardiovascular diseases are one of the leading causes of morbidity and mortality and the costs related to arteriosclerosis demonstrate a considerable economic burden ${ }^{1}$. Arterial stiffness and endothelial dysfunction are the first signs of arteriosclerosis and they have been established already in children and adolescents ${ }^{2,3}$. In adults, increased arterial stiffness has been found to predict subsequent clinical cardiovascular events ${ }^{4}$. Therefore, early identification of children and adolescents with increased arterial stiffness is of importance in order to prevent arteriosclerotic cardiovascular diseases in later years".

Poor cardiorespiratory fitness has been associated with higher carotid and femoral artery stiffness and aortic intima media thickness (IMT) and elasticity in adolescents 5 ,6. Better cardiorespiratory fitness in adolescence also has been linked to lower femoral artery stiffness and carotid IMT at the age of $36^{7}$. Furthermore, obesity has been consistently related to stiffer carotid and aortic arteries among youth ${ }^{8}$. Higher levels of habitual physical activity have been associated with lower arterial stiffness, lower aortic IMT, and improved endothelial function in children and adolescents in some ${ }^{9-11}$, but not all studies ${ }^{12-15}$. Furthermore, constantly high levels of vigorous physical activity between ages 13 and 36 have been linked to lower arterial stiffness at the age of 36 year ${ }^{16}$. Finally, the results of some previous studies suggest that exercise training has favorable effects on flow-mediated dilation as a marker of endothelial function in overweight and obese children and adolescents ${ }^{17}$.

Children and adolescents with chronic diseases or physical disabilities may have an increased risk of arteriosclerosis ${ }^{18}$. The evidence suggest that children and adolescents with chronic diseases or physical disabilities have lower cardiorespiratory fitness ${ }^{19}$, higher prevalence of overweight and obesity ${ }^{19,20}$, lower levels of physical activity ${ }^{20,21}$, and they participate less often in organized sports $^{20}$, than their apparently healthy or normally developing peers. Children and adolescents with chronic disease or disabilities may also have increased arterial stiffness ${ }^{22}$. Studies among adults also suggest that arterial stiffness is particularly important marker of subsequent cardiovascular morbidity and mortality among those with chronic cardiovascular or metabolic diseases ${ }^{4}$. However, one small study found no differences in arterial structure and function between children with cerebral palsy (CP) and normally developing children with similar levels of physical activity and body adiposity ${ }^{23}$. Nevertheless, there are no studies on the associations of cardiorespiratory fitness, body adiposity, and sports participation with arterial stiffness in 
a large sample of children and adolescents with chronic diseases or physical disabilities. The aim of the present study was to investigate the associations of cardiorespiratory fitness, body adiposity, and sports participation with arterial stiffness in children and adolescents with chronic diseases or physical disabilities. We also studied if there are thresholds for cardiorespiratory fitness and the measures of body adiposity that are associated with increased arterial stiffness.

\section{METHODS}

\section{Participants}

The present analyses are based on the data from the Health in Adapted Youth Sports (HAYS) Study and the Sport-2-Stay-Fit (S2SF) Study. These studies are designed to investigate the associations of sports participation and exercise training with physical fitness, physical activity, body adiposity, cognition, cardiovascular health, and quality of life in children and adolescents with chronic diseases or physical disabilities. The study designs are published in detail elsewhere ${ }^{24,25}$.

The children and adolescents for the HAYS Study and S2SF Study were recruited in the Netherlands among different patients' associations, pediatric physical therapy practices, Wilhelmina Children's Hospital in Utrecht, De Hoogstraat Rehabilitation Center in Utrecht, Fitkids practices, Schools for special education, and adapted sports organizations. The inclusion criteria for the HAYS Study and the S2SF Study was that participants had to understand the Dutch language, understand simple instructions, and be able to perform physical fitness tests. All ambulatory children and adolescents and wheelchair users were eligible to participate. Children and adolescents using an electric wheelchair, having a progressive disease, who participated in other research projects, or who had contra-indications for performing a maximal exercise test were excluded.

\section{Ethical approval}

The study protocols were approved by the Medical Ethics Committee of the University Medical Center Utrecht, the Netherlands (METC number: 14-332/c and 14-118/m). All participants and the parents of participants under 18-years-of-age provided their informed written consent. Studies were conducted in accordance to the Helsinki declaration. 


\section{Assessment of cardiorespiratory fitness}

Peak oxygen uptake $\left(\mathrm{VO}_{\text {2peak }}\right)$ as a measure of cardiorespiratory fitness was assessed either by an adapted 10-meter incremental shuttle run test, by a 10-meter incremental shuttle ride test, or by an incremental cardiopulmonary exercise test on an electronically braked Ergoline cycle ergometer (Ergoselect 200 K, Ergoline, Bitz, Germany) ${ }^{24}$. The test modality was based on the evaluation of children's ambulatory ability, mode of daily locomotion, type of sports, and safety issues. All children with a congenital cardiopulmonary disease underwent an incremental cardiopulmonary exercise test with continuous electrocardiography (ECG) monitoring on a cycle ergometer. Participants who were able to walk or run performed an incremental shuttle run test and wheelchair users performed a shuttle ride test. Altogether $64 \%$ of the participants performed a shuttle run test, $11 \%$ a shuttle ride test, and $24 \%$ a cycle ergometer test. All the test procedures have been described in detail previously ${ }^{24}$.

Respiratory gases were collected using pediatric masks (Hans-Rudolph, Shawnee, Kansas, USA) during the test by a calibrated metabolic cart (Cortex Metamax, Samcon bvba, Melle, Belgium). Regardless of testing modality, respiratory gases were measured directly by the breath-by-breath method from the 3-min resting steady-state period to the post-exercise rest and were averaged over consecutive 10-s periods.

Children and adolescents were verbally encouraged to exercise until voluntary exhaustion. The exercise test was considered maximal, if the subjective and objective criteria indicated maximal effort and maximal cardiorespiratory capacity (i.e. flushing, sweating, heart rate $>180, \mathrm{RER}>1.0$, or plateau of $\mathrm{VO}_{2}$ ). Cardiorespiratory fitness was defined as $\mathrm{VO}_{\text {2peak }}$ per body weight and $\mathrm{VO}_{\text {2peak }}$ per $\mathrm{kg}$ fat free mass (FFM).

\section{Assessment of body size and body adiposity}

Body size and composition were measured after emptying the bladder. Body height was measured by stadiometer (Seca, Hamburg, Germany) in ambulant participants. Among participants using wheelchair the body height was measured in a supine position using a measuring tape. In case of spasticity of the lower limbs, arm span width was measured to the nearest centimeter from middle fingertip to fingertip. Body weight was measured by standard scale (Seca, Hamburg, Germany). Participants who used a wheelchair and who were not able to stand on a scale were measured using a wheelchair scale (Stimag B.V., Lisse, the Netherlands). Body mass index (BMI) was calculated as body weight (kg) / body height $(\mathrm{m})^{2}$ for ambulant participants and as body weight $(\mathrm{kg}) /$ the arm 
span length. We used arm span adjustment of $\times 0.95$ and $\times 0.90$ for participants with central neurological disorders in mid lumbar lesions and high lumbar/thoracic lesions, respectively ${ }^{26}$. Waist circumference was measured by an unstretchable measuring tape at the level of the navel. BMI-standard deviation score (SDS) and waist circumference-SDS were computed using national reference values ${ }^{27}$. Body fat percentage and FFM were measured by bioelectrical impedance analyses using Bodystat Quadscan 4000 device (EuroMedix, Leuven, Belgium).

\section{Assessment of sports participation}

To allow a comparison between children and adolescents with chronic diseases or physical disabilities who participated in organized sports and those without regular sports participation we recruited sports participants from a broad range of participation in sports including recreational level as well as high level competitive sports ${ }^{24}$. The study participants reported how often they participated in organized sports on a questionnaire. In the present study, we defined regular sports participation as any involvement in organized sports at least 2 times per week.

\section{Assessment of arterial stiffness}

Aortic PWV (PWVao), as a measure of arterial stiffness, and augmentation index (AIX\%), as measure of peripheral arterial tone, were assessed by non-invasive oscillometric tonometry device (Arteriograph, TensioMed Ltd, Budapest, Hungary) from the right arm. PWVao and AIX\% derived from the Arteriograph analyses have been validated against an invasive method in adults. The correlation of invasively assessed PWVao and AIX\% to PWVao and AIX\% measured by the Arteriograph has been found to be strong ( $r>0.90)$ with a reasonable agreement between oscillometric tonometry and invasive methods ${ }^{28}$. Before the measurement, participants were asked to rest in a supine position for 10 minutes. Age and sex-specific SDS-norm values for PWVao and AIX\% were calculated based on the data of over a 4500 Caucasian children and adolescents ${ }^{29,30}$. A higher PWVa indicates a higher aortic stiffness and a higher AIX\% indicates a higher peripheral arterial tone.

Systolic blood pressure was also assessed by the Arteriograph device (TensioMed Ltd, Budabest, Hungary) in a supine position after ten-minute rest. 


\section{Statistical methods}

Basic characteristics between boys and girls were compared using the Student's t-test, the Mann-Whitney U-test, or the Chi Square-test. The associations of cardiorespiratory fitness and body adiposity as independent variables with PWVao and AIX\% as dependent variables were studied using linear regression analyses adjusted for age and sex. The differences in PWVao and AIX\% between sport participants and non-sport participants were investigated using general linear models (GLM) adjusted for age and sex. The data on the associations of cardiorespiratory fitness, body adiposity, and sports participation with PWVao and AIX\% were also mutually adjusted.

All data were additionally controlled for systolic blood pressure, the mode of exercise testing, and diagnose (cardiovascular disease vs. other).

Receiver operating characteristics (ROC) curves were used to investigate the optimal cutoff for $\mathrm{VO}_{2 \text { peak' }}$ waist circumference, BMI-SDS, and body fat percentage to identify children and adolescents at or over +1SD of PWVao and AIX\% reference values ${ }^{29,30}$. The area under the curve (AUC) is considered a measure of the effectiveness of the predictor variable to correctly identify children and adolescents at or above +1SD of PWVao and AIX\% (sensitivity) and to correctly identify participants (specificity) below +1SD of PWVao and AIX\%. An AUC of 1 represents the ability to perfectly identify children and adolescents at or above +1SD of PWVao and AIX\% from other participants, whereas an AUC of 0.5 indicates no greater predictive ability than chance alone.

The optimal cutoff was determined by the Youden index ${ }^{31}$, which is the maximum value of $\mathrm{J}$ that is computed as: sensitivity + specificity -1 .

The effect modification of sex was investigated by general linear models (GLM). Because we found no statistically significant sex-interactions between the measures of cardiorespiratory fitness and body adiposity and the outcome variables, we performed all analyses with data of boys and girls combined.

Student's t-test, the Mann-Whitney U-test, the Chi Square-test, GLM analyses, and the linear regression analyses were performed using the SPSS Statistics, Version 23.0 (IBM Corp., Armonk, NY, USA). The ROC curve analyses were performed using MedCalc Statistical Software, Version 16.1 (MedCalc Software bvba, Ostend, Belgium). A P-value of $<0.05$ was considered as statistically significant. 


\section{RESULTS}

\section{Descriptive characteristics}

Complete data on variables used in the present analyses were available for 140 children and adolescents with chronic diseases or physical disabilities ( 86 boys, 54 girls). Children and adolescents who were excluded ( $N=37,20$ boys, 17 girls) from the present analyses because of the missing data did not differ from those who were included in waist circumference or BMI-SDS. Children and adolescents who were included in the present analyses were slightly older than those who were excluded from the present analyses $(\mathrm{P}=0.029)$.

Among the included children and adolescents, boys were taller, had a lower body fat percentage, higher $\mathrm{VO}_{\text {2peak' }}$ and a lower AIX\% than girls (Table 1). Seventy-six (56\%) of the included children and adolescents participated in sports. Altogether 17 children and adolescents had a cardiovascular disease, four had a pulmonary disease, 10 had a metabolic disease, 11 had a musculoskeletal/orthopedic disability, 82 had a neuromuscular disease/disability, six had an immunological/hematological disease, three had cancer, and seven had epilepsy (Table 1). There were no age-differences among the children and adolescents in different diagnosis groups $(P=0.682)$. 
Table 1: Descriptive characteristics of the study population.

\begin{tabular}{lllll}
\hline & All & Boys (N=84) & Girls (N=56) & $P$-value \\
\hline Age (years) & $14.3(2.7)$ & $14.1(2.7)$ & $14.7(2.9)$ & 0.078 \\
Body height $(\mathrm{cm})$ & $160(14.3)$ & $162.7(15.9)$ & $157.9(10.9)$ & 0.033 \\
Body weight $(\mathrm{kg})$ & $54.8(16.6)$ & $56.7(18.4)$ & $51.7(12.7)$ & 0.059 \\
Body mass index* $\left(\mathrm{kg} / \mathrm{m}^{2}\right)$ & $20.0(5.2)$ & $20.2(5.6)$ & $19.7(5.1)$ & 0.681 \\
Body mass index-standard deviation score & $0.68(1.3)$ & $0.83(1.3)$ & $0.43(1.3)$ & 0.078 \\
Prevalence of overweight $(\%)$ & 39.3 & 43 & 33.3 & 0.253 \\
Waist circumference $(\mathrm{cm})$ & $75.7(13.3)$ & $75.6(14.2)$ & $75.9(12.1)$ & 0.888 \\
Waist circumference- standard deviation score & $0.8(1.3)$ & $0.7(1.5)$ & $1.1(1.1)$ & 0.062 \\
Body fat percentage $(\%)$ & $23.9(9.7)$ & $21.2(9.4)$ & $28.1(8.7)$ & $<0.001$ \\
Peak oxygen uptake $(\mathrm{L} / \mathrm{min})$ & $2.1(1.0)$ & $2.5(0.9)$ & $1.8(0.4)$ & $<0.001$ \\
Peak oxygen uptake $(\mathrm{ml} / \mathrm{kg} / \mathrm{min})^{\star}$ & $40.0(15.0)$ & $44.0(15.0)$ & $36.0(11.0)$ & $<0.001$ \\
Peak oxygen uptake $(\mathrm{ml} / \mathrm{FFM} / \mathrm{min})^{\star}$ & $52.9(13.7)$ & $56.5(14.8)$ & $51.1(8.1)$ & $<0.001$ \\
Aortic pulse wave velocity $(\mathrm{m} / \mathrm{s})^{*}$ & $5.8(1.3)$ & $5.8(1.2)$ & $5.8(1.1)$ & 0.098 \\
Aortic pulse wave velocity-standard deviation score* & $-0.17(1.71)$ & $-0.21(1.7)$ & $-0.04(1.7)$ & 0.189 \\
Aortic augmentation index (\%)* & $9.0(10.4)$ & $7.7(11.4)$ & $10.1(10.3)$ & 0.005 \\
Aortic augmentation index (\%)-standard deviation score * & $0.19(1.23)$ & $0.17(1.2)$ & $0.25(1.2)$ & 0.245 \\
\hline
\end{tabular}

FFM, fat free mass. The data are mean (standard deviations), median (interquartile range*), or percentages and the $P$-values from the $t$-test for independent samples for continuous variables with normal distribution and Mann-Whitney U-test for continuous variables with skewed distribution, or Chi-square for prevalence of overweight.

\section{Associations of cardiorespiratory fitness body adiposity, and sports participation with arterial stiffness}

$\mathrm{VO}_{\text {2peak }}$ per body weight and $\mathrm{VO}_{\text {2peak }}$ per FFM were inversely and waist circumference directly associated with PWVao after adjustment for age and sex (Table 2). However, the relationship of $\mathrm{VO}_{2 \text { peak }}$ per body weight $(B=-0.133,95 \% \mathrm{Cl}=-0.315$ to $0.050, \mathrm{P}=0.152$ ) and $\mathrm{VO}_{\text {2peak }}$ per FFM ( $B=-0.137,95 \% \mathrm{Cl}=-0.291$ to $\left.0.017, \mathrm{P}=0.082\right)$ to $\mathrm{PWVa}$ were no longer statistically significant after further adjustment for waist circumference. Additional adjustment for systolic blood pressure, the mode of exercise testing, or diagnose had no effect on these associations (data not shown). 
Table 2: Associations of cardiorespiratory fitness and body adiposity with arterial stiffness in 140 children and adolescents with chronic diseases or physical disabilities.

\begin{tabular}{lllllll}
\hline & \multicolumn{3}{l}{ Aortic pulse wave velocity $(\mathrm{m} / \mathrm{s})$} & \multicolumn{4}{l}{ Aortic augmentation index (\%) } \\
\hline & $\mathrm{B}$ & $95 \% \mathrm{Cl}$ & $P$ & $\mathrm{~B}$ & $95 \% \mathrm{Cl}$ & $P$ \\
Peak oxygen uptake (mL/kg/min) & -0.222 & -0.386 to -0.059 & 0.008 & -0.100 & -0.271 to 0.070 & 0.247 \\
Peak oxygen uptake (mL/fat free mass $/ \mathrm{min})$ & -0.173 & -0.329 to -0.017 & 0.030 & -0.120 & -0.281 to 0.041 & 0.142 \\
Waist circumference (cm) & 0.254 & 0.093 to 0.414 & 0.002 & -0.215 & -0.381 to -0.049 & 0.012 \\
Body mass index-standard deviation score & 0.141 & -0.026 to 0.307 & 0.097 & -0.218 & -0.382 to -0.054 & 0.010 \\
Body fat percentage (\%) & 0.036 & -0.127 to 0.198 & 0.664 & 0.016 & -0.150 to 0.183 & 0.847 \\
\hline
\end{tabular}

The data are standardized regression coefficients and their $95 \%$ confidence intervals adjusted for age and sex.

Waist circumference and BMI-SDS were inversely associated with AIX\% after adjustment for age and sex. Further adjustment for the measures of cardiorespiratory fitness or sports participation had no effect on these associations (data not shown). However, further adjustment for systolic blood pressure slightly attenuated the association between waist circumference and $\mathrm{AIX} \%(B=-0.166,95 \% \mathrm{Cl}=-0.343$ to $0.010, \mathrm{P}=0.064)$. Additional adjustment for the mode of exercise testing, or diagnose had no effect on these associations (data not shown).

Sports participation was not associated with PWVao or AIX\% after adjustment for age and sex $(P>0.40)$. The associations of cardiorespiratory fitness, body adiposity, sports participation with PWVao and AIX\% remained similar when PWVao-SDS and AIX\%-SDS were used as outcome measures or waist circumference-SDS was used as an independent variable (data not shown). 

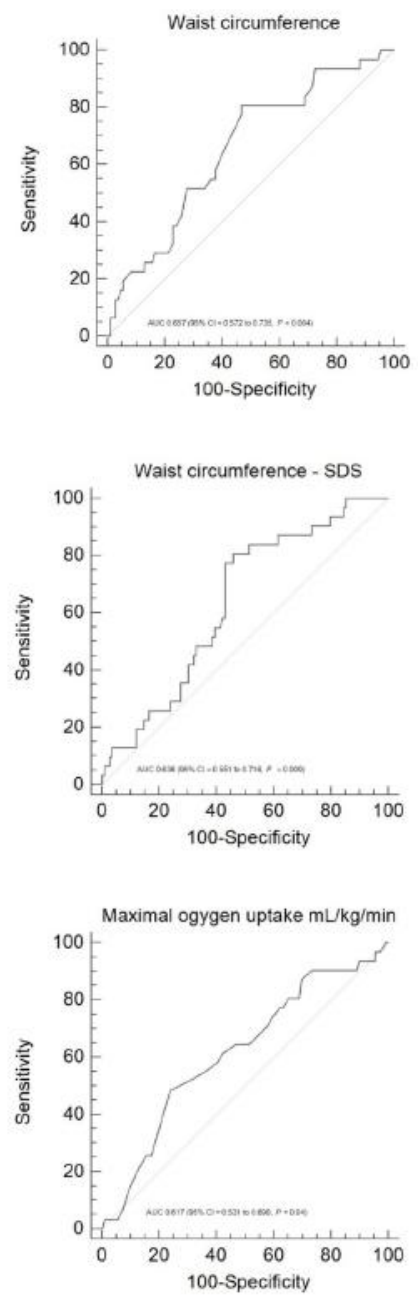

Figure 1: ROC curves of the efficacy of the measures of cardiorespiratory fitness and body adiposity to identify children and adolescents with chronic diseases or physical disabilities with increased aortic pulse wave velocity ( $\geq 1$ standard deviation from reference values ${ }^{28}$. AUC indicates the area under the curve (95\% confidence interval, $\mathrm{Cl}$ ). 


\section{Ability of cardiorespiratory fitness and body adiposity to identify children and adolescents with increased arterial stiffness}

The ROC curve analyses revealed that the optimal cutoff for waist circumference to identify children and adolescents $\geq 1$ SD of PWV-SDS was $>73 \mathrm{~cm}(95 \% \mathrm{Cl}=66$ to 78$)$ with a sensitivity of $81 \%$, a specificity of $53 \%$, and the Youden index of 0.3386 (Figure 1.). The corresponding cutoff for waist circumference-SDS was $>-0.05$ units $(95 \% \mathrm{Cl}=-0.09$ to -0.02 ) with a sensitivity of $81 \%$, a specificity $54 \%$, and the Youden index of 0.3477 . The optimal cutoff for $\mathrm{VO}_{2 \text { peak }}$ per body weight was $<35 \mathrm{ml} / \mathrm{kg} / \mathrm{min}(95 \% \mathrm{Cl} 27$ to 40 ) with a sensitivity of $48 \%$, a specificity of $76 \%$, and the Youden index of 0.2453 . These analyses indicated that children and adolescents with a higher waist circumference and a lower $\mathrm{VO}_{2 \text { peak }}$ per body weight were more likely to have increased arterial stiffness.

The optimal cutoff for $\mathrm{VO}_{2 \text { peak }}$ per FFM to identify children and adolescents $\geq 1 \mathrm{SD}$ of AIX\%-SDS was $<51 \mathrm{ml} / \mathrm{kg} \mathrm{FFM} / \mathrm{min}$ (95\% Cl 46 to 66 ) with a sensitivity of $64 \%$, a specificity of $66 \%$, and the Youden index of 0.3036 suggesting that children and adolescents with poorer cardiorespiratory fitness had increased AIX\% compared to those with better cardiorespiratory fitness (Figure 2.).

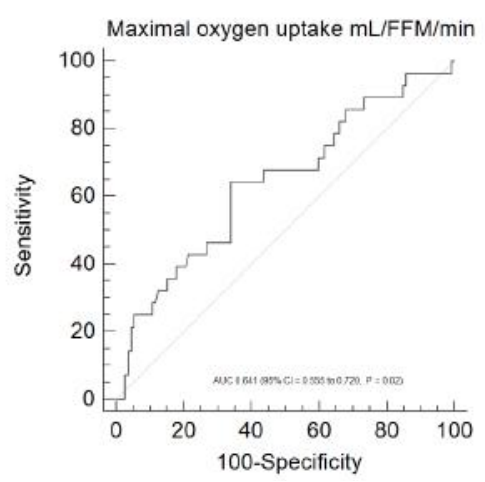

Figure 2: ROC curve of the efficacy of cardiorespiratory fitness to identify children and adolescents with chronic diseases or physical disabilities with increased peripheral arterial tone (augmentation index $(A I X \%) \geq 1$ standard deviation from reference values ${ }^{29}$. AUC indicates the area under the curve ( $95 \%$ confidence interval, Cl). FFM $=$ fat free mass. 


\section{DISCUSSION}

In the present study, we found inverse associations of the measures of cardiorespiratory fitness with aortic stiffness among children and adolescents with chronic disease or physical disabilities. However, the relationships between cardiorespiratory fitness and aortic stiffness were partly explained by waist circumference. We also found that a higher waist circumference had strong and consistent relationship to a higher aortic stiffness. Furthermore, higher waist circumference and BMI-SDS were associated with a lower peripheral arterial tone as indicated by a lower AIX\%. Finally, we observed no relationship between sports participation and arterial stiffness.

To the best of our knowledge, this is the first study on the associations of directly assessed $\mathrm{VO}_{\text {2peak }}$ with arterial stiffness among children and adolescents with chronic diseases or physical disabilities. In conjunction with some other studies, we found that better cardiorespiratory fitness was linked to lower aortic stiffness ${ }^{5,6}$. However, the associations of $\mathrm{VO}_{2 \text { peak }}$ per body weight and $\mathrm{VO}_{\text {2peak }}$ per FFM with arterial stiffness were partly explained by waist circumference. Similarly, one study found that an inverse association between cardiorespiratory fitness and arterial stiffness was explained by body adiposity among children aged 10 years ${ }^{32}$. These results are in line with the observations that the associations between $\mathrm{VO}_{2 \text { peak }}$ relative to body weight and cardiometabolic risk factors are confounded by body adiposity 33,34.

In our previous study, maximal work load by FFM as a measure of cardiorespiratory fitness, was inversely associated with arterial stiffness in children aged 6-8-years independent of body fat percentage ${ }^{34,35}$. We found that $\mathrm{VO}_{2 \text { peak }}$ relative to FFM was attenuated after further adjustment for waist circumference, but remained at borderline significance. Furthermore, controlling for BMI-SDS or body fat percentage had no effect on the relationship between $\mathrm{VO}_{\text {2peak }}$ relative to FFM and arterial stiffness. These results together indicate that better cardiorespiratory fitness is related to more compliant arteries and that this relationship is not completely due to lower levels of body adiposity in subjects with higher cardiorespiratory fitness. However, more research on the associations of cardiorespiratory fitness with arterial fitness with an appropriate scaling of $\mathrm{VO}_{2 \text { peak }}$ are warranted to further clarify the independent role of higher cardiorespiratory fitness of reduced arterial stiffness in children and adolescents. 
Nevertheless, our results suggest in addition to weight management, improvements in cardiorespiratory fitness may improve arterial stiffness in children and adolescents with chronic diseases or physical disabilities.

Previous studies have suggested a threshold of $35-46 \mathrm{~mL} / \mathrm{kg} / \mathrm{min}$ for $\mathrm{VO}_{2 \text { peak }}$ to identify apparently healthy children with increased cardiometabolic risk ${ }^{36}$. We found that a $\mathrm{VO}_{\text {2peak }}$ per body weight lower than $35 \mathrm{~mL} / \mathrm{kg} / \mathrm{min}$ was the optimal threshold for identifying those with increased PWVao and the threshold for identifying children and adolescents with increased AIX\% was $51 \mathrm{~mL} / F F M / m i n$. These slight differences in the cutoffs are probably due to the differences in the outcome measures, methods used to assess cardiorespiratory fitness and to measure or estimate $\mathrm{VO}_{2 \text { peak }}$ as well as the populations studied. We also analyzed boys and girls together to achieve a better statistical power whereas other studies have provided separate cutoffs for boys and girls. However, our results along with the results from previous studies suggest that $\mathrm{VO}_{\text {2peak }}$ below $35-40 \mathrm{~mL} /$ $\mathrm{kg} / \mathrm{min}$ is related to increased cardiometabolic risk in children and adolescents.

Obesity has been consistently linked to increased arterial stiffness in children and adolescents $^{8}$. Similarly, we found that particularly waist circumference was directly associated with arterial stiffness in children and adolescents with chronic diseases and physical disabilities independent of cardiorespiratory fitness. However, we found relatively weak associations of BMI-SDS and body fat percentage with arterial stiffness. An explanation for these inconsistent findings may be that abdominal adiposity has a pronounced negative impact on arterial health in children and adolescents ${ }^{37}$. Furthermore, we found that higher levels of body adiposity were related to lower arterial tone at rest. $\mathrm{We}^{35}$ and others ${ }^{38}$ have previously observed inverse associations between body adiposity and peripheral arterial tone in children and adolescents. One reason for these observations may be that overweight may increase arterial diameter and thereby compensate the negative effects of body adiposity on arterial stiffness ${ }^{38}$.

We observed that waist circumference exceeding $73 \mathrm{~cm}$ and waist circumference-SDS above -0.05 units were the optimal cut-offs for identifying children and adolescents with increased arterial stiffness. These cut-offs corresponding to an average waist circumference in the Dutch population, suggest that waist circumference already at normal range at the population level is associated with increased arterial stiffness in children and adolescents with chronic diseases or physical disabilities. These findings are supported by the study showing an increased cardiovascular mortality over a 40 
year follow-up already among those who had a BMI at the mid-normal range during adolescence ${ }^{39}$.

Previous studies have found either inverse or no association between habitual physical activity and the measures of arterial stiffness in children and adolescents 13,40,41. We observed no differences in arterial stiffness between sports participants and non-sports participants. One reason for our observations may be that sports participation among children and adolescents with chronic diseases or physical disabilities is insufficient in frequency, duration, or intensity to elicit favorable effects on arterial stiffness. Accordingly, there is some evidence that despite the high prevalence of sports participation, the majority of children and adolescents with chronic diseases and physical disabilities fail to meet the physical activity recommendations ${ }^{42}$. Another explanation may be that there may not be a large difference in total habitual physical activity among sports participants and non-participants ${ }^{23}$.

The strengths of the present study include valid and reproducible methods used to assess cardiorespiratory fitness, body composition, and arterial stiffness in a relatively large sample of children and adolescents with chronic diseases or physical disabilities. This study had few limitations. We were not able to assess pubertal status of the participants, nor were dietary factors recorded. We also used sports participation as a proxy for physical activity instead of objectively measured physical activity. We defined chronic disease using a non-categorical approach that considers chronically-ill young people as one population rather than specific disease classes ${ }^{43}$. The current sample size prohibited a sub-group analysis in specifying the disease classes. Furthermore, we analyzed boys and girls combined because of the limited statistical power to analyze boys and girls separately. We found no evidence on the effect modification of sex, but the results of some previous studies suggest that the association between cardiorespiratory fitness and arterial health is stronger in boys than in girls ${ }^{7}$. Furthermore, longitudinal studies are needed to study whether the effects of arterial stiffness during childhood and adolescence on cardiovascular diseases in adulthood are different in boys and girls. In conclusion, lower cardiorespiratory fitness and a higher waist circumference were associated with a higher arterial stiffness in children and adolescents with chronic diseases or physical disabilities in the present study. However, the associations of cardiorespiratory fitness were partly explained by waist circumference. Furthermore, we found no association between sports participation and arterial stiffness. We also found that thresholds of $<35 \mathrm{~mL} / \mathrm{kg} / \mathrm{min}$ for $\mathrm{VO}_{2 \text { peak' }}>73 \mathrm{~cm}$ for waist circumference, and $>-0.05$ 
units for waist circumference-SDS were associated with increased arterial stiffness. Taken together, these results suggest that interventions aiming to decrease body adiposity and to improve cardiorespiratory fitness may improve arterial stiffness children and adolescents with chronic diseases or physical disabilities. However, intervention studies are warranted to confirm the findings of the present study.

\section{Acknowledgement}

The authors would like to thank the Dutch Organization of Health Research (ZONMW) for their unconditional grant. Grant number: 525001005.

\section{REFERENCES}

1. Piepoli MF, Hoes AW, Agewall S, Albus C, Brotons C, Catapano AL, Cooney MT, Corra U, Cosysns B, Deaton C, Graham I, Hall MS, Hobbs FDR, Lochen ML, Lollgen H, MarquesVidal P, Perk J, Prescott E, Redon J, Richter DJ, Sattar N, Smulders Y, Tiberi M, van der Worp HB, van Dis I, Verschuren WMM, Binno S. 2016 european guidelines on cardiovascular disease prevention in clinical practice: The sixth joint task force of the european society of cardiology and other societies on cardiovascular disease prevention in clinical practice (constituted by representatives of 10 societies and by invited experts)developed with the special contribution of the european association for cardiovascular prevention \& rehabilitation (EACPR). Eur Heart J 2016;37(29):2315-2381. doi: 10.1093/eurheartj/ehw106.

2. McGill HC,Jr, McMahan CA, Herderick EE, Malcom GT, Tracy RE, Strong JP. Origin of atherosclerosis in childhood and adolescence. Am J Clin Nutr 2000;72(5 Suppl):1307S-1315S. doi: 10.1093/ajcn/72.5.1307s.

3. Fernhall B, Agiovlasitis S. Arterial function in youth: Window into cardiovascular risk. J Appl Physiol (1985). 2008;105(1):325-333. doi: 10.1152/japplphysiol.00001.2008.

4. Vlachopoulos C, Aznaouridis K, Stefanadis C. Prediction of cardiovascular events and allcause mortality with arterial stiffness: A systematic review and meta-analysis. J Am Coll Cardiol 2010;55(13):1318-1327. doi: 10.1016/j.jacc.2009.10.061.

5. Pahkala K, Laitinen TT, Heinonen OJ, et al. Association of fitness with vascular intimamedia thickness and elasticity in adolescence. Pediatrics 2013;132(1):e77-84. doi: 10.1542/ peds.2013-0041.

6. Ferreira I, Twisk JW, Stehouwer CD, van Mechelen W, Kemper HC. Longitudinal changes 
in .VO2max: Associations with carotid IMT and arterial stiffness. Med Sci Sports Exerc 2003;35(10):1670-1678. doi: 10.1249/01.MSS.0000089247.37563.4B.

7. Ferreira I, Twisk JW, Van Mechelen W, Kemper HC, Stehouwer CD, Amsterdam Growth and Health Longitudinal Study. Current and adolescent levels of cardiopulmonary fitness are related to large artery properties at age 36: The amsterdam growth and health longitudinal study. Eur J Clin Invest 2002;32(10):723-731. doi: 1066.

8. Cote AT, Phillips AA, Harris KC, Sandor GG, Panagiotopoulos C, Devlin AM. Obesity and arterial stiffness in children: Systematic review and meta-analysis. Arterioscler Thromb Vasc Biol 2015;35(4):1038-1044. doi: 10.1161/atvhaba.114.305062.

9. Pahkala K, Heinonen OJ, Lagstrom $\mathrm{H}$, et al. Vascular endothelial function and leisure-time physical activity in adolescents. Circulation 2008;118(23):2353-2359. doi: 10.1161/ circulationaha.108.791988.

10. Pahkala K, Heinonen OJ, Simell O, et al. Association of physical activity with vascular endothelial function and intima-media thickness. Circulation 2011;124(18):1956-1963. doi: 10.1161/circulationaha.111.043851.

11. Ried-Larsen M, Grontved A, Kristensen PL, Froberg K, Andersen LB. Moderate-andvigorous physical activity from adolescence to adulthood and subclinical atherosclerosis in adulthood: Prospective observations from the european youth heart study. Br J Sports Med 2015;49(2):107-112. doi: 10.1136/bjsports-2013-092409.

12. Walker DJ, Maclntosh A, Kozyrskyj A, Becker A, McGavock J. The associations between cardiovascular risk factors, physical activity, and arterial stiffness in youth. J Phys Act Health 2013;10(2):198-204. doi: 2011-0121.

13. Melo X, Santa-Clara H, Pimenta NM, et al. Intima-media thickness in 11- to 13-year-old children: Variation attributed to sedentary behavior, physical activity, cardiorespiratory fitness, and waist circumference. J Phys Act Health. 2015;12(5):610-617. doi: 10.1123/jpah.2013-0501.

14. Reed KE, Warburton DE, Lewanczuk RZ, et al. Arterial compliance in young children: The role of aerobic fitness. Eur J Cardiovasc Prev Rehabil 2005;12(5):492-497. doi: 00149831200510000-00012.

15. Idris NS, Evelein AM, Geerts CC, Sastroasmoro S, Grobbee DE, Uiterwaal CS. Effect of physical activity on vascular characteristics in young children. Eur J Prev Cardiol 2015;22(5):656-664. doi: 10.1177/2047487314524869.

16. van de Laar RJ, Ferreira I, van Mechelen W, Prins MH, Twisk JW, Stehouwer CD. Lifetime vigorous but not light-to-moderate habitual physical activity impacts favorably on carotid 
stiffness in young adults: The amsterdam growth and health longitudinal study. Hypertension 2010;55(1):33-39. doi: 10.1161/HYPERTENSIONAHA.109.138289.

17. Dias KA, Green DJ, Ingul CB, Pavey TG, Coombes JS. Exercise and vascular function in child obesity: A meta-analysis. Pediatrics 2015;136(3):e648-59. doi: 10.1542/peds.20150616.

18. Rimmer JA, Rowland JL. Physical activity for youth with disabilities: A critical need in an underserved population. Dev Neurorehabil 2008;11(2):141-148. doi: 10.1080/17518420701688649.

19. 19. Kotte EM, Winkler AM, Takken T. Fitkids exercise therapy program in the Netherlands. Pediatr Phys Ther 2013;25(1):7-13. Accessed 7/7/2017 9:21:13 AM. doi: 10.1097/PEP.0b013e318276c9bf.

20. Neter JE, Schokker DF, de Jong E, Renders CM, Seidell JC, Visscher TL. The prevalence of overweight and obesity and its determinants in children with and without disabilities. J Pediatr 2011;158(5):735-739. doi: 10.1016/j.jpeds.2010.10.039.

21. Carlon SL, Taylor NF, Dodd KJ, Shields N. Differences in habitual physical activity levels of young people with cerebral palsy and their typically developing peers: A systematic review. Disabil Rehabil. 2013;35(8):647-655. doi: 10.3109/09638288.2012.715721.

22. Cheung YF. Arterial stiffness in the young: Assessment, determinants, and implications. Korean Circ J 2010;40(4):153-162. doi: 10.4070/kcj.2010.40.4.153.

23. Martin AA, Cotie LM, Timmons BW, Gorter JW, Macdonald MJ. Arterial structure and function in ambulatory adolescents with cerebral palsy are not different from healthy controls. Int J Pediatr 2012;2012:168209. doi: 10.1155/2012/168209.

24. Lankhorst K, van der Ende-Kastelijn K, de Groot J, et al. Health in adapted youth sports study (HAYS): Health effects of sports participation in children and adolescents with a chronic disease or physical disability. Springerplus 2015;4:796-015-1589-z. eCollection 2015. doi: 10.1186/s40064-015-1589-z.

25. Zwinkels M, Verschuren O, Lankhorst K, et al. Sport-2-stay-fit study: Health effects of after-school sport participation in children and adolescents with a chronic disease or physical disability. BMC Sports Sci Med Rehabil 2015;7:22-015-0016-7. eCollection 2015. doi: 10.1186/s13102-015-0016-7.

26. Dosa NP, Foley JT, Eckrich M, Woodall-Ruff D, Liptak GS. Obesity across the lifespan among persons with spina bifida. Disabil Rehabil 2009;31(11):914-920. doi: 10.1080/09638280802356476.

27. Schonbeck Y, Talma H, van Dommelen P, et al. Increase in prevalence of overweight in 
dutch children and adolescents: A comparison of nationwide growth studies in 1980, 1997 and 2009. PLoS One 2011;6(11):e27608. doi: 10.1371/journal.pone.0027608.

28. Horvath IG, Nemeth A, Lenkey Z, et al. Invasive validation of a new oscillometric device (arteriograph) for measuring augmentation index, central blood pressure and aortic pulse wave velocity. J Hypertens 2010;28(10):2068-2075. doi: 10.1097/HJH.0b013e32833c8a1a.

29. Hidvegi EV, Illyes M, Benczur B, et al. Reference values of aortic pulse wave velocity in a large healthy population aged between 3 and 18 years. J Hypertens 2012;30(12):23142321. doi: 10.1097/HJH.0b013e328359562c.

30. Hidvegi EV, Illyes M, Molnar FT, Cziraki A. Influence of body height on aortic systolic pressure augmentation and wave reflection in childhood. J Hum Hypertens 2015;29(8):495501. doi: 10.1038/jhh.2014.118.

31. Perkins NJ, Schisterman EF. The inconsistency of "optimal" cutpoints obtained using two criteria based on the receiver operating characteristic curve. Am J Epidemiol 2006;163(7):670-675. doi: kwj063.

32. Sakuragi S, Abhayaratna K, Gravenmaker KJ, et al. Influence of adiposity and physical activity on arterial stiffness in healthy children: The lifestyle of our kids study. Hypertension 2009;53(4):611-616. doi: 10.1161/HYPERTENSIONAHA.108.123364.

33. Shaibi GQ, Cruz ML, Ball GD, et al. Cardiovascular fitness and the metabolic syndrome in overweight latino youths. Med Sci Sports Exerc 2005;37(6):922-928. doi: 00005768200506000-00004.

34. Tompuri T, Lintu N, Savonen K, et al. Measures of cardiorespiratory fitness in relation to measures of body size and composition among children. Clin Physiol Funct Imaging 2015;35(6):469-477. doi: 10.1111/cpf.12185.

35. Veijalainen A, Tompuri T, Haapala EA, et al. Associations of cardiorespiratory fitness, physical activity, and adiposity with arterial stiffness in children. Scand J Med Sci Sports 2016;26(8):943-950. doi: 10.1111/sms.12523.

36. Adegboye AR, Anderssen SA, Froberg K, et al. Recommended aerobic fitness level for metabolic health in children and adolescents: A study of diagnostic accuracy. Br J Sports Med 2011;45(9):722-728. doi: 10.1136/bjsm.2009.068346.

37. Arnberg K, Larnkjaer A, Michaelsen KF, Molgaard C. Central adiposity and protein intake are associated with arterial stiffness in overweight children. J Nutr 2012;142(5):878-885. doi: 10.3945/jn.111.150672.

38. Cote AT, Harris KC, Panagiotopoulos C, Sandor GG, Devlin AM. Childhood obesity and cardiovascular dysfunction. J Am Coll Cardiol 2013;62(15):1309-1319. doi: 10.1016/j. 
jacc.2013.07.042.

39. Twig G, Yaniv G, Levine $H$, et al. Body-mass index in 2.3 million adolescents and cardiovascular death in adulthood. N Engl J Med 2016;374(25):2430-2440. doi: 10.1056/NEJMoa1503840.

40. Palve KS, Pahkala K, Magnussen CG, et al. Association of physical activity in childhood and early adulthood with carotid artery elasticity 21 years later: The cardiovascular risk in young finns study. J Am Heart Assoc 2014;3(2):e000594. doi: 10.1161/JAHA.113.000594.

41. Haapala EA, Vaisto J, Veijalainen A, et al. Associations of objectively measured physical activity and sedentary time with arterial stiffness in pre-pubertal children. Pediatr Exerc Sci 2017;29(3):326-335. doi: 10.1123/pes.2016-0168.

42. Ng K, Rintala P, Tynjala J, et al. Physical activity trends of finnish adolescents with longterm illnesses or disabilities from 2002-2014. J Phys Act Health 2016;13(8):816-821. doi: 10.1123/jpah.2015-0539.

43. Stein RE, Jessop DJ. A noncategorical approach to chronic childhood illness. Public Health Rep 1982;97(4):354-362. 




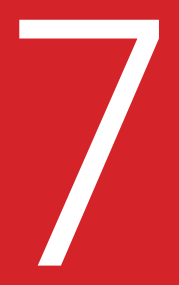

\section{Sports participation related to injuries and illnesses among youth with chronic diseases: results of the health in adapted youth sports study}

Kristel Lankhorst Janke de Groot Tim Takken Frank Backx 


\section{ABSTRACT}

Background. Although sports participation leads to important health enhancement for youth with chronic diseases or physical disabilities (CDPD), it may pose an increased risk for injury or illness. This study investigated the incidence, type, severity and risks to (sports-related) injuries and illnesses among youth with CDPD.

Methods. For one calendar year, every two weeks, the characteristics of injuries and illnesses were registered by an online questionnaire and phone-based interview. Physical activity level was measured with the Activ8 during one week. Complete data was available of 103 youngsters with CDPD (61 boys, 42 girls), with a mean age of 14.4 $(S D=2.7)$ years. The personal characteristics, the injury and illness rates per 1000 hours of PA were investigated per group of organized sports participation per week $(0,1$ or $\geq 2$ times $\mathrm{p} / \mathrm{wk}$ ).

Results. Almost half of the youngsters sustains one or more injuries or illnesses during one year, $46 \%$ and $42 \%$ resp. The injury rate per 1000 hours of PA between 0,1 and $\geq 2$ times per week of sports participation was $0.84,1.88,133$ resp. and the illness rate was $1.87,1.88$ and 1.18 resp. The rates were not statistically different. Most reported health problems had no subsequent restriction (49\%) or other minor consequences $(21 \%)$ in school, physical education or sports participation. Most reported health problems were contusions (41\%) at the lower extremity (74\%) and flue plus fever (58\%).

Conclusions. Participation in sports $\geq 2$ times per week does not pose a significant increased risk in the incidence of injury or illness per 1000 hours of PA in youth with CDPD compared to once weekly or no sports participation. Athletes who participate in sports at least twice weekly get injured mostly during their sporting activities, while peers who do participate in sports once a week or not at all, get injured during less intense physical activities during physical education lessons, ADL or non-organized sports and play in leisure time. The social impact of injuries or illnesses was limited. 


\section{Single statement summarizing the clinical relevance:}

Participation in sports at least twice weekly gives no higher risk in the incidence of injury per 1000 hours of physical activity in youth with CDPD compared with once or no participation in sports per week. Parents should encourage and support their children with CDPD to participate in sports, especially from a physical and psychosocial health perspective. Personalized strategies are needed and should be implemented into pediatric health care, PE and into the sports context to minimize the risk of injury during leisure time physical activities including organized sports participation in youth with CDPD. 


\section{INTRODUCTION}

Sports participation has important health benefits in both healthy youth and peers with chronic diseases or physical disabilities (CDPD) ${ }^{1-5}$. Studies has shown strong associations between being member of a sports club and the amount of moderatevigorous physical activity (MVPA) and vigorous activity levels (VPA) in youth with CDPD; those youngsters with CDPD are twice likely to meet international physical activity (PA) recommendations ${ }^{5-7}$. Meeting adequate PA levels supports a healthier lifestyle. In addition, sports participation also has major positive health effects. It contributes to a better fitness, a higher degree of PA, a higher quality of life, a better self-image and children find themselves more athletic skilled ${ }^{4,5}$. At the same time, sports participation is also known to lead to sports-related injuries and illnesses, as shown in adults, healthy youth and among youth with CDPD $^{7-9}$.

Sports injuries among healthy youth have a considerable impact on their participation and performance in subsequent activities ${ }^{8,10}$. A longer existing injury or illness can limit participation in sports or lead to dropping out of sports or fear to return to sports among healthy youth ${ }^{11}$. Moreover, research among healthy youth shows that a low level of PA entails a higher risk of being injured when they become more active, while there is only limited evidence regarding sports participation and injuries in youth with CDPD ${ }^{12,13}$. For youngsters with CDPD it is already a challenge to reach adequate levels of PA due to the existing social and environmental barriers for sports and exercise participation ${ }^{14,15}$. It is even harder to pursue an active and healthy lifestyle through participation in sports, when sports participation is associated with (fear of) injuries and / or illnesses. In addition, there is a reasonable fear among parents of children with CDPD that sports participation undoubtedly leads to sport-related injuries. As a consequence of that injury, their child could experience additional limitations in their daily lives, i.e. being unable to perform their daily activities independently anymore or need more help with it from their parents or caregivers ${ }^{16}$. These negative experiences and believes with regard to sports participation can further limit the support to allow their child to be active in sports. In addition, a previous systematic review among adult athletes with disabilities recommends longitudinal studies to gain more understanding and insight in factors influencing injuries and illnesses ${ }^{17-20}$.

Therefore the aim of this study is to investigate the incidence, type, severity and risks of (sports-related) injuries and illnesses among youth with CDPD using a longitudinal approach. 


\section{METHODS}

\section{Study design}

The present study is part of the Health in Adapted Youth Sports (HAYS) Study, which involved an analysis of data about health-related fitness, PA and psychosocial health in youth with CDPD ${ }^{3-5,21}$. This study was approved by the Medical Ethics Committee of the University Medical Center Utrecht, Utrecht, the Netherlands (METC number: 14-332/ c). The present sub study is a longitudinal cohort study specifically evaluating injuries and illnesses related to sports participation. The procedures and protocols of the HAYS Study have been published previously in more detail ${ }^{21}$.

This study has two objectives; 1) to determine the incidence, type and severity of injuries or illnesses, 2) to calculate the injury and illness rates per 1000 hours of PA per group among youth with CDPD participating in organized sports once or twice a week and peers who do not participate in sports at all. These objectives are researched by means of an injury and illness registration system for one calendar year among youth with CDPD. This longitudinal cohort study followed Strengthening the Reporting of Observational studies in Epidemiology (STROBE) guidelines ${ }^{22}$.

\section{Participants}

Youngsters with CDPD were recruited for participation in the HAYS study between October 2014 and October 2016. The follow-up period and data collection of injuries and illnesses lasted till October 2017. The children and adolescents were recruited in the Netherlands among different patients associations, pediatric therapy practices, Wilhelmina Children's Hospital in Utrecht, De Hoogstraat Rehabilitation Center in Utrecht, Fitkids network, schools for special education for children with a disability, and sports clubs. Young athletes were recruited form a broad range of participation in sports: from recreational level to high level competitive sports.

Participants were eligible for this study when they were ambulatory, aged from 8 to 19 years with CDPD, and diagnosed with one or more cardiovascular, pulmonary, musculoskeletal, metabolic or neuromuscular disorders according to the classification of the American College of Sports Medicine ${ }^{23}$.

Informed consent was provided by all participants and by the parents of participants under 18 years of age. In line with Dutch law, no parental informed consent was required for participants aged 18 years and above. 
The HAYS cross-sectional sample involved 140 participants with CDPD, with a mean age (SD) of 14.4 (2.7) years (Table 1 and flowchart 1).

\section{Procedure and data collection}

An overview of the followed procedures and data collection of the study are summarized in flowchart 2. Data collection consisted of; 1) a baseline assessment with the child or young adult and parent(s), 2) objectively measured PA level of the participants during one school week and, 3) a two weekly registration of each injury or illness for one calendar year that followed after the baseline assessment. 
Flowchart 1: Number of participants included and dropped-out in the longitudinal study.

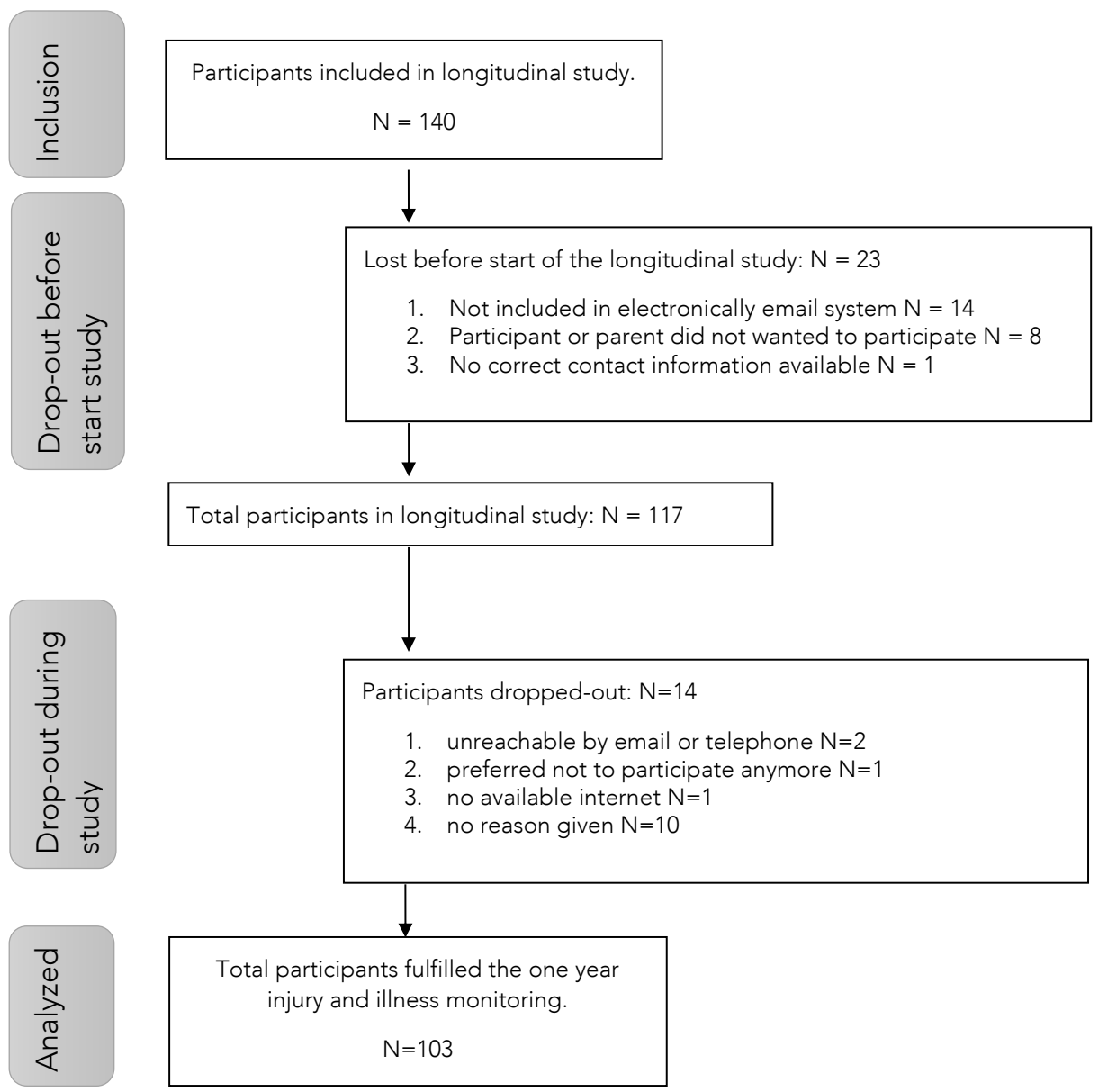


Flowchart 2: Online questionnaire and phone based assessment of injury or illness.

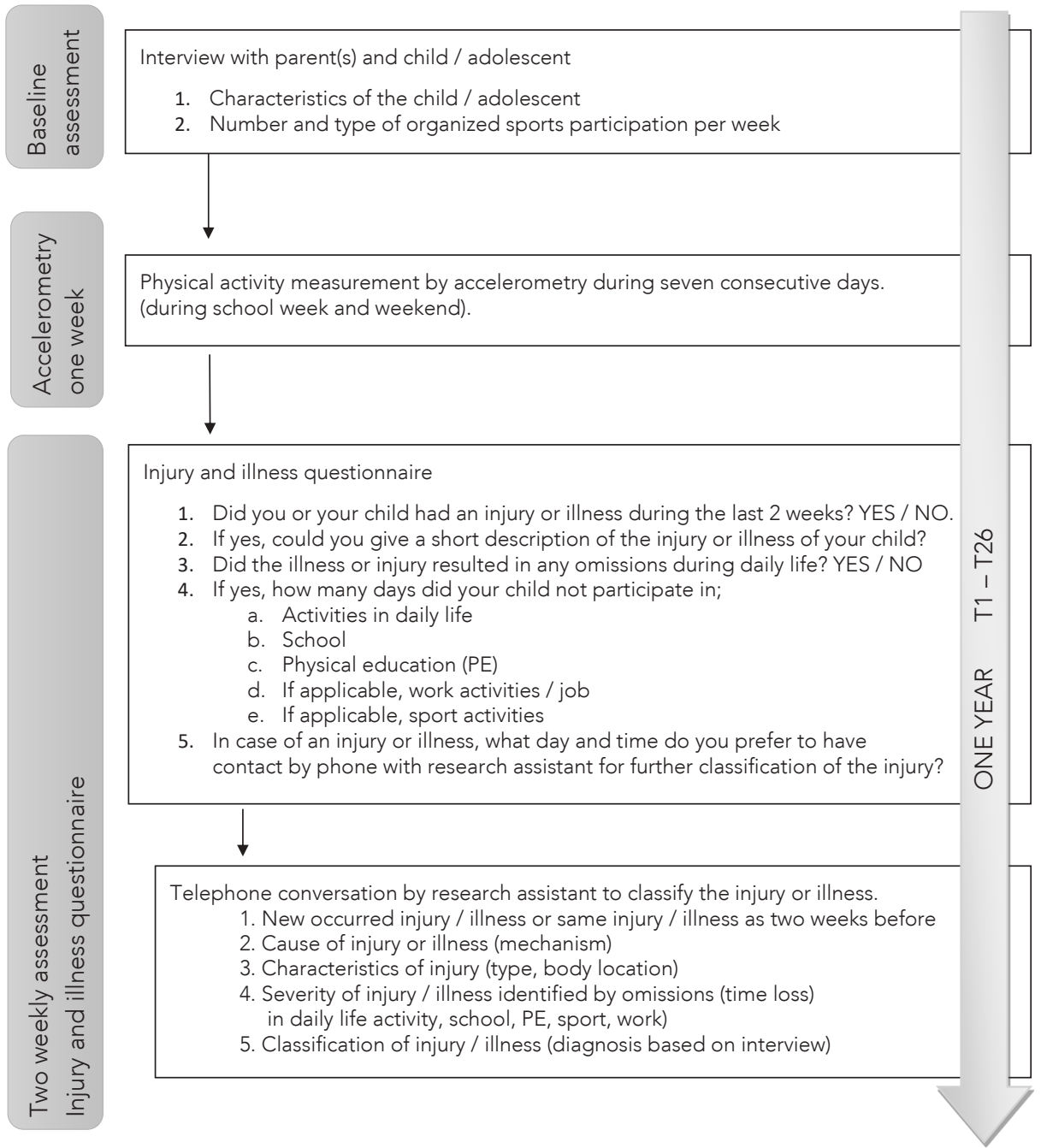


The characteristics of the child or young adult were collected by the baseline assessment, including age, sex, medical diagnosis, participation in physical education (PE) and the number and type of sports participation in organized sports per week. The medical diagnoses were further classified into categories according to the American College of Sports Medicine (23). Sports participation was identified using the following three standardized questions used by the Dutch Institute of Health and Environment ${ }^{24}$ :
1) do you participate in sports?
2) what is / are the type of organized sport(s)?
3) what is the frequency of participation in organized sports per week?

In this study, participants were classified by the frequency of participation in organized sports per week to gain insight into sports-related injuries, non-sports-related injuries i.e. injuries related to PA during leisure time. This resulted in the following three groups: group $0=$ no participation in organized sport at all; group $1=$ sports participation at sport club one time per week, group 2 = sports participation at sport club two or more times per week.

We also investigated whether the more serious sports participants (two or more times of sports participation $\mathrm{p} / \mathrm{wk}$.) run a higher risk of being injured or ill compared to the less serious peers who participate in sports once per week (group 1) and not at all (group 0 ). Group 1 and 0 were taken together as one group for this additional analysis. PA was measured using an activity monitor, the Activ8 (2M Engineering Ltd. Valkenswaard, The Netherlands). The Activ8 is a valid one-sensor ambulatory monitoring system and has been validated for use in youth with and without motor impairments ${ }^{25}$. Each subject wore the sensor on the dominant leg, fixed with Tegaderm ${ }^{\mathrm{TM}}$ (3M, Delft, the Netherlands) waterproof skin tape during seven consecutive days for 24 hours each day. The type, duration and frequency of PA in daily life (active vs inactive) were measured during a school week and one weekend. In order to calculate and interpret the data of waking hours gathered with the Activ8, also sleeping time was recorded in a diary. The total active time in minutes per day during leisure time, PE and organized sports per week was used for calculations. The analysis and results of the PA data of the studied children and adolescents of the HAYS study are described elsewhere in more detail 5 .

The monitoring of injuries and / or illnesses during the one calendar year follow-up period was measured by use of an online questionnaire. This questionnaire was developed 
based on recommendations of the Dutch Ministry of Health, Welfare and Sport (VWS) (26) and designed in Formdesk, an online web-based tool (Innovero Sofware Solutions B.V., Wassenaar, The Netherlands). Following the baseline assessment, the participants and / or their parents received an email with a hyperlink to the online questionnaire every two weeks during one calendar year (flowchart 2). The questionnaire included five simple questions concerning suffered injuries and / or illnesses during the past two weeks, resulting in 26 measurements per participant. The participants received a reminder by e-mail when the questionnaire was not completed within three days. After three more days, the research assistant contacted the participant by telephone when the questionnaire was not completed, preventing an incomplete dataset. We performed a structured interview by phone in case of an injury or illness reported in the online questionnaire. In a personal interview we registered the type and body location of the injury or type of illness and the severity of the injury or illness.

\section{Definitions of injury and illness}

The injury definition according to the National Athletic Injury Registration System $(\text { NAIRS })^{20}$ was adapted for use in this study and was defined as follows:

'Any new musculoskeletal pain, feeling or injury resulting from participation in recreational PA or sports and cause changes in physical activities including sports activities, regardless of whether or not time is lost from PA, sports training or competition.' An illness was defined and adapted for use in this study as:

'Any new illness that cause changes in physical activities including sports activities, regardless of whether or not time is lost from PA or sports training or competition. ${ }^{27}$

Injuries and illnesses were further classified by the number of days of participation restriction in school and $\mathrm{PE}$, in agreement with previous injury surveillance study ${ }^{28}$ and according to the NAIRS ${ }^{20}$. Reported injuries or illnesses were classified as non-time loss (NTL) injuries or illnesses when the injury or illness complaint only had a participation limitation on the same day of the injury or illness complaint and not the day after ${ }^{28}$. Reported injuries or illnesses were classified as time-loss $(T L)$ injuries or illnesses when there was a participation restriction of at least one day after the day of onset of the injury or illness complaint. To indicate the severity of the TL injuries and illnesses, the TL injury or illness were further subcategorized as follows: minor (1 -7 days lost), moderate (8 - 21 days lost) or severe (> 21 days $)^{20,28}$. 


\section{Primary outcome - absolute incidence, characteristics and severity of injuries and illnesses}

The data regarding the occurrence of injuries (body location and type) and illnesses (type) and consequences (time-loss in days of return to school, PE and participation in sports) were collected for all three groups.

\section{Secondary outcome - injury and illness rates per 1000 hours PA}

The injury and illness rates per 1000 hours of PA was calculated for each group (group 0, 1 and 2). An injury or illness rate indicates how many injuries or illnesses occur per episodes of exposure to sport and / or PA.

The injury and illness rate is calculated by the following formula:

Injury or illness rate $=$

(the number of injuries or illnesses during one calendar year /

the total exposure to PA during one calendar year) $\times 1000$ hours.

\section{Statistical analysis}

Descriptive analyses were used to profile characteristics of the three groups. ANOVA and post-hoc tests were used determining the differences between the groups for age, length, weight, BMI and BMI-age standard deviation score (SDS). The Kruskall-Wallis test was used determining the differences between the three groups for sex and prevalence of diseases or disabilities. Determining the differences between the three groups for the incidence of injuries and illnesses (injury and illness rates) during one calendar year followup the chi-square test was used. The dependent variable is the occurrence of injuries and illnesses within one calendar year and the amount of organized sports participation per week as independent variables. Analyses were performed using the SPSS Statistics, Version 23.0 (IBM Corp., Armonk, NY, USA), calculation of the 95\% confidence intervals for injury and illness rates were performed using MedCalc for Windows, version 17.9 (MedCalc Software, Ostend, Belgium). A p value $<0.05$ was considered statistically significant. 


\section{RESULTS}

\section{Participants' characteristics}

Table 1: Characteristics of the participants per (sports)-group.

\begin{tabular}{|c|c|c|c|c|c|}
\hline Sports participation per week & $\begin{array}{l}\text { Group } 0 \\
\text { (non-sports) }\end{array}$ & $\begin{array}{l}\text { Group } 1 \\
\text { (sports } 1 x / w k \text { ) }\end{array}$ & $\begin{array}{l}\text { Group } 2 \\
\text { (sports } \geq 2 x / w k \text { ) }\end{array}$ & Total & $\begin{array}{l}p- \\
\text { value }\end{array}$ \\
\hline Number of participants & 18 & 21 & 64 & 103 & \\
\hline Number of boys (\%)† & $9(50)$ & $8(38)$ & $44(69)$ & $61(59)$ & $0.032^{\S}$ \\
\hline Age in years $(S D) \ddagger$ & $15.4(2.7)$ & $14.2(2.8)$ & $14.1(2.7)$ & $14.4(2.7)$ & 0.219 \\
\hline Height in $\mathrm{cm}(\mathrm{SD}) \neq$ & $165.3(9.5)$ & $159.2(13.2)$ & $161.2(14.7)$ & $161.9(12.5)$ & 0.361 \\
\hline Weight in $\mathrm{kg}(\mathrm{SD}) \ddagger$ & $58.2(13.5)$ & $50.7(16.4)$ & $53.7(17.6)$ & $54.2(15.8)$ & 0.385 \\
\hline $\mathrm{BMl}(\mathrm{SD}) \ddagger$ & $21.1(3.7)$ & $19.7(4.6)$ & $20.2(3.9)$ & $20.2(4.1)$ & 0.546 \\
\hline $\mathrm{BMI}-$ age SDS (SD) $\ddagger$ & $0.59(1.2)$ & $0.11(1.9)$ & $0.51(1.2)$ & $0.44(1.4)$ & 0.449 \\
\hline Medical diagnosis (\%)† & & & & & 0.411 \\
\hline - Cardiovascular disease & $3(17)$ & $4(19)$ & $4(6)$ & $11(11)$ & \\
\hline -Pulmonary disease & 0 & $2(9)$ & $5(8)$ & $7(7)$ & \\
\hline -Metabolic disease & $1(6)$ & $1(5)$ & $6(9)$ & $8(8)$ & \\
\hline -Musculoskeletal / orthopedic disability & $1(6)$ & $1(5)$ & $6(9)$ & $8(8)$ & \\
\hline - Neuromuscular disease / disability & $6(33)$ & $9(43)$ & $31(49)$ & $46(46)$ & \\
\hline -Immunological / hematological disease & $5(28)$ & $4(19)$ & $6(9)$ & $15(15)$ & \\
\hline -Cancer & 0 & 0 & $1(2)$ & $1(1)$ & \\
\hline -Epilepsy & $2(10)$ & 0 & $5(8)$ & $7(7)$ & \\
\hline
\end{tabular}

BMI; body mass index, SD; standard deviation, SDS; standard deviation score, + Kruskall-Wallis test for sex and prevalence of diseases or disabilities per group. $¥$ ANOVA for age, length, weight, BMI and $B M I$-age SDS. \& Significant difference.

Of 140 children and adolescents with CDPD who were invited to participate, 103 completed the prospective one calendar year injuries and illnesses monitoring and only their data were analyzed for the current study. Reasons for dropout during the one calendar year prospective monitoring are presented in flowchart 1. We lost 23 (16\%) participants before the start of the longitudinal study mainly caused by faults in our electronically email system or participants / parents did not wanted to participate. Further, fourteen participants (10\%) dropped-out during the follow-up period of the study. The drop-out of participants was not related to personal characteristics (i.e. diagnosis, age, sex) and was random divided between the three sub-groups.

The participants' characteristics (sex, age, medical diagnosis, height, weight, BMI and BMI SDS) and P-value per group are displayed in Table 1.

The vast majority of the group had a neuromuscular disease (46 out of 103), with Gross Motor Function Classification System (GMFCS) classification of 1 or 2 . There was a significant difference between the number of participants per group and for sex in group 2, 44 boys versus 20 girls ( $P$-value $=0.031)$. 


\section{Injury incidence, characteristics and severity}

In total, 46\% ( $\mathrm{N}=47)$ of the participants with CDPD reported 86 injuries during one calendar year follow-up. Most of the registered injuries (70\%) occurred in group 2 (exercising at least twice a week in sports). Almost half of the registered injuries in group 2 resulted in minor (1-7 days) and moderate (8-21 days) time loss in sports participation. While in group 0 and group 1 resp. $89 \%$ and 59\% of the reported injuries could be classified as NTL, this was different in group 2 with only $40 \%$ being classified as NTL. Most of the injuries were articular contusions or distortions (41\%), followed by muscles strains (24\%), no severe injuries like concussions were reported (Table 3). The majority of the reported injuries were located at the lower extremity (74\%). A third of the injuries occurred during organized sports (31\%) and only in group 2.

Table 2: Incidence and severity of injuries and illnesses categorized according return to play (PE or sports) per group over one calendar year.

\begin{tabular}{|c|c|c|c|c|}
\hline Sports participation per week & $\begin{array}{l}\text { Group } 0 \\
\text { (Non-sports) }\end{array}$ & $\begin{array}{l}\text { Group } 1 \\
\text { (Sports 1x/wk) }\end{array}$ & $\begin{array}{l}\text { Group } 2 \\
\text { (Sports } \geq 2 x / w k \text { ) }\end{array}$ & $\begin{array}{l}\text { Total } \\
\text { (\%) }\end{array}$ \\
\hline Number of participants & 18 & 21 & 64 & 103 \\
\hline \multicolumn{5}{|l|}{ INJURIES } \\
\hline Number of participants with an injury (\%) & $5(28)$ & $7(33)$ & $35(55)$ & $47(46)$ \\
\hline Total number of injuries registered (\%) & $9(10)$ & $17(20)$ & $60(70)$ & 86 \\
\hline \multicolumn{5}{|l|}{ Severity of injuries } \\
\hline No time loss (NTL) (\%) & $8(89)$ & $10(59)$ & $24(40)$ & $42(49)$ \\
\hline Minor (1-7 days) (\%) & 0 & $3(18)$ & $15(25)$ & $18(21)$ \\
\hline Moderate (8-21 days) (\%) & 0 & $1(6)$ & $13(22)$ & $14(16)$ \\
\hline Severe $(>21$ days) $(\%)$ & $1(11)^{*}$ & $3(17)$ & $8(13)$ & $12(14)$ \\
\hline \multicolumn{5}{|l|}{ ILLNESSES } \\
\hline Number of participants with illnesses (\%) & $9(50)$ & $9(43)$ & $25(39)$ & $43(42)$ \\
\hline Total number of illnesses registered (\%) & 20; range 1-7 (22) & 17; range $1-3(19)$ & 53 range; $1-6(59)$ & 90 \\
\hline \multicolumn{5}{|c|}{ Severity of illnesses with restriction for return to school $(N=90)$} \\
\hline No time loss (NTL) (\%) & $5(25)$ & $2(12)$ & $10(19)$ & $17(20)$ \\
\hline Minor (1-7 days) (\%) & $12(60)$ & $12(71)$ & $31(59)$ & $55(64)$ \\
\hline Moderate (8-21 days) (\%) & $1(5)$ & $3(18)$ & $6(11)$ & $10(12)$ \\
\hline Severe (>21 days) (\%) & $2(10)$ & 0 & $6(11)$ & $8(9)$ \\
\hline \multicolumn{5}{|c|}{ Severity of illnesses for return to $P E /$ Sports ${ }^{*}(N=90)$} \\
\hline No time loss (NTL) (\%) & $15(75)$ & $10(59)$ & $9(17)$ & $34(40)$ \\
\hline Minor (1-7 days) (\%) & $2(10)$ & $4(23)$ & $30(57)$ & $36(42)$ \\
\hline Moderate (8-21 days) (\%) & $2(10)$ & $3(18)$ & $7(13)$ & $12(14)$ \\
\hline Severe (>21 days) (\%) & $1(5)$ & 0 & $7(13)$ & $8(8)$ \\
\hline
\end{tabular}

Group $0=$ non-sports group, group $1=$ once a week of sports participation, group 2 = at least two times per week of sports participation. NTL; no time loss, i.c. injuries resulted in a participation restriction on the same day of injury complaint but no subsequent restriction, $T L$ (minor, moderate and severe); injuries or illness resulted in restriction of participation of at least one day subsequent of the date of injury or illness complaint. *Severity of injury or illness; for group 0 it is operationalized as return to physical education, for group 1 and group 2 return to sports. 
Table 3: Type, body location and context in which the injury occurred, categorized per group.

\begin{tabular}{|c|c|c|c|c|}
\hline Type of injury & $\begin{array}{l}\text { Group } 0 \\
\text { (Non-sports) }\end{array}$ & $\begin{array}{l}\text { Group } 1 \\
\text { (Sports } 1 x / w k)\end{array}$ & $\begin{array}{l}\text { Group } 2 \\
\text { (Sports } \geq 2 x / w k \text { ) }\end{array}$ & Total (\%) \\
\hline Total number of injuries registered & 9 & 17 & 60 & 86 \\
\hline Articular contusion / distortion (\%) & $3(33)$ & $4(24)$ & $28(47)$ & $35(41)$ \\
\hline Muscles strains (\%) & $2(22)$ & $7(41)$ & $12(20)$ & $21(24)$ \\
\hline Muscle, tendon (partial) rupture, hematoma / edema (\%) & - & $1(6)$ & $5(8)$ & $6(7)$ \\
\hline $\begin{array}{r}\text { Epicondylitis / tendinitis, } \\
\text { inflammation (\%) }\end{array}$ & - & $3(17)$ & $4(7)$ & 7 (9) \\
\hline Open wound / blister (\%) & $2(22)$ & $1(6)$ & $4(7)$ & $7(9)$ \\
\hline (sub)luxation (\%) & - & - & $3(5)$ & $3(3)$ \\
\hline Fracture (\%) & $1(11)$ & - & $2(3)$ & $3(3)$ \\
\hline \multicolumn{5}{|l|}{ (chondropathy, ossification) (\%) } \\
\hline Body location & $\begin{array}{l}\text { Group } 0 \\
\text { (Non-sports) }\end{array}$ & $\begin{array}{l}\text { Group } 1 \\
\text { (sports } 1 x / \text { wk) }\end{array}$ & $\begin{array}{l}\text { Group } 2 \\
\text { (sports } \geq 2 x / w k \text { ) }\end{array}$ & Total (\%) \\
\hline $\begin{array}{l}\text { Total number of injuries registered } \\
\text { Lower extremity }(n=64)\end{array}$ & 9 & 17 & 60 & 86 \\
\hline Hip - upper leg (\%) & - & - & $11(18)$ & $11(13)$ \\
\hline Knee - lower leg (\%) & $4(44)$ & $7(41)$ & $15(25)$ & $26(30)$ \\
\hline Ankle (\%) & - & $2(12)$ & $12(20)$ & $14(16)$ \\
\hline Foot (\%) & $4(44)$ & $2(12)$ & $7(12)$ & $13(15)$ \\
\hline \multicolumn{5}{|l|}{ Upper extremity $(\mathrm{N}=11)$} \\
\hline Shoulder (\%) & - & - & $1(2)$ & $1(1)$ \\
\hline Fingers (\%) & - & $4(23)$ & $6(10)$ & $10(12)$ \\
\hline \multicolumn{5}{|l|}{ Spine $(N=10)$} \\
\hline Upper (\%) & $1(12)$ & - & $5(8)$ & $6(7)$ \\
\hline Lower (\%) & - & $2(12)$ & $2(3)$ & $4(5)$ \\
\hline Other (face) $(\mathrm{N}=1)$ & - & - & $1(2)$ & $1(1)$ \\
\hline Context in which injury occurred & $\begin{array}{l}\text { Group } 0 \\
\text { (Non-sports) }\end{array}$ & $\begin{array}{l}\text { Group } 1 \\
\text { (sports } 1 x / \text { wk) }\end{array}$ & $\begin{array}{l}\text { Group } 2 \\
\text { (sports } \geq 2 x / w k \text { ) }\end{array}$ & Total (\%) \\
\hline Total number of injuries registered & 9 & 17 & 60 & 86 \\
\hline Organized sports (\%) & & & & $27(31)$ \\
\hline Team (contact) sports ${ }^{\mathrm{a}}(\%)$ & - & - & $19(32)$ & \\
\hline Individual sports ${ }^{\mathrm{b}}(\%)$ & - & - & $8(13)$ & \\
\hline Non-organized sports and play in leisure time ${ }^{c}(\%)$ & $6(67)$ & $3(18)$ & $14(23)$ & $23(27)$ \\
\hline Physical education (\%) & $1(11)$ & $6(35)$ & $5(9)$ & $12(14)$ \\
\hline Activities in daily living (walking, bicycling) (\%) & $2(22)$ & $8(47)$ & $14(23)$ & $24(28)$ \\
\hline
\end{tabular}

a Soccer, ice hockey, adapted volleyball, basketball, water polo, ${ }^{b}$ road cycling, swimming, athletics, fitness, " jumping the trampoline, rowing, sailing, skiing. 


\section{Illness incidence, characteristics and severity}

A total of 90 illnesses during one calendar year were reported by 43 participants (42\%) (Table 2). Most of the illnesses were reported in group 2 (59\%). Overall, the majority of the illnesses (64\%) resulted in a minor time loss (1-7 days) for participation in school, no differences were seen between the three groups. Only $9 \%$ of the illnesses were severe (>21 days). The severity of the illness for return to sports was the highest for group 2 (57\%; 1-7 days), compared to group 1 and group 0 for which most of the illnesses resulted in no time loss for return to PE or sports (75\% and 59\% resp). Flu and fever were the most commonly reported illnesses (58\%) followed by symptoms of fatigue (18\%). In addition, there were single cases of inflammation, asthma, migraine, epileptic attack, sleeping apnea, shingles and pertussis, which together accounted for $24 \%$ of the total reported illnesses.

\section{Injury and illness rate per 1000 hours of PA}

The calculated injury rate per 1000 hours of PA was for group 0,1 and 2; 0.84, 1.88 and 1.33 resp. The illness rates per 1000 hours of PA was 1.87, 1.88 and 1.18 resp. for participation restriction on the same day of injury or illness complaint but no subsequent restriction. The differences between the three groups were not statistical different (Table 4 and 5). The illness rate per 1000 hours of PA differed significant between group 2 $(\mathrm{N}=64)$ compared to group $0+$ group 1 taken together $(\mathrm{N}=39), \mathrm{P}=0.028$. 
Table 4: Injury rate per 1000 hours of physical activity and comparison of injury rates per group.

\begin{tabular}{|c|c|c|c|c|c|c|}
\hline $\begin{array}{l}\text { Group } \\
\text { comparisons }\end{array}$ & $\begin{array}{l}\text { Mean minutes } \\
\text { PA per day } \\
\text { (range min- } \\
\text { max) }\end{array}$ & $\begin{array}{l}\text { Cumulative } \\
\text { hours of PA } \\
\text { during one } \\
\text { year per } \\
\text { group }\end{array}$ & $\begin{array}{l}\text { Number of } \\
\text { injuries } \\
(95 \% \mathrm{Cl})\end{array}$ & $\begin{array}{l}\text { Injury rate } \\
(95 \% \mathrm{Cl})\end{array}$ & $\begin{array}{l}\operatorname{IRD}(95 \% \mathrm{Cl}) \\
\operatorname{IRR}(95 \% \mathrm{Cl})\end{array}$ & $\begin{array}{l}p- \\
\text { valuet }\end{array}$ \\
\hline $\begin{array}{r}\text { Group 0 } \\
\text { (non-sports) + } \\
\text { group } 1 \\
\text { (sports } 1 \times / w k \text { ) }\end{array}$ & $134.6(59-244)$ & 19693 & 26 & 1.32 (0.9 to 1.9$)$ & $\begin{array}{l}\text { IRD } \\
-0.015(-0.6 \text { to } 0.6) \\
\text { IRR } \\
0.99(0.6 \text { to } 1.6)\end{array}$ & 0.962 \\
\hline $\begin{array}{r}\text { Vs. } \\
\text { Group } 2 \\
\text { (sports } \geq 2 x / w k \text { ) }\end{array}$ & $171.8(73-292)$ & 44937 & 60 (45.8 to 77.2$)$ & 1.33 (1.0 to 1.7$)$ & & \\
\hline $\begin{array}{r}\text { Group } 0 \\
\text { (non-sports) } \\
\text { Vs. }\end{array}$ & $146.2(80-244)$ & 10674 & $9(4.1$ to 17.1$)$ & $0.84(0.38$ to 1.6$)$ & $\begin{array}{l}\text { IRD } \\
1.04(-17.1 \text { to } 17.7)\end{array}$ & 0.275 \\
\hline $\begin{array}{r}\text { Group } 1 \\
\text { (sports 1x/wk) }\end{array}$ & $123.6(59-182)$ & 9019 & 17 (9.9 to 27.2 ) & 1.88 (1.1 to 3.1$)$ & & \\
\hline $\begin{array}{r}\text { Group } 1 \\
\text { (sports } 1 \times / w k \text { ) } \\
\text { Vs. }\end{array}$ & $123.6(59-182)$ & 9019 & 17 (9.9 to 27.2 ) & 1.88 (1.1 to 3.1$)$ & $\begin{array}{l}\text { IRD } \\
0.55(-6.3 \text { to } 17.2)\end{array}$ & 0.387 \\
\hline $\begin{array}{r}\text { Group } 2 \\
\text { (sports } \geq 2 x / w k \text { ) }\end{array}$ & $171.8(73-292)$ & 44937 & 60 (45.8 to 77.2$)$ & 1.33 (1.0 to 1.7$)$ & & \\
\hline $\begin{array}{r}\text { Group } 2 \\
\text { (sports } \geq 2 x / w k \text { ) } \\
\text { Vs. }\end{array}$ & $171.8(73-292)$ & 44937 & 60 (45.8 to 77.2$)$ & 1.33 (1.0 to 1.7$)$ & $\begin{array}{l}\text { IRD } \\
0.49(-17.6 \text { to } 7.2)\end{array}$ & 0.295 \\
\hline $\begin{array}{r}\text { Group } 0 \\
\text { (non-sports) }\end{array}$ & $146.2(80-244)$ & 10674 & $9(4.1$ to 17.1$)$ & $0.84(0.38$ to 1.6$)$ & & \\
\hline
\end{tabular}

$P A$; physical activity, Cl; confidence interval, vs; versus, IRD; incidence rate difference, IRR; incidence rate ratio, †Determined with Chi-square test, * significant difference $P$-value $\leq 0.05$.

Table 5: Illness rate per 1000 hours of physical activity and comparison of illness rates per group.

\begin{tabular}{|c|c|c|c|c|c|c|}
\hline $\begin{array}{l}\text { Group } \\
\text { comparisons }\end{array}$ & $\begin{array}{l}\text { Mean minutes } \\
\text { PA per day } \\
\text { (range min- } \\
\text { max) }\end{array}$ & $\begin{array}{l}\text { Cumulative } \\
\text { hours of PA } \\
\text { during one } \\
\text { year per } \\
\text { group }\end{array}$ & $\begin{array}{l}\text { Number of } \\
\text { illnesses } \\
(95 \% \mathrm{Cl})\end{array}$ & $\begin{array}{l}\text { Illness rate } \\
(95 \% \mathrm{Cl})\end{array}$ & $\begin{array}{l}\text { IRD } \\
(95 \% \mathrm{Cl}) \\
\text { IRR } \\
(95 \% \mathrm{Cl})\end{array}$ & $p$-value \\
\hline $\begin{array}{r}\text { Group } 0 \\
\text { (non-sports) + } \\
\text { group } 1 \\
\text { (sports } 1 \times / w k \text { ) }\end{array}$ & $134.6(59-244)$ & 19693 & 37 (26.1 to 51 ) & $\begin{array}{l}1.88 \\
(1.4 \text { to } 1.2)\end{array}$ & $\begin{array}{l}\text { IRD }= \\
0.7(0.07 \text { to } 1.31) \\
I R R= \\
1.6(1.0 \text { to } 2.5)\end{array}$ & $0.028 *$ \\
\hline $\begin{array}{r}\text { Vs. } \\
\text { Group } 2 \\
\text { (sports } \geq 2 x / w k \text { ) }\end{array}$ & 171.8 (73-292) & 44937 & 53 (39.7 to 69.3) & 1.18 (1.1 to 1.6$)$ & & \\
\hline $\begin{array}{r}\text { Group 0 } \\
\text { (non-sports) } \\
\text { Vs. }\end{array}$ & $146.2(80-244)$ & 10674 & 20 (12.2 to 30.9$)$ & 1.87 (1.9 to 1.3 ) & $\begin{array}{l}\mathrm{IRD}= \\
-1.12(-1.23 \text { to } \\
1.20)\end{array}$ & 0.986 \\
\hline $\begin{array}{r}\text { Group } 1 \\
\text { (sports } 1 \times / w k \text { ) }\end{array}$ & $123.6(59-182)$ & 9019 & 17 (9.9 to 27.2$)$ & 1.88 (1.9 to 1.3$)$ & $\begin{array}{l}\text { IRR }= \\
0.99(0.5 \text { to } 2.0)\end{array}$ & \\
\hline $\begin{array}{r}\text { Group } 1 \\
\text { (sports } 1 \times / w k \text { ) }\end{array}$ & $123.6(59-182)$ & 9019 & 17 (9.9 to 27.2) & 1.88 (1.9 to 1.3$)$ & $\begin{array}{l}\text { IRD }= \\
0.7(-0.1 \text { to } 1.5)\end{array}$ & 0.090 \\
\hline $\begin{array}{r}\text { Vs. } \\
\text { Group } 2 \\
\text { (sports } \geq 2 x / w k \text { ) }\end{array}$ & $171.8(73-292)$ & 44937 & 53 (39.7 to 69.3) & 1.18 (1.1 to 1.6$)$ & $\begin{array}{l}\text { IRR }= \\
1.59 \text { (0.9 to } 2.8)\end{array}$ & \\
\hline $\begin{array}{r}\text { Group } 2 \\
\text { (sports } \geq 2 x / w k \text { ) } \\
\text { Vs. }\end{array}$ & 171.8 (73-292) & 44937 & 53 (39.7 to 69.3) & 1.18 (1.1 to 1.6$)$ & $\begin{array}{l}\mathrm{IRD}= \\
0.7(1.5 \text { to } 0.1) \\
\mathrm{IRR}=\end{array}$ & 0.075 \\
\hline $\begin{array}{r}\text { Group } 0 \\
\text { (non-sports) }\end{array}$ & $146.2(80-244)$ & 10674 & 20 (12.2 to 30.9$)$ & 1.87 (1.9 to 1.3 ) & $0.63(0.4$ to 1.1$)$ & \\
\hline
\end{tabular}

PA; physical activity, $\mathrm{Cl}$; confidence interval, vs; versus, IRD; incidence rate difference, IRR; incidence rate ratio, † Determined with Chi-square test, * significant difference $P$-value $\leq 0.05$. 


\section{DISCUSSION}

The aim of this study was to investigate the incidence, type, severity and risks of (sportsrelated) injuries and illnesses among youth with CDPD using a longitudinal approach. We found that participation in sports $\geq 2$ times per week does not pose an increased risk in the incidence of injury or illness per 1000 hours of PA in youth with CDPD compared to once weekly or no sports participation.

Children and adolescents with CDPD are increasingly stimulated to participate in sports and exercise ${ }^{29}$. Actual participation minimizes physical inactivity, optimizes physical functioning, promotes inclusion in society and enhances overall well-being in youth with CDPD ${ }^{4,5}$. Given all these benefits, fear of injury frequently remains a barrier to participate in sports ${ }^{11}$. The question rises whether all the major physical and psychosocial health benefits outweigh the risk of getting injured or ill through sports participation.

To the best of our knowledge this is the first longitudinal study on identifying and comparing injuries and illnesses among sporting and non-sporting youth with CDPD. We found no presumptive evidence that sports participation results in significant higher injury and illness rates among youth with CDPD. A current systematic review reported inconsistent research outcomes about the impact of sports participation on injury rates among healthy youth (age 6 to 15 years) ${ }^{30}$. Some studies concluded that sports participation is the most risky to get or sustain an injury, while current literature in healthy youth without CDPD show that the absolute number of injuries occurring during leisure time and PE are consequently as high as during sports ${ }^{30}$.

Our study showed comparable results according to absolute numbers of injuries and context where injuries occurred. Logically, when you do not participate in sports, you are not exposed to a higher risk that sports entails, only to risks related to daily life situations which is in line with our study. Non-sporting participants also get injured, not from sports participation but they get injured by less intense physical activities; PE lessons, ADL or non-organized sports and play in leisure time. Interestingly, youth participating in sport $\geq 2$ times per week were less likely to get injured in daily life situations. We can suggest, they have better motor skills or participate in low-risk sports, which makes them less vulnerable to an injury.

\section{Injury and illness type and severity}

Although the absolute number of injuries and illnesses are high in sports participants, the types of injuries and illnesses reported in the current study have no or minimal 
impact on being able to participate in school, PE or sports. The most reported injuries in our study were contusions / distortions or muscles strains, and located at the lower extremities. Our findings are in line with results of previous studies in both healthy youth and high school athletes with disabilities ${ }^{17,31}$, while in Paralympic athletes most of the injuries were related to overuse (tissue inflammation and pain) ${ }^{32}$. According to time loss by sustaining an injury, our findings are similar with several studies, in which sports injuries suffered by high school athletes with disabilities and Paralympic adult athletes resulted in no or minor loss of training time ${ }^{18,31-33}$. According to the severity of illnesses, preliminary results in Paralympic adult athletes shows that a higher training load results in a higher number of illnesses (infections) and the type of locomotion seems related to the incidence of illness, i.e. wheelchair athletes reported a high number of upper respiratory tract infections compared to able-bodied athletes ${ }^{32}$. The illness severity in the study of Fahger et al. (2017) was minor, 1-3 days of time loss of training, which is comparable with our study findings, although these studies are not comparative on study design, participants' age, medical diagnose and sports level with our research. For instance, the majority of the study population of Ramirez et al. (2008) had a mental disorder like autism and were on average older (18 years), whereas the study population of Fagher et al. (2017) were adult athletes with visual impairments, or were wheelchair dependent. The studies of Blauwet et al. (2016) and Derman et al. (2013) followed the athletes of the London 2012 Paralympic games during 14 days. All these studies, however, show similar results, that the severity of injuries and illnesses are low for peoples' ADL and / or sports participation. Remarkably, in our study, the incidence illness rate is the lowest in youngsters who participates in sports at least two times per week compared to their peers without any sports participation or only once. This result might suggests that regular participation in sports of at least two times a week could have a protective effect evolving illnesses.

\section{Strengths and limitations}

This study was the first large study to evaluate injuries and illnesses among sporting and non-sporting youth with CDPD during one calendar year. Strong points are the prospective longitudinal data monitoring to obtain all necessary data and the objective direct measurement of PA by using accelerometry. In addition, the incidence of injuries and illnesses are based on exposure of PA, which is a key factor ${ }^{34,35}$.

Obviously, this study also has some limitations. We measured PA during one school 
week and weekend, assuming that this measurement is a representative week. The injury and illness rate formula assumes that the random sample of seven days (school week) objectively measured PA distributed over the full study period represents the PA experience of the whole sample and can be used to derive estimates of the population experience over that period. Use of the PA measurements during one school week and extrapolated for one calendar year is a limitation of the study. Future research should measure PA during a longer period of time and during holidays, were PA levels are probably different from PA during school weeks. Further, the injuries and illnesses were subjective reported by the parent and / or child; not objectified by a physician or physical therapist as ideally recommended (34). Participants from all over the Netherlands were enrolled in our study, therefore a physical consultation of injury or illness was not feasible. As a solution, we choose a structured interview by phone to further analyze the injury or illness reported in the online questionnaire. Even so, feasibility of this methodology was time-consuming and required a high degree of precise working, i.e. checking the incoming questionnaires and the presence of an injury or illness. In a pilot study of Fagher et al, the use of a novel eHealth-based application for self-report in Paralympic athletes was generally feasible and usable ${ }^{32}$, and seemed less time-consuming compared to our technique. The use of new methods developed for Paralympic athletes may be recommended for use in future recreational-level research to collect this type of data. Moreover there were more boys compared to girls in our sport-2 group. This may have influenced our results as evidence in healthy youth shows that girls are at increased risk of injuries while participating in PA compared to boys. Low levels of PA and/or physical fitness seemed to increase injury incidence levels, but the exact mechanisms remains unclear ${ }^{30}$. Future studies should take aspects like training history, training status and physical fitness level into account and may also investigate how the level of sport participation is related to injury and illness risks in order to develop risk profiles and injury prevention programs in more detail for youth with CDPD ${ }^{32,34}$.

\section{CONCLUSIONS}

Participation in sports twice a week does not pose an increased risk in the incidence of injury or illness per 1000 hours of PA in youth with CDPD compared to once or no participation in sports per week. The impact of injuries or illnesses was only minor. Given the evident health benefits for youth with CDPD without obvious risks, sports participation at least twice weekly in youth with CDPD is highly recommended. A next 
step would be to conduct studies to identify specific variables (i.e. physical fitness, type and training history of sports) that could prevent injuries and illnesses.

\section{Acknowledgements}

We thank all the research assistants for their contributions in data collection, as representatives of the educational program of Master Sports Physiotherapy and Master Pediatric Physiotherapy of the University of Applied Sciences in Utrecht, the Netherlands. We thank all the children, adolescents and their parents who participated in this study. The authors would like to thank the Dutch Organization of Health Research (ZONMW) for their unconditional grant. Grant number: 525001005.

\section{REFERENCES}

1. Janssen I, Leblanc AG. Systematic review of the health benefits of physical activity and fitness in school-aged children and youth. Int J Behav Nutr Phys Act 2010 May 11;7:405868-7-40.

2. Khan KM, Thompson AM, Blair SN, Sallis JF, Powell KE, Bull FC, et al. Sport and exercise as contributors to the health of nations. Lancet 2012 Jul 7;380(9836):59-64.

3. Haapala EA, Lankhorst K, de Groot J, Zwinkels M, Verschuren O, Wittink H, et al. The associations of cardiorespiratory fitness, adiposity and sports participation with arterial stiffness in youth with chronic diseases or physical disabilities. Eur J Prev Cardiol 2017 Jul;24(10):1102-1111.

4. Te Velde SJ, Lankhorst K, Zwinkels M, Verschuren O, Takken T, de Groot J, et al. Associations of sport participation with self-perception, exercise self-efficacy and quality of life among children and adolescents with a physical disability or chronic disease-a cross-sectional study. Sports Med Open 2018 Aug 15;4(1):38-018-0152-1.

5. Lankhorst K, Takken T, Zwinkels M, van Gaalen L, te Velde S, Backx F, et al. Sports participation, physical activity, and health-related fitness in youth with chronic diseases or physical disabilities: The Health in Adapted Youth Sports study. J Strength Cond Res 2019;Published Ahead-of-Print - Last Updated: May 02, 2019.

6. Ng K, Tynjala J, Sigmundova D, Augustine L, Sentenac M, Rintala P, et al. Physical activity among adolescents withlLong-term illnesses or disabilities in 15 European Countries. Adapt Phys Activ Q 2017 Oct 06:1-10.

7. Ng KW, Tynjala J, Rintala P, Kokko S, Kannas L. Do adolescents with long-term 
illnesses and disabilities have increased risks of sports related injuries? Inj Epidemiol 2017 Dec;4(1):13-017-0112-0. Epub 2017 May 1.

8. Finch C, Cassell E. The public health impact of injury during sport and active recreation. J Sci Med Sport 2006 Dec;9(6):490-497.

9. Emery CA. Risk factors for injury in child and adolescent sport: a systematic review of the literature. Clin J Sport Med 2003 Jul;13(4):256-268.

10. Siesmaa EJ, Blitvich JD, Finch CF. A systematic review of the factors which are most influential in children's decisions to drop out of organised sport. In: Farelli AD (ed). Sport Participation: Health Benefits, Injuries and Psychological Effects. NY: Nova Science Publishers, Inc.; 2011.

11. Siesmaa EJ, Blitvich JD, Telford A, Finch CF. Factors that are most influential in children's continued and discontinued participation in organized sport: The role of injury and injury risk perceptions. In: Farelli AD, editor. Sport Participation: Health Benefits, Injuries and Psychological Effects.: Nova Science Publishers, Inc.; 2011. p. 47-84.

12. Bloemers F, Collard D, Paw MC, Van Mechelen W, Twisk J, Verhagen E. Physical inactivity is a risk factor for physical activity-related injuries in children. Br J Sports Med 2012 Jul;46(9):669-674.

13. Verhagen E, Collard D, Paw MC, van Mechelen W. A prospective cohort study on physical activity and sports-related injuries in 10-12-year-old children. Br J Sports Med 2009 Dec;43(13):1031-1035.

14. Bloemen MA, Backx FJ, Takken T, Wittink H, Benner J, Mollema J, et al. Factors associated with physical activity in children and adolescents with a physical disability: a systematic review. Dev Med Child Neurol 2015 Feb;57(2):137-148.

15. Burghard M, de Jong NB, Vlieger S, Takken T. 2017 Dutch Report Card(+): Results From the first physical activity report card plus for Dutch youth with a chronic disease or disability. Front Pediatr 2018 Apr 30;6:122.

16. Bloemen MA, Verschuren $O$, van Mechelen C, Borst HE, de Leeuw AJ, van der Hoef M, et al. Personal and environmental factors to consider when aiming to improve participation in physical activity in children with Spina Bifida: a qualitative study. BMC Neurol 2015 Feb 10;15:11-015-0265-9.

17. Fagher K, Lexell J. Sports-related injuries in athletes with disabilities. Scand J Med Sci Sports 2014 Oct;24(5):e320-31.

18. Blauwet CA, Cushman D, Emery C, Willick SE, Webborn N, Derman W, et al. Risk of injuries in Paralympic track and field differs by impairment and event discipline: A pro- 
spective cohort study at the London 2012 Paralympic Games. Am J Sports Med 2016 Jun;44(6):1455-1462.

19. Shi X, Shi J, Wheeler KK, Stallones L, Ameratunga S, Shakespeare T, et al. Unintentional injuries in children with disabilities: a systematic review and meta-analysis. Inj Epidemiol 2015 Dec;2(1):21-015-0053-4. Epub 2015 Sep 15.

20. van Mechelen W, Hlobil H, Kemper HC. Incidence, severity, aetiology and prevention of sports injuries. A review of concepts. Sports Med 1992 Aug;14(2):82-99.

21. Lankhorst K, van der Ende-Kastelijn K, de Groot J, Zwinkels M, Verschuren O, Backx F, et al. Health in Adapted Youth Sports Study (HAYS): health effects of sports participation in children and adolescents with a chronic disease or physical disability. Springerplus 2015 Dec 22;4:796-015-1589-z. eCollection 2015.

22. von Elm E, Altman DG, Egger M, Pocock SJ, Gotzsche PC, Vandenbroucke JP, et al. The Strengthening the Reporting of Observational Studies in Epidemiology (STROBE) Statement: guidelines for reporting observational studies. Int J Surg 2014 Dec;12(12):14951499.

23. Durstine LJ, Moore GE, Painter P, Roberts S,O. ACSM's Exercise Management for Persons with Chronic Diseases and Disabilities. 3rd ed.: Human Kinetics, Champaign, IL; 2009.

24. Hollander dEL, Milder IE, Proper KI. Beweeg- en sportgedrag van mensen met een chronische aandoening of lichamelijke beperking, RIVM rapport, Bilthoven; 2015;2015-0064.

25. Lankhorst K, van den Berg-Emons RJ, Bussmann JBJ, Horemans HLD, de Groot JF. A novel tool for quantifying and promoting physical activity in youths with typical development and youths who are ambulatory and have motor disability. Phys Ther 2019 Mar 1;99(3):354-363.

26. Valkenburg $H$, van Nunen M, Ormel W, Vriend I. Handboek Epidemiologie Sportblessures, Stichting Consument en Veiligheid, Amsterdam, 2010;4.1.

27. Timpka T, Alonso JM, Jacobsson J, Junge A, Branco P, Clarsen B, et al. Injury and illness definitions and data collection procedures for use in epidemiological studies in Athletics (track and field): consensus statement. Br J Sports Med 2014 Apr;48(7):483-490.

28. Dompier TP, Powell JW, Barron MJ, Moore MT. Time-loss and non-time-loss injuries in youth football players. J Athl Train 2007 Jul-Sep;42(3):395-402.

29. Murphy NA, Carbone PS, American Academy of Pediatrics Council on Children With Disabilities. Promoting the participation of children with disabilities in sports, recreation, and physical activities. Pediatrics 2008 May;121(5):1057-1061.

30. Nauta J, Martin-Diener E, Martin BW, van Mechelen W, Verhagen E. Injury risk during 
different physical activity behaviours in children: a systematic review with bias assessment. Sports Med 2015 Mar;45(3):327-336.

31. Ramirez Marizen M. Sports injuries to high school athletes with disabilities. Pediatrics 2009-2;123(2):690-6.

32. Fagher K, Jacobsson J, Dahlstrom O, Timpka T, Lexell J. An eHealth application of selfreported sports-related injuries and illnesses in Paralympic Sport: Pilot feasibility and usability study. JMIR Hum Factors 2017 Nov 29;4(4):e30.

33. Derman W, Schwellnus M, Jordaan E, Blauwet CA, Emery C, Pit-Grosheide P, et al. IIIness and injury in athletes during the competition period at the London 2012 Paralympic Games: development and implementation of a web-based surveillance system (WEB-IISS) for team medical staff. Br J Sports Med 2013 May;47(7):420-425.

34. Weiler R, Van Mechelen W, Fuller C, Verhagen E. Sport Injuries Sustained by Athletes with Disability: A Systematic Review. Sports Med 2016 Aug;46(8):1141-1153.

35. inch C. A new framework for research leading to sports injury prevention. J Sci Med Sport 2006 May;9(1-2):3-9; discussion 10. 


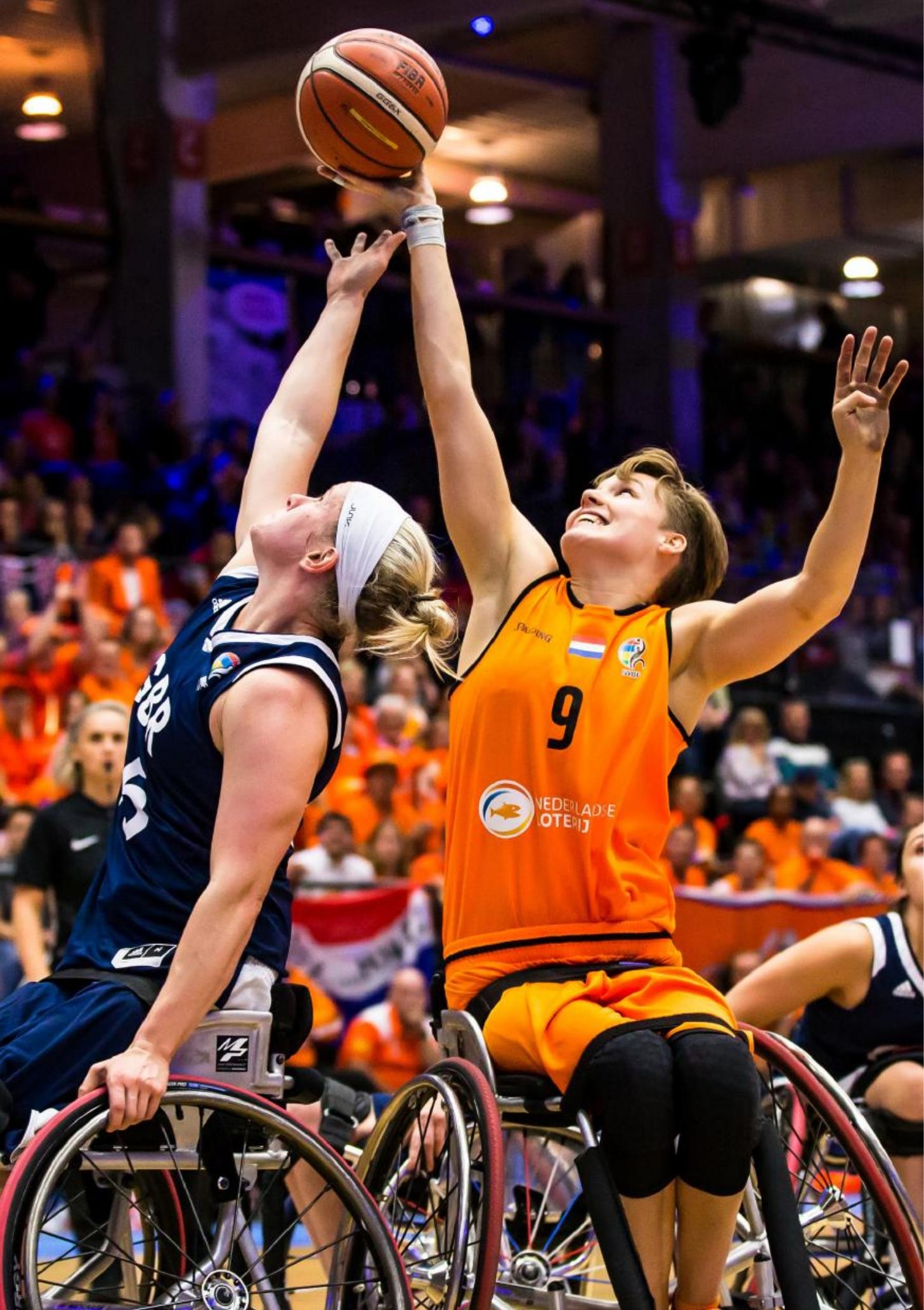




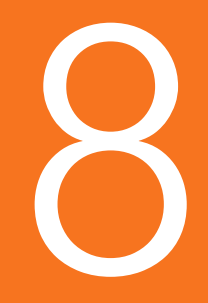

\section{Instruments measuring physical activity in persons who use a wheelchair:}

a systematic review of measurement properties

Kristel Lankhorst

Michiel Oerbekke

Rita van den Berg-Emons

Tim Takken

Janke de Groot

Archives of Physical Medicine and Rehabilitation 2019; September: Accepted. 


\section{ABSTRACT}

Objective. To systematically review the evidence evaluating validity or reliability of self-reported and device-based instruments to measure PA in individuals who use a wheelchair and making recommendations for the selection of PA outcomes tools.

Data Sources. Pubmed, Embase, and CINAHL were systematically searched.

Study Selection. Studies reporting measurement properties of instruments to assess PA in individuals who use a wheelchair.

Data Extraction. The COSMIN checklist was used to assess the methodological quality of the included studies and the measurement properties of instruments assessing PA were examined.

Data Synthesis. The search yielded 5341 records, 61 were considered relevant, 21 articles were included. A best evidence synthesis was performed on nine studies including four self-reported instruments and thirteen studies including eight device-based instruments. One study evaluated both self-reported and device-based instruments. The overall methodological quality of all studies ranged from poor to excellent. Variable levels of evidence were found for both the validity and reliability for self-reported instruments and for criterion validity for device-based instruments.

Conclusion. The PASIPD and PARA-SCl seems the most promising self-reported instruments for measuring the intensity of PA. Device-based instruments that can be used for measuring both the intensity and type of PA are the GENEactive, Actigraph GT3X+, Actiheart or the PAMS, showing moderate evidence for a positive rating of criterion validity. For measuring the type of PA the PAMS and VitaMove are suitable, showing both good evidence for a positive rating of criterion validity. 


\section{INTRODUCTION}

A low level of physical activity (PA) is a well-known risk factor for many diseases, for example for developing cardiovascular diseases, osteoporosis and type 2 diabetes ${ }^{1}$. Studies have shown that in comparison with the able-bodied population, manual wheelchair users (MWU) might even be more at risk for developing disease related to unfavourable PA, due to the long periods of sitting time in the wheelchair ${ }^{2-4}$. At the same time, it is often hypothesized that low levels of PA lead to a vicious cycle of deconditioning, even more decreased mobility and further decline of PA in daily life ${ }^{5}$.

Current standards promote a healthy lifestyle that consists optimal levels of PA ${ }^{6-8}$. Therefore optimizing levels of PA in MWU is an important treatment goal for health care professionals working with this population ${ }^{5}$. To further evaluate the effectiveness of interventions targeting PA, relationship between PA and health outcomes in MWU, valid instruments are needed to assess PA.

While both self-reported (subjective measurement) and device-based (objective measurement) instruments measuring PA have been developed and validated for clinical populations who are ambulatory, the use and the psychometric properties of these instruments are not that easily transferable to those who use a manual wheelchair for daily mobility.

There are two important factors of influence on the usage and the validity of instruments; 1) the sensor location and 2) applicability of current predictive models for manual wheelchair application. The sensor wearing placement of the device and sensor configuration in the ambulatory population, i.e. leg or waist may not be suitable for assessment of movement in manual wheelchair activities like walking versus manual wheelchair propulsion, or cycling versus hand biking. For recognizing active propulsion, at least two sensors are necessary to record movement of hand and wheel independently. In addition, the use of energy expenditure (EE) prediction models derived from raw accelerometer data or estimation of the metabolic estimation of task (MET) from questionnaires to identify intensity (light, moderate, vigorous, high) are developed for ambulatory persons.

While several instruments are commonly used to measure PA in research, measurement properties (e.g. validity or reliability) are not always known for wheelchair activities ${ }^{10-12}$. In addition, clear guidelines or recommendations are lacking about how to assess PA, including the intensity and type of activity in a valid and reliable manner.

Therefore the aim of this systematic review was to summarize the evidence on measurement properties (content, construct and criterion validity or reliability) 
of instruments measuring the intensity and / or type of PA in MWU and making recommendations for the selection of PA outcomes tools.

\section{METHODS}

\section{Data Sources and Searches}

A literature search was conducted up to July 2019 in the following electronic databases: MEDLINE/Pubmed, CINAHL and Embase. The complete search strategy of MEDLINE/ Pubmed, CINAHL and Embase can be found in supplemental appendix 1, where the complete search string is displayed. The general topics areas searched were; physical activity (sedentary behaviour, inactive lifestyle, activity), energy expenditure, instrument (accelerometry, questionnaire, sensor), mode of mobility (wheelchair, non-ambulant). The search string was based on a validated search filter for finding studies on measurement properties as published by the COSMIN group ${ }^{13}$. No date restrictions were applied to the search. The protocol for the search was not published a priori. Overall methodology of this systematic review is based on the guideline for systematic reviews of outcome measurement instruments ${ }^{14,15}$.

\section{Study Selection}

Initial screening of titles was performed by one of the reviewers $(\mathrm{MO})$ to exclude obvious non fitting titles and duplicate references by use of RefWorks (C) 2019 ProQuest LLC. A pragmatic strategy of combining auto- and hand-searching duplicates by use of RefWorks (C) 2019 ProQuest LLC was applied ${ }^{16}$. Titles, abstracts and full-text were then independently reviewed for eligibility by two reviewers (MO, KL). Any discrepancies in the agreement were discussed with a third reviewer (JdG) until consensus was reached. Finally, the reference lists of included studies were manually searched for additional studies.

Articles were eligible if; 1) the study sample contained individuals who use manual wheelchairs, 2) two or more activities of daily living were evaluated, 3) at least one measurement property of an instrument measuring PA was assessed, 4) self-reported (subjective measures) or device-based instruments (objective measures) were evaluated, 5) the instruments are for sale and currently supported by the manufacturer for use. The choice for inclusion of two or more types of activities (i.e. lying, sitting, hand biking, wheelchair propulsion) or activities at different intensities (light, moderate, vigorous) was done in order to evaluate PA in a broader spectrum and to give optimal recommendations 
to clinicians about valid and reliable instruments to monitor PA in daily live. The type of PA is defined as the identification of body postures (e.g., sitting, standing) and body movements (e.g., walking, cycling). The intensity of PA is defined as the estimation of energy expenditure / MET's. Both perspectives of PA are based on movement counts ${ }^{17}$. Articles were excluded when written in another language than English or Dutch, were (systematic) reviews, study proposals or protocols, case studies or series, books or book chapters, poster abstracts, conference abstracts, correspondence or commentaries.

\section{Data Extraction and Quality Assessment}

One reviewer $(\mathrm{MO})$ extracted data using a standard extraction form, this was checked by the second reviewer $(\mathrm{KL})$. Table $1 \mathrm{a}$ and $1 \mathrm{~b}$ shows the data extracted from the included articles, the extracted data were: 1) type and administration of instruments; 2) author and year; 3) characteristics of study sample, i.e. number of wheelchair users in study population, diagnosis and mean age or range; 4) studied measurement property, i.e. validity or reliability in table $1 \mathrm{a}$, and used instrument for criterion validity in table $1 \mathrm{~b}$; 5) study outcomes. The studied measurement property for self-reported instruments were content validity, structural validity, criterion validity, hypothesis testing, the internal consistency and the test - retest reliability. The studied measurement property for device-based instruments was overall criterion validity; one study evaluated hypothesis testing and internal consistency for two device-based instruments. 


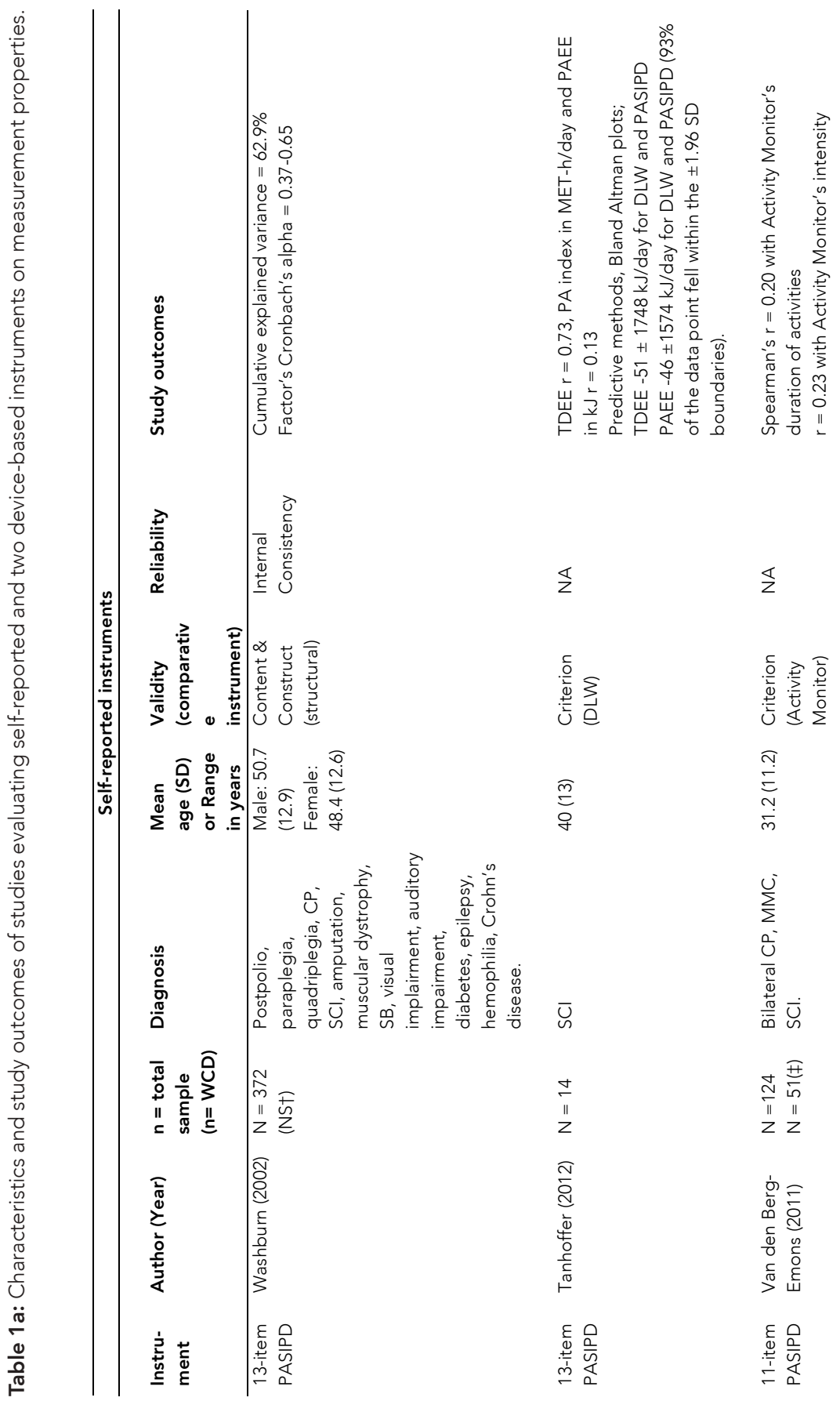




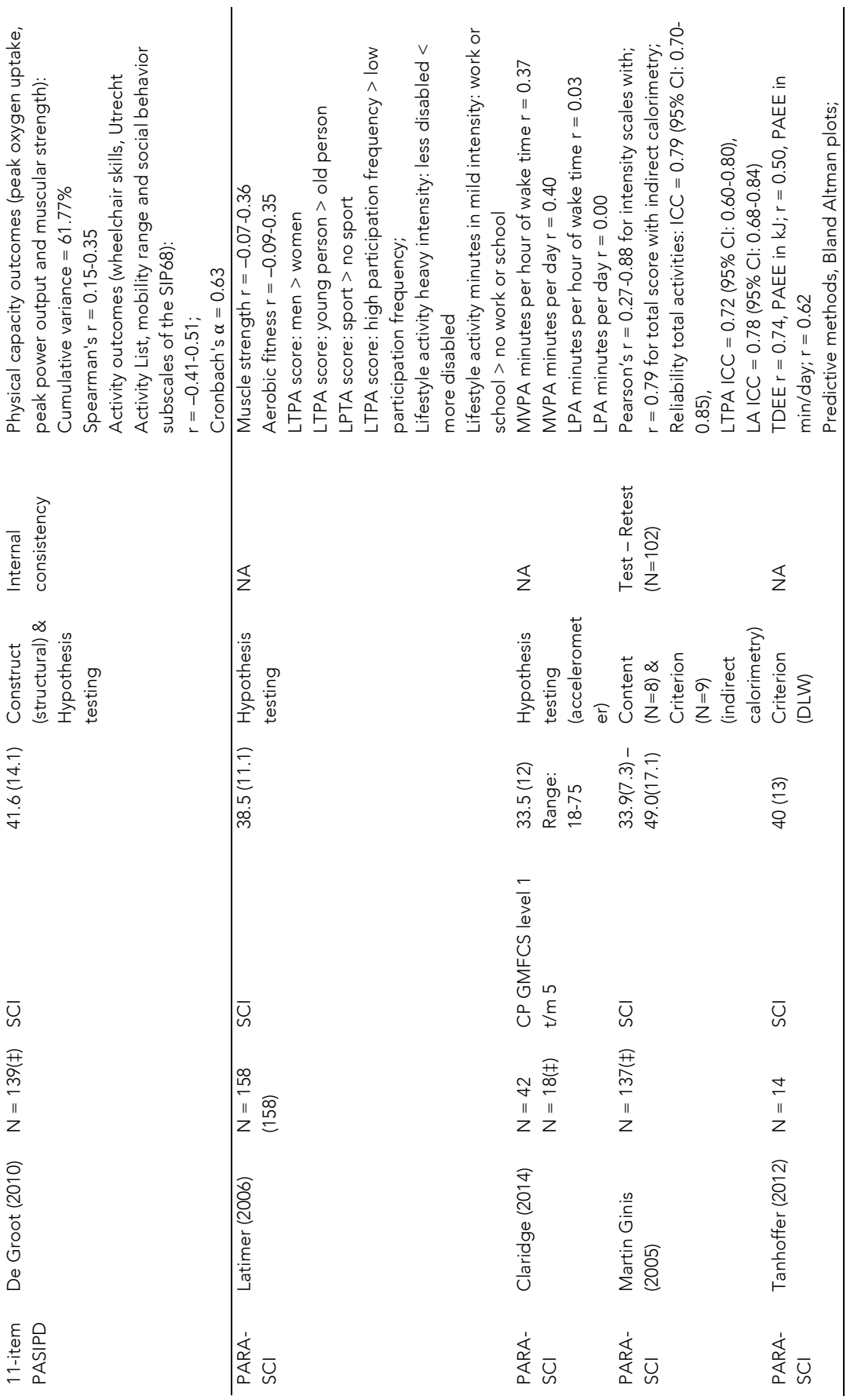




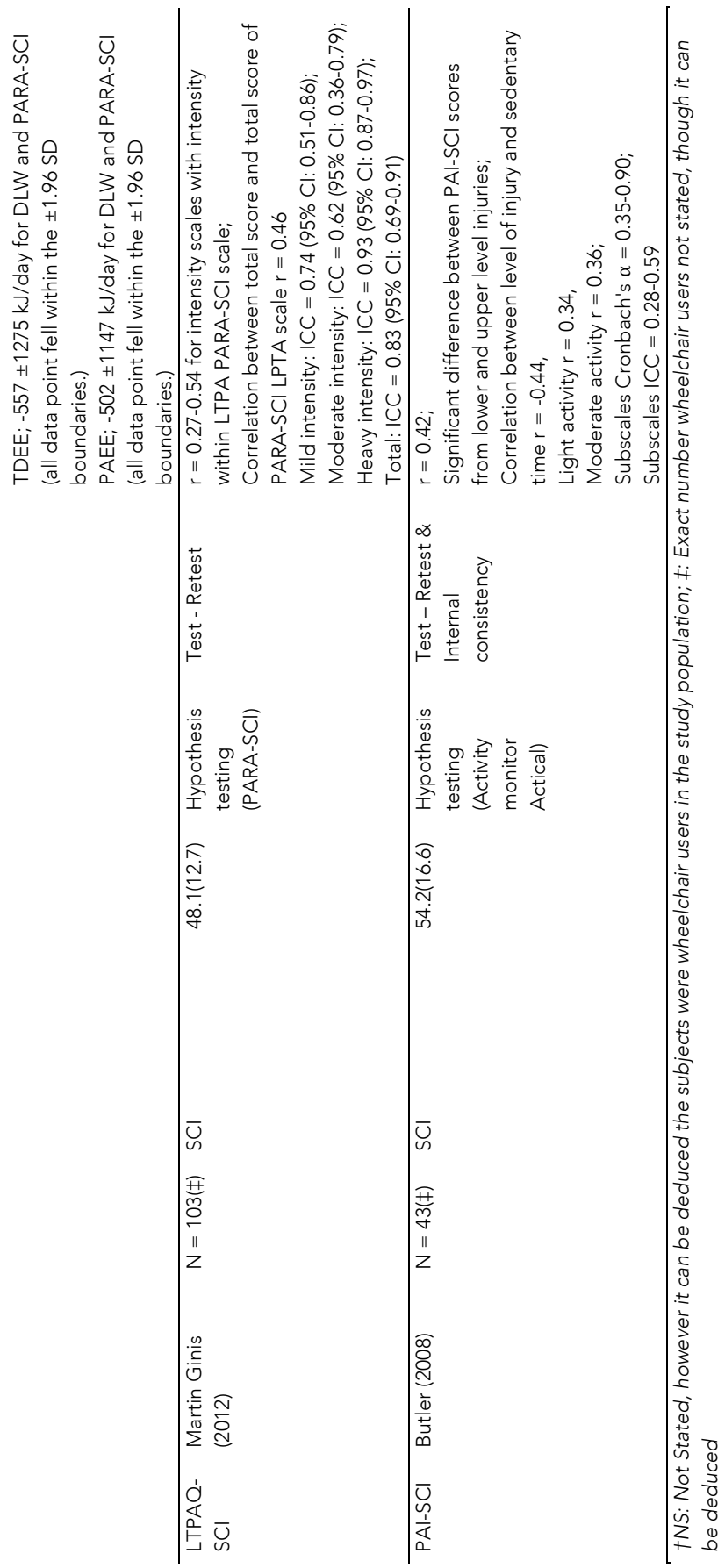




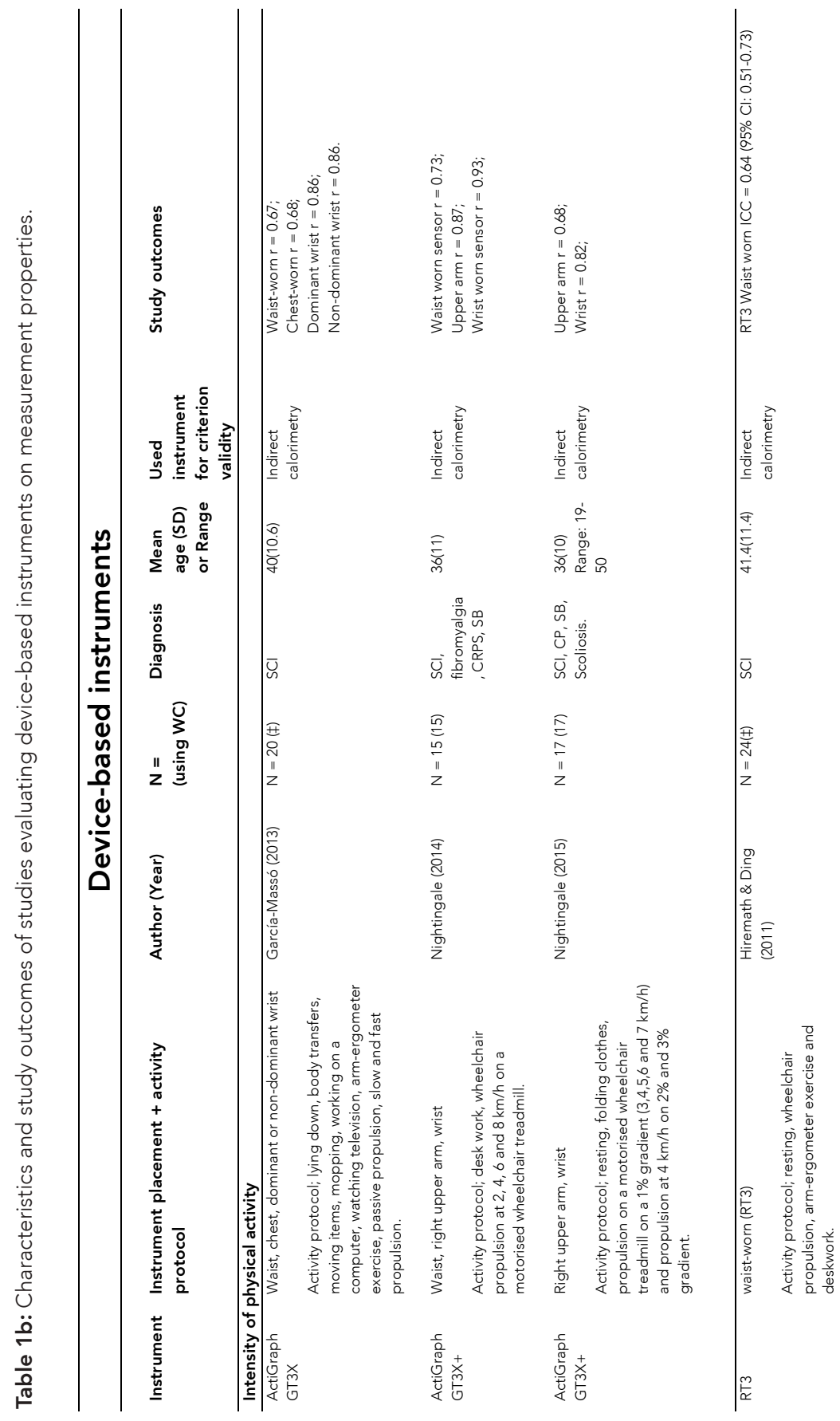




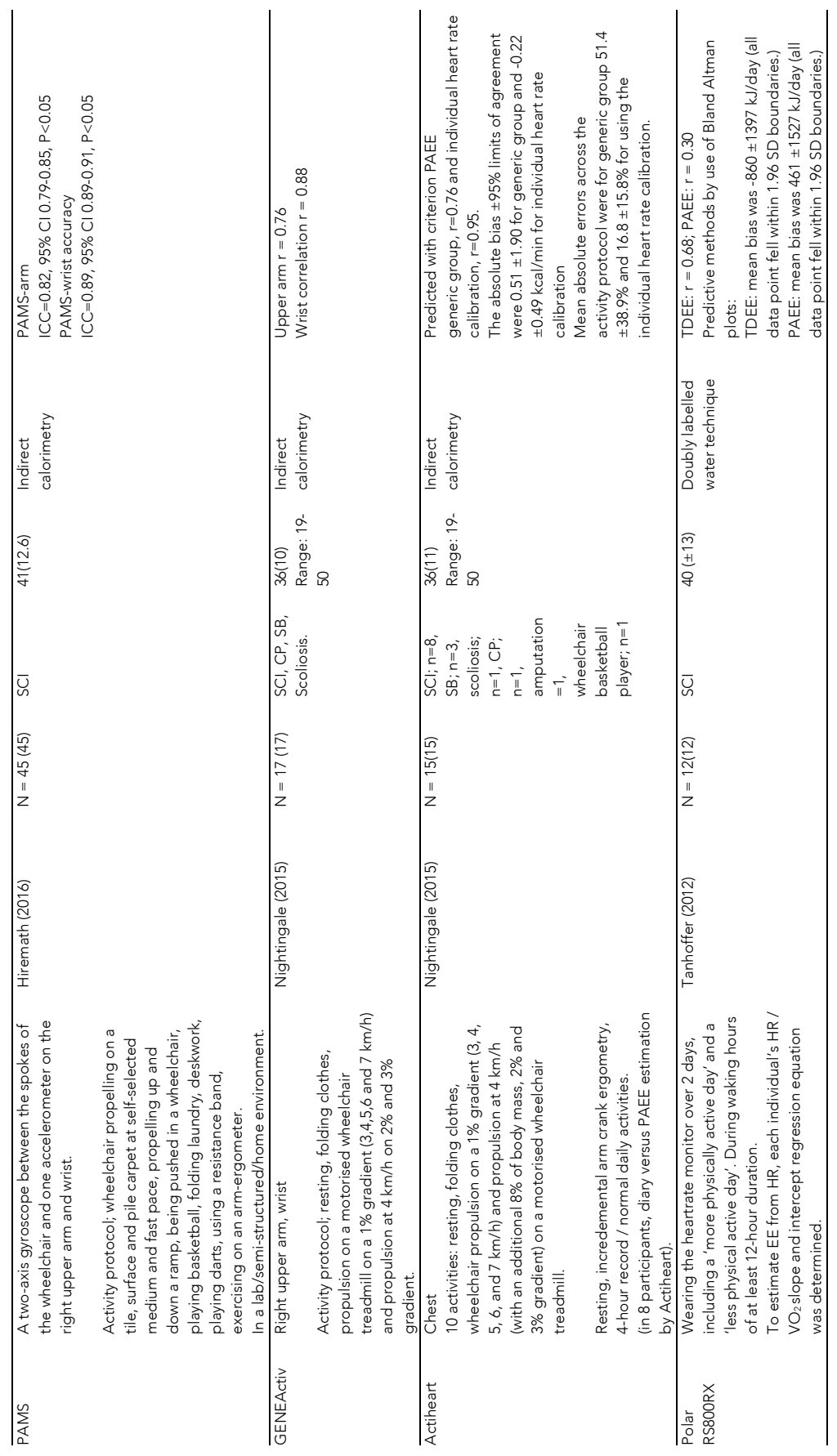




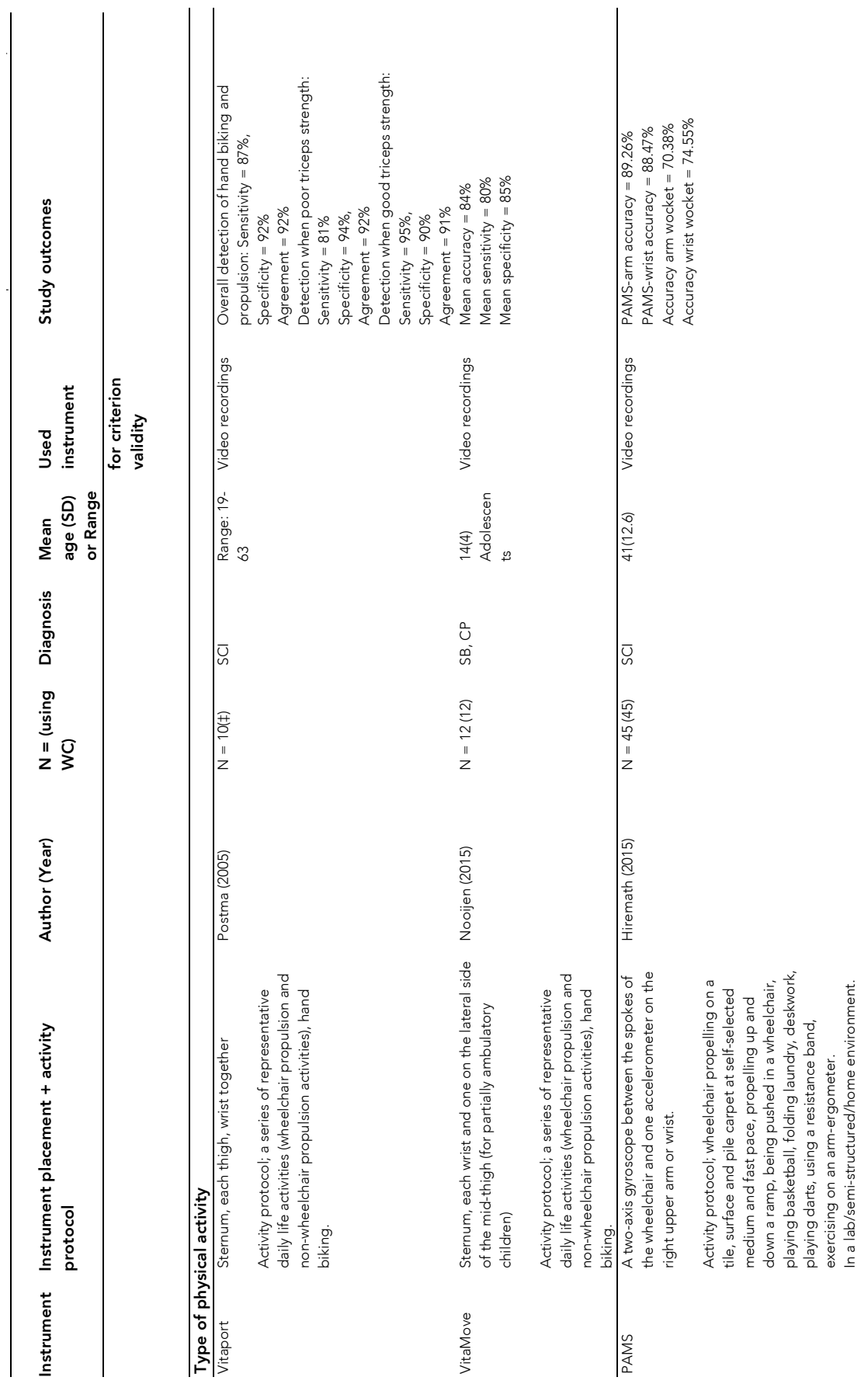




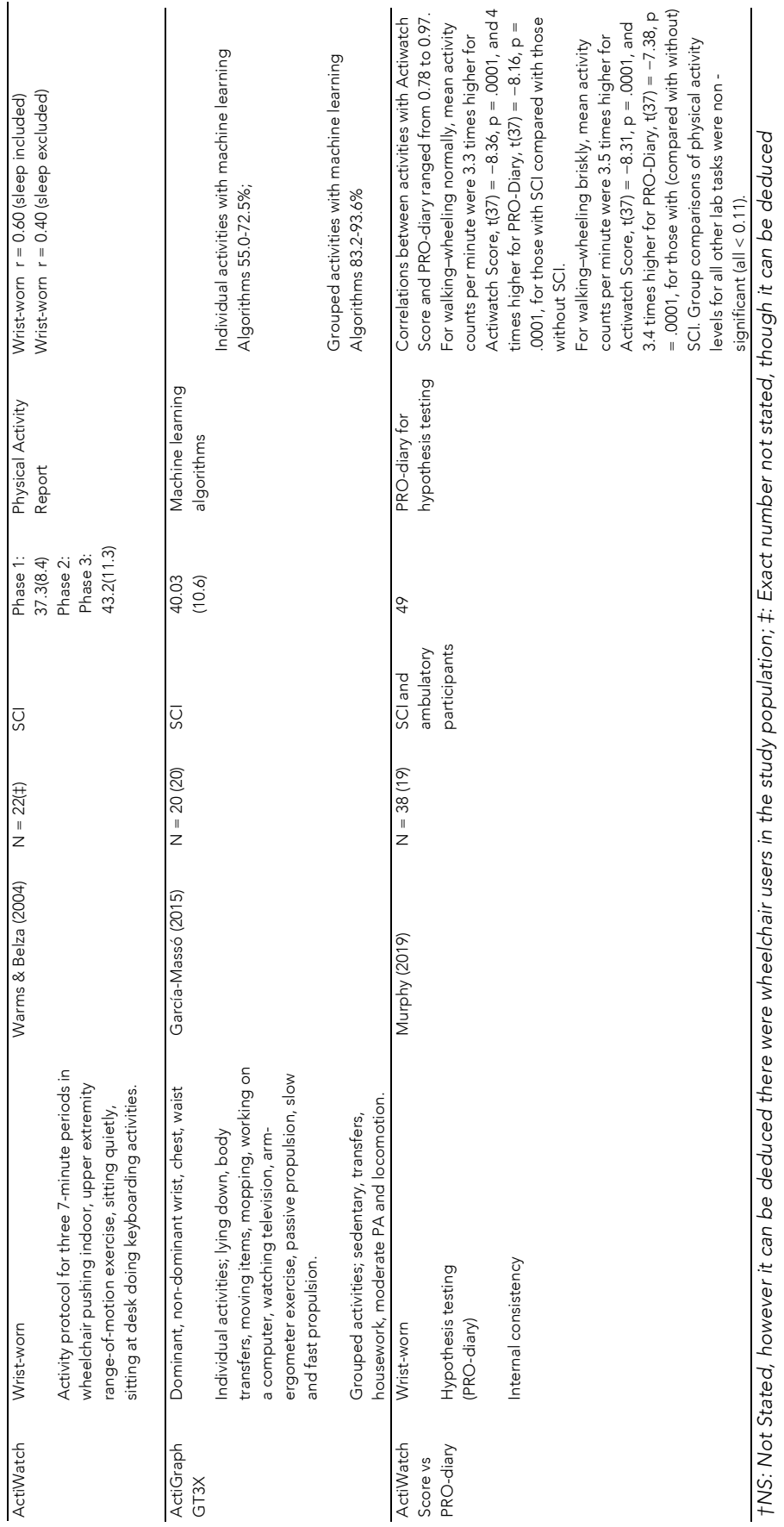




\section{Assessment of the methodological quality of the included studies}

Two reviewers ( $K L$ and $\mathrm{MO}$ ) independently assessed the methodological quality of the included studies using the Consensus-based Standards for the selection of health Measurement Instruments (COSMIN) checklist $^{18}$. The COSMIN checklist is a modular tool and contains 12 boxes: ten boxes can be used to assess the methodological quality of studies on measurement properties, and 2 boxes contain general requirements. The four-point Consensus-based standard for the selection of COSMIN checklist was chosen to assess the methodological quality of studies on measurement properties ${ }^{19}$. The items of each box were rated with the four-point scoring system: 'excellent', 'good', 'fair' and 'poor'. To rate the methodological quality, the lowest rating of any item in a box was taken ('worse score counts' method) according to the COSMIN guidelines. Disagreement between the authors regarding the 'worse score count' of an article was resolved with a third reviewer $(\mathrm{JdG})$ until consensus was reached. There is one item about sample size in every box, with minimal requirement of $\mathrm{N}=30$ for an adequate sample size. Since the COSMIN guidelines were originally developed for self-reported outcomes, these sample size requirements do not necessarily apply for device-based instruments were a smaller sample size for evaluation of criterion validity is often appropriate and common ${ }^{20,21}$. A lower sample size was only approved if an adequate power analysis or post hoc analysis was described. The scoring procedure for the item about sample size was only modified for evaluation of criterion validity in device-based measurement instruments and not for the self-reported outcomes. This scoring modification is in line with an article by Mitchell et al. ${ }^{22}$

\section{Assessment of the outcome of measurement properties}

The outcome measurement properties could be qualified as 'positive' (+), 'indeterminate' (?), and 'negative' (-) as shown in table $2 \mathrm{a}^{19}$. As some studies in the review assessed the sensitivity and specificity of a device-based instrument, an additional rating was added for criterion validity (table $2 \mathrm{~b}$ ). For example, when there are convincing arguments that gold standard is 'gold' AND (correlation OR intraclass correlation (ICC) with gold standard is $\geq 0.70$ ) OR sensitivity / specificity or accuracy is $80-100 \%$, the outcome measurement properties were qualified as 'positive' (+). 
Table 2a: Quality criteria for study outcomes - patient related outcomes (Based on Terwee et al. 2007)9.

\section{Property Rating Outcome quality criteria (OQ)}

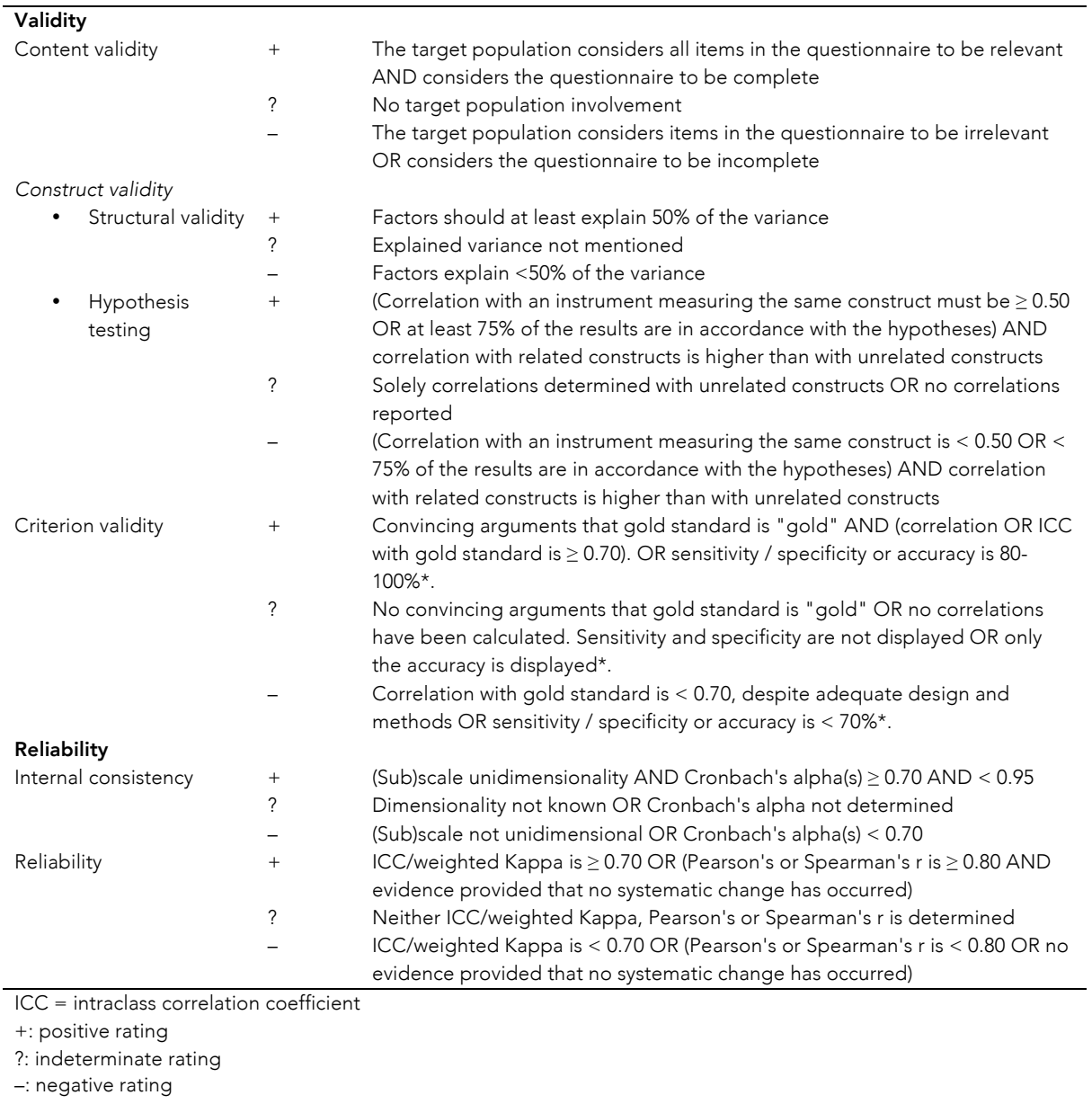

\section{*Note}

For device-based instrument measurements, assessing the sensitivity and specificity or accuracy of a device are normally rated as; excellent (++), good (+), moderate ( ), weak (-) or not clear (?). In order to be clear and consistent with the description of the ratings for self-reported and device-based instruments together displayed in the tables and text, we use the same ratings for the sensitivity and specificity outcome measure according to Terwee et al. 2007. This makes that the outcome quality of sensitivity and specificity rated as excellent (++) and good (+) are merged as positive (+); moderate ( ) and weak (-) as negative (-) and not clear (?) as indeterminate (?). 


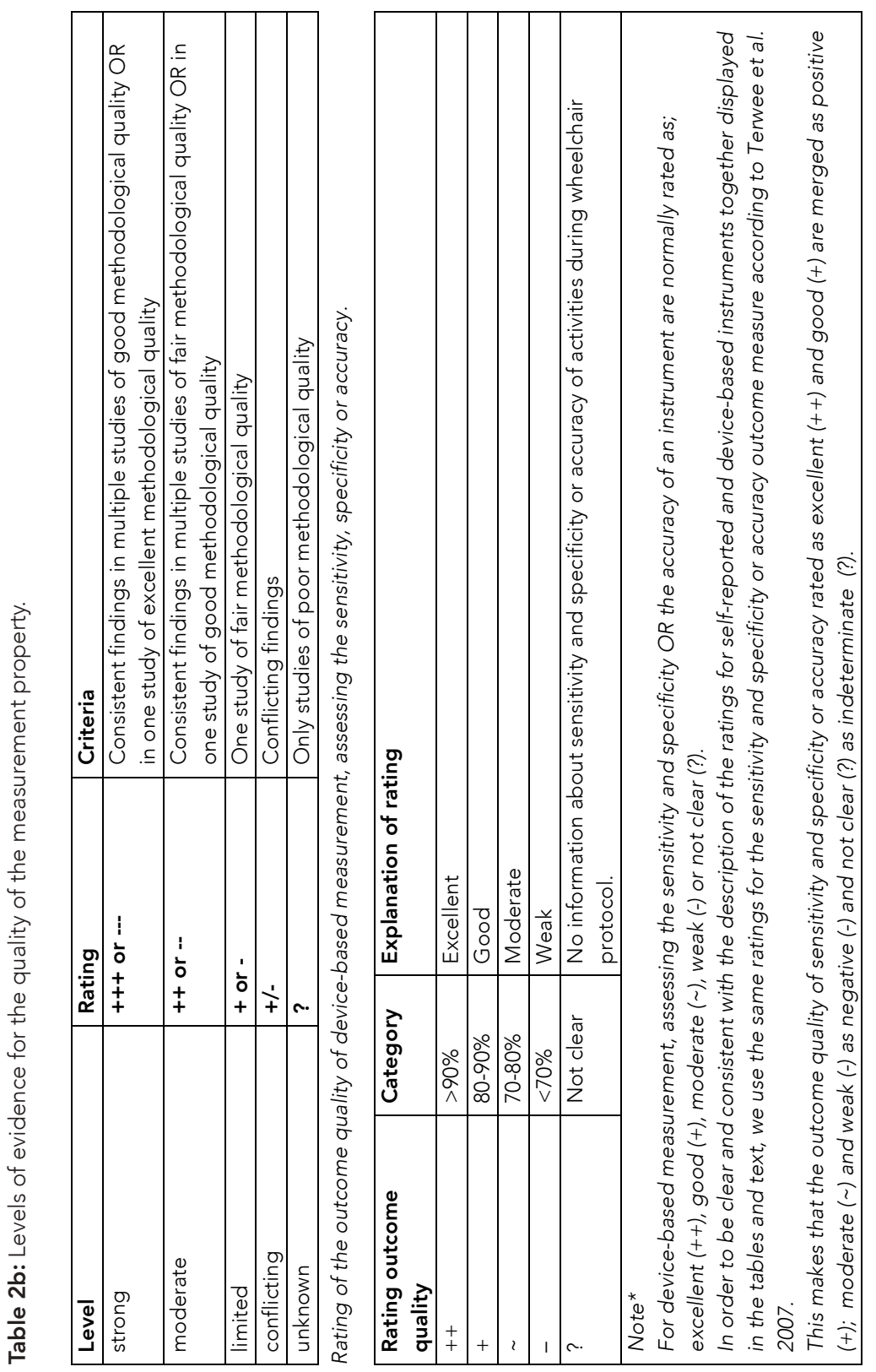




\section{Best evidence synthesis}

A best evidence synthesis was performed because methodology of pooling of measurement properties was not possible with many different outcome measures. ${ }^{13,19}$. Data for the best evidence synthesis were interpreted by three authors, KL (PhD student and physical therapist), MO (physical therapist and health scientist) and JdG (PhD, physical therapist and medical physiologist). As proposed by the Cochrane Back Review Group, the best evidence synthesis is generated by combining the level of evidence (strong, moderate, limited, conflicting, unknown, see table 2b) and the study outcomes (positive (+), indeterminate (?) and negative (-), see table 2a).

For example, the estimation of energy expenditure (EE) of the GeneActiv with wearing position at the wrist shows a correlation of 0.88 with indirect calorimetry which results in a 'positive' (+) study outcome rating (table 2a) and the methodological quality of the study was rated 'good' (table 2b). There is one study with good methodological quality of the GeneActiv for wearing position at the wrist, which results in a moderate level of evidence (table 2b). In conclusion, there is a moderate level of positive evidence for criterion validity of the GeneActiv for wearing position at the wrist.

\section{RESULTS}

\section{Included studies}

The search strategy identified 5341 potentially relevant articles from three databases after removing duplicates, 4024 records were screened (figure 1). In total, 56 full-text articles were deemed relevant based on title and abstract. The reference tracking of the included studies did generate five additional relevant studies and 41 articles were excluded based on full text. One article was added by an expert, this article was not found by use of our search strategy because the used words in the title, abstract and key words did not match the search strategy. In total, 61 full-text articles were assessed for eligibility. Finally, 21 studies met the inclusion criteria for this systematic review. 


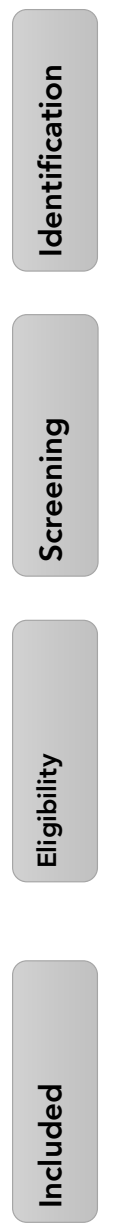

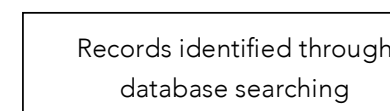

$$
(n=5341)
$$

Additional records identified through other sources

$$
(n=6)
$$
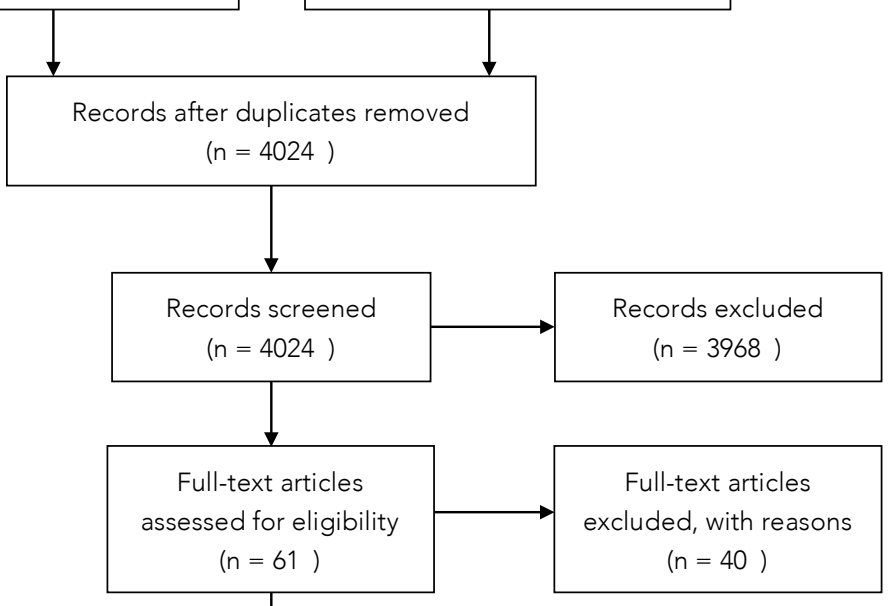

Studies included in

qualitative synthesis

$$
(n=21)
$$

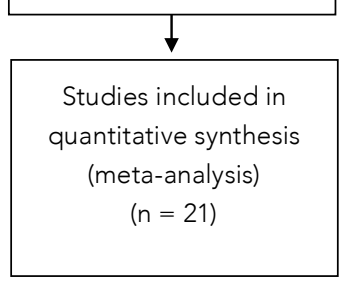

Figure 1: Flowchart identification, screening, eligibility and included studies. 
The characteristics of self-reported and device-based instruments in studies reporting measurement properties are displayed in table $1 \mathrm{a}$ and table $1 \mathrm{~b}$ resp. The methodological quality of the studies, the outcome quality of the measurement property and the level of evidence using the COSMIN checklist and criteria are reported in table 3 and table 4. A best evidence synthesis was performed on nine studies including four self-reported instruments (table 3) and on thirteen studies including eight device-based instruments (table 4). One study evaluated both self-reported and device-based instruments ${ }^{23}$. The overall methodological quality of all studies ranged from poor to excellent. First, the self-reported outcome measures will be discussed, followed by device-based outcome measures for assessment organized by either the intensity or type of PA in MWU. Supplemental appendix 2 gives a description of each of the included instruments in this systematic review. 


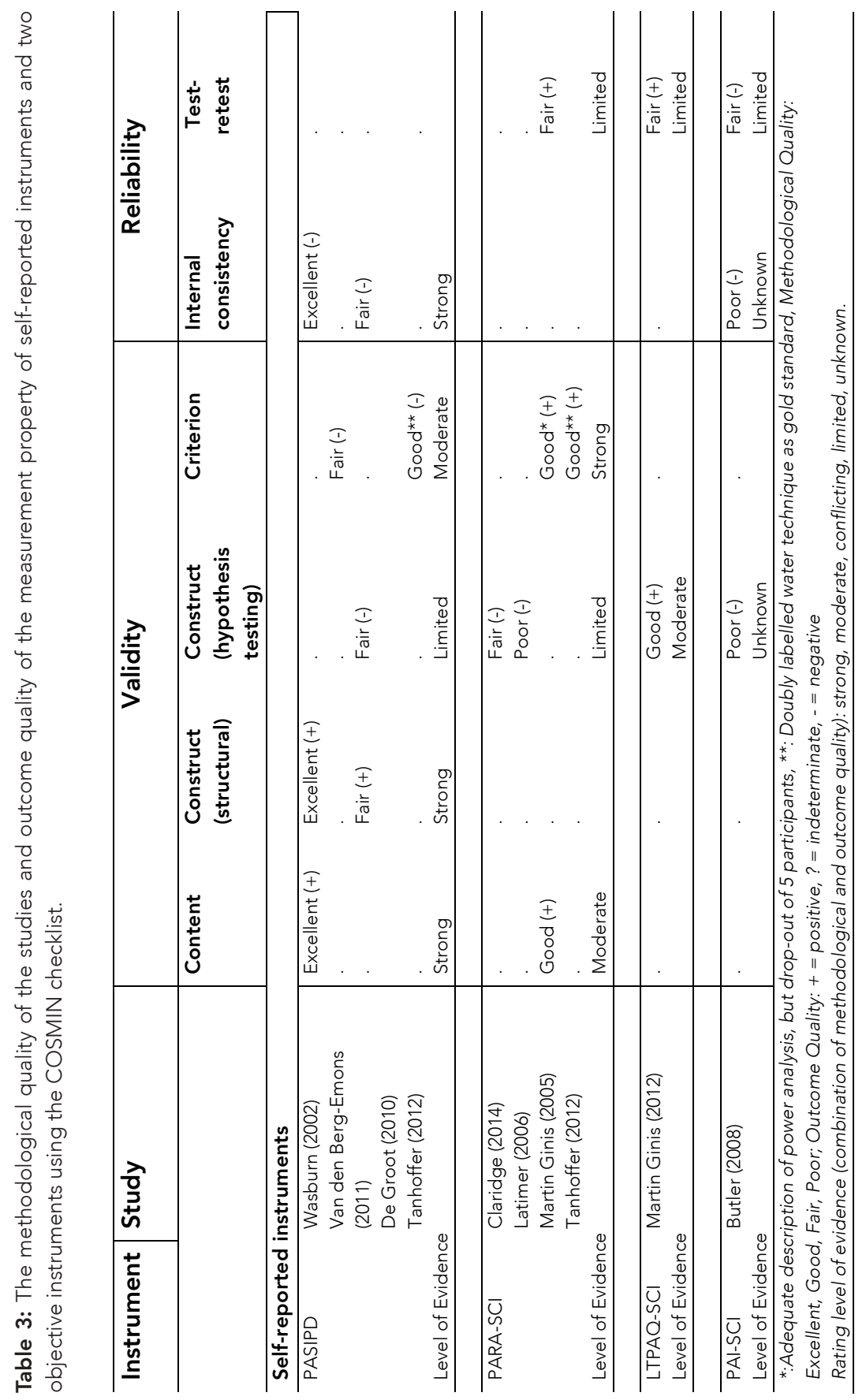


Table 4: The methodological quality of the studies and outcome quality of the measurement property of device-based instruments on criterion validity using the COSMIN checklist.

\begin{tabular}{|c|c|c|c|c|}
\hline Instrument & Study & Outcome & Quality & $\begin{array}{l}\text { Level of } \\
\text { evidence }\end{array}$ \\
\hline \multicolumn{5}{|l|}{ ActiGraph GT3X+ } \\
\hline Chest & $\begin{array}{l}\text { García-Massó } \\
\text { (2013) }\end{array}$ & $r=0.68$ & Fair (-) & Limited \\
\hline Waist & $\begin{array}{l}\text { García-Massó } \\
\text { (2013) } \\
\text { Nightingale } \\
(2014)\end{array}$ & $\begin{array}{l}r=0.67 \\
r=0.73\end{array}$ & $\begin{array}{l}\text { Fair }(-) \\
\text { Fair }(+)\end{array}$ & Conflicting \\
\hline Right upper arm & $\begin{array}{l}\text { Nightingale } \\
\text { (2015) } \\
\text { Nightingale } \\
(2014)\end{array}$ & $\begin{array}{l}r=0.68 \\
r=0.87\end{array}$ & $\begin{array}{l}\text { Good (-) } \\
\text { Fair }(+)\end{array}$ & Conflicting \\
\hline Right wrist & $\begin{array}{l}\text { Nightingale } \\
\text { (2015) } \\
\text { Nightingale } \\
\text { (2014) }\end{array}$ & $\begin{array}{l}r=0.82 \\
r=0.93\end{array}$ & $\begin{array}{l}\text { Good (+) } \\
\text { Fair }(+)\end{array}$ & Moderate \\
\hline Non-dominant wrist & $\begin{array}{l}\text { García-Massó } \\
\text { (2013) }\end{array}$ & $r=0.86$ & Fair (+) & Limited \\
\hline \multicolumn{5}{|l|}{ Actiheart } \\
\hline $\begin{array}{l}\text { Generic group } \\
\text { Individual heart rate calibration } \\
\text { group }\end{array}$ & $\begin{array}{l}\text { Nightingale } \\
\text { (2015) }\end{array}$ & $\begin{array}{l}r=0.76 \\
r=0.95\end{array}$ & $\begin{array}{l}\text { Good (+) } \\
\text { Good (+) }\end{array}$ & Moderate \\
\hline \multicolumn{5}{|l|}{ Polar RS800RX } \\
\hline $\begin{array}{l}\text { TDEE** } \\
\text { PAEE** }\end{array}$ & $\begin{array}{l}\text { Tanhoffer } \\
(2012)\end{array}$ & $\begin{array}{l}r=0.68 \\
r=0.30\end{array}$ & $\begin{array}{l}\text { Good (-) } \\
\text { Good (-) }\end{array}$ & Moderate \\
\hline \multicolumn{5}{|l|}{ GeneActiv } \\
\hline $\begin{array}{l}\text { Right upper arm } \\
\text { Right wrist }\end{array}$ & $\begin{array}{l}\text { Nightingale } \\
(2015)\end{array}$ & $\begin{array}{l}r=0.76 \\
r=0.88\end{array}$ & $\begin{array}{l}\text { Good (+) } \\
\text { Good (+) }\end{array}$ & Moderate \\
\hline \multicolumn{5}{|l|}{ RT3 } \\
\hline Waist & $\begin{array}{l}\text { Hiremath \& } \\
\text { Ding (2011) }\end{array}$ & $\begin{array}{l}\text { ICC = } 0.64 \\
(95 \% \text { CI: } 0.51-0.73)\end{array}$ & Good (-) & Moderate \\
\hline PAMS & & & & \\
\hline $\begin{array}{l}\text { Right upper arm } \\
\text { Right wrist }\end{array}$ & $\begin{array}{l}\text { Hiremath } \\
\text { (2016) } \\
\text { Hiremath } \\
\text { (2016) } \\
\end{array}$ & $\begin{array}{l}I C C=0.82,95 \% \text { Cl } 0.79- \\
0.85, P<0.05 \\
I C C=0.89,95 \% \text { Cl } 0.89- \\
0.91, P<0.05\end{array}$ & $\begin{array}{l}\text { Good (+) } \\
\text { Good (+) }\end{array}$ & Moderate \\
\hline
\end{tabular}




\begin{tabular}{|c|c|c|c|c|}
\hline Instrument & Study & Outcome & Quality & $\begin{array}{l}\text { Level of } \\
\text { evidence }\end{array}$ \\
\hline \multicolumn{5}{|l|}{ Vitaport / Vitamove } \\
\hline \multirow[t]{2}{*}{ Sternum/thigh/wrist } & Postma (2005) & $\begin{array}{l}\text { Sensitivity }=87 \% \\
\text { Specificity }=92 \% \\
\text { Agreement }=92 \%\end{array}$ & Good (+) & Strong \\
\hline & Nooijen (2015) & $\begin{array}{l}\text { Mean accuracy }=84 \% \\
\text { Mean sensitivity }=80 \% \\
\text { Mean specificity }=85 \%\end{array}$ & Good (+) & \\
\hline \multicolumn{5}{|l|}{ PAMS } \\
\hline $\begin{array}{l}\text { Spokes/upper arm } \\
\text { Spokes/wrist } \\
\text { Right upper arm } \\
\text { Right wrist }\end{array}$ & $\begin{array}{l}\text { Hiremath } \\
\text { (2015) } \\
\text { Hiremath } \\
(2015)\end{array}$ & $\begin{array}{l}\text { PAMS-arm accuracy = } \\
89.26 \% \\
\text { PAMS-wrist accuracy = } \\
88.47 \% \\
\text { Accuracy arm wocket = } \\
70.38 \% \\
\text { Accuracy wrist wocket = } \\
74.55 \%\end{array}$ & $\begin{array}{l}\text { Excellent } \\
(+) \\
\text { Excellent } \\
(+) \\
\text { Excellent } \\
(+) \\
\text { Excellent } \\
(+)\end{array}$ & $\begin{array}{l}\text { Strong } \\
\text { Strong }\end{array}$ \\
\hline \multicolumn{5}{|l|}{ Actigraph GT3X } \\
\hline Individual activities & García-Massó & & & Limited \\
\hline Dominant wrist & (2015) & $55.0-61.4 \%$ & Fair (-) & \\
\hline Non-dominant wrist & & $61.5-63.3 \%$ & Fair (-) & \\
\hline All (wrists, chest, waist) & & $65.9-72.5 \%$ & Fair (-) & \\
\hline Grouped activities & García-Massó & & & Limited \\
\hline Dominant wrist & (2015) & $83.2-85.9 \%$ & Fair (+) & \\
\hline Non-dominant wrist & & $83.9-87.0 \%$ & Fair $(+)$ & \\
\hline All (wrists, chest, waist) & & $89.5-93.6 \%$ & Fair (+) & \\
\hline
\end{tabular}

\section{Actiwatch}

\begin{tabular}{llllc}
\hline Wrist & Warms \& Belza & $r=0.60$ (sleep included) & Poor (-) & Unknown \\
& $(2004)$ & $r=0.40$ (sleep excluded) & & \\
\hline Actiwatch vs PRO-diary ${ }^{a}$ & Murphy (2019) & $r=0.78-0.97$ & Fair (+) & Limited
\end{tabular}

*:Adequate description of power calculation, ${ }^{\star \star}$ Criterion: Doubly labelled water technique. ${ }^{\text {a: }}$ :hypothesis testing and internal consistency, comparison activity counts wheelchair use and ambulatory activities. Methodological Quality:

Excellent, Good, Fair, Poor; Outcome Quality: + = positive, ? = indeterminate, - = negative

\section{Self-reported instruments assessing the intensity of PA}

\section{PASIPD}

Four studies investigated the content validity, construct validity (structural validity and hypothesis testing), criterion validity and internal consistency ${ }^{23-26}$ of the 11- or 13-item Physical Activity Scale for individuals with Physical Disabilities (PASIPD). Double labeled water was used as criterion in one study ${ }^{23}$, whereas an activity monitor was used as criterion in another study ${ }^{25}$. Two studies investigated properties of the 11 item PASIPD 24,25. Because it was not reported if there were missing items and if there were missing items, how they were handled, the methodological quality was rated as fair for these two studies. Combining methodology and outcomes, best evidence synthesis for the 
PASIPD shows 1) strong levels of positive evidence for content and structural validity, 2) moderate negative evidence on criterion validity, 3) limited negative evidence on hypothesis testing and 4) strong negative evidence on internal consistency.

\section{PARA-SCI}

The criterion validity, content validity, construct validity (hypothesis testing) and reliability (test-retest) were examined for the Physical Activity Recall Assessment for People with Spinal Cord Injury (PARA-SCI) in four studies ${ }^{23,27-29}$. The methodological quality of one reliability study ${ }^{28}$ was rated fair resulting in a limited level of positive evidence for reliability (ICC total activities $=0.79$ ). There is limited negative evidence on hypothesis testing ${ }^{27,29}$, a strong level of positive evidence for criterion validity ${ }^{23,28}$ and a moderate level of positive evidence for content validity ${ }^{28}$. The PARA-SCI has not been evaluated for structural validity (construct) and internal consistency (reliability).

\section{LTPAQ-SCI}

Only one study evaluated the Leisure Time Physical Activity Questionnaire for people with Spinal Cord Injury (LTPAQ-SCI) on construct validity (hypothesis testing) and reliability (test-retest) ${ }^{30}$. The correlation between the total score of the PARA-SCI and the PARA-SCI LPTA scale was 0.46. Therefore there is moderate positive evidence on hypothesis testing. The ICC's of the different intensity scales of the LPTA varied between 0.62 (moderate intensity) and 0.93 (heavy intensity). There is a limited level of positive evidence for test-retest reliability.

\section{PAI-SCI}

One study evaluated construct validity (hypothesis testing), internal consistency and reliability (test-retest) for the Physical Activity Inventory for patients with Spinal Cord Injury (PAI-SCl) ${ }^{31}$. The evidence for hypothesis testing and internal consistency is unknown because of a poor methodology of the study and there is a limited level of negative evidence for test-retest reliability.

\section{Measurement properties of device-based instruments}

For device-based instruments only criterion validity was evaluated (table 4). For intensity assessment doubly labelled water technique was used in one study as criterion ${ }^{23}$, while the other seven studies used indirect calorimetry as a criterion. For assessment of type 
of PA, video recordings, physical activity report or machine learning algorithms were used as criteria. Double labeled water, indirect calorimetry, video recording and machine learning algorithms were considered appropriate criteria for validation of the device ${ }^{32}$.

\section{Device-based instruments measuring the intensity of activity}

Actigraph GT3X+

The validity of the assessment of the intensity of activities measured by the Actigraph GT3X+ was evaluated in three studies ${ }^{33-35}$. There were five different placements of the Actigraph at the body which were evaluated (non-dominant wrist, waist, chest, right upper arm, right wrist). For measuring the intensity of activities with the Actigraph GT3X+, there is moderate levels of positive evidence (two studies, one with fair and the other with good methodology) for validity ( $r=0.82$ and 0.93$)$ for placement at the right wrist ${ }^{33,34}$ and limited positive evidence on validity $(r=0.82)$ for placement at the nondominant wrist ${ }^{35}$. There is a limited level of negative evidence for validity $(r=0.68)$ using placement at the chest ${ }^{35}$. There are conflicting findings for the placement at the right upper arm and the waist. The quality of the methodology of the studies were rated fair to good and the correlations varied from 0.67 to $0.8734,35$.

\section{GENEActive}

In one study, the criterion validity of the GENEActive was determined for resting, folding clothes, propulsion on a motorized wheelchair treadmill at five different speeds and three different gradients ${ }^{33}$. Placement of the device at both the right upper arm and wrist was examined. The methodological quality of this study was good and outcomes positive ( $r=0.76$ and 0.88$)$. Therefore there is moderate positive evidence on validity of the GENEActive for both locations.

\section{RT3}

The validity of the waist worn RT3 accelerometer was determined for resting, wheelchair propulsion (at 3 different speeds), exercise on an arm ergometer (at 3 different speeds and workloads), and deskwork ${ }^{36}$. The methodological quality was rated as good and outcome

quality as negative (ICC $=0.64$ ), therefore there is a moderate level of negative evidence for criterion validity for the RT3 at the waist. 


\section{PAMS}

Hiremath et al. 2016 developed a Physical Activity Monitor System (PAMS), a two-axis gyroscope in combination with an accelerometer ${ }^{37}$. In the study, the criterion validity of two placements (right wrist and upper arm) was evaluated by use of indirect calorimetry as criterion during various physical activities in people with $\mathrm{SCl}$ using a wheelchair. There is moderate positive evidence on criterion validity for placements both on the right upper arm (ICC $=0.82)$ as right wrist $(I C C=0.89)$.

\section{Heartrate derived measures}

Two studies looked at HR derived measures instead of accelerometry to predict EE during PA. The Actiheart (a combined accelerometer and heartrate monitor) was evaluated in one study ${ }^{38}$. There is a moderate level of positive evidence for validity of the Actiheart when using the individual heartrate calibration option of the device in combination with the acceleration signals of the device. The found correlations with indirect calorimetry were 0.76 and 0.95 .

At the same time, a study regarding a heartrate monitor (Polar RS800RX) ${ }^{23}$, using the DLW technique as criterion, showed moderate negative evidence on validity $(r=0.68$ and 0.30) for the Polar RS800RX to predict EE during PA. Polar measures the heartbeat only, not in combination with acceleration signals like the Actiheart.

\section{Device-based instruments measuring the type of activity}

Two studies evaluated the criterion validity of the Vitaport / VitaMove. The VitaMove is the successor of the Vitaport, using the same algorithms, therefore the quality of the measurement property were taken together. With a standard protocol consisting of a series of representative daily life activities (wheelchair propulsion, non-wheelchair propulsion activities and hand biking), in a semi-natural setting, the output of the Vitaport was compared to video recordings in both adults ${ }^{39}$ and youth ${ }^{40}$. The overall agreement was $92 \%$ and the mean accuracy was $84 \%$. The methodology quality was rated good. Therefore there is a strong level of positive evidence for validity detecting the type of activities with the Vitamove.

\section{PAMS}

Hiremath et al. 2015 evaluated four test conditions for the validation of the PAMS, a combination of a two-axis gyroscope, attached to the spokes of the wheelchair and 
one accelerometer placed on the right upper arm or at the wrist of the individual who use a wheelchair ${ }^{41}$. In addition, the accelerometer placement at the wrist or the upper arm were evaluated separately. In this study, the subjects performed ten activities in a lab setting (table 2b) and executed the same ten activities in a semi structured home environment. With use of the video recordings, the overall accuracy of the placement of the PAMS at the spokes at the wheelchair in combination with the arm and wrist placements were respectively $89.3 \%$ and $88.5 \%$. Overall, there is strong levels of positive evidence for criterion validity for detecting the type of PA with the PAMS.

\section{Actigraph GT3X}

One study assessed the criterion validity of the Actigraph GT3X with use of a machine learning algorithm ${ }^{42}$. Ten different activities (table $2 \mathrm{~b}$ ) were evaluated, with a variable accuracy of individual activities between 55.0-69.3\% and an accuracy of grouped activities between 83.2-93.6\%. The methodological quality was rated fair. Therefore, there is limited negative evidence on criterion validity regarding measuring individual activities and limited positive evidence on criterion validity for measuring grouped activities with the Actigraph GT3X.

\section{Actiwatch}

The criterion validity of the wrist-worn Actiwatch with a four day physical activity record was examined in one study ${ }^{43}$. The methodological quality was rated poor because the criterion used was a physical activity report. Therefore the level of evidence is unknown for the rating of criterion validity for this device. Furthermore, the construct validity (hypothesis testing) and reliability (internal consistency) was evaluated in one other study ${ }^{44}$. There is limited positive evidence on internal consistency and construct validity for both the Actiwatch and the comparative instrument the PRO-diary.

\section{DISCUSSION}

The purpose of this review was to summarize the level of evidence for different measurement properties of instruments measuring PA in MWU and making recommendations for the selection of PA outcomes tools. A systematic literature search yielded twenty-one studies that included four self-reported instruments (questionnaires) and eight device-based instruments (accelerometers and gyroscopes). The self-reported 
instruments identified measured the intensity and duration of PA.

\section{Self-reported instruments}

We found four questionnaires, two with reasonable level of evidence, the PASIPD and the PARA-SCl, and two not, the LTPAQ-SCl and the PAI-SCl. Three questionnaires (PARA-SCI, LTPAQ-SCl, PAI-SCI) were specifically developed for persons with SCl and not tested in other populations. None of the found questionnaires were tested in youth, only in adults who use a wheelchair. Two questionnaires (LTPAQ-SCl, PAI-SCI) focused solely on leisure time physical activity.

The PAI-SCI was assessed in one study ${ }^{31}$. Because of a poor methodology of the study we cannot recommend the use of this questionnaire at this time.

Although the PASIPD showed strong levels of positive evidence for content and construct validity (structural), the estimation of physical activity energy expenditure (PAEE) by use of the PASIPD is not valid because in one study, the correlation was 0.13 between the estimated PAEE with the criterion DLW technique ${ }^{23}$. We found based on two studies ${ }^{23,25}$, moderate negative evidence on criterion validity to measure PA in daily life. Construct validation is often considered to be less powerful than criterion validation ${ }^{45}$. Therefore, it is questionable to use the PASIPD to measure PA. More research is needed to give a stronger level of evidence based recommendation for usage of this instrument.

The PARA-SCl seems valid to measure PA ${ }^{23,28}$. This is based on the number and the quality of studies evaluating measurement properties of this instrument. However, the usage of this questionnaire could only be recommended in persons with $\mathrm{SCl}$ who use a wheelchair because this questionnaire is specifically developed and evaluated in and for this population. Future research is necessary to give a more specific and evidence based recommendation on whether or not to use this questionnaire in a wider population MWU (i.e. children, other diagnosis groups rather than $\mathrm{SCl}$ only) and should focus on both the reliability (test-retest) ${ }^{28}$ and the generalizability of the PARA-SCI.

The LTPAQ-SCl is developed by use of the subscale 'leisure time physical activity' of the PARA-SCl. The structural validity (construct validity) and internal consistency (reliability) of the PARA-SCI were not evaluated, therefore we do not know the uni-dimensionality of the subscales (the LTPAQ-SCI) or the correlations between the subscales of the PARA$\mathrm{SCl}$. It is therefore questionable to use just one subscale of the PARA-SCI as a selfcontainable questionnaire (LTPAQ-SCI). In addition, the LTPAQ-SCI showed overall a low test-retest reliability correlation with activities with a low intensity while on the subscales 
of mild and heavy intensity a high correlation was detected ${ }^{30}$. This suggest that the LTPAQ-SCl is less able to measure and monitor low intensity of PA during leisure time. In addition, not all studies looking at validity of questionnaires used appropriate criteria measures, e.g. the gold standard double labelled water, direct or indirect calorimetry ${ }^{18,35}$. Based on above mentioned results, future research could compare all four questionnaires in the same group and relate them to device-based instruments measuring PA in MWU in order to know which self-reported instrument could be used the best to measure PA. According to the results of this systematic review, the PASIPD seems to be the most researched and the most promising self-reported instruments to measure PA in MWU (the PASIPD) and the PARA-SCI to assess PA in persons with $\mathrm{SCl}$ who use a wheelchair 24-29.

\section{Device-based instruments}

For the device-based instruments the criterion validity was mainly evaluated. In one study, the construct validity of the Actiwatch and reliability between the Actiwatch and PRO-diary was evaluated. Because the criterion validity is unknown; these devices will not be further discussed. The PAMS and the Actigraph GT3X are the only devices that have been evaluated on criterion validity for both the intensity level of activities and classifying the type of activities. Of the device-based instruments included in this systematic review, only the PAMS seems valid to assess both intensity and the type of PA $37,41,46$.

\section{Measuring the intensity of physical activity}

Six devices were identified for measuring the intensity of PA. The Actigraph GT3X+, GENEactiv, PAMS and Actiheart are recommended for assessment of the intensity of PA in adults who use a wheelchair $33,34,37,38$. The GENEactiv was validated in adults with cerebral palsy (CP), spina bifida (SB), spinal cord injury (SCl) and persons with scoliosis who use a wheelchair. The best wearing position seems to be on the wrist or the upper arm ${ }^{33}$. The Actigraph GT3X+ is a similar device, the same best-evidence was found, and best wearing position for this device is also at the wrist ${ }^{33,34}$. To measure the intensity of PA with the PAMS, two sensors are needed with one sensor placed at the wrist or upper arm and one at the spokes of the wheelchair. This can be complicated when the person switches wheelchairs during sports activities. A different approach is the use of HR derived outcomes. Simply using raw HR data measured with a HR monitor is not valid to predict PAEE in people who use a wheelchair. There is a large degree of inter 
individual variance in cardiovascular function and response to exercise (the HR-PAEE relationship) ${ }^{23}$. Based on HR only, the PAEE cannot be estimated properly in people who use a wheelchair ${ }^{38}$. The Actiheart, a combined accelerometer and HR monitor is proven valid to estimate the PAEE, when the individual heart rate calibration algorithm of the device is used instead of the general algorithm ${ }^{38}$. The combination of a HR monitor and an accelerometer to estimate EE is also supported by a recently published article, which evaluated the ReSense, a newly developed accelerometer with integrated heartrate monitor, in $\mathrm{MWU}$ with $\mathrm{SCl}{ }^{47}$.

No studies were identified in this review evaluating devices for measuring EE in children or young adults who use a wheelchair for daily mobility. Therefore, there is a need for studies which specifically focus on the criterion validation of devices in this population.

\section{Measuring the type of physical activity}

Five devices were identified for measuring the type of PA. Both the PAMS and Vitamove are recommended for use, detecting the type of PA in the population who use a wheelchair. The PAMS was validated in adults with $\mathrm{SCl}{ }^{41}$. A recommendation for future research is to validate the PAMS for a broader population MWU, with all kind of disabilities and especially for younger age groups. The Vitamove device showed its validity in both adults with $\mathrm{SCl}$ and youth with $\mathrm{CP}$ and $\mathrm{SB}$ 39,40.

While many studies use different instruments to report on PA in clinical populations, the vast majority of studies were conducted with individuals with $\mathrm{SCl}$, which is a highly select client group. This is a considerable bias. The developed and validated algorithms for the $\mathrm{SCl}$ population is not necessarily also recommended and generalizable for use in other MWU / diagnosis groups. There are differences in participants' metabolic response to exercise, which may be attributable to differences in body composition, spinal cord lesion level and amount of body muscle mass. These factors influences the estimation of physical activity EE. In addition, there might be variation between participants in biomechanical efficiency due to differences in wheeling experience, skill level, and strength of the muscles involved in wheelchair propulsion. The latter has a particular influence on the detection of wheelchair activities, the type of PA. Future research should therefore be focused at validating instruments for objective measurements in other diagnosis groups than just those with a $\mathrm{SCl}$.

Most of the studies in this systematic review evaluated the validity of accelerometers measuring the intensity or type of PA in a lab environment, instead of a real-life or semi- 
natural environment like the two studies of the VitaMove ${ }^{39,40}$, which makes the external validity unknown. In addition, measuring both the intensity and the type of activity in MWU has the advantage that advice regarding a healthy lifestyle can be made. It is currently unclear how much a person must be physically active for a healthy lifestyle. Wheeling $3 \mathrm{~km}$ per day for a healthy lifestyle in $\mathrm{MWU}$ with an $\mathrm{SCl}$ is recommended ${ }^{47}$, which is based on a validated algorithm identifying the type and estimation of the intensity of different activities in a lab setting, but is not yet validated for a real-world setting. Future research should focus on developing algorithms measuring both the type and intensity of physical activity of daily living outside the lab as well for development of physical activity guidelines in wheelchair users.

\section{Strenghts and limitations}

A strength of this systematic review is the use of a highly sensitive and validated search filter $(97,4 \%)$ for finding studies on measurement properties, developed by Terwee et al. (2009) ${ }^{13}$. The use of a validated search filter also ensures the reproducibility of the search methods.

While the COSMIN checklist was originally developed for self-reported instruments ${ }^{19}$ and not for performance outcomes, it is commonly used for reviews looking at measurement properties of the latter ${ }^{48,49}$. For future research, there is a need for a valid tool to critically appraise methodological quality of measurement outcomes. In addition, many studies in this systematic review have not provided a clear description of how missing items were handled in the analysis. This means that the study received a lower score for the methodological quality of the study which ultimately influenced the level of evidence negatively.

The established inclusion criteria have proved to be a limitation of the study. We were unable to include a number of studies with good methodological and outcome quality. The Sensewear ${ }^{50-52}$ and ReSense ${ }^{47}$ are objective measurement instruments that have been evaluated in studies and are recommended for use in daily practice and for research purposes. Unfortunately, the Sensewear is no longer for sale and is not supported by the manufacturer anymore. While the ReSense has been developed and validated by a research group and is not yet available widely to consumers. Therefore we had to exclude these studies from this systematic review. In addition, we were also unable to include an article from Leving at al. ${ }^{53}$ this research group has developed and 
validated an accelerometer (Activ8), which seems a promising tool, that can detect the types of wheelchair activity and the instrument contains a feedback tool for the user of daily PA. However, they performed the validation study with ambulatory adults (who are not familiar with wheelchair use) instead of people who depend on a wheelchair in daily life and are used to and experienced in wheelchair propulsion. For that reason we had to exclude this article. Overall, the use of accelerometers to measure PA for research goals or practical implications is complicated because in a short time many different accelerometers have become available and are still being developed whose validity is often unknown.

\section{CONCLUSION}

The PASIPD seems to be the most researched and the most promising self-reported instruments to measure PA in MWU and the PARA-SCl to assess PA in MWU with $\mathrm{SCl}$. Device-based instruments that can be used for determining intensity of PA in adults who use a wheelchair are the GENEactive, Actigraph GT3X+, Actiheart and the PAMS. For measuring the type of PA, the PAMS is a valid device in adult who use a wheelchair and the VitaMove is proven valid in both adults with $\mathrm{SCl}$ as in the pediatric population MWU with SB or CP. It is important to realize that most of the instruments are restricted to measuring either intensity or the type of PA; this is important when choosing an instrument. Only the PAMS has been shown valid for assessment of both constructs.

\section{Acknowledgements}

Grant (PRO-4-03) of the Dutch Foundation Innovation Alliance (SIA-RAAK), part of the Dutch Organization for Scientific Research (NWO). 


\section{Abbreviations}

CINAHL; Cumulative Index to Nursing and Allied Health Literature

COSMIN; COnsensus-based Standards for the selection of health Measurement Instruments CP: Cerebral Palsy

CRPS; Chronic Regional Pain Syndrome

DLW; doubly labelled water technique

EE; Energy Expenditure

HR; Heartrate

HR-PAEE; Heart Rate - Physical Activity Energy Expenditure

ICC; Intraclass Correlation Coeficient;

JdG; Janke de Groot

$\mathrm{KL}$; Kristel Lankhorst

LA; Lifestyle Activity

LPA; Light Physical Activity

LTPA; Leisure Time Physical Activity

LTPAQ-SCl; Leisure Time Physical Activity Questionnaire for people with Spinal Cord Injury $\mathrm{MO}$; Michiel Oerbekke

MMC; meningomyelocele

MSE; mean signed percent error

MVPA; Moderate to vigorous physical activity

MWU; manual wheelchair users

$\mathrm{N}$; Number

NA; Not applicable

PA; Physical Activity

PAI-SCl; Physical Activity Inventory for patients with Spinal Cord Injury

PAEE; physical activity-associated energy expenditure

PAMS; Physical Activity Monitor System

PARA-SCl; Physical Activity Recall Assessment for People with Spinal Cord Injury

PASIPD; Physical Activity Scale for individuals with Physical Disabilities

r; Correlation

SB: Spina Bifida

SCl; Spinal Cord Injury

TDEE; total daily energy expenditure 


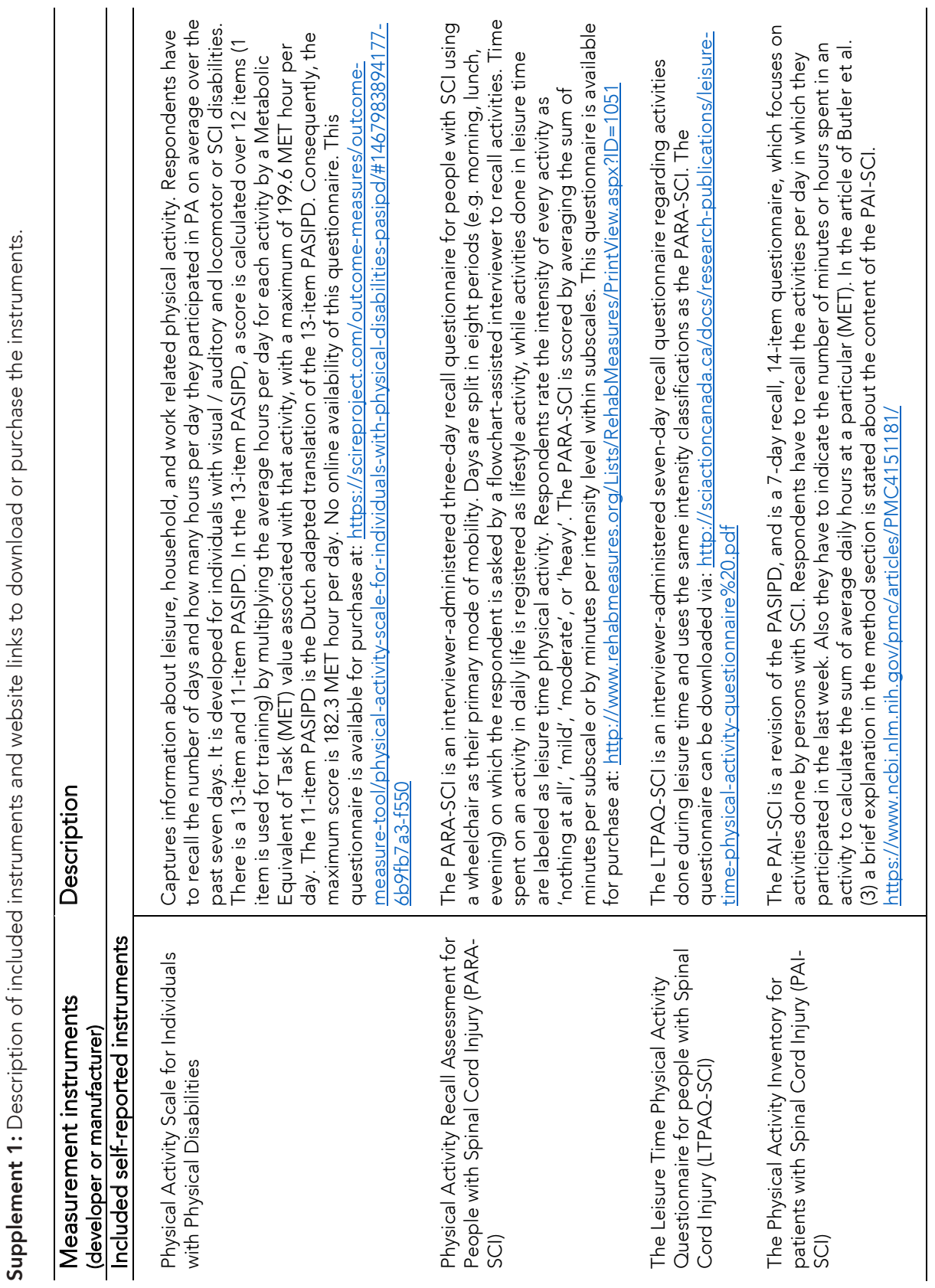




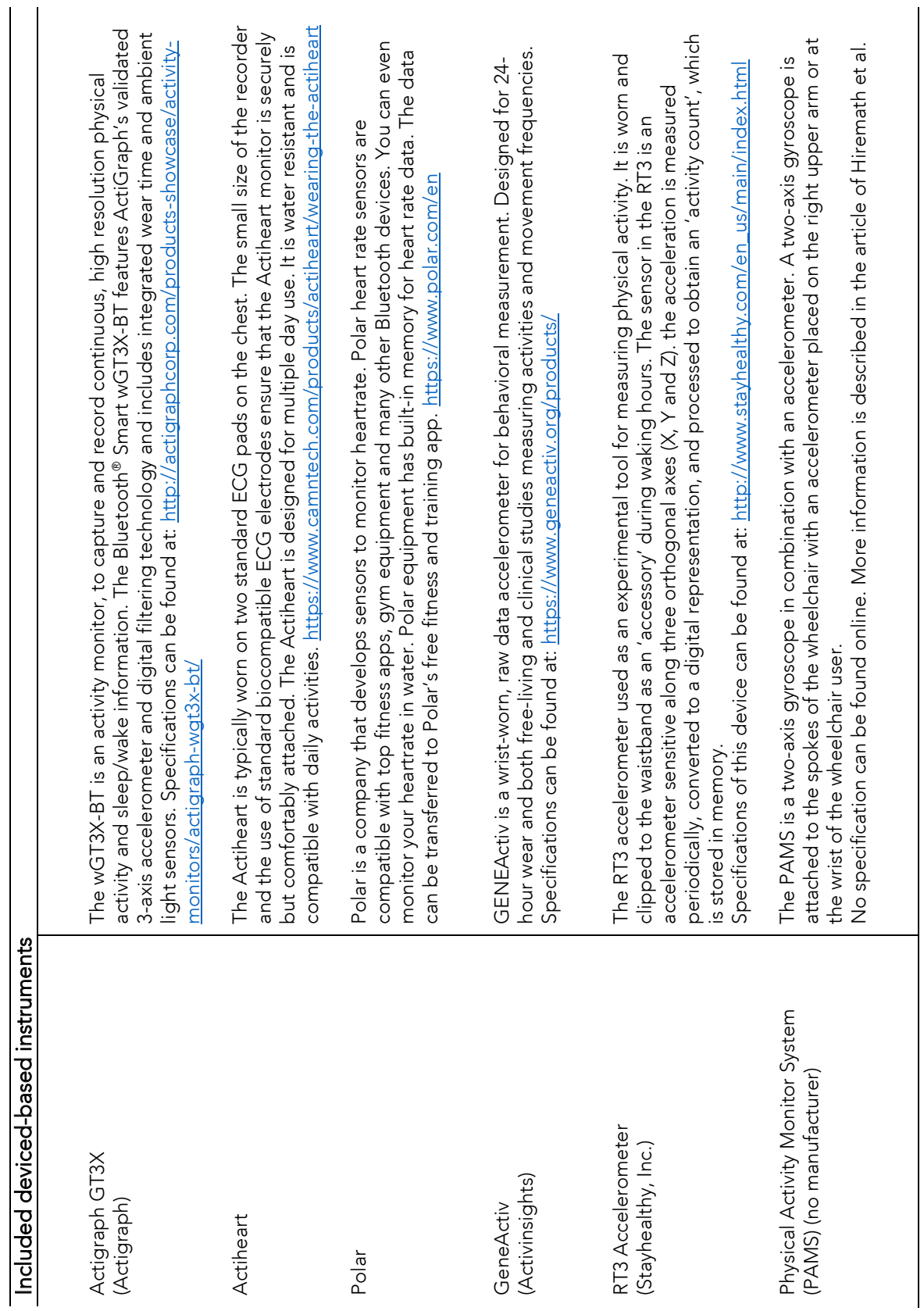




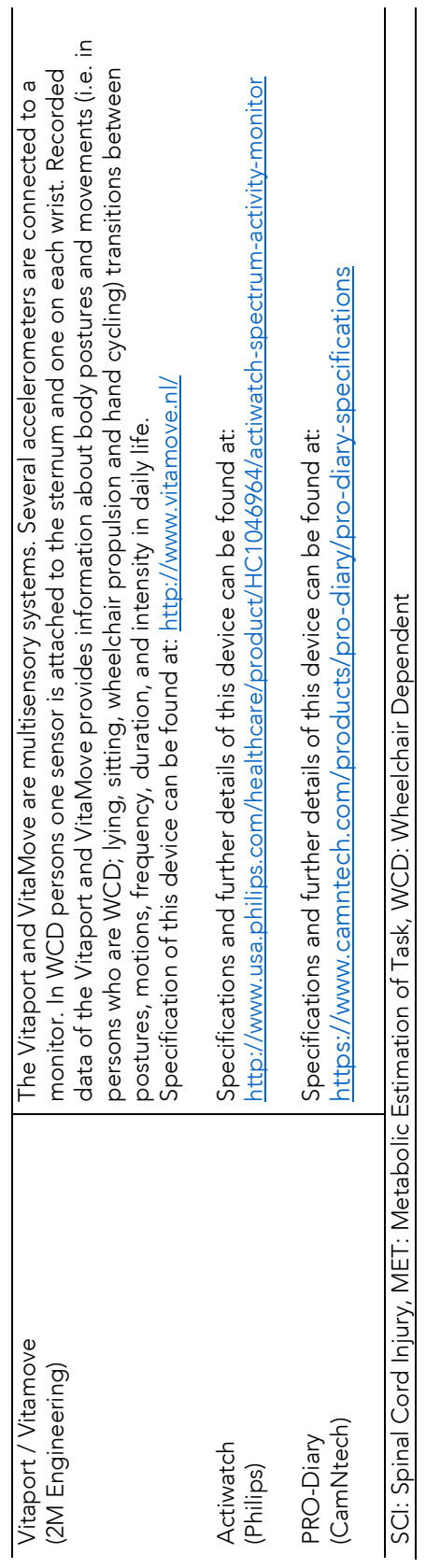




\section{REFERENCES}

1. Despres JP. Physical activity, sedentary behaviours, and cardiovascular health: When will cardiorespiratory fitness become a vital sign? Can J Cardiol 2016;32(4):505-513. doi: 10.1016/j.cjca.2015.12.006.

2. Flank P, Wahman K, Levi R, Fahlstrom M. Prevalence of risk factors for cardiovascular disease stratified by body mass index categories in patients with wheelchair-dependent paraplegia after spinal cord injury. J Rehabil Med 2012;44(5):440-443. doi: 10.2340/16501977-0964.

3. Flank P, Fahlstrom M, Bostrom C, Lewis JE, Levi R, Wahman K. Self-reported physical activity and risk markers for cardiovascular disease after spinal cord injury. J Rehabil Med 2014;46:886-890. doi: 10.2340/16501977-1857.

4. Liang H, Chen D, Wang Y, Rimmer JH, Braunschweig CL. Different risk factor patterns for metabolic syndrome in men with spinal cord injury compared with able-bodied men despite similar prevalence rates. Arch Phys Med Rehabil 2007;88(9):1198-1204. doi: S00039993(07)00384-X.

5. Durstine JL, Painter P, Franklin BA, Morgan D, Pitetti KH, Roberts SO. Physical activity for the chronically ill and disabled. Sports Med 2000;30(3):207-219.

6. Proper KI, Singh AS, van Mechelen W, Chinapaw MJ. Sedentary behaviors and health outcomes among adults: A systematic review of prospective studies. Am J Prev Med 2011;40(2):174-182. doi: 10.1016/j.amepre.2010.10.015.

7. Thorp AA, Owen N, Neuhaus M, Dunstan DW. Sedentary behaviors and subsequent health outcomes in adults a systematic review of longitudinal studies, 1996-2011. Am J Prev Med 2011;41(2):207-215. doi: 10.1016/j.amepre.2011.05.004.

8. Wilmot EG, Edwardson CL, Achana FA, Davies MJ, Gray LJ, Khunti K, Yates T, Biddle SJ. Sedentary time in adults and the association with diabetes, cardiovascular disease and death: Systematic review and meta-analysis. Diabetologia 2012;55(11):2895-2905. doi: $10.1007 / \mathrm{s} 00125-012-2677-z$

9. Kooijmans $\mathrm{H}$, Horemans HL, Stam HJ, Bussmann JB. Valid detection of self-propelled wheelchair driving with two accelerometers. Physiol Mea. 2014;35(11):2297-2306. doi: 10.1088/0967-3334/35/11/2297.

10. Maher CA, Williams MT, Olds T, Lane AE. Physical and sedentary activity in adolescents with cerebral palsy. Dev Med Child Neurol 2007;49(6):450-457. doi: DMCN450.

11. Shkedy Rabani A, Harries N, Namoora I, Al-Jarrah MD, Karniel A, Bar-Haim S. Duration and patterns of habitual physical activity in adolescents and young adults with cerebral palsy. Dev Med Child Neurol 2014;56(7):673-680. doi: 10.1111/dmcn.12394. 
12. Warms CA, Whitney JD, Belza B. Measurement and description of physical activity in adult manual wheelchair users(). Disabil health journal 2008;1(4):236-244. doi: 10.1016/j. dhjo.2008.07.002.

13. Terwee CB, Jansma EP, Riphagen II, de Vet HC. Development of a methodological PubMed search filter for finding studies on measurement properties of measurement instruments. Qual Life Res 2009;18(8):1115-1123. doi: 10.1007/s11136-009-9528-5.

14. Vet de, H, Terwee C, Mokkink, LB, Knol, DL. Measurement in medicine (3th ed.) New York: Cambridge University Press; 2014.

15. The COSMIN group. Guideline for systematic reviews of outcome measurement instruments. https://www.cosmin.nl/tools/guideline-conducting-systematic-reviewoutcome-measures/.

16. Qi X, Yang M, Ren W, Jia J, Wang J, Han G, Fan D. Find duplicates among the PubMed, EMBASE, and cochrane library databases in systematic review. PLoS One 2013;8(8):e71838. doi: 10.1371/journal.pone.0071838.

17. Bussmann JB, van den Berg-Emons RJ. To total amount of activity..... and beyond: Perspectives on measuring physical behavior. Front Psychol 2013;4:463. doi: 10.3389/ fpsyg.2013.00463.

18. Cooper RA, Koontz AM, Ding D, Kelleher A, Rice I, Cooper R. Manual wheeled mobility - current and future developments from the human engineering research laboratories. Disabil Rehabil 2010;32:2210-2221. doi: 10.3109/09638288.2010.517599.

19. Terwee $\mathrm{CB}$, Bot SD, de Boer MR, et al. Quality criteria were proposed for measurement properties of health status questionnaires. J Clin Epidemiol 2007;60(1):34-42. doi: S08954356(06)00174-0.

20. Leving M.T., Horemans H.L.D., Vegter R.J.K., De GS, Bussmann J.B.J., van der WL. Validity of consumer-grade activity monitor to identify manual wheelchair propulsion in standardized activities of daily living. PLOS ONE 2018;13(4). doi: 10.1371/journal. pone.0194864.

21. Fanchamps MHJ, Horemans HLD, Ribbers GM, Stam HJ, Bussmann JBJ. The accuracy of the detection of body postures and movements using a physical activity monitor in people after a stroke. Sensors (Basel) 2018;18(7):10.3390/s18072167. doi: E2167.

22. Mitchell LE, Ziviani J, Oftedal S, Boyd RN. A systematic review of the clinimetric properties of measures of habitual physical activity in primary school aged children with cerebral palsy. Res Dev Disabil 2013;34(8):2419-2432. doi: 10.1016/j.ridd.2013.04.013.

23. Tanhoffer RA, Tanhoffer Al, Raymond J, Hills AP, Davis GM. Comparison of methods to 
assess energy expenditure and physical activity in people with spinal cord injury. J Spinal Cord Med 2012;35(1):35-45. doi: 10.1179/2045772311Y.0000000046.

24. de Groot S, van der Woude LH, Niezen A, Smit CA, Post MW. Evaluation of the physical activity scale for individuals with physical disabilities in people with spinal cord injury. Spinal Cord 2010;48(7):542-547. doi: 10.1038/sc.2009.178.

25. van den Berg-Emons RJ, L'Ortye AA, Buffart LM, et al. Validation of the physical activity scale for individuals with physical disabilities. Arch Phys Med Rehabil 2011;92:923-928. doi: 10.1016/j.apmr.2010.12.006.

26. Washburn RA, Zhu W, McAuley E, Frogley M, Figoni SF. The physical activity scale for individuals with physical disabilities: Development and evaluation. Arch Phys Med Rehabil 2002;83(2):193-200. doi: http://dx.doi.org/10.1053/apmr.2002.27467.

27. Claridge EA, McPhee PG, Timmons BW, Ginis KA, MacDonald MJ, Gorter JW. Quantification of physical activity and sedentary time in adults with cerebral palsy. Med Sci Sports Exerc 2014. doi: 10.1249/mss.0000000000000589.

28. Ginis KA, Latimer AE, Hicks AL, Craven BC. Development and evaluation of an activity measure for people with spinal cord injury. Med Sci Sports Exerc 2005;37(7):1099-1111. doi: 00005768-200507000-00004.

29. Latimer AE, Ginis KA, Craven BC, Hicks AL. The physical activity recall assessment for people with spinal cord injury: Validity. Med Sci Sports Exerc 2006;38(2):208-216. doi: 10.1249/01.mss.0000183851.94261.d2.

30. Martin Ginis KA, Phang SH, Latimer AE, Arbour-Nicitopoulos K. Reliability and validity tests of the leisure time physical activity questionnaire for people with spinal cord injury. Arch Phys Med Rehabil 2012;93:677-682. doi: 10.1016/j.apmr.2011.11.005.

31. Butler JA, Miller T, O'Connell S, Jelinek C, Collins EG. Physical activity inventory for patients with spinal cord injury. SCI Nursing 2008;25:20-29.

32. Kelly P, Fitzsimons C, Baker G. Should we reframe how we think about physical activity and sedentary behaviour measurement? validity and reliability reconsidered. Int J Behav Nutr Phys Act 2016;13:32-016-0351-4. doi: 10.1186/s12966-016-0351-4.

33. Nightingale TE, Walhin JP, Thompson D, Bilzon JL. Influence of accelerometer type and placement on physical activity energy expenditure prediction in manual wheelchair users. PLoS One 2015;10(5):e0126086. doi: 10.1371/journal.pone.0126086.

34. Nightingale TE, Walhim JP, Thompson D, Bilzon JL. Predicting physical activity energy expenditure in manual wheelchair users. Med Sci Sports Exerc 2014;46:1849-1858. doi: $10.1249 /$ mss.0000000000000291. 
35. Garcia-Masso X, Serra-Ano P, Garcia-Raffi L, Sanchez-Perez E, Lopez-Pascual J, Gonzalez LM. Validation of the use of actigraph GT3X accelerometers to estimate energy expenditure in full time manual wheelchair users with spinal cord injury. Spinal Cord 2013;51:898-903.

36. Hiremath SV, Ding D. 3066485; evaluation of activity monitors in manual wheelchair users with paraplegia. J Spinal Cord Med 2011;34:110-117. doi: 10.1179/107902610x129111659 75142.

37. Hiremath SV, Intille SS, Kelleher A, Cooper RA, Ding D. Estimation of energy expenditure for wheelchair users using a physical activity monitoring system. Arch Phys Med Rehabil 2016;97(7):1146-1153.e1. doi: 10.1016/j.apmr.2016.02.016.

38. Nightingale TE, Walhin JP, Thompson D, Bilzon JL. Predicting physical activity energy expenditure in wheelchair users with a multisensor device. BMJ Open Sport Exerc Med 2015;1(1):10.1136/bmjsem-2015-000008. eCollection 2015. doi: bmjsem-2015-000008.

39. Postma K, Bussmann J, Sluis T, Bergen M, Stam H. Validity of the detection of wheelchair propulsion as measured with an activity monitor in patients with spinal cord injury. Spinal Cord 2005;43(9):550-557.

40. Nooijen CFJ, De Groot JF, Stam HJ, Van DB, Bussmann HBJ. Validation of an activity monitor for children who are partly or completely wheelchair-dependent. J Neuroeng Rehabil 2015;12.

41. Hiremath SV, Intille SS, Kelleher A, Cooper RA, Ding D. Detection of physical activities using a physical activity monitor system for wheelchair users. Med Eng Phys 2015;37:6876. doi: 10.1016/j.medengphy.2014.10.009.

42. Garcia-Masso X, Serra-Ano P, Gonzalez LM, Ye-Lin Y, Prats-Boluda G, Garcia-Casado J. Identifying physical activity type in manual wheelchair users with spinal cord injury by means of accelerometers. Spinal Cord 2015; 53, 772-777.

43. Warms CA, Belza BL. Actigraphy as a measure of physical activity for wheelchair users with spinal cord injury. Nurs Res 2004;53:136-143.

44. Murphy SL, Kratz AL, Zynda AJ. Measuring physical activity in spinal cord injury using wrist-worn accelerometers. Am J Occup Ther 2019;73(1):7301205090p1-7301205090p10. doi: 10.5014/ajot.2019.027748.

45. Vet dH, Terwee C, Mokkink L, Knol D. 6.4 criterion validity. in: measurement in medicine. practical guide to biostatistics and epidemiology. In: 3th ed. New York, United States of America: Cambridge University Press; 2013:159.

46. Hiremath SV, Ding D, Cooper RA. Development and evaluation of a gyroscope-based 
wheel rotation monitor for manual wheelchair users. J Spinal Cord Me. 2013;36:347-356. doi: $10.1179 / 2045772313 y .0000000113$

47. Popp WL, Richner L, Brogioli M, et al. Estimation of energy expenditure in wheelchairbound spinal cord injured individuals using inertial measurement units. Front Neurol 2018;9:478. doi: 10.3389/fneur.2018.00478.

48. Bartels B, de Groot JF, Terwee CB. The six-minute walk test in chronic pediatric conditions: A systematic review of measurement properties. Phys Ther 2013;93(4):529-541. doi: 10.2522/ptj.20120210.

49. Dobson F, Hinman RS, Hall M, Terwee CB, Roos EM, Bennell KL. Measurement properties of performance-based measures to assess physical function in hip and knee osteoarthritis: A systematic review. Osteoarthritis Cartilage 2012;20(12):1548-1562. doi: 10.1016/j. joca.2012.08.015.

50. Tsang K, Hiremath SV, Cooper RA, Ding D. Evaluation of custom energy expenditure models for SenseWear armband in manual wheelchair users. J Rehabil Res Dev 2015;52(7):793-803. doi: 10.1682/JRRD.2014.08.0188.

51. Hiremath SV, Ding D, Farringdon J, Vyas N, Cooper RA. Physical activity classification utilizing SenseWear activity monitor in manual wheelchair users with spinal cord injury. Spinal Cord 2013;51:705-709. doi: 10.1038/sc.2013.39.

52. Hiremath SV, Ding D, Farringdon J, Cooper RA. Predicting energy expenditure of manual wheelchair users with spinal cord injury using a multisensor-based activity monitor. Arch Phys Med Rehabil 2012;93:1937-1943. doi: 10.1016/j.apmr.2012.05.004.

53. Leving MT, Horemans HLD, Vegter RJK, de Groot S, Bussmann JBJ, van der Woude LHV. Validity of consumer-grade activity monitor to identify manual wheelchair propulsion in standardized activities of daily living. PLoS One 2018;13(4):e0194864. doi: 10.1371/journal. pone.0194864. 

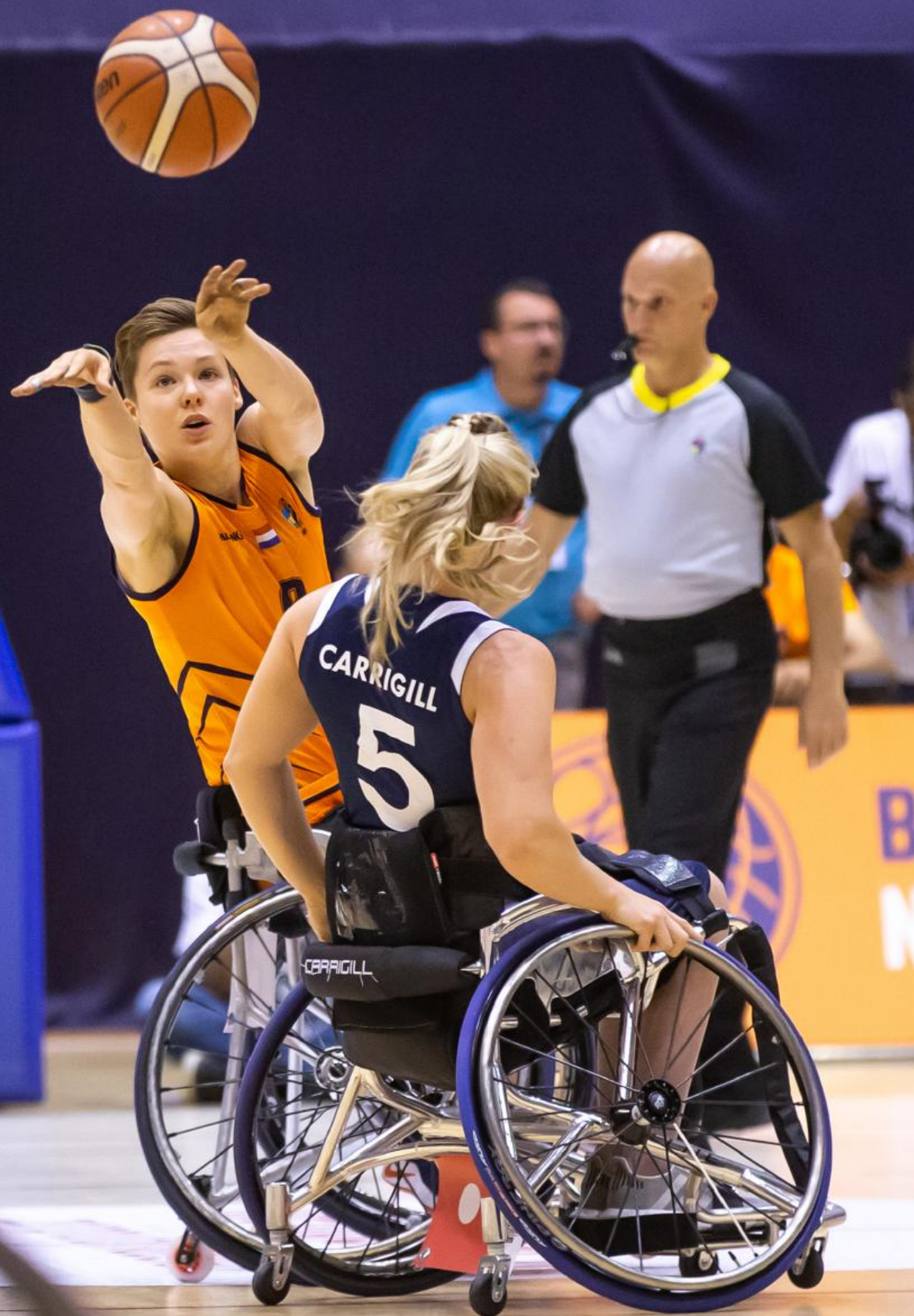


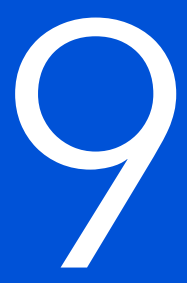

\section{General discussion}

Kristel Lankhorst 
The main objective of this study was to investigate the association of (adapted) sports participation with health-related fitness, physical activity, psychosocial health, and injuries and illness among youngsters with CDPD. A secondary objective was to develop and validate an instrument to measure physical activity in ambulatory youngsters with and without motor disability. Furthermore, based on scientific evidence, recommendations were made for instruments measuring physical activities in daily life in youngsters who use a wheelchair.

In the following paragraphs, the main findings, theoretical considerations, interpretation of results, methodological considerations, practical implementation, future perspectives, recommendations and conclusions are summarized and discussed.

\section{MAIN FINDINGS}

\section{In summary:}

Youngsters with CDPD participating at least twice weekly in (adapted) organized sports performed better on all health-related outcome parameters, compared with their non-sporting peers and those who participated in sports once a week. They had significant higher $\mathrm{VO}_{\text {2peak' }}$ achieved higher power on the muscle power sprint test (MPST), were faster on the $10 \times 5 \mathrm{~m}$ sprint test, had higher mean grip strength, and were able to jump further horizontally (Chapter 4).

Youngsters with CDPD participating at least twice weekly had significant lower waist: hip circumference ratio standard deviation scores (SDS) and lower percentages of fat mass, compared with their non-sporting peers and those who participated in sports once a week (Chapter 4).

Youngsters with CDPD participating at least twice weekly in sports were more physically active during school days (> 30 minutes per day) and during the weekend (25 minutes per day), compared to their non-sporting peers and those who participated in sports once per week (Chapter 4).

The positive association between sports participation and peak oxygen uptake was influenced by an increased physical activity (PA) level (31\%). We did not observe any significant association between sports participation and sedentary time (Chapter 4).

Participation in (adapted) organized sports at least twice weekly in youngsters with CDPD contributes to all domains of health-related quality of life and 
feelings of athletic competence (Chapter 5).

Children (10 - 12 years of age), but not adolescents (13 to 18 years of age), participating in sports reported higher feelings of social acceptance. Sports participation was strongly associated with exercise self-efficacy in both children and adolescents (Chapter 5).

Lower cardiorespiratory fitness and a higher waist circumference were associated with a higher arterial stiffness in youngsters with CDPD. The association between cardiorespiratory fitness and arterial stiffness was no longer statistically significant after adjustment of waist circumference. No association between sports participation and arterial stiffness was found (Chapter 6).

Thresholds of less than $35 \mathrm{ml} / \mathrm{kg} / \mathrm{min}$ for $\mathrm{VO}_{\text {2peak' }}$ more than $73 \mathrm{~cm}$ for waist circumference and over -0.05 units for waist circumference SDS were associated with increased arterial stiffness (Chapter 6). These results suggest that waist circumference already at normal range at the population level is associated with increased arterial stiffness. Interventions aiming to decrease body adiposity and to improve cardiorespiratory fitness may improve arterial stiffness among youngsters with CDPD.

Participation in sports at least two times a week does not pose a significant increased risk in the incidence of injury or illness per 1000 hours of PA in youngsters with CDPD compared to once weekly or no sports participation (Chapter 7).

Sports participants who participate in sports at least two times a week get injured mostly during their sporting activities, while peers who participate in sports once a week or not at all, get injured during less intense physical activities like physical education (PE) lessons, activities of daily living (ADL) or non-organized sports and play in leisure time (Chapter 7 ).

The Activ8 is a valid tool measuring the type of physical (in)activity in daily life in youngsters with typical development and peers with motor disability, and can be used to monitor and evaluate interventions targeting PA (Chapter 3).

According to current literature, the PASIPD and PARA-SCl seems the most promising self-reported instruments for measuring the intensity of PA in people who use a wheelchair (Chapter 8).

The GENEactive, Actigraph GT3X+, Actiheart and the PAMS, showed positive criterion validity to measure the intensity of PA in people who use a wheelchair. 
For measuring the type of PA the PAMS and VitaMove are suitable, showing both good evidence for criterion validity. The practical usage of each of these instruments in daily life varies (Chapter 8). Use of a heart rate monitor with individual calibration function, is an useful, easy and inexpensive option.

\section{Theoretical considerations}

The associations studied in this thesis are based on the model of Shephard \& Bouchard', as described in the general introduction in which associations between health-related fitness and morbidity and mortality are assumed. In children and adolescents, however, these life-threatening diseases or behaviors are not directly addressed by the model. Our underlying motivation therefore is the prevention of life-threatening diseases at a later age by intervention at an earlier age. At the start of this study, our knowledge of preventive strategies such as increasing physical activity by regular sports participation among youngsters with physical disability or chronic disease (CDPD) was limited. Figure 1 is a schematic representation of the relations studied in this thesis, based on the model of Shephard \& Bouchard for adults, but adapted for children and adolescents. 


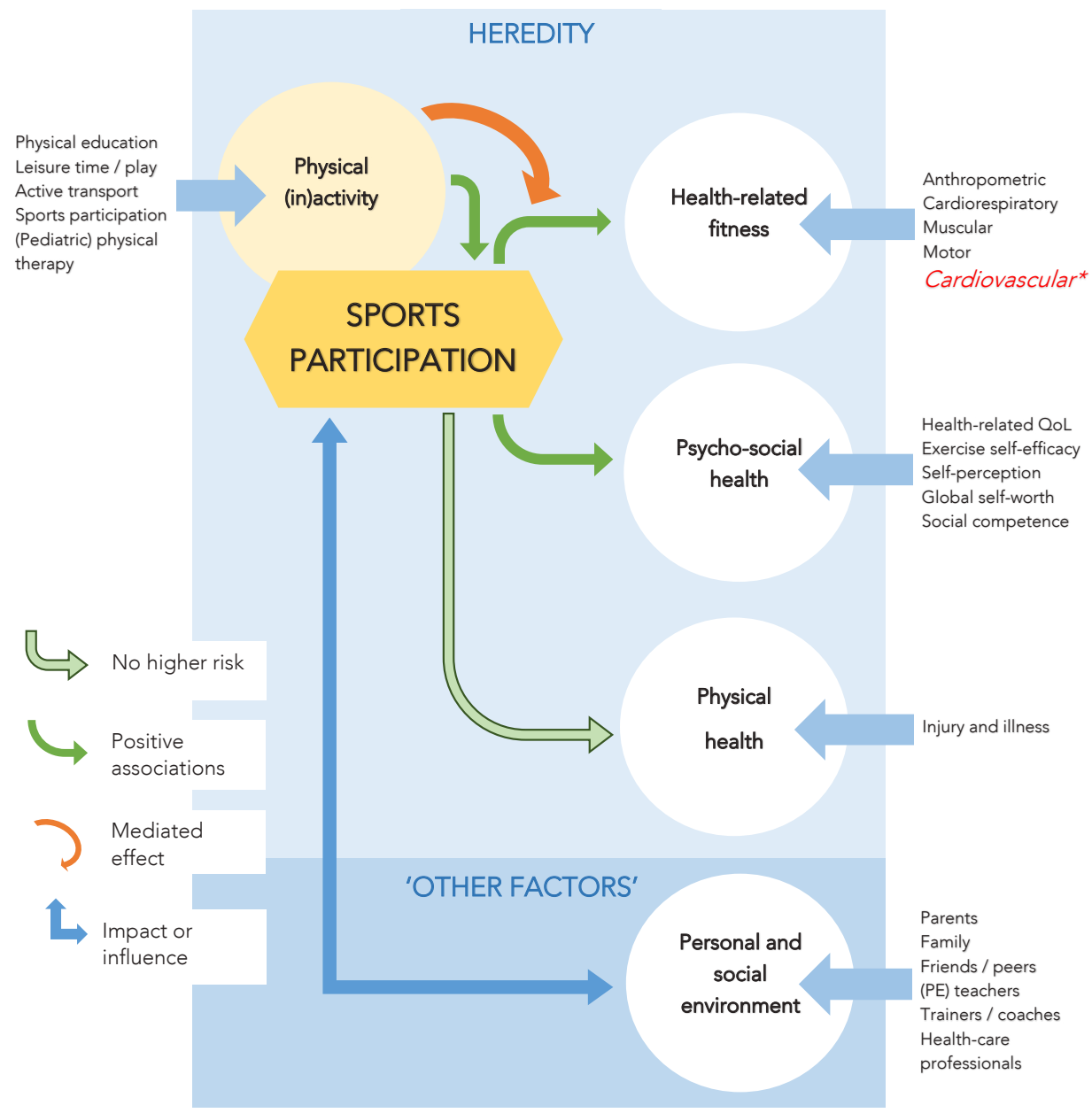

Figure 1: Schematic representation of the relations studied in this thesis.

*Sports participation was not associated with cardiovascular outcome parameters (arterial stiffness). QoL: quality of life: PE: physical education. 


\section{INTERPRETATIONS OF RESULTS}

\section{Study population}

The population studied in the current thesis is heterogeneous, based on medical diagnoses. Therefore, the population enrolled in this study cannot be representative of the total population of children and adolescents with chronic diseases or physical disability (CDPD) in the Netherlands. National data show pulmonary diseases (mainly asthma) to have the greatest prevalence (13.7\%), followed by neurological diseases (8.9\%)2. Almost half of the participants studied in this thesis have a neuromuscular disorder, i.e. cerebral palsy (CP) or spina bifida (SB), the largest patient group seen within pediatric rehabilitation medicine.

$\mathrm{CP}$ and $\mathrm{SB}$ are permanent disorders in terms of the development of movement and posture. Signs and symptoms of these disorders vary across individuals and for each diagnosis. Individuals with neuromuscular disorders often experience problems with daily functioning, having poor fundamental movement skills due to muscle impairments. These muscle impairments result in reduced strength and coordination in affected muscles, so more time is needed to complete motor tasks ${ }^{3,4}$. In addition, problems with cognitive functioning and mental health are common in individuals with $\mathrm{CP}$ or SB5. In this thesis, all children and adolescents with a CDPD, independent of their diagnosis or level of mobility (except those using a powered wheelchair) were included. The Functional Mobility Scale (FMS) ${ }^{6}$ was used to classify participants, based on their level of mobility. To specify the functional mobility in more detail in youngsters with neuromuscular disorders (CP and SB), the Gross Motor Function Classification System (GMFCS) $^{7,8}$ was used for participants with CP and the adapted Hoffer classification ${ }^{9}$ for participants with SB. Youngsters with CP or SB in this thesis were all rated with a FMS score of 6 (able to walk independently on all surfaces) or 5 (able to walk independently on level surfaces but requiring a rail for stairs). From the perspective of functional mobility, individuals with these scores are the least restricted in daily life due to their neuromuscular disorder. All other participants with a chronic disease or disability were rated with a FMS score of 6 .

We recruited participants via schools for special education, pediatric physical therapy practices, (adapted) sports organizations and via the outpatient clinic of the Wilhelmina Children's Hospital (Utrecht, the Netherlands). As described in the general introduction, next to the HAYS study, the Sport-2-Stay-Fit (S2SF) study ${ }^{10}$ was performed concurrently by our research group. The S2SF study was executed within schools for special 
education, at both primary and secondary level. Some participants of the S2SF study also participated in the HAYS study. This selective approach of recruitment may have resulted in a population that is more in line with the population of pediatric rehabilitation medicine, rather than with the total population of youngsters with CDPD in the Netherlands². Interestingly, it was easier to recruit sports participants with CDPD for participation in this study than non-sporting peers. It is likely that youngsters who are physically active through sports participation are more attracted to a study that focuses on sports which are familiar to them, than their peers who do not have (positive) athletic experience. Moreover, it was easier to approach the sporting group for participation, contacting sport organizations being a simple and effective way of recruiting potential sporting participants.

\section{Sports participation, health-related fitness and physical activity}

Youngsters with CDPD participating in organized sports at least twice weekly benefit optimally from the positive effects of sports ${ }^{11}$. Youngsters with CDPD participating at least twice weekly in sports were more physically active during school days ( $>30$ minutes per day) and during the weekend ( 25 minutes per day) than their non-sporting peers and those who participated in sports once a week. Physical activity was a strong predictor of aerobic fitness, whereas total sedentary time had no effect on peak oxygen uptake. In particular, youngsters with CP or SB with muscle weakness showed in our study that they can achieve $\mathrm{VO}_{\text {2peak }}$ values within the normal range for healthy Dutch peers. In addition, anaerobic fitness, agility and strength measurement outcomes were significant higher in sports participants compared to their non-sporting peers and those who participated in sports once a week; organized sports contributes to better muscular function (Panel 9.1: health-related fitness and muscular function).

Parallel to the HAYS study, the S2SF study was performed by our research group, measuring similar outcome measures. The main objective of the S2SF study was to investigate the effects of a short-term high-intensity interval training (HIIT) followed by a school-based sports program once a week for six months in youngsters with CDPD. The HIIT program (8 weeks) resulted in improvements in agility, anaerobic and aerobic fitness, while $\mathrm{VO}_{\text {2peak }}$ levels remained stable. These results indicates that sports participation once a week (at school) is sufficient to maintain, but insufficient to improve health-related fitness. These outcome, indicate that a frequency of at least twice a week is needed to achieve improvement on $\mathrm{VO}_{2 \text { peak }}$. 


\section{Panel 9.1: health-related fitness and muscular function}

Joris is a 14-year old boy diagnosed with spastic, hemilateral cerebral palsy (CP). According to the GMFCS, he is classified as Level I. He walks and runs independently at home and at school (FMS 6). He is a very talented soccer player. At the time he participated in this research, he was playing in the Dutch CP Football talent team. He began training more intensively and more frequently, from 2 to at least 5 times per week in the past year. He showed progression in his football skills and he was also less restricted by his condition. He became stronger, both in muscle function and fitness level, which seemed like positive (side) effects.

As CP Football is a team sport, classification aims at ensuring fairness with regard to the impact of impairment between both teams. To accomplish this, the players are allocated to sports classes depending on how much their impairment impacts performance in their sport. CP Football has 3 classes; FT1, FT2 and FT3. For example, in FT1, the condition limits sport performance more than FT2 and FT3. To ensure a fair game between teams, each team has to have one FT1 player on the field at all times and is not allowed to have more than one FT3 player on the field.

Unfortunately, Joris' progression resulted in a less restricted classification for CP Football (from FT2 to FT3), which meant that, due to his positive progression in terms of aerobic and anaerobic performance, he became 'too good'. There was no place for another FT3 player in the team. Consequently, he was not selected for the CP Football talented team for the next year.

It is well known that being overweight or obese in childhood is associated with a higher risk of cardiovascular diseases, various types of cancer and premature death in adulthood ${ }^{12-14}$. The percentage of typically-developing youngsters aged 12 to 18 with overweight (13.8\%) and obesity (2.3\%) increased significantly between 1990 and 2017, among both Dutch boys and girls15,16. Of Dutch youngsters with CDPD, 14\% of the children aged 4 to 12 years and 19\% of the youngsters aged 12 to 18 years are overweight or obese17. The increasing trend and high percentages is alarming for their future health, for both typically developing youngsters and their peers with CDPD. As a result of the S2SF study, youngsters with CDPD who participated in sports once a week for 45 minutes had lower percentages of fat mass after six months ${ }^{10}$. In our study, youngsters with CDPD participating in sports at least twice weekly had a significant lower waist-hip circumference ratio score and a lower percentage of fat mass than their non-sporting peers and those who participated in sports once a week, while those with a pathological gait pattern had a significantly higher percentage of fat mass and a higher waist-hip circumference ratio compared to peers with typically gait pattern.

These results indicates that sports participation once per week already contributes to a 
lower percentage of fat mass, as the S2SF study shows. However, sports participation of at least twice a week is even better as it contributes to multiple health-related outcomes (aerobic and anaerobic fitness, physical activity level, agility and strength), especially for those youngsters with a pathological gait pattern.

\section{Psychosocial health}

Besides the positive associations with health-related fitness and PA, organized sports participation at least twice weekly resulted also in better psychosocial health outcomes; 1) a better health-related quality of life, 2) feelings of athletic competence, 3) greater feelings of social acceptance and 4) greater exercise self-efficacy ${ }^{18}$.

\section{Panel 9.2: Psychosocial health}

"Participation in sports gives me more self-confidence, self-compassion, and I am more confident in life." Ellis van Loenhout, World Champion Paralympic road cyclist, 2014.

In the S2SF study, no improvements were observed within the psychosocial domain from a school-based sports program once a week for six months ${ }^{19}$, which indicates that school-based sports may have different impacts than sports club participation. In the S2SF study, a school-based sports program was chosen, to remove possible barriers to sports participation. The underlying thought was that a school setting offers a familiar environment with supportive and well-educated trainers, acceptance, and no additional transportation to and from a sports club. In addition, school-based interventions are thought to be the most universally applicable and effective way to counteract low PA and fitness, since children and adolescents spend at least half of their waking hours in this setting ${ }^{20}$. Improvements in anaerobic fitness and reduced fat mass were observed in the S2SF study, while no improvements were observed within the psychosocial domain. There is a possibility that, despite the benefits of school-based sport, sports participation at a club might possess components that engage children in a different way than do school-based sports ${ }^{21}$. For example, children playing in sports teams may have more intrinsic motivation than do youngsters who play at school for rewards or recognition from others ${ }^{22}$. Besides, children who play sports in school settings may be more prone to discontinue in sports participation after graduation because they have more barriers in adapting to PA participation to a new setting ${ }^{23}$, so school-based sports may not be the 
solution to overcoming all barriers. This outcome emphasizes even more the importance of finding other ways to enable organized sports participation for youngsters with CDPD. One possibility may be practicing individual sports which are less hindered by barriers and are therefore more easy to participate in than team sports for youngsters with CDPD. In addition, the advantage of participation in individual adapted forms of sports is that youngsters can better focus on their abilities rather than their inabilities ${ }^{24}$. However, involvement in a team sport at a sports club, and interaction with others in this context, allows youngsters to develop their self-concept, especially related to the physical and social domains. Sports club and team-based sports participation may therefore have different impacts on psychosocial health outcomes than do individual-based sports ${ }^{18}$. It is my recommendation to investigate the influence of team versus individual sports participation on psychosocial health.

\section{Cardiovascular health}

In our study, sports participation was positively associated with all health-related fitness outcomes, with the exception of cardiovascular health (arterial stiffness) ${ }^{11,25}$. This was the only outcome parameter as a sub-domain of health-related fitness where sports participation had no direct association (Figure 1). Poor cardiorespiratory fitness (a low peak oxygen uptake) and higher waist circumference were associated with increased arterial stiffness (higher pulse wave velocity (PWV)) among youngsters with CDPD. Better cardiorespiratory fitness is related to more compliant arteries, whereas lower levels of body adiposity could not explain the relationship in our study ${ }^{25}$. Presumably, hereditary factors, social environment and lifestyle behavior (nutritional intake) had an impact on this relationship. These (sub)domains, according to the model of Shephard \& Bouchard, were not investigated in this study. A systematic review on dietary and dietary measures nutrients as monotherapy for arterial stiffness showed that adding omega- 3 to the diet resulted in a decrease in $\mathrm{PWV}^{26}$. At the same time, salt restriction, soy-rich food, moderate alcohol consumption and smoking cessation were also associated with a decreased PWV27. It should be noted, however, that alcohol use or smoking behavior was almost non-existent in youngsters in our research. Furthermore, social and personal environmental and hereditary factors such as: 1) secondhand smoking, 2) paternal hypertension, and 3) maternal obesity turned out to be additional, independent risk factors forhigherPWV. The aforementioned hereditary factors, personal and environmental variables, not investigated in this study, are recommended for future research. 
Knowledge of the impact of environmental variables and heredity will provide insight and help support the development of specific (behavioral) interventions for both children and their parents to prevent early arterial stiffness. In addition, it is important to determine the optimal training regime in terms of frequency, duration, and intensity (dose-response relationships) of sport activities to elicit favorable effects on arterial stiffness. Currently, the results of this dissertation and other studies indicate that interventions aimed at reducing body adiposity (i.e. diet and facilitating healthy nutrition habits) and improving cardiorespiratory fitness (exercise) may improve arterial stiffness among youngsters with CDPD.

\section{Physical health}

From the literature, we know that an unfavorable body composition, low levels of PA and/or physical fitness levels are related to poor fundamental movement skills ${ }^{28-30}$ and increased injury levels ${ }^{31}$. Sports participants in the HAYS study scored better on all anaerobic tests than their non-sporting peers and those who participated in sports once a week ${ }^{11}$. Fundamental movement skills are required to achieve optimal performance on anaerobic tests ${ }^{32}$. In our study, sports participation at least twice weekly does not pose a higher risk of (sports)-related injuries in youngsters with CDPD ${ }^{33}$, which probably indicates that fundamental movement skills are well trained and developed in youngsters who participate in sports at least twice weekly. In addition, poor fundamental movement skills negatively influence the degree of physical activity ${ }^{34}$. The sporting participants in our study were more active overall during the weekend and schooldays than their non-sporting peers or those who participated once a week, which contributes to a healthy lifestyle.

The fear of (sports-related) injuries in youngsters with CDPD and their parents is baseless, while even youngsters who do not participate in sports get injured. Athletes who participate in sports at least twice weekly get injured mostly during their sporting activities, while peers who participate in sports once a week or not at all get injured during less intense physical activities, such as during physical education lessons, $A D L$ or non-organized sports and play in leisure time. Fortunately, the social impact (severity) of (sports-related) injuries was limited overall, but must still be an important focus for further research, with focus on the prevention of (sports-related) injuries. It would be interesting to investigate the association between incidence of injury and health-related fitness and PA outcomes in order to gain insights into the exact mechanisms and risk of 
injuries. Follow-up research with the HAYS dataset is therefore recommended. With that knowledge, sports injury prevention training programs could be developed, including strategies that target all known risk factors for (sports-related) injury in youngsters with CDPD.

\section{METHODOLOGICAL CONSIDERATIONS}

\section{Study design}

The design of the HAYS study was a cross-sectional one ${ }^{35}$, which fitted the aim and allowed us to include a large and diverse group within an age range of 10 to 18 years and with varying medical diagnoses. However, the cross-sectional design limited conclusions on causality. Itmaybethat thosewho are physically fitandathleticallycompetent experience a better quality of life, or those who feel more socially accepted are more likely to participate in (adapted) organized sports. A longitudinal design would have allowed analyses focusing on underlying pathways.

The crudeness of the measure of sports participation can be seen as a study limitation. In our study, no association between sports participation and arterial stiffness was found while all other outcome parameters of health-related fitness were positively correlated $^{11}$. It may be that sports participation as a dichotomous outcome measure has insufficient distinctive capacity (statistically) to identify beneficial effects on arterial stiffness. Therefore it seems worthwhile to investigate the relationship between the objectively measured physical activity and arterial stiffness.

The number of years of sports participation, as well as the duration, intensity and type of the sports activities, has not been measured. The positive associations that we have found between sports participation and psychosocial health parameters ${ }^{18}$ could be further explored with this sports-specific additional information. It may be that team sports have different impacts on psycho-social health parameters than do individual sports, for example ${ }^{34}$. Furthermore, the duration of sports participation could influence the athletic skills level of an individual which could be preventive of getting injured. However, pre-puberal children often change their type of sports activity, which makes it more complex to assemble a complete picture and develop insight into the long-term effects of sports.

\section{Outcome measures}

We used an extensive set of measurements to gather data in different domains of health, 
according to the model of Shephard \& Bouchard'. We used physical examination, measurement instruments to objectify PA levels and health-related fitness, digital questionnaires and telephone-based interviews to identify injuries and illnesses, during one calendar year. All measurement instruments and performance tests used in this study are feasible, easy to use, and proven valid and reliable in youngsters with CDPD. In addition, the measurement outcomes of all tests from the current study can be used as a reference, which makes it possible to put the test outcome of our young patients or sports participants with CDPD in perspective with their sporting and non-sporting peers. PWV is a good marker of vascular wall stiffness and an important predictor of cardiovascular disease ${ }^{36}$. From this perspective, it can be concluded that measurement of arterial stiffness has the potential to be used for additional screening of early signs of vascular dysfunction or arterial stiffness, especially in children and adolescents at risk (overweight and obesity) of developing cardiovascular diseases ${ }^{37}$. The measurement of the PWV by use of the Arteriograph is non-invasive, safe, inexpensive, feasible in children and adolescents and quick to implement in preventive health examination 36,38 .

Large-scale observational studies have used objective monitoring of PA by accelerometry. This technical innovation has substantially increased our knowledge of PA and how PA is associated with health outcomes in the young. However, interpreting PA intensity data from accelerometry during childhood and adolescence is challenging. Methodological issues include the definition of PA intensity thresholds (predictive equations for metabolic equivalent of tasks (METs) with an algorithm specified for children and adolescents with (DPD), and there is no consensus on the most appropriate PA intensity thresholds to use when measuring children's PA by accelerometry $^{39,40}$. For these reasons, in our research we measured the type (lying, sitting, standing, walking, running, cycling) and duration of PA with accelerometry, instead of PA intensity. Accelerometers to measure the type of PA were available and validated in healthy adults, in diverse patient groups and in adults who use wheelchairs for daily mobility ${ }^{41}$. No valid accelerometer for measuring the type of PA was available for use in youngsters with or without motor disability at the start of this study. To measure the type of PA in daily life, we validated the Activ8 for use in youngsters with and without motor impairment ${ }^{42}$. It is a major strength of this dissertation that there is now a validated device for use in a broad pediatric population, with and without motor impairment.

With reference to the model introduced at the beginning of this discussion, the impact of the social and physical environment, lifestyle behaviors and personal attributes 
have not been investigated in this thesis. These are defined as 'other factors' in the model of Shephard \& Bouchard'. Each individual is born with a certain set of genes, grows up in a certain environment and develops a certain behavior pattern ${ }^{43,44}$. Every individual is part of different systems (parents, family, friends, peers, classmates, sports mates, (PE) teachers, trainers or coaches, health-care professionals etc.) and interacts in various environments (home, playground, school, sports club, rehabilitation center etc. ${ }^{43,44}$. Every system or environment evokes certain behaviors, and each individual will respond in their own manner. Sports participation (from recreational to elite level) has positive and negative consequences, with different experiences and beliefs, for youngsters and their parents. In the HAYS study, discrepancies in beliefs between youngsters and their parents were evident (see Panel 9.4). Negative experiences or beliefs of the child itself, their parents or social environment can limit support or participation in sports. Optimal understanding of the impact and influence of personal and environmental factors by quantitative research is needed for optimal support and guidance of PA and sports participation.

\section{PRACTICAL IMPLEMENTATION}

We were able to use and analyze objectively PA data measured with the Activ8 in $75 \%$ of the participants. Missing data were mainly due to technical problems with Activ8. Participants wore the Activ8 24/7, even during swimming and bathing activities. However, the Activ8 is not waterproof and, although we secured it to avoid water damage (waterproof and skinfold tape), this may have resulted in technical problems. Furthermore, the study of Kotte et al. shows that the feasibility of using the Activ8 in pediatric physical therapy practice is limited ${ }^{45}$, due to 1) difficulties applying an accelerometer, 2) reluctance of children and their parents to wear an accelerometer and 3) technical difficulties in reading and charging the accelerometer, which were considered complicated by therapists. The study of Kotte et al..$^{45}$ and Pettee Gabriel et al. ${ }^{44}$ emphasizes the gap between feasibility of accelerometry and technology in general for research purposes and their implementation in rehabilitation to achieve therapeutic goals.

Within sports, from recreational to elite level, portable technology, like fitness trackers, heart rate monitors, GPS devices and smart watches, for optimizing sports performance is usual ${ }^{46}$. In addition, big data are increasingly being used for health care purposes $^{47}$. Newtechnological innovations, if applied correctly, can provide insights into an 
individual's performance, both in research and in practice, that we were previously unable to gain. In addition, technology, such as the use of digital resources, can contribute to more effective collaboration between different disciplines. As an example, the systematic measurement of injuries and illnesses during three years was complicated, inefficient and time-consuming in this thesis ${ }^{33}$, which was partly due to the limited digital resources available for us to use. At athlete level, injuries and illnesses are often registered in an online system by the athlete, to which the trainer or coach has access. If such online registration systems were accessible for recreational sports participants or patients, for health-care professionals and for researchers working in the sports domain, the collected data could contribute to improving care and sports performance, and could be used for epidemiological research purposes. Unfortunately, duetoobstaclesindataprotectionandfunding, toomanyopportunitiesarestill being missed to realize innovation and to implement improvements in health care more widely ${ }^{48}$.

\section{FUTURE PERSPECTIVES}

\section{Sports specific barriers and opportunities}

In the Netherlands, we have many different organizations committed to making sports participation possible for youngsters with CDPD. There is an increasing focus on sports performance of athletes with disabilities up to and including Paralympics. More and more people with disabilities can participate in local sports events and competitions that are being organized in municipalities. Adapted and inclusive sports participation is growing; running events are nowalso accessibletohand cyclists, forexample. However, each municipality has its own local policies, so there are local differences in how much attention and financial help there is to support organized sports participation for individuals with a disability. To enable organized sports participation for youngsters with CDPD in their own home environment, a number of developments are needed at sports clubs (i.e. facilities, guidance and support), and there is a need for acceptance by society (i.e. peers, parents and trainers) and for family support (i.e. attitude, active involvement and transportation) $)^{49}$. To indicate specifically what parents of children with a disability encounter in society, Panel 9.3 provides an overview of a number of frequently voiced experiences by parents of children who participated in the HAYS study. It is important to mention that it was not an official part of the HAYS study to investigate barriers and opportunities with regard to sports participation. Nevertheless, thestatements 
correspond to the results of recent qualitative research studying facilitators and barriers to performing activities and participation in children with cerebral palsy from the caregiver's perspective ${ }^{49}$.

Panel 9.3 emphasizes the importance of a multidisciplinary approach, with professionals from the medical, social, sport and educational domains working together for youngsters with CDPD to overcome barriers and discover the possibilities of inclusive sports participation.

\section{Panel 9.3: an overview of a number of sport-specific experienced barriers with brief recommendations}

1) Adapted sports aids, prostheses, wheelchairs and hand bikes are sometimes required for participation in sports activities safely and without additional risk of injury. Access to sports aids is limited particularly for children and adolescents, because they are still growing: a tailor-made prosthesis does not last long and is therefore quite expensive. Financial arrangements for sports aids, prosthesis, wheelchairs and hand bikes differ per municipality, may often change and may be ambiguous. It often happens that a device for sports is not reimbursed, because another similar device has already been purchased for use in daily life.

2) There are a number of obstacles that restrict the accessibility of (adapted) sports. The accessibility of sports locations and forms of sport can be limited, but can sometimes be increased by simple adjustments, like an extra handrail or wheelchair-friendly pavement.

3) Information about suitable sports is often hard to find, and the right guidance for both accessibility and suitable sports can sometimes be decisive. Neighborhood teams and sports coaches can raise awareness of the range of sports available locally. Sports providers could be more open to youngsters with a chronic disease or disability and search together with them and their parents for opportunities to solve existing problems.

4) The significance of sports for health should receive more, and sometimes earlier, attention in treatment and/or rehabilitation. Professionals working in rehabilitation medicine should create awareness of the benefits of sports participation for health from the first stage of the rehabilitation.

5) Insufficient knowledge and expertise of sports coaches and trainers in the field of guiding children with a chronic disorder, especially at the recreational level of sports participation, limits access. It is therefore important to implement evidence-based information through workshops within a sports organization. 


\section{Regular and adapted organized sports participation}

Fortunately, steps are being taken at policy level to improve, support and facilitate inclusive sports participation for this vulnerable group of children and adolescents. Recently, there have been three main developments in the Netherlands.

Firstly, a lifestyle intervention is included in the health insurance ${ }^{50}$. Proven effective lifestyle interventions focusing on healthier food and eating habits, more exercise and, if necessary, individual psychological treatment to support behavioral change are included. Secondly, the Dutch coalition agreement stipulates that there must be a national prevention strategy that focuses on reducing smoking and preventing smoking at a young age, obesity in childhood and adolescence and excessive alcohol consumption ${ }^{51,52}$. There were already a number of youth projects; 'Jongeren op Gezond Gewicht', 'Gezonde school' and 'Gezonde schoolkantine', which are being strengthened and/or accelerated by this prevention accord ${ }^{53}$. Thirdly, based on the coalition agreement 'Trust in the future', the sports accord was established in 201854. The Ministry of Health, Welfare and Sport (VWS), Association of Sports and Municipalities (VSG), Association of Dutch Municipalities (VNG) and Dutch Olympic Committee*Dutch Sports Federation (NOC*NSF) are the strategic partners of this national sports accord. Attention is paid to diversity in the composition of sports associations, development of open sports clubs and accessible access to sports for children. More than 150 parties are involved in successfully implementing this sports accord in the Netherlands. To achieve this, the strategic partners have formulated sixambitions, for which objectives and interventions have been worked out. The ambitions are: 1) integration of sports and exercise, 2) establishing sustainable sports infrastructure, 3) vital sports and exercise organizations, 4) developing a positive sports culture, 5) teaching movement skills from an early age, and 6) elite athlete that inspires. One part of the ambition is to have more children comply with exercise guidelines and to reverse the downward spiral of children's competence in fundamental movement skills. The ambition is targeted at all children between the ages of 0 and 12 years. In terms of taking sufficient exercise, there is attention to the drop-out from sports and exercise of youngsters between 12 and 18 years of age. The interventions described fit in perfectly with the findings of this thesis and subsequent recommendations for practice. In the recommendations section, two points have been highlighted and worked out specifically for youngsters with CDPD, based on the results of our HAYS study and other research. 
With these political developments, and especially from a financial point of view, there are more opportunities for professionals to promote healthy and active behavior, such as participation in organized sports, in the field of rehabilitation medicine and in the social and sports domains. The next step is the adequate implementation of proven effective intervention programs targeting an active and healthy lifestyle among youngsters with CDPD in the field of rehabilitation medicine and in the social and sports domains, and this requires a specific approach. To be effective in both the health and sports domains, health care professionals, educational program makers, researchers, neighborhood teams and sports coaches should work together ${ }^{55}$. They should bring their knowledge (scientific and experience-based) together into behavior lifestyle programs ${ }^{56}$, while neighborhood coaches can raise awareness of the range of sports available in the surroundings ${ }^{55}$.

Furthermore, educating future professionals (students) in the preventive health and sports domain could be an effective and efficient strategy for implementing innovative evidence-based tools or interventions. As an example, the research project ("What moves you ?!") which recently started focuses on the development of toolboxes for improving participation in physical activity in children with disabilities ${ }^{57}$. With that perspective, collaboration between researchers, educational program makers and future professionals from different backgrounds is important to successfully implement research outcomes into educational programs and society. RAAK-PRO and the National ScientificAgenda (NWA) promotes the quality of applied research atuniversities of applied sciences and strengthens the research capacity of the research groups involved. This is in close cooperation with the national knowledge network and professional practice ${ }^{58}$.

\section{RECOMMENDATIONS}

\section{Development of programs targeting PA and sports participation}

Youngsters with and without CDPD often do not meet the guidelines for healthy PA 59,60 but increasing physical activity is very complex ${ }^{61}$. An important finding in our study is the association between PA and age in children and adolescents with CDPD. PA levels are declining with increasing age, also observed in typically-developing youngsters. In the latter, patterns of increased physical inactivity and sedentary behavior may even track into adulthood ${ }^{62,63}$. This trend is still being researched in the population with CDPD. Low levels of PA will also result in poor fundamental movement skills and increased risk of 
overweight and of developing chronic conditions ${ }^{64,65}$. In the Netherlands, inspectors of education have found that the movement skills of primary school pupils had decreased over the past 10 years ${ }^{54}$. In addition, children with poor fundamental movement skills experience less pleasure in sports, and more frequently stand on the sidelines because they cannot catch up with their peers when playing or doing gymnastics. Consequently, the chance of quitting sport altogether is greater ${ }^{34}$. Early fostering of broad fundamental movement skills and enjoyment of sport ensure that children can discover and develop their talents, but also that youngsters continue being physically active throughout their lives, i.e. long-term athletic development ${ }^{34}$. It is crucial that professionals adopt a systematic approach to long-term athletic development for youngsters of all ages, abilities, and aspirations. It is therefore important in the first place that children and adolescents with CDPD meet the guidelines for physical activity (Table 1).

Table 1: Physical activity guidelines for youngsters with chronic diseases or physical disabilities.

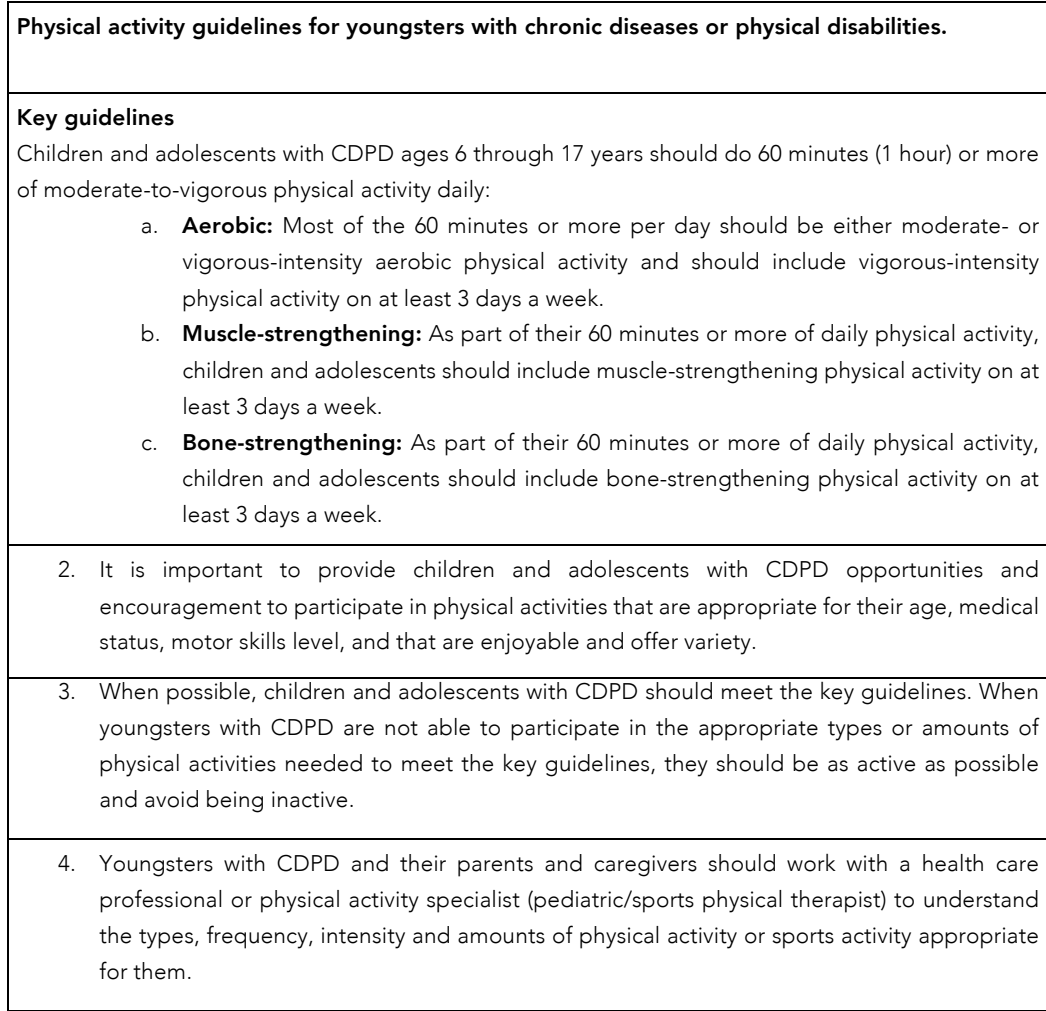


Participation in sport can be a means of achieving the goal of being intensively physically active at least 3 times a week (aerobic, muscle-strengthening and bone-strengthening). Coaches, physical educators, and trainers should develop programming to improve fundamental movement skills, as these are a predictor of PA levels. Engagement in sports can enhance fundamental movement skills and participation in sports is recommended for that purpose, but may need to take place with a different coaching approach in youngsters with CDPD (e.g., a more mastery-oriented approach with the greatest focus on task competency)22. Table 2 gives ten pillars for successful long-term athletic development in youngsters with CDPD. It might be advisable to encourage initial participation in less competitive or individual sports when movement skills are poor to start with. It is possible that low levels of some fundamental movement skills among obese children or those with more severe disabilities result in avoidance of competitive sports, since doing poorly may lead to negative psychological outcomes (i.e., low levels of enjoyment and confidence). During puberty and among girls, dropout from sports participation is high and support of sports participation is then especially important. Supporting strategies should target the youngsters, their parents and caregivers and all other persons in the social environment of youngsters with CDPD. 
Table 2: Ten pillars for successful long-term athletic development in youngsters with CDPD.

\section{Ten pillars for successful long-term athletic development in youngsters with CDPD}

1. For long-term athletic development, youngsters of all ages with CDPD should engage in organized sports activities that promote physical fitness, physical activity and psychosocial wellbeing at least twice weekly.

2. Sports-specific training programs should accommodate the highly-individualized and nonlinear nature of the growth, maturation and development of youngsters with CDPD.

3. Youngsters with CDPD should be encouraged to enhance their physical fitness and physical activity from early childhood, with a primary focus on a broad range of fundamental movement skill development and on the fun aspects of sports.

4. Health and wellbeing of the child or adolescent should always be the central focus of longterm athletic development programs.

5. From adolescence, there should be a shift from fundamental movement skills-oriented development to sport-specific development in training, where movement skills are trained more selectively in accordance with the sport.

6. Youngsters with CDPD should participate in (organized) sports at least twice weekly, helping reduce the risk of injury and ensure their ongoing participation in long-term athletic development programs.

7. Long-term athletic development programs should provide all youngsters with CDPD a range of training modes to enhance both health- and movement skill-related components of fitness.

8. Practitioners should use relevant monitoring and assessment tools specifically developed and validated for youngsters with CDPD as part of an effective long-term athletic development strategy.

9. Practitioners working with youngsters with CDPD should systematically progress and individualize training programs for successful long-term athletic development.

10. Qualified professionals and sound pedagogical approaches are fundamental to the success of long-term athletic development programs in youngsters with CDPD. 
Panel 9.4 gives a selection of statements by parents of children who participated in the HAYS study.

\section{Panel 9.4: statements of parents about their children participating in the HAYS study}

'I am not sure if my child is able to pursue all these sport specific tests, whereas the child reacts: 'Mom, I am familiar with some of the tests, I do them during physical education lessons at school! I can do this!'

'I am very surprised, my child is able to do all these exercises, I did not know that he is capable like that'.

'Normally, at home, the only thing he likes to do is online gaming. Surprised that my child is so enthusiastic about performing all these sports specific tests. Maybe we have to look for a suitable sport'.

\section{Exercise guidelines}

There is insufficient knowledge and expertise among sports coaches and trainers in guiding youngsters with CDPD, especially at the recreational level of sports participation. There are exercise guidelines to optimize sports performance in typically-developing youngsters ${ }^{34}$. In rehabilitation medicine, improving fitness levels is an important goal and youngsters with CDPD have been trained with success ${ }^{66}$ : an eight-week High Intensity Interval Training (HIIT) was proven feasible and safe when applied in children and adolescents with CDPD in the S2SF study ${ }^{67}$. Professionals (trainers, coaches, PE teachers, sports physical therapists) working in the sports domain can use the same training guidelines as for typically-developing youngsters for improving sport performance in youngsters with CDPD. There is no reason so far to believe that exercise guidelines for healthy children cannot be used for peers with CDPD. There is no need to be reluctant. It may take the trainer more time in the beginning to get to know the child with a specific health problem, and it takes some effort to find out what works and what does not. Trainers may facilitate the child to explore their own capabilities and some creativity and perseverance is then required from the trainers. Children and adolescents often know very well what works and what doesn't for them, and coordination and contact with the parents is important when there are uncertainties. Individuals with a neuromuscular disease in particular often experience reluctance of their trainer to engage ${ }^{68}$. Trainers, sports coaches and PE 
teachers should be trained so that they can better understand and guide youngsters with CDPD and their parents towards a specific sport for optimal sports performance. Collaboration between professionals working in rehabilitation medicine and education and sports domain is important for that goal.

\section{CONCLUSIONS}

\section{Support for sports participation}

According to the main findings of this thesis, (organized) sports participation at least twice weekly is an excellent way to improve or maintain physical activity levels, healthrelated fitness and psychosocial health. In addition, sports participation does not pose an increased risk of injuries and illnesses. Sports organizations play a crucial role in the realization of the global recommendations for youngsters with CDPD to accumulate at least 60 minutes per day of moderate-to-vigorous aerobic PA, of which at least three times per week should be vigorous PA, muscle and bone strengthening, in addition to the activity they undertake as part of everyday living ${ }^{60,69}$. As pointed out in the introduction, 1 in 4 youngsters grows up with a chronic condition ${ }^{2}$. It is recommended that sports organizations, health care professionals and physical education teachers strengthen their role in the promotion of regular physical activity and sport for healthy active living. Inclusion of youngsters with CDPD in community sports, organized regular or adapted sports requires extra effort for optimal guidance and support because several sports-specific barriers exist.

\section{Mission}

Enabling organized sports participation (regular or adapted) for every child or adolescent with a chronic disease or physical disability in their own living environment. 


\section{REFERENCES}

1. Shephard RJ, Bouchard C. Principal components of fitness: Relationship to physical activity and lifestyle. Can J Appl Physiol 1994;19(2):200-214.

2. Hal van L, Tierolf B, Rooijen van M, Hoff van der M. Een actueel perspectief op kinderen en jongeren met een chronische aandoening in Nederland: Omvang, samenstelling en participatie. April 2019;ISBN 978-90-5830-936-5.

3. Schoenmakers MA, de Groot JF, Gorter JW, Hillaert JL, Helders PJ, Takken T. Muscle strength, aerobic capacity and physical activity in independent ambulating children with lumbosacral spina bifida. Disabil Rehabil 2009;31(4):259-266. doi: 10.1080/09638280801923235.

4. Verschuren O, Maltais DB, Douma-van Riet D, Kruitwagen C, Ketelaar M. Anaerobic performance in children with cerebral palsy compared to children with typical development. Pediatr Phys Ther 2013;25(4):409-413. doi: 10.1097/PEP.0b013e3182a47022.

5. Kohleis K, Storck M, Geissler-Preuss S, Hirsch A, Kuhn FD, Ortfeld S, Rapp M, Bode H. Risk factors for mental health problems in children with cerebral palsy and spina bifida. Klin Pediatr 2019;231(1):28-34. Accessed 5/14/2019 10:40:02 AM. doi: 10.1055/a-0664-0832.

6. Graham HK, Harvey A, Rodda J, Nattrass GR, Pirpiris M. The functional mobility scale (FMS). J Pediatr Orthop 2004;24(5):514-520. doi: 00004694-200409000-00011.

7. Wood E, Rosenbaum P. The gross motor function classification system for cerebral palsy: A study of reliability and stability over time. Dev Med Child Neurol 2000;42(5):292-296.

8. Palisano RJ, Rosenbaum P, Bartlett D, Livingston MH. Content validity of the expanded and revised gross motor function classification system. Dev Med Child Neurol 2008;50(10):744750. doi: 10.1111/j.1469-8749.2008.03089.x.

9. Schoenmakers MA, Gulmans VA, Gooskens RH, Pruijs JE, Helders PJ. Spinal fusion in children with spina bifida: Influence on ambulation level and functional abilities. Eur Spine J 2005;14(4):415-422. doi: 10.1007/s00586-004-0768-3.

10. Zwinkels M. From exercise training to school-based sports, the effects on fitness and health in youth with physical disabilities. [Dissertation] Utrecht University; 2018.

11. Lankhorst K, Takken T, Zwinkels M, et al. Sports participation, physical activity, and healthrelated fitness in youth with chronic diseases or physical disabilities: The Health in Adapted Youth Sports study. J Strength Cond Res 2019. doi: 10.1519/JSC.0000000000003098. activity in children. Clin Physiol Funct Imaging 2008;28(3):133-144. doi: 10.1111/j.1475097X.2008.00788.x. 
13. Jimenez-Pavon D, Kelly J, Reilly JJ. Associations between objectively measured habitual physical activity and adiposity in children and adolescents: Systematic review. Int J Pediatr Obes 2010;5(1):3-18. Accessed 7/7/2017 9:28:46 AM. doi: 10.3109/17477160903067601.

14. LaMonte MJ, Blair SN. Physical activity, cardiorespiratory fitness, and adiposity: Contributions to disease risk. Curr Opin Clin Nutr Metab Care 2006;9(5):540-546. doi: 10.1097/01. mco.0000241662.92642.08.

15. Stevens G, van Dorsselaer S, Boer M, de Roos S, Duinhof E, ter Bogt T, van den Eijnden R, Kuyper L, Visser D, Vollebergh W, de Looze M. HBSC 2017. Gezondheid en welzijn van jongeren in Nederland. Utrecht: Universiteit Utrecht Faculteit Sociale Wetenschappen, Algemene Sociale Wetenschappen. 2018.

16. Ministry of Public Health. Gezondheidsenquete/leefstijlmonitor CBS, overgewicht. https:// www.volksgezondheidenzorg.info/onderwerp/overgewicht/cijfers-context/trends\# node-trend-overgewicht-kinderen. Updated 2017.

17. Jong de NB, Takken T, Berg van de SW, Vos GCW. Active healthy kids the Netherlands. http://www.super-lab.nl/wp-content/uploads/Report_Card-2018-ENG-website.pdf. 2018.

18. Te Velde SJ, Lankhorst K, Zwinkels M, et al. Associations of sports participation with self-perception, exercise self-efficacy and quality of life among children and adolescents with a physical disability or chronic disease - a cross-sectional study. Sports Med Open 2018;4(1):38-018-0152-1. doi: 10.1186/s40798-018-0152-1.

19. Zwinkels M, Verschuren $\mathrm{O}$, Balemans A, et al. Effects of a school-based sports program on physical fitness, physical activity, and cardiometabolic health in youth with physical disabilities: Data from the Sport-2-Stay-Fit study. Front Pediatr 2018;6:75. doi: 10.3389/ fped.2018.00075.

20. Kriemler S, Meyer U, Martin E, van Sluijs EM, Andersen LB, Martin BW. Effect of schoolbased interventions on physical activity and fitness in children and adolescents: A review of reviews and systematic update. Br J Sports Med 2011;45(11):923-930. doi: 10.1136/ bjsports-2011-090186.

21. Merkel DL. Youth sport: Positive and negative impact on young athletes. Open Access J Sports Med 2013;4:151-160. doi: 10.2147/OAJSM.S33556.

22. Geidne S, Quennerstedt M, Eriksson C. The youth sports club as a health-promoting setting: An integrative review of research. Scand J Public Health 2013;41(3):269-283. doi: $10.1177 / 1403494812473204$.

23. Eime RM, Payne WR. Linking participants in school-based sport programs to community clubs. J Sci Med Sport 2009;12(2):293-299. doi: 10.1016/j.jsams.2007.11.003. 
24. Yazicioglu K, Yavuz F, Goktepe AS, Tan AK. Influence of adapted sports on quality of life and life satisfaction in sport participants and non-sport participants with physical disabilities. Disabil Health J 2012;5(4):249-253. doi: 10.1016/j.dhjo.2012.05.003.

25. Haapala EA, Lankhorst K, de Groot J, Zwinkels M, Verschuren O, Wittinnk H, Backx FJ, Visser-Meily A, Takken T. The associations of cardiorespiratory fitness, adiposity and sports participation with arterial stiffness in youth with chronic diseases or physical disabilities. Eur J Prev Cardiol 2017;24(10):1102-1111. doi: 10.1177/2047487317702792.

26. Pase MP, Grima NA, Sarris J. The effects of dietary and nutrient interventions on arterial stiffness: A systematic review. Am J Clin Nutr 2011;93(2):446-454. doi: 10.3945/ ajcn.110.002725.

27. Steppan J, Barodka V, Berkowitz DE, Nyhan D. Vascular stiffness and increased pulse pressure in the aging cardiovascular system. Cardiol Res Pract 2011;2011:263585. doi: 10.4061/2011/263585.

28. Lubans DR, Morgan PJ, Cliff DP, Barnett LM, Okely AD. Fundamental movement skills in children and adolescents: Review of associated health benefits. Sports Med 2010;40(12):1019-1035. doi: 10.2165/11536850-000000000-00000

29. Webster EK, Martin CK, Staiano AE. Fundamental motor skills, screen-time, and physical activity in preschoolers. J Sport Health Sci 2019;8(2):114-121. doi: 10.1016/j. jshs.2018.11.006.

30. Bolger LE, Bolger LA, O'Neill C, Coughlan E, O'Brein W, Lacey S, Burns C. Accuracy of children's perceived skill competence and its association with physical activity. J Phys Act Health 2018:1-8. doi: 10.1123/jpah.2017-0371.

31. Nauta J, Martin-Diener E, Martin BW, van Mechelen W, Verhagen E. Injury risk during different physical activity behaviours in children: A systematic review with bias assessment. Sports Med 2015;45(3):327-336. doi: 10.1007/s40279-014-0289-0.

32. Hrysomallis C. Balance ability and athletic performance. Sports Med 2011;41(3):221-232. doi: 10.2165/11538560-000000000-00000.

33. Lankhorst, K., de Groot, J., Tim Takken, Backx, F., on behalf of the HAYS study group. Sports participation related to injuries and illnesses among youth with chronic diseases: Results of the Health in Adapted Youth Sports study. BMC Sports Sci Med Rehab (under review)

34. Lloyd RS, Cronin JB, Faigenbaum AD, et al. National Strength and Conditioning Association position statement on long-term athletic development. J Strength Cond Res 2016;30(6):1491-1509. doi: 10.1519/JSC.0000000000001387. 
35. Lankhorst K, van der Ende-Kastelijn K, de Groot J, Zwinkels M, Verschuren O, Backx F, Visser-Meily A, Takken T. Health in Adapted Youth Sports study (HAYS): Health effects of sports participation in children and adolescents with a chronic disease or physical disability. Springerplus 2015;4:796-015-1589-z. eCollection 2015. doi: 10.1186/s40064-0151589-z.

36. Townsend RR. Arterial stiffness: Recommendations and standardization. Pulse (Basel) 2017;4(Suppl 1):3-7. doi: 10.1159/000448454.

37. Thurn D, Doyon A, Sozeri B, Bayazit A, Canpolat N, Duzova A, Querfeld U, Schmidt B, Schaefer F, Wuhl E, Melk A. Aortic pulse wave velocity in healthy children and adolescents: Reference values for the Vicorder device and modifying factors. Am J Hypertens 2015;28(12):1480-1488. doi: 10.1093/ajh/hpv048.

38. Noortman LCM, Haapala EA, Takken T. Arterial stiffness and its relationship to cardiorespiratory fitness in children and young adults with a Fontan circulation. Pediatr Cardiol 2019;40(4):784-791. doi: 10.1007/s00246-019-02065-8.

39. Bussmann JB, van den Berg-Emons RJ. To total amount of activity..... and beyond: Perspectives on measuring physical behavior. Front Psychol 2013;4:463. doi: 10.3389/ fpsyg.2013.00463.

40. Chinapaw M, Altenburg T, Brug J. Sedentary behaviour and health in children - evaluating the evidence. Prev Med 2015;70:1-2. doi: 10.1016/j.ypmed.2014.10.029.

41. Lankhorst K, Oerbekke M, Berg-Emons R, Takken T, Groot J de. Instruments measuring physical activity in individuals who use wheelchairs: A systematic review of measurement properties using the COSMIN criteria. Arch Phys Med Rehab (under review)

42. Lankhorst K, van den Berg-Emons RJ, Bussmann JBJ, Horemans HLD, de Groot JF. A novel tool for quantifying and promoting physical activity in youths with typical development and youths who are ambulatory and have motor disability. Phys Ther 2019;99(3):354-363. doi: 10.1093/ptj/pzy152.

43. Flores FS, Rodrigues LP, Copetti F, Lopes F, Cordovil R. Affordances for motor skill development in home, school, and sport environments: A narrative review. Percept Mot Skills 2019;126(3):366-388. doi: 10.1177/0031512519829271.

44. Pettee Gabriel KK, Morrow JR,Jr, Woolsey AL. Framework for physical activity as a complex and multidimensional behavior. J Phys Act Health 2012;9 Suppl 1:S11-8.

45. Kotte E, Veenhof C, Winkler A, Horemans H, Takken T, Groot de J. Monitoring physical activity in primary pediatric physical therapy practice: Difficulties, opportunities and a case study illustration. Submitted, Pediatr Phys Ther 2019. 
46. Schaars D. The top fitness trends in 2019: Draagbare technologie, groepstraining en HIIT. https://www.allesoversport.nl/artikel/de-top-fitness-trends-in-2019-draagbare-technologie-groepstraining-en-hiit/. Updated November 13, 2018.

47. Kools F. Big data in healthcare. https://www.maastrichtuniversity.n//news/big-data-healthcare. Updated April 25th, 2019.

48. ZonMw. Verspreiden van implementatiekennis, kennissyntheses. https://www.zonmw.nl/ nl/over-zonmw/maatschappelijke-impact/implementatie-overzicht/implementatiebeleid/ verspreiden-van-implementatiekennis/kennissyntheses/.

49. Earde PT, Praipruk A, Rodpradit P, Seanjumla P. Facilitators and barriers to performing activities and participation in children with cerebral palsy: Caregivers' perspective. Pediatr Phys Ther 2018;30(1):27-32. doi: 10.1097/PEP.0000000000000459.

50. Schaars D. Gecombineerde leefstijl interventies (GLI) in de basiszorgverzekering. https://www.allesoversport.nl/artikel/gecombineerde-leefstijl-interventies-gli-in-de-basiszorgverzekering/. Updated February 19, 2019.

51. Leemrijse C, Kappen H, Boeije H. Sport en bewegen door mensen met een lichamelijke beperking belemmeringen en mogelijkheden. Nivel. 2019, Utrecht, Netherlands (ISBN 978-94-6122-541-2).

52. Rijksinstituut voor Volksgezondheid en Milieu. Loket gezond leven, erkende interventies/ jeugd. ministerie van volksgezondheid, welzijn en sport. https://interventies.loketgezondleven.nl/interventieoverzicht1/. Updated 2019.

53. Rijksinstituut voor Volksgezondheid en Milieu. Gezondheid en preventie; maatregelen in het nationaal preventieakkoord. https://www.rijksoverheid.nl/onderwerpen/gezondheid-en-preventie/nationaal-preventieakkoord. Updated 2019.

54. Bruins B, Bolsius L, van Zanen J, Bolhuis A. Nationaal sportakkoord, sport verenigt Nederland. Ministerie van Volksgezondheid, Welzijn en Sport. 2018.

55. Wagemakers A, Molleman G. Buurtsportcoaches slaan brug tussen zorg en sport. ZonMw. https://mediator.zonmw.nl/mediator-33/buurtsportcoaches-slaan-brug-tussen-zorg-ensport/. Updated June, 2019.

56. Ministerie van volksgezondheid, welzijn en sport. Alles over erkende effectieve gecombineerde leefstijlinterventies. kenniscentrum sport, ede. https://www.kenniscentrumsport.nl/sportinterventies-en-beweeginterventies/alles-over-erkende-effectieve-gecombineerde-leefstijlinterventies/. Updated 2019.

57. Wittink H, Lugt van der R, Renes R, et al. Wat beweegt jou?! https://www.onderzoek.hu.nl/ Projecten/Wat-beweegt-jou. Updated 2018. 
58. Nationaal Regieorgaan Praktijkgericht Onderzoek SIA. Nationaal regieorgaan praktijkgericht onderzoek SIA zet zich in voor meer en nog beter praktijkgericht onderzoek door hogescholen. http://www.regieorgaan-sia.nl/. Updated 2019.

59. Burghard M, Knitel K, van Oost I, Tremblay MS, Takken T, Dutch Physical Activity Report Card Study Group. Is our youth cycling to health? results from the Netherlands' 2016 report card on physical activity for children and youth. J Phys Act Health 2016;13(11 Suppl 2):S218-S224. doi: 10.1123/jpah.2016-0299.

60. Burghard M, de Jong NB, Vlieger S, Takken T. 2017 Dutch report card+: Results from the first physical activity report card plus for Dutch youth with a chronic disease or disability. Front Pediatr 2018;6:122. doi: 10.3389/fped.2018.00122.

61. Verschuren $\mathrm{O}$, Peterson MD, Balemans AC, Hurvitz EA. Exercise and physical activity recommendations for people with cerebral palsy. Dev Med Child Neurol 2016;58(8):798808. Accessed 12/19/2016 11:09:27 AM. doi: 10.1111/dmcn.13053.

62. Biddle SJ, Gorely T, Stensel DJ. Health-enhancing physical activity and sedentary behaviour in children and adolescents. J Sports Sci 2004;22(8):679-701. Accessed 12/19/2016 11:21:40 AM. doi: 10.1080/02640410410001712412.

63. Ortega FB, Konstabel K, Pasquali E, et al. Objectively measured physical activity and sedentary time during childhood, adolescence and young adulthood: A cohort study. PLoS One 2013;8(4):e60871. doi: 10.1371/journal.pone.0060871.

64. Hills AP, King NA, Armstrong TP. The contribution of physical activity and sedentary behaviours to the growth and development of children and adolescents: Implications for overweight and obesity. Sports Med 2007;37(6):533-545.

65. Tompsett C, Sanders R, Taylor C, Cobley S. Pedagogical approaches to and effects of fundamental movement skill interventions on health outcomes: A systematic review. Sports Med 2017;47(9):1795-1819. doi: 10.1007/s40279-017-0697-z.

66. Zwinkels M, Takken T, Ruyten T, Visser-Meily A, Verschuren O. Body mass index and fitness in high-functioning children and adolescents with cerebral palsy: What happened over a decade? Res Dev Disabil 2017;71:70-76. doi: https://doi.org/10.1016/j.ridd.2017.09.021.

67. Zwinkels $\mathrm{M}$, Verschuren $\mathrm{O}$, de Groot JF, et al. Effects of high-intensity interval training on fitness and health in youth with physical disabilities. Pediatr Phys Ther 2019;31(1):84-93. doi: 10.1097/PEP.0000000000000560.

68. Hollander dEL, Milder IE, Proper KI. Beweeg- en sportgedrag van mensen met een chronische aandoening of lichamelijke beperking. Bilthoven; RIVM rapport 2015-0064.

69. Takken T. Nederlandse jeugd zevende op mondiale beweegranglijst. https://www.allesoversport. nl/artikel/nederlandse-jeugd-zevende-op-mondiale-beweegranglijst/. Updated May 24, 2019. 



\section{Nederlandse samenvatting}

Kristel Lankhorst 
Sportparticipatie laat bij kinderen en jongeren een positieve relatie laat zien met zowel de fysieke als ook de psychosociale gezondheid. Regelmatig sporten is dus belangrijk. Echter, jongeren met een fysieke beperking of een chronische ziekte sporten minder in vergelijking met hun leeftijdsgenoten. Slechts $26 \%$ van de jongeren met een chronische aandoening sport één keer per week bij een sportvereniging, vergeleken met $71 \%$ van hun niet-chronisch zieke leeftijdsgenoten. Terwijl voor deze populatie een actieve levensstijl zeer belangrijk is voor het bereiken van een optimaal niveau van fysieke en psychosociale gezondheid zowel op de korte als de lange termijn. Er zijn verschillende manieren om gezondheidsproblemen te voorkomen en een actieve leefstijl te bevorderen. Geregeld sporten bij een sportvereniging is daarvan een voorbeeld. Echter, voor jongeren met een chronische ziekte of een lichamelijke beperking is het niet vanzelfsprekend om te sporten bij een sportvereniging. Het doel van de Health in Adapted Youth Sports (HAYS) studie is daarom ook, om zowel de negatieve als positieve relaties van sport voor kinderen en jongeren met een chronische ziekte of lichamelijke beperking te onderzoeken. De resultaten zullen inzichtelijk maken of sportparticipatie een positieve invloed heeft op het bereiken van een optimaal niveau van gezondheid en lichamelijke activiteit bij bovengenoemde doelgroep kinderen en jongeren. Het onderzoek kan resulteren in het formuleren van adviezen voor professionals die binnen de gezondheidszorg met deze kinderen en jongeren werken, waardoor zij deze doelgroep beter kunnen begeleiden.

Het protocol van de HAYS studie wordt beschreven in hoofdstuk 2. In deze studie zijn er twee groepen kinderen en jongeren met een chronische ziekte of lichamelijke beperking met elkaar vergeleken. De eerste groep sport tenminste twee keer per week bij een sportvereniging en de andere groep sport één keer bij een sportvereniging of helemaal niet. Er is bij beide groepen kinderen gekeken naar de verschillen met betrekking tot fitheid, dagelijkse lichamelijke activiteit, psychosociale gezondheid en risico op (sportgerelateerde) blessures en ziektes. In deze studie zijn kinderen en jongeren in de leeftijd van 10-19 jaar met een lichamelijke beperking of chronische ziekte meegenomen die in staat zijn om zelfstandig te lopen. "Sport" is gedefinieerd als deelname aan een georganiseerde sport, tenminste twee keer per week gedurende een periode van 3 maanden of meer. 


\section{Doelgroep van de HAYS studie}

Aan dit onderzoek hebben jongeren deelgenomen met een chronische ziekte of een fysieke beperking. De ziekten en aandoeningen die de kinderen en jongeren hebben bleken zeer divers. We hebben kinderen gerekruteerd via scholen voor speciaal onderwijs, kinderfysiotherapiepraktijken, (aangepaste) sportorganisaties en via de polikliniek van het Wilhelmina Kinderziekenhuis. Ook hebben kinderen en jongeren die aan het Sport2-Stay-Fit (S2SF) onderzoek hebben deelgenomen meegedaan. Het S2SF onderzoek liep parallel aan het HAYS onderzoek, waarbij dezelfde uitkomstparameters werden gemeten. Het S2SF onderzoek richtte zich op het meten van de effectiviteit van een naschools-sportprogramma bij kinderen en jongeren met een chronische ziekte of een fysieke beperking. De ziekten en aandoeningen die voorkwamen in het HAYS onderzoek waren: hart- en vaatziekten (aangeboren hartziekten), longaandoeningen (astma), metabole ziekten (diabetes mellitus), spier- of skeletaandoeningen, niet-progressieve spieraandoeningen, aandoeningen als gevolg van een hersenbeschadiging (cerebrale parese, spina bifida), immunologische en hematologische aandoeningen, kanker en epilepsie.

\section{Het meten van lichamelijk activiteit}

In de HAYS studie hebben kinderen en jongeren deelgenomen met onder andere Spina Bifida of Cerebrale Parese. Deze groep jongeren ervaart als gevolg van hun aandoening spasticiteit en / of verlamming van de spieren, wat het lopen beperkt. Tot op heden was er nog geen goed meetinstrument om de dagelijkse lichamelijke activiteit te meten van kinderen en jongeren met een loopbeperking. Om de dagelijkse lichamelijke activiteit te kunnen meten bij de kinderen en jongeren die deelnemen aan de HAYS studie is in hoofdstuk $\mathbf{3}$ een fysieke activiteitenmonitor (Activ8) gevalideerd voor gebruik bij kinderen en jongeren met en zonder een beperking van het looppatroon. Dit hoofdstuk laat zien dat de Activ8 de dagelijkse activiteiten nauwkeurig kan meten - zoals liggen, zitten, staan, lopen, fietsen en rennen - , van zowel kinderen en jongeren mét als zonder een loopbeperking. Daarnaast kan het meetinstrument gebruikt worden om interventies gericht op fysieke activiteit te monitoren en te evalueren. De Activ8 is op basis van de uitkomsten van dit onderzoek ingezet om de lichamelijk activiteit te meten van alle deelnemers in de HAYS studie. 


\section{De impact van georganiseerd (aangepast) sporten}

In de hoofdstukken 4, 5, 6 en 7 zijn de resultaten van de HAYS studie te lezen. In hoofdstuk 4 staat beschreven wat de impact van sportdeelname is op fitheid (zuurstofopname, spierkracht, sprintsnelheid, lichaamsgewicht, vetpercentage) en lichamelijke activiteit. Het blijkt dat kinderen en jongeren die minstens twee keer in de week sporten bij een sportclub beter presteren op alle fysieke uitkomstparameters in vergelijking met hun leeftijdsgenootjes die niet of één keer per week sporten. De meer frequente sportgroep heeft 1) een significant hogere zuurstofopname $\left(\mathrm{VO}_{2 \text { peak }}\right)$, 2) bereikte een hoger maximaal vermogen op de muscle power sprint test, 3 ) is sneller op de $10 \times 5$ meter sprinttest, 4) heeft gemiddeld een hogere handknijpkracht en 5) was in staat om verder te springen. De kinderen en jongeren die minstens twee keer per week aan sport deden, bleken een gezonder gewicht, een lagere body mass index (het gewicht in verhouding tot lichaamslengte) en gemiddeld een lager vetpercentage te hebben in vergelijking met hun leeftijdsgenootjes die niet of één keer per week sporten. Ook bleken zij actiever in het dagelijks leven; gedurende een schoolweek zijn zij gemiddeld meer dan 30 minuten per dag langer actief en gedurende het weekend is dat gemiddeld 25 minuten per dag langer vergeleken met hun niet sportende of één keer per week sportende leeftijdsgenootjes. De positieve relatie tussen sportdeelname en de zuurstofopname $\left(\mathrm{VO}_{2 \text { peak }}\right)$ werd voor $31 \%$ beïnvloed door de dagelijkse lichamelijke activiteit. De mate van inactiviteit (liggen en zitten) had geen invloed op de positieve relatie tussen sportdeelname en de zuurstofopname $\left(\mathrm{VO}_{\text {2peak }}\right)$.

Hoofdstuk 5 beschrijft de impact van sportdeelname op de psychosociale gezondheid bij kinderen en jongeren met een chronische ziekte of fysieke beperking. Degenen die minstens twee keer per week aan sport doen hebben een hogere kwaliteit van leven en voelen zich atletisch competenter in vergelijking met hun niet of één keer per week sportende leeftijdsgenootjes. Kinderen (10-12 jaar), maar niet de jongeren (13-18 jaar), die minstens twee keer per week aan sport deelnemen ervaren een hoger gevoel van sociale acceptatie. Daarnaast blijkt dat wanneer men tenminste twee keer per week sport, dit sterk geassocieerd is met een hogere mate van beweging gerelateerde zelfredzaamheid. 
Sportdeelname van tenminste twee keer in de week laat dus een positieve relatie zien met fitheid, lichamelijk activiteit en psychosociale gezondheid bij kinderen en jongeren met een chronische ziekte of fysieke beperking. Echter betekent dit niet dat we deze positieve relatie terug zien bij de cardiorespiratoire fitheid en de stijfheid van de arteriën.

Het onderzoek in hoofdstuk 6 beschrijft dat een lage fitheid en een grotere buikomtrek beide zijn gerelateerd aan een hogere slagaderlijke stijfheid. Een verhoogde slagaderlijke stijfheid verhoogd het risico op het ontwikkelen van hart- en vaatziekten. Echter, de relatie tussen de fitheid en de slagaderlijke stijfheid werd deels verklaard door de buikomtrek. Na een uitgebreide analyse konden we concluderen dat kinderen en jongeren met een chronische ziekte of fysieke beperking met een buikomtrek van $>73$ $\mathrm{cm}$ en een zuurstofopname van $<35 \mathrm{ml} / \mathrm{kg} / \mathrm{min}$ zeer waarschijnlijk een hogere stijfheid van de slagaderen hebben. Deze resultaten suggereren dat interventies die gericht zijn op het faciliteren van een gezond gewicht en lichaamssamenstelling en het verbeteren van de fitheid mogelijkerwijs bijdragen aan het verbeteren van de slagaderlijke stijfheid. Interventieonderzoek zal echter moeten uitwijzen of deze aannames terecht zijn.

Naast de positieve invloed van sportdeelname op de gezondheid, bestaan er ook veronderstellingen dat sport resulteert in het oplopen van blessures of het verergeren van de bestaande chronische ziekte of aandoening. Deze veronderstellingen kunnen aanleiding zijn om niet deel te nemen aan georganiseerd sporten. Hoofdstuk 7 beschrijft het risico op het krijgen van (sportgerelateerde) blessures of ziekten. In dit onderzoek is een vergelijking gemaakt tussen kinderen en jongeren met een chronische ziekte of fysieke beperking die minstens twee keer per week deelnemen aan sport in vergelijking met leeftijdsgenootjes die niet of één keer per week sporten. Resultaten uit dit onderzoek tonen aan dat sportdeelname van tenminste twee keer in de week niet een significant hoger risico op de incidentie van een blessure of ziekte per 1000 uur lichamelijke activiteit met zich meebrengt in vergelijking met leeftijdsgenootjes die niet of eenmaal per week deelnemen aan sport. Elk kind of elke jongere loopt een even groot risico op, op het krijgen van een blessure of een ziekte. Degene die minstens twee keer per week deelnemen aan sport lopen voornamelijk een blessure op door hun, terwijl de kinderen en jongeren die niet of één keer per week sporten, blessures oplopen in het dagelijks leven. Dat gebeurt voornamelijk tijdens gymles op school, activiteiten in het dagelijks leven en niet-georganiseerde sport- en spelactiviteiten in de vrije tijd. 
Op basis van de resultaten van de hoofdstukken 4, 5, 6 en 7 kan aan kinderen en jongeren met een chronische ziekte of fysieke beperking geadviseerd worden om tenminste twee keer in de week deel te nemen aan (aangepast) georganiseerd sporten. Het is nu zeer wenselijk dat sportdeelname bij een sportclub voor iedereen uit deze doelgroep ook daadwerkelijk mogelijk wordt gemaakt. Er bestaan immers nog vele barrières waardoor het nog niet vanzelfsprekend is dat deze kwetsbare groep kinderen en jongeren onbezorgd kan sporten bij een sportclub bij hen in de buurt. Door sportdeelname bij een sportclub in hun eigen leefomgeving mogelijk te maken kunnen deze kinderen en jongeren zowel op schooldagen als ook in het weekend minstens twee keer per week lichamelijk actief zijn.

\section{Het meten van lichamelijke activiteit bij mensen in een rolstoel}

Nu we de impact van georganiseerde sportdeelname kennen voor de ambulante populatie (zij die niet gebonden zijn aan een rolstoel) kinderen en jongeren met een chronische ziekte of fysieke aandoening, ontstaat de volgende vraag wat de impact van sportparticipatie is voor hen die gebruik maken van een rolstoel in het dagelijks leven. Hiervoor is het belangrijk om ook de mate van lichamelijke activiteit te kunnen meten. Een meetinstrument dat in de ambulante populatie kinderen en jongeren wordt gebruikt kan niet per definitie gebruikt worden voor de jeugd in een rolstoel. In hoofdstuk 8 bestuderen we op basis van bestaande literatuur welk meetinstrument er op dit moment voorhanden is voor het meten van de lichamelijke activiteit bij personen die gebruik maken van een rolstoel in het dagelijks leven. De twee vragenlijsten die veelbelovend lijken, zijn de Physical Activity Scale for Individuals with Physical Disabilities (PASIPD) en de Physical Activity Recall Assessment for People with Spinal Cord Injury (PARA-SCI). Daarnaast zijn er vier objectieve meetinstrumenten (activiteitenmonitoren) die op een valide manier de intensiteit van lichamelijke activiteit in het dagelijks leven meten. Dit zijn de GENEactive, Actigraph GT3X+, Actiheart en de PAMS. Om het type lichamelijk activiteit te meten zijn zowel de PAMS als ook de VitaMove valide instrumenten. De praktische toepasbaarheid verschilt per instrument. Ook hebben we uit de bestaande literatuur kunnen concluderen dat een hartslagmeter op basis van individuele kalibratie (het instellen van hartslagzones) een makkelijke en goedkope vervanger is, wanneer de hierboven genoemde activiteitenmonitoren voor volwassenen niet voorhanden zijn. 
De bevindingen van dit proefschrift zijn in hoofdstuk 9 in perspectief geplaatst binnen de huidige wetenschappelijk kennis en het (aangepast) georganiseerd sportklimaat in Nederland. Nu we weten dat sportdeelname van minstens twee keer in de week een positieve impact heeft op de gezondheid van kinderen en jongeren met een chronische ziekte of fysieke beperking, is het noodzakelijk dat sportdeelname ook mogelijk wordt gemaakt.

Gelukkig is er toenemende aandacht voor (aangepast) sporten voor kinderen en jongeren met een chronische ziekte of fysieke beperking. Het huidige regeerakkoord is daar een goed voorbeeld van. Om georganiseerde sportdeelname mogelijk te maken voor elk kind en jongere met een chronische ziekte of fysieke beperking in hun eigen woonomgeving, staan we nog wel voor een aantal uitdagingen. Denk bijvoorbeeld aan het toegankelijk maken van sportfaciliteiten, het bieden van de juiste begeleiding en ondersteuning, acceptatie door leeftijdsgenoten, ouders en trainers. Maar ook ondersteuning van familie (transport, actieve participatie en een positieve houding) is nodig om sportdeelname bij een sportclub mogelijk te maken voor onderhavige doelgroep. Inclusie van kinderen en jongeren met een chronische aandoening of fysieke beperking in het reguliere sportaanbod, aangepast sporten en/of sporten binnen een eigen gemeenschap vereist extra aandacht. Om optimale begeleiding en ondersteuning mogelijk te maken zullen eerst verschillende sportspecifieke barrières moeten worden weggenomen. Het is belangrijk dat sportorganisaties, gezondheidszorgprofessionals en gymdocenten hun krachten bundelen en lichamelijke activiteit en sportdeelname promoten voor een gezonde levensstijl bij deze jeugdigen. 



\section{Dankwoord}

Kristel Lankhorst 
Het is zover, het moment dat ik mijn dankwoord schrijf. Het moment dat ik afscheid neem van mijn reis als $\mathrm{PhD}$ student. Op reis gaan is spannend, een nieuw avontuur met nieuwe kansen, mogelijkheden en uitdagingen. Deze reis ga ik niet vergeten, het heeft mooie en leerzame momenten opgeleverd, waardevolle samenwerkingen en vrienden voor het leven. Op deze momenten blik ik terug in dit dankwoord. Deze reis heb ik niet alleen afgelegd, ik ben veel inspirerende mensen tegengekomen die allemaal op hun eigen manier een bijdrage hebben geleverd aan de totstandkoming van dit prachtige proefschrift, waar ik enorm trots op ben.

Allereerst, alle 163 kinderen en jongeren. Jullie hebben vol enthousiasme meegedaan aan dit onderzoek. ledereen van jullie had zijn eigen unieke verhaal, een verhaal dat maakt waarom het zo belangrijk is dat sporten bij een sportclub mogelijk moet worden gemaakt voor ieder kind en voor iedere jongere. Jullie plezier, energie en doorzettingsvermogen heb ik als motiverend ervaren. Jullie hebben mij geleerd om lol te hebben, grappen te maken en te relativeren. Ook ben ik jullie ouders dankbaar, zij die de tijd en energie konden vinden om jullie te begeleiden voor deelname aan dit onderzoek. Speciale dank gaat uit naar Elles; wat ontzettend mooi dat jij het Health in Adapted Youth onderzoek een 'gezicht' hebt gegeven door je medewerking aan de kennisclip. Ik krijg mooie reacties.

Prof. Dr. Backx, beste Frank, ik waardeer het ontzettend, dat jij in een gevorderd stadium van mijn proefschrift, mijn promotor wilde zijn. Bedankt voor de inspirerende gesprekken op het gebied van de sportgeneeskunde, de constructieve, prettige en persoonlijke samenwerking. Als promotor hield jij het overzicht en zorgde je ervoor dat ik mijn planning op orde had. Ook attendeerde je me op verschillende sportgerelateerde congressen en symposia, waar ik onze resultaten kon presenteren. Ik wil je ook bedanken voor de prettige gesprekken op de momenten dat ik, door verschillende omstandigheden, het moeilijk had om het laatste gedeelte van mijn PhD project te voltooien. Je bemoedigende woorden en het vertrouwen in mij waardeer ik enorm. Ik hoop dat we elkaar in de toekomst blijven tegenkomen, zodat ik van je mag blijven leren.

Dr. de Groot, beste Janke, zes jaar geleden werd ik onder andere door jou aangenomen voor het Fit for the Future! project en het HAYS onderzoek. Vanuit de HU was jij mijn begeleider. Je kritische en overkoepelende blik heeft een belangrijke bijdrage geleverd 
aan de artikelen. Je hebt mij geleerd om het commentaar van de reviewers op onze artikelen in perspectief te plaatsen. Je bleef me er op attenderen, dat de boodschap voor de professional in de praktijk duidelijk geformuleerd moest worden. Ik wil je daarnaast bedanken voor de persoonlijke gesprekken die ik met je heb gehad en de hulp om de balans te vinden tussen werk en privé.

Dr. Takken, beste Tim, samen met Janke heb jij mij aangenomen en mij begeleidt binnen het HAYS onderzoek. Vanaf dat moment heb jij mij meegenomen en geïnspireerd op het vlak van de klinische inspanningsfysiologie binnen de kindergeneeskunde. Ik heb erg veel van jou als expert op dit gebied mogen leren, je kennis is onuitputtelijk. Ik ben je dankbaar dat ik de mogelijkheid kreeg om op door jou georganiseerde congressen onze onderzoeksresultaten te presenteren. Het PWP congres in Thessaloniki zal ik niet snel vergeten, de busreis naar de kloosters was niet bepaald een goed voorbeeld van voldoende fysieke activiteit, het leidde wel tot een goed gesprek dat ik als zeer waardevol heb ervaren.

Geachte leden van de beoordelingscommissie, Prof. Dr. Anne Visser-Meily, Prof. Dr. Kors van der Ent, Prof. Dr. Marian Jongmans, Prof. Dr. Philip van der Wees en Prof. Dr. Rienk Dekker, bedankt voor het lezen en beoordelen van mijn proefschrift, ik verheug me op onze gedachtenwisseling.

Prof. Dr. Janssen, beste Thomas, bedankt dat jij mijn proefschrift wilt lezen en mijn opponent bent tijdens mijn verdediging, ik kijk ernaar uit. Daarnaast heb jij mij drie jaar geleden ook warm ontvangen op het moment dat ik even niet meer wist hoe ik nu verder moest met mijn PhD traject. Bedankt voor je raad en het wijzen van de juiste weg.

Ook wil ik al mijn co-auteurs bedanken, jullie input voor de manuscripten is van onschatbare waarde. Lieve Maremka, het was ongelooflijk leuk en prettig om samen met jou te kunnen optrekken tijdens onze PhD projecten. Ik heb bewondering voor je organisatorische vaardigheden en het stellen van prioriteiten. Ik heb daar veel van geleerd. Heel tof ook dat we nu samen praktisch een vervolg geven aan de uitkomsten van onze PhD trajecten. Ik waardeer je enthousiasme en ik hoop nog lang met je te mogen samenwerken op het vlak van toegepaste inspanningsfysiologie en trainingsleer. Beste Karin, als mede-promovendi van de HAYS studie, hebben we samen de opzet en de eerste metingen van de studie mogen doen. Je kennis en vaardigheden vanuit de sportgeneeskunde hebben een belangrijke bijdrage geleverd. 
Beste Saskia, als post-doc onderzoeker werd jij betrokken bij het HAYS onderzoek. Uit een berg ruwe data heb jij met je gestructureerde manier van werken een belangrijke bijdrage geleverd aan hoofdstuk 5 . Je was daarnaast altijd bereid om mij te helpen met statistische vraagstukken. Bedankt daarvoor.

Beste Leendert, dat we samen de accelerometrie-data zouden gaan verwerken met MATLAB van wat nu hoofdstuk 4 is geworden, had ik tijdens onze studietijd bij bewegingswetenschappen niet kunnen bedenken. Ik ben je dankbaar voor je MATLAB vaardigheden, je heldere uitleg en oplossingsgerichte werkwijze. Daarnaast heb ik ook bewondering voor de weg die je nu bent ingeslagen. Samen met Bart en jullie bedrijf Monkey Moves werken jullie op een betekenisvolle manier aan de motorische ontwikkeling van kinderen.

Dear Eero, thank you for your support and writing skills for chapter 6. It was great working with you together in Utrecht. You and your family enjoyed the Netherlands, like I enjoyed your beautiful country Finland last winter. When I visit Jyväskylä sometime in the future, I will drop by to give you a 'pot pindakaas' for your daughters.

Beste Michiel, vanaf het begin van mijn promotietraject ben jij betrokken geweest bij de totstandkoming van de systematische review. Het heeft lang geduurd, voordat dit manuscript werd geaccepteerd voor publicatie. Om die reden bedankt voor je geduld, kritische blik en prettige en constructieve samenwerking voor het manuscript. Ik wens je een mooie wetenschappelijke carrière toe.

Beste Olaf, bedankt voor je constructieve feedback op de manuscripten en de prettige samenwerking die ik over de jaren heb mogen ervaren.

Beste Rita, jouw passie voor onderzoek en de klinische toepasbaarheid daarvan binnen de revalidatiegeneeskunde zijn ongekend. Jij hebt mij inzicht gegeven, samen met je collega's Carla, Herwin en Hans, in de wereld van de fysieke activiteiten monitoring. Je begeleiding binnen het Fit for the Future! project was effectief en prettig. De twee hoofdstukken over het valideren van de Activ8 en de systematische review over het meten van fysieke activiteit zijn de resultaten van een mooie samenwerking tussen de Hogeschool Utrecht en het Erasmus MC.

Alle consortium partners wil ik bedanken voor het meedenken, inspireren en het in de praktijk brengen van de onderzoeksresultaten.

Angelique, bedankt voor je inzet vanuit je rol als kinderfysiotherapeut voor het Fit for the Future! project, maar ook als moeder, dat je je twee zoons bereid hebt gevonden 
om deel te nemen aan de validatie studie van de Activ8. Ik heb genoten van hun enthousiaste deelname.

Beste Elles, je expertise als onderzoeker binnen de kinderfysiotherapie en Fitkids heb ik gewaardeerd. De samenwerking die we hadden op het vlak van de fysieke activiteiten monitoring binnen het Fit for the Future! project heb ik als zeer waardevol ervaren. Daarnaast was het fijn dat we deels samen hebben kunnen optrekken in de allerlaatste fase van ons PhD traject. Ik kijk ernaar uit om het 'kunstje' van jou af te kijken, een week voor mijn verdediging. Ik wens je veel succes en plezier!

Dr. Wittink, beste Harriet, bedankt dat ik me binnen jouw Lectoraat Leefstijl en Gezondheid (LLG) heb mogen ontwikkelen als onderzoeker.

Ik wil de (oud-) onderzoekers en collega's van het LLG bedanken voor de leuke discussies, waardevolle feedback en / of hulp bij de metingen: Marleen, Janke O, Michiel, Manon, Imke, Marike, Petra, Jacqueline O, Edwin, Francois, Esther, Jan, Stefan, Jacqueline N, bedankt!

Beste Tim B, vanuit je rol als coördinator van het inspannings-lab bij het LLG heb je me ontzettend goed geholpen bij het uitvoeren van de metingen voor het HAYS onderzoek. Ook zorgde jij ervoor dat de problemen die we frequent hadden met de meetapparatuur op tijd weer opgelost waren. Ik vind het leuk dat we nog steeds collega's zijn en onze passie voor de inspanningsfysiologie met elkaar kunnen delen.

Veel heb ik ook geleerd bij het fysiologenoverleg in het WKZ, ik heb het altijd als erg inspirerend ervaren. Dank aan allen die aanwezig waren voor de inspirerende input, voor de feedback en het meedenken.

Praktijkgericht onderzoek doen bij de Hogeschool Utrecht betekent ook de inbedding van onderzoek in het onderwijs. Naast alle collega's wil ik ook alle studenten bedanken die ik in de loop der jaren met veel plezier heb mogen begeleiden als onderzoeker en docent. Als eerste wil ik de wisselende teams van studenten bedanken die zich wekelijks hebben ingezet om de blessures en ziekten bij de kinderen en jongeren gedurende 3 jaren te monitoren. Vervolgens de studenten die het land door zijn gereisd om kinderen bij sportverenigingen te testen, de meetdagen in het lab op de Hogeschool Utrecht, en de totstandkoming van literatuurstudies en afstudeerscripties. Alle inzet en medewerking heeft bijgedragen aan het resultaat van dit proefschrift. Een diepe buiging voor al het werk dat jullie met enthousiasme hebben geleverd. Bijzonder dank aan, in willekeurige volgorde: Eefje, Marije, Myrthe, Marlous, Marieke, Anne, Sandra, Yusi, Lieke, Celine, 
Desi, Annemarel, Irma, Marlies, Milou, Sandra, Petra, Anneke, Lisanne, Jorien, Selina, Coco, Anne Roos, Liesbeth, Adam, Alwin, Tiana, Saskia, Lysanne, Veerle, Moise, Kamiel, Rick, Priscilla, Yorick en Ilse.

Onderzoek en onderwijs, de afgelopen jaren heb ik getracht het zo goed mogelijk met elkaar te combineren. Dat was niet gelukt zonder de hulp van mijn collega docenten. Allereerst gaat mijn dank uit naar Jorrit, als hoofd van de Master Sportfysiotherapie. Jij hebt het voor mij mogelijk gemaakt dat ik onderwijs en onderzoek met elkaar kon combineren. Je ondersteunde mij op momenten dat het onderzoek 'voorrang' nodig had. En dan mijn huidige collega's van de Master Sportfysiotherapie, lieve Stefan, Sarina, Mohammed, Sijmen en Jeroen. De vrijdagen waren voor mij een prettige start van mijn weekend. Ik heb de leuke gesprekken en sportiviteit altijd gewaardeerd. Voor jou, Stefan, wat was het inspirerend om samen met jou voor de klas te staan. Het waren voor mij veelal momenten van ontspanning, plezier en bevlogenheid voor het vak dat we samen deelden. Lieve Martine, naast collega ook vriendin geworden. Reizen, hardlopen, werken en promotieperikelen, we hebben het samen kunnen delen. Bedankt.

Beste Esther, wat een geluk dat we elkaar hebben getroffen bij het RehabMove congres in Groningen afgelopen jaar. Wat een mooie samenwerking hebben wij kunnen bewerkstelligen. Onderzoek en praktijk samen laten komen en praktische handvaten geven. Samen met je team met onder andere Lorraine en Marie-Louise, bundelen we onze krachten, om sport mogelijk te maken voor alle kinderen en jongeren in hun eigen leefomgeving. Ik heb er alle vertrouwen in dat we zullen blijven samenwerken in de toekomst. Ik vind het een eer dat jij het voorwoord hebt geschreven van dit proefschrift, een voorbeeld en inspiratiebron voor velen. Bedankt.

Beste Ilse, bedankt voor de prachtige foto's die dit proefschrift kleuren en je creatieve inbreng en het ontwerp voor de omslag van dit boekje. Beste Anne, hartelijk bedankt voor het vormgeven van mijn proefschrift. Het bleek meer werk dan van te voren gedacht, maar het resultaat is prachtig geworden.

Vrienden! Jullie zijn allemaal inspirerende mensen voor mij, ontzettend dankbaar dat jullie er altijd voor me zijn, ik zou niet zonder jullie kunnen. Lieve Barbara, Femke, Anne Marie en Evelyn, ik ben jullie dankbaar voor jullie lieve woorden en onvoorwaardelijke steun tijdens mijn promotietraject. FC Dubbelfrisss, wat is het heerlijk om onderdeel te zijn van dit fantastische zaalvoetbalteam. Bedankt dat we samen kunnen inspannen 
en ontspannen. De Oost-borrel groep, fijn om zo'n gelijkgestemde groep vrienden om me heen te hebben. A'damse BW chickies, het is prachtig dat we elkaar hebben leren kennen bij het studeren in Enschede en Amsterdam. De weekendjes weg en avondjes uit zijn geweldig. Ik kijk uit naar de volgende edities. Cirkel 103; kracht, liefde en overvloed. Dankbaar dat ik jullie afgelopen jaar heb ontmoet en heb leren kennen. Lieve Frederik, wat fijn dat jij in mijn leven bent op dit moment, ik kijk uit naar onze spannende avonturen.

Dan nu de plek om mijn paranimfen Wendy, Josine en Marjolein te bedanken (ja Marjolein, jij bent gewoon stiekem mijn 3 e paranimf). Lieve Josine, wat ben ik blij met jou als mijn vriendin, waarmee ik een groot deel van mijn sociale-, sportieve leven en vrienden deel. Hardlopen, schaatsen, wielrennen, zaalvoetballen en op stap gaan. Wij kunnen dat heel goed. Ik bewonder je om je stappen die je zet in je wetenschappelijke carrière en ik ben om die reden ook heel blij dat jij mijn paranimf wilt zijn. Je weet op de juiste momenten mij gerust te stellen en me te laten relativeren door de goede en rake grappen die je maakt. Lieve Marjolein, wat ben ik ontzettend blij dat ik jou heb leren kennen via Josine, drie jaar geleden op de Jaap Eden baan. Naast dat je mijn sportvriendin bent, ben je ook een vriendin waar ik veel steun van ervaar. Dat jij je hebt ingezet om geld op te halen voor het hersentumorfonds (en indirect voor mijn vader) door de Mont Ventoux te beklimmen heb ik als bijzonder ervaren. Ik kijk uit naar al onze sportieve uitdagingen en naar mijn promotiefeest in Amsterdam die jij samen met Josine mogelijk maakt.

Lieve Wendy, 'zussie', ik ben ontzettend trots op je en blij dat je mijn paranimf wilt zijn. Hoe jij alle ballen hoog weet te houden: je carrière, je gezin, verbouwing van jullie huis samen met Bram; petje af. Jullie prachtige kinderen, Hanna, Hidde en Norah, ze maken me elke keer zo enorm blij. Ik vind het fantastisch om hun tante 'Shizzle' te zijn. Lieve Bram, bedankt dat je ons onderzoek in beeld heb gebracht met je bedrijf MVOTV. Ontzettend fijn dat ik altijd bij jullie kan komen logeren op momenten dat ik er even tussenuit wil zijn. De mooie gesprekken, de lekkere sushi, de vakanties op Terschelling, de mooie hardloopuitdagingen, laten we dat vooral blijven doen. Bedankt dat ik me altijd welkom voel bij jullie. 
Lieve Leon, Nicole en Lize, ik heb grote bewondering voor jullie. Hoe jullie omgaan met tegenslagen maar ook hoe jullie in staat zijn om geluk en liefde te delen met de mensen om jullie heen. Jullie nuchtere blik op de wereld en de humor die jullie samen hebben, heerlijk vind ik dat. Jullie zijn een grote steun voor mij, en ik weet dat ik altijd bij jullie terecht kan. Dank daarvoor.

Lieve Stefan, wat enorm trots ben ik op je broertje. Dat jij, zo plotseling uit noodzaak, de melkveehouderij van pap en mam zelfstandig runt. Lieve Nikki, wat een prachtmens ben je, ik geniet van de grappen die jullie samen maken en de gekheid die jullie beide in jullie hebben. Bedankt voor de steun die ik van jullie ervaar.

Lieve pap en mam, jullie hebben mij geleerd om door te zetten, als je ergens aan begint maak je het ook af. Jullie hebben mij geleerd mijn eigen keuzes te maken, gestimuleerd om te gaan studeren en het beste uit mezelf te halen. Jullie ongekende positiviteit, nuchtere blik, vertrouwen en onvoorwaardelijke liefde hebben ervoor gezorgd dat dit proefschrift er nu ligt. Wat ben ik blij dat we dit moment, mijn verdediging samen kunnen vieren! Ik kijk terug op bijzondere momenten, onze reis naar Noorwegen, Finland en onlangs nog het beklimmen van de Mont Ventoux. Pap, wat ongelooflijk bijzonder was het, dat ik met jou die berg op ben gefietst en dat we samen op de top aankwamen waar mam ons toejuichte bij de finish. Bedankt dat jullie me laten zien dat plezier maken in het leven zo belangrijk is.

$\mathrm{Nu}$ is de tijd aangebroken om deze reis af te sluiten en nieuwe dromen waar te maken. Ik kijk uit naar mijn backpackavontuur in Zuid-Amerika en de 2 Oceans Marathon in ZuidAfrika. Maar voordat ik mijn nieuwe reis en avonturen start, wil ik eerst samen met jullie proosten op dit succes. Laten we er een groot feest van maken, ik proost op vol leven! 




\section{About the author}

Kristel Lankhorst 


\section{CURRICULUM VITAE}

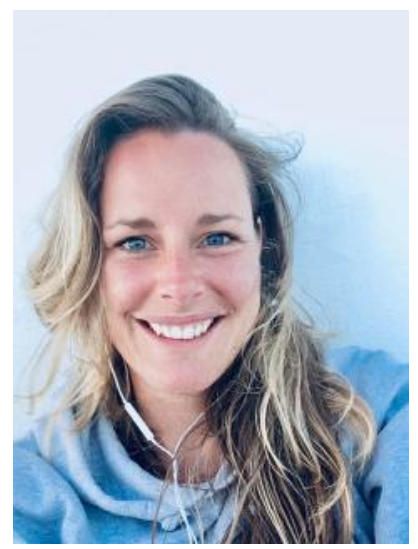

Kristel Lankhorst was born in Wijhe, the Netherlands, on March $11^{\text {th }}, 1984$. After graduating from the University of Applied Sciences in Enschede as Physical Therapist (PT) in 2006, were she was an active member of the study association for physiotherapy and podiatry (S.V. Tabula Rasa). After working one year of work experience as PT, she moved from Enschede to Amsterdam, to study Human Movement Sciences at the VU University in Amsterdam. She wanted to explore and learn more about the scientific background of physical therapy, rehabilitation and sports.

During her study she worked as a PT in a private practice for back \& neck problems and treated work-related physical problems of employees at a law firm. In her free time she was active member of the study association of the faculty of Human Movement Sciences (V.I.B.) and of the sports association for cycling and ice-speed skating (SKITS). She successfully finished her Master internship on the impact of combined skin sparing mastectomy and immediate subpectoral prosthetic reconstruction on the pectoralis major muscle function. The Master internship was in close collaboration with the department of plastic surgery at the Antoni van Leeuwenhoek Hospital. Parallel to her Master program she has obtained her teaching qualification for higher education. In 2009, she received her Master of Science degree.

Two months of traveling in New Zeeland and Australia followed before she started working as a PT and junior researcher at the department of physiotherapy and rehabilitation medicine at the VU Medical Center in Amsterdam. Her work at the hospital resulted in a Dutch publication; Is physical exercise during chemotherapy feasible for cancer patients? During one year she combined her work at the VU Medical Center with working as a lecturer at the Master Program Physical Therapy, specialization Sports Physical Therapy, of the HU University of Applied Sciences Utrecht. In 2013 she got the opportunity to start a PhD program in the Research group Lifestyle and Health of the HU University of Applied Sciences Utrecht. She participated within two research projects 'Fit for the Future!' and 'Health in Adapted Youth Sports'. She investigated the impact 
of (adapted) organized sports participation on health-related fitness, physical activity, psychosocial functioning and risk of sport-related injuries and illnesses in youth with a chronic disease or physical disability. During her $\mathrm{PhD}$, she combined research with lecturing activities by integrating research into the education program. She developed two modules for the Master Program Physical Therapy; 'Sports Physical Therapy and the Adapted Athlete' and 'Sports Physical Therapy and Youth Sports'.

Kristel lives in Amsterdam. Quality time with friends and family is important for her. She loves backpacking around the world and is a sports fanatic. She likes to go for a run in her free time, go cycling with friends, playing indoor soccer with FC Dubbelfrisss, is a member of the gym for crossfit, circuit training, yoga, and interval-running classes. During wintertime she likes speed skating at the ice-arena but preferably on frozen lakes. 


\section{PUBLICATIONS}

\section{International publications}

Lankhorst K, Takken T, Zwinkels M, van Gaalen L, Velde ST, Backx F, Verschuren O, Wittink H, de Groot J. Sports Participation, Physical Activity, and Health-Related Fitness in Youth With Chronic Diseases or Physical Disabilities: The Health in Adapted Youth Sports Study. J Strength Cond Res. 2019 Mar 13.

Lankhorst K, van den Berg-Emons RJ, Bussmann JBJ, Horemans HLD, de Groot JF. A Novel Tool for Quantifying and Promoting Physical Activity in Youths With Typical Development and Youths Who Are Ambulatory and Have Motor Disability. Phys Ther. 2019 Mar 1;99(3):354-363.

Te Velde SJ, Lankhorst K, Zwinkels M, Verschuren O, Takken T, de Groot J; Associations of sport participation with self-perception, exercise self-efficacy and quality of life among children and adolescents with a physical disability or chronic disease-a cross-sectional study. Sports Med Open. 2018 Aug 15;4(1):38. doi: 10.1186/s40798-018-0152-1.

Zwinkels M, Verschuren O, Balemans A, Lankhorst K, Te Velde S, van Gaalen L, de Groot J, Visser-Meily A, Takken T. Effects of a School-Based Sports Program on Physical Fitness, Physical Activity, and Cardiometabolic Health in Youth With Physical Disabilities: Data From the Sport-2-Stay-Fit Study. Front Pediatr. 2018 Mar 26;6:75.

Lankhorst K, Haapala EA*, de Groot J, Zwinkels M, Verschuren O, Wittink H, Backx FJ, Visser-Meily A, Takken T. The associations of cardiorespiratory fitness, adiposity and sports participation with arterial stiffness in youth with chronic diseases or physical disabilities. Eur J Prev Cardiol. 2017 Jul;24(10):1102-1111.

Lankhorst K, van der Ende-Kastelijn K*, de Groot J, Zwinkels M, Verschuren O, Backx F, Visser-Meily A, Takken T. Health in Adapted Youth Sports Study (HAYS): health effects of sports participation in children and adolescents with a chronic disease or physical disability. Springerplus. 2015 Dec 22;4:796.

Zwinkels M, Verschuren O, Lankhorst K, van der Ende-Kastelijn K, de Groot J, Backx F, Visser-Meily A, Takken T; Sport-2-Stay-Fit study group. Sport-2-Stay-Fit study: Health effects of after-school sport participation in children and adolescents with a chronic disease or physical disability. BMC Sports Sci Med Rehabil. 2015 Oct 6;7:22. 
Hage JJ, van der Heeden JF, Lankhorst K, Romviel SM, Vluttters ME, Woerdeman LA, Visser B, Veeger HE. Impact of combined skin sparing mastectomy and immediate subpectoral prosthetic reconstruction on the pectoralis major muscle function: a preoperative and postoperative comparative study. Ann Plast Surg. 2014;72(6):631-7.

\section{Submitted publications}

Lankhorst K, Oerbekke M, van den Berg-Emons R, Takken T, de Groot J. Instruments measuring physical activity in persons who use a wheelchair: a systematic review of measurement properties. Archives of Physical Medicine and Rehabilitation, accepted for publication.

Lankhorst K, de Groot J, Takken T, Backx FJ. Sports participation related to injuries and illnesses among youth with chronic diseases: results of the health in adapted youth sports study. BMC Sports Science, Medicine and Rehabilitation, under review.

\section{National publications}

Duijf M, Lankhorst K, Zwinkels M. Sporten is gezond, ook voor kinderen en jongeren met een chronische aandoening of lichamelijke beperking! https://www.allesoversport. nl/ 13 januari 2018.

Lankhorst K, Geleijn E, Huijsmans R, Dekker J, Boven E. Is fysieke training tijdens chemotherapie voor patiënten met kanker haalbaar? Ned Tijdschr Oncol 2017;14:90-9.

Tuijtelaars J, Lankhorst K, Zwinkels M, Duijf M, Takken T. Testen fitheid bij kinderen met een chronische aandoening of beperking. https://www.allesoversport.nl/3 oktober 2016.

Zwaan W, Lankhorst K, Rehorst J. Pillen slikken, de rem erop! Pijnstillers en ontstekingsremmers zijn funest voor sporters. Sportgericht 2016;5:34.

Lankhorst K, Zwinkels M, De Groot J, Verschuren O, Takken T. Is sport gezond voor chronisch zieke jongeren? Sportgericht 2016;3:25.

Van der Pijl K, Lankhorst K. Revaliderende sporter met diabetes Type 1, beperkingen of uitdagingen? Sportgericht 2016;2:26. 
Van den Berg I, Daane K, Gereke K, Den Hartog B, Hilgersom H, Westerhof A, Lankhorst K. Behandelprotocol voor het patello-femoraal pijnsyndroom. Sportgericht 2014;1:18.

\section{PRESENTATIONS}

\section{International scientific conferences and presentations}

Lankhorst K. The impact of (adapted) organized sports participation on health in youth with a chronic disease or physical disability, Health in Adapted Youth Sports Study. Presentation. Summer School Pediatric Sport and Exercise Medicine, July $15^{\text {th }}$ 2019, Utrecht, the Netherlands.

Lankhorst K. The impact of (adapted) organized sports participation on health in youth with a chronic disease or physical disability, Health in Adapted Youth Sports Study. Presentation. $6^{\text {th }}$ International Rehabmove State-of-the-art congress, December 12-14 ${ }^{\text {th }}$ 2018, Groningen, the Netherlands.

Lankhorst K. Sports participation, physical activity, and health-related fitness in youth with chronic diseases or physical disabilities: Health in Adapted Youth Sports Study. Presentation. Summer School Pediatric Sport and Exercise Medicine, August 15 $5^{\text {th }}$ 2017, Utrecht, the Netherlands.

Lankhorst K. Sports participation, physical activity, and health-related fitness in youth with chronic diseases or physical disabilities: Health in Adapted Youth Sports Study. Presentation. VvBN PhD-day Human Movement Sciences. December $1^{\text {th }} 2017$, Rotterdam, The Netherlands.

Lankhorst K, van den Berg-Emons R, Bussmanns J, Horemans H, de Groot J. A novel tool to quantify and promote physical activity in youth and ambulatory youth with a motor disability. Presentation. Pediatric Work Physiology meeting XXX. October 3-8 ${ }^{\text {th }}$ 2017, Thessaloniki, Greece.

De Groot J, on behalf of Lankhorst K, Haapala EA, Zwinkels M, Verschuren O, Wittink H, Backx FJ, Visser-Meily A, Takken T. The associations of cardiorespiratory fitness, adiposity and sports participation with arterial stiffness in youth with chronic diseases or physical disabilities. Presentation. World Confederation for Physical Therapy, 2-4 ${ }^{\text {th }}$ July 2017, Cape Town, South Africa. 
De Groot J, on behalf of Lankhorst K, van den Berg-Emons R, Bussmanns J, Horemans $\mathrm{H}$, Stam H, de Groot J. Criterion validity of a novel feedback device to assess physical behavior in youth. Poster presentation. World Confederation for Physical Therapy, 2-4 ${ }^{\text {th }}$ July 2017, Cape Town, South Africa.

Lankhorst K, van den Berg-Emons R, Bussmann J, Horemans H, Stam H, Takken T, de Groot J. Measuring physical behavior in youth. Poster Pitch and Presentation. $3^{\text {rd }}$ European Workshop on Clinical Pediatric Exercise Testing. November 11-12 th 2016, Zeist, the Netherlands.

Lankhorst K, van den Berg S, Zwinkels M, van der Ende-Kastelijn K, Verschuren O, Takken T, Backx F, de Groot J. Injuries in children and adolescents with a physical disability or chronic disease: a cross-sectional retrospective study: preliminary results. Poster presentation. Pediatric Work Physiology meeting XXIX, September 9-13 $3^{\text {th }}$ 2015, Utrecht, the Netherlands.

Lankhorst K, van der Ende-Kastelijn K, Zwinkels M, Muselaers E, Verschuren O, Takken T, Backx F, de Groot J. Sport participation reduces sedentary time, but does it improve physical fitness in youth with a physical disability or chronic disease? Poster presentation. Pediatric Work Physiology meeting XXIX, September 9-13 ${ }^{\text {th }}$ 2015, Utrecht, the Netherlands.

Lankhorst K, Oerbekke M, van den Berg-Emons R, Takken T, de Groot J. Instruments measuring physical behavior in wheelchair users: a systematic review of measurement properties. Poster presentation. European Workshop on Clinical Pediatric Exercise Testing. November 7-8 ${ }^{\text {th }}$ 2014, Zeist, the Netherlands.

Lankhorst K. van der Ende-Kastelijn K, de Groot J, Zwinkels M, Verschuren O, Backx F, Visser-Meily A, Takken T. Health in Adapted Youth Sports study: health effects of sports participation in children and adolescents with a chronic disease or physical disability. Utrecht Summer School, April 14 $4^{\text {th }}$ 2014, Utrecht, the Netherlands. 


\section{National scientific conferences and presentations}

Lankhorst K, Zwinkels M. Gezondheidseffecten van sport voor kinderen en jongeren met een chronische ziekte. Presentatie. Symposium Kind en Bewegen - innovaties in de zorg voor kinderen. Hogeschool Utrecht, Kinderbewegingscentrum WKZ, kenniscentrum revalidatiegeneeskunde Utrecht, 3 november 2017, Utrecht.

Lankhorst K, Te Velde SJ, Zwinkels M, Verschuren O, Takken T, de Groot J. Associations of sport participation with self-perception, exercise self-efficacy and quality of life among children and adolescents with a physical disability or chronic disease-a crosssectional study. Poster Presentatie. Symposium Kind en Bewegen - innovaties in de zorg voor kinderen. Hogeschool Utrecht, Kinderbewegingscentrum WKZ, kenniscentrum revalidatiegeneeskunde Utrecht, 3 november 2017, Utrecht.

Lankhorst K, de Groot J, Takken T, Backx FJ. Blessures bij kinderen en jongeren met een fysieke beperking of chronische ziekte. Hebben sportende kinderen meer blessures? Presentatie. Najaarscongres Nederlandse Vereniging voor Kinderfysiotherapie (NVFK) congres, 6 november 2015, Maarssen.

Lankhorst K. Health in Adapted Youth Sports (HAYS): De relatie tussen sportparticipatie en gezondheid van kinderen met een chronische ziekte of lichamelijke beperking. Presentatie. Dag van het Sportonderzoek, 29 oktober 2015, Zwolle.

Lankhorst K, van der Ende-Kastelijn K, Zwinkels M, Muselaers E, Verschuren O, Takken T, van den Berg-Emons R, de Groot J. Sport participatie vermindert sedentaire tijd, maar verbetert het ook de fysieke fitheid bij jeugd met een fysieke beperking of chronische ziekte? Presentatie. Dag van het Sportonderzoek, 29 oktober 2015, Zwolle.

Lankhorst K, van der Ende-Kastelijn K, Zwinkels M, van den Berg S, Verschuren O, Takken T, Backx F, de Groot J. Blessures bij kinderen en jongeren met een fysieke beperking of chronische ziekte: Een retrospectieve studie: eerste resultaten. Presentatie. Dag van het Sportonderzoek, 29 oktober 2015, Zwolle.

Lankhorst K, van der Ende-Kastelijn K, de Groot J, Zwinkels M, Verschuren O, Backx F, Visser-Meily A, Takken T. Health in Adapted Youth Sports (HAYS): De relatie tussen sportparticipatie en gezondheid van kinderen met een chronische ziekte of lichamelijke beperking. Presentatie. Dag van het Sportonderzoek, 30 oktober 2014, Nijmegen. 


\section{Presentations at faculties, for (medical) professionals and other activities}

Lankhorst K. De impact van sport deelname op de gezondheid van jongeren met een chronische ziekte of fysieke beperking. Presentatie. Landelijke trainers dag, Esther Vergeer Foundation, 5 juli 2019, Arnhem.

Lankhorst K. Gezondheid en sport voor kinderen en jongeren met een chronische ziekte. Presentatie. Landelijke Fitkids dag, 8 juni 2018, Zeist.

Lankhorst K, Zwinkels M. Sporten met een beperking. Workshop. Symposium Kind en Bewegen - innovaties in de zorg voor kinderen. Hogeschool Utrecht, Kinderbewegingscentrum WKZ, kenniscentrum revalidatiegeneeskunde Utrecht, 3 november 2017, Utrecht.

Lankhorst K, van den Berg-Emons RJ, Bussmann JBJ, Horemans HLD, de Groot JF. De validiteit van de Activ8 bij rolstoel rijdende kinderen. Presentatie. Fit for the Future! Faculteit Revalidatiegeneeskunde, Erasmus Universiteit, 9 oktober 2017, Rotterdam.

Lankhorst K, Zwinkels M, de Groot J, Takken T. Blessures bij kinderen en jongeren met een fysieke beperking of chronische ziekte Hebben sportende kinderen meer blessures? Presentatie. Terugkomdag ouders en kinderen op de Supportbeurs, 28 mei 2016, Utrecht.

Lankhorst K, van den Berg-Emons RJ, Bussmann JBJ, Horemans HLD, de Groot JF. Validiteit studie Activ8. Presentatie. Werkveld- / scholingsdag Fit for the Future!, Faculteit Gezondheidszorg, Hogeschool Utrecht, 16 januari 2016, Utrecht.

Lankhorst K, van den Berg-Emons RJ, Bussmann JBJ, Horemans HLD, de Groot JF. De validiteit van de Activ8 bij jongeren met en zonder een beperking. Presentatie. Fit for the Future! Faculteit Revalidatiegeneeskunde, Erasmus Universiteit, 22 september 2015, Rotterdam.

Lankhorst K, Zwinkels M, Takken T, de Groot J, Verschuren O, MVOTV. Kennisclip HAYS en S2SF studies. 6 november 2017. https://youtu.be/VuWS63avfsM. 




\section{'Enabling organized sports participation}

(regular or adapted) for every child or adolescent with a chronic disease or physical disability in their own living environment.'

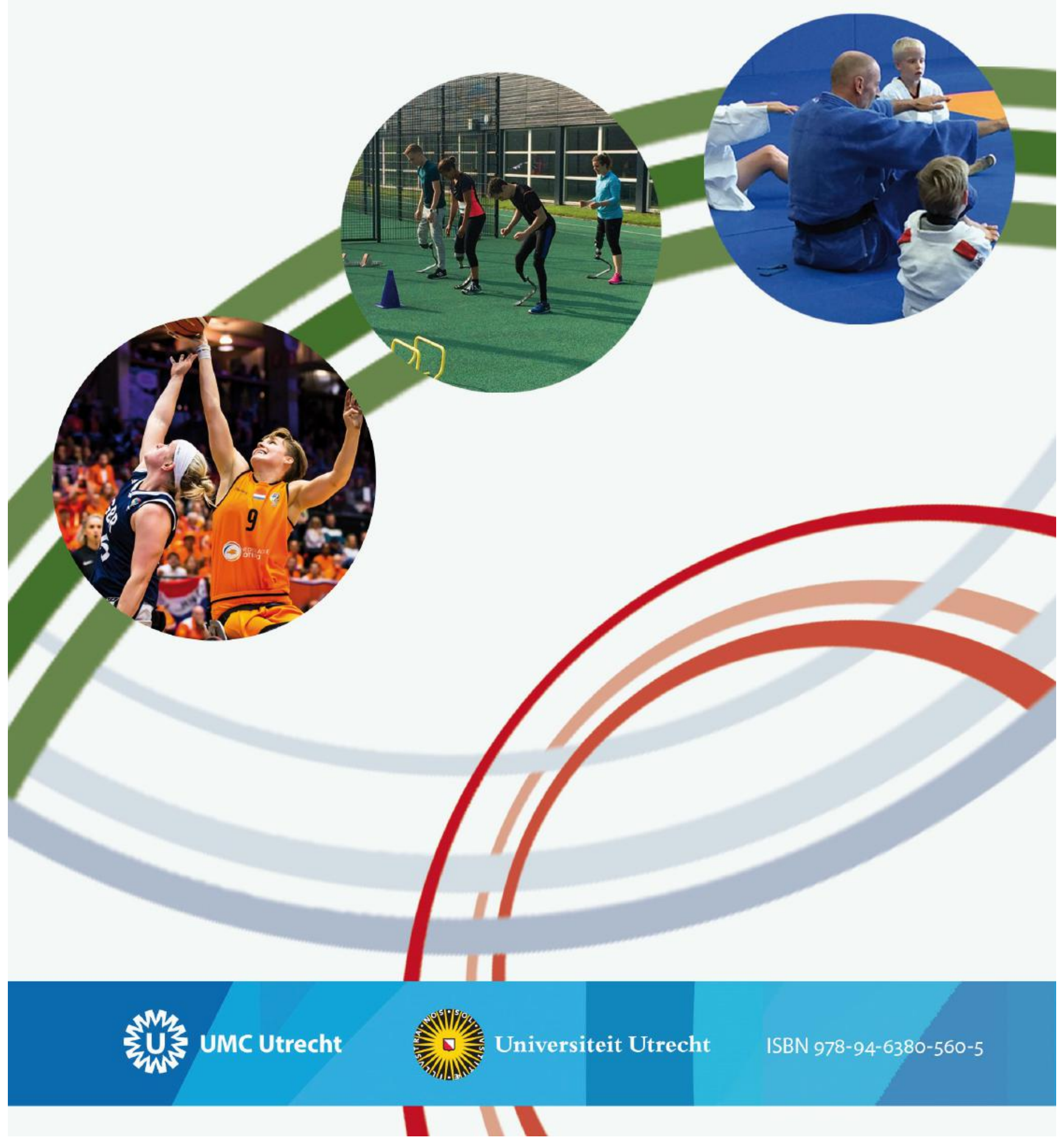


'Enabling organized sports participation (regular or adapted) for every child or adolescent with a chronic disease or physical disability in their own living environment.'

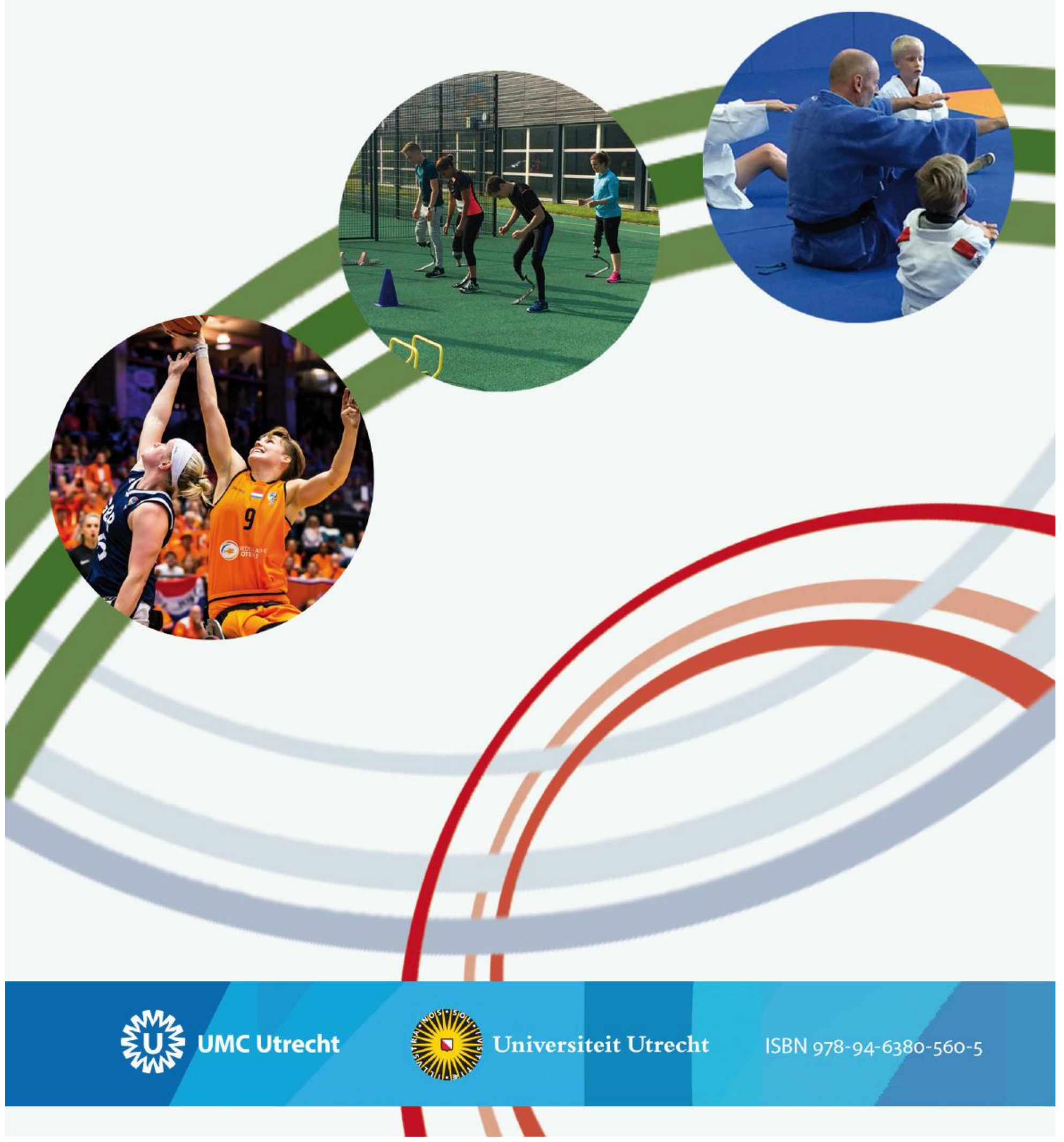

